MILAGROS VICTORIA FUERTES AMPUERO

ANÁLISE NUMÉRICA E ANALÍTICA DE ATERROS REFORÇADOS SOBRE SOLOS MOLES COM UMA CAMADA SUPERFICIAL DE AREIA 


\title{
ANÁLISE NUMÉRICA E ANALÍTICA DE ATERROS REFORÇADOS SOBRE SOLOS MOLES COM UMA CAMADA SUPERFICIAL DE AREIA
}

\author{
Dissertação apresentada à Escola \\ Politécnica da Universidade de São Paulo \\ para obtenção do título de Mestre em \\ Engenharia.
}

Área de concentração: Engenharia

Geotécnica

Orientador: Prof. Dr. Marcos Massao Futai 
Este exemplar foi revisado e alterado em relação à versão original, sob responsabilidade única do autor e com a anuência de seu orientador.

São Paulo, de setembro de 2012.

Assinatura do autor

Assinatura do orientador

\section{FICHA CATALOGRÁFICA}

Fuertes Ampuero, Milagros Victoria

Análise numérica e analítica de aterros reforçados sobre solos moles com uma camada superficial de areia / M.V. Fuertes Ampuero. -- ed.rev. -- São Paulo, 2012.

$176 \mathrm{p}$.

Dissertação (Mestrado) - Escola Politécnica da Universidade de São Paulo. Departamento de Engenharia de Estruturas e Geotécnica.

1. Aterros 2. Aterro sobre solos moles 3. Aterros reforçados 4. Geossintéticos I. Universidade de São Paulo. Escola Politécnica. Departamento de Engenharia de Estruturas e Geotécnica II. t. 
É justamente a possibilidade de realizar um sonho que torna a vida interessante Paulo Coelho.

Es justamente la posibilidad de realizar un sueño lo que hace que la vida sea interesante Paulo Coelho. 


\section{À minha família amada}

Aos meus pais, Victoria e Victor,

Amo vocês.

À memoria do meu avô Evaristo que nos deixou recentemente. 


\section{AGRADECIMENTOS}

À Deus por me permitir acreditar nesse sonho, por não me deixar desistir, e por ter me dado saúde e força para que conseguisse realizá-lo.

Ao professor Marcos Massao Futai pelo ensino, a paciência e pela sua orientação tão importante no desenvolvimento da pesquisa.

À minha família, que mesmo distante, me acompanhou em todos os momentos. Aos meus pais pela educação que vocês me deram e por terem me proporcionado tudo que precisei. À minha mãe, pelo apoio e conselhos. Ao meu pai, pelo apoio e por acreditar que eu podia. Serei eternamente grata.

Às minhas irmãs, Erika e Katia pela cumplicidade, amizade e carinho, que apesar da distancia estiveram comigo no coração. E a meu irmãozinho Alexander.

Aos professores da Pós-Graduação em Geotecnia da Escola Politécnica, ao professor Carlos de Sousa Pinto pelo entusiasmo no ensino, Waldemar C. Hachich, Jorge Nader e Fernando Marinho pelas aulas e pela paciência.

Aos professores Faiçal Massad e Mauricio Abramento pelas importantes sugestões fornecidas no exame de qualificação.

Aos funcionários do Laboratório de Mecânica dos Solos, Joaquim e Antônio, pela ajuda nas as aulas de laboratório.

Ao meu tio John Ampuero pela ajuda no meu primeiro estágio pré-profissional num Laboratório de Mecânica dos Solos.

Ao Mario Roca pela amizade, pelos ensinamentos, por acreditar em mim e por me incentivar a não andar pelos caminhos já percorridos se não a fazê-los.

E de forma especial ao Myke Ruiz, pelo amor e carinho que sempre me dedicou. Por me apoiar nos momentos mais difíceis, por saber me escutar e por compreender a minha ausência. Obrigada por me fazer feliz.

Aos colegas e amigos da casa que me ensinaram um pouco mais da cultura brasileira, João Vitor, Talita, William e Simone.

Aos amigos da salinha do laboratório, ao Lauro pela ajuda de sempre, à Lia e Dani pela amizade e companheirismo durante o mestrado.

Aos meus amigos peruanos, Hector pela ajuda para iniciar o mestrado, ao Jorge pela amizade e ajuda na chegada ao Brasil.

À Veroska, Brian e o Elvis pelo convívio, as brincadeiras, os jantares para 
desestressar e por me fazerem sentir mais perto do Perú.

À Huesker, na pessoa do Eng. Flávio Montez e a Eng. Cristina Smith por colaborar com esta pesquisa.

À CAPES pela bolsa de apoio à pesquisa.

E a todos os que de uma forma ou de outra me ajudaram e acompanharam durante a elaboração deste trabalho e a estadia no Brasil. Obrigada! 


\section{RESUMO}

Os aterros reforçados sobre solo mole de resistência crescente com a profundidade, podem apresentar problemas durante o processo construtivo com respeito às rupturas e aos recalques inesperados. O presente trabalho visa avaliar o comportamento dos aterros reforçados a través de um estudo numérico, levando aos aterros até a ruptura sob condição não-drenada devido ao carregamento rápido, com o objetivo de estimar a influência da rigidez do reforço nas deformações, além disso, estudar o mecanismo da interação solo-reforço para um aterro reforçado. Foi utilizada a metodologia apresentada por Hinchberger \& Rowe (2003), que leva em conta os recalques imediatos durante e após a construção. As análises numéricas de tensão-deformação foram realizadas pelo software PHASE 2, a calibração do programa foi feita com a literatura de aterros reforçados. Pretendeu-se mostrar a influência de uma camada superficial de areia sobre a argila mole na altura de ruptura e na deformação do reforço.

Pelo método de elementos finitos foi definida uma metodologia para calcular as deformações do reforço para uma altura determinada e avaliar a estabilidade mediante o método de equilíbrio limite. Além disso, essa metodologia pode ser empregada para dimensionar o reforço requerido para um determinado fator de segurança.

Palavras-chave: Aterro sobre solos moles, aterros reforçados, geossintéticos. 


\begin{abstract}
Reinforced embankments on soft clayey soil where the strength increases with depth may present problems during construction process relative to failure and unexpected settlements. This study aims to evaluate the embankments behavior with a numerical study; the embankments were taken to failure in the undrained shear strength condition due to rapid upload to study the effect of reinforcement tensile stiffness on the reinforcement strains. Besides, it aimed to study the mechanism of soil-reinforcement interaction for a reinforced embankment. The method of Hinchberger \& Rowe (2003) was used, which considers the displacements before and post construction. The numeric analysis of stress-strain was performed by the software PHASE 2; the calibration of the software was made according to published reinforced embankment literature. The study intends to show the influence of a sand layer above the clayey soil, on the failure height and reinforcement strains. Based on finite elements methods, a methodology was defined to estimate the reinforcement strains for a required design height and to study the stability by performing limit equilibrium analysis. Furthermore, this methodology could be used to specify the required reinforcement stiffness for a specific factor of safety.
\end{abstract}

Key-words: embankment on soft clayey soil, reinforced embankment, geosynthetic 


\section{LISTA DE FIGURAS}

Figura 2-1 llustração dos possíveis estágios da gênese das Planícies Sedimentares Paulistas (Suguio e Martin, 1981 apud Massad, 2003). 5

Figura 2-2 Resultados de ensaios de tração de geotêxteis de diferentes processos de fabricação (Koerner, 1994). .......................................8

Figura 2-3 Curvas de Resistencia x Deformabilidade (Batista, 2007).................9

Figura 2-4 Estrutura típica de solo reforçado (Bonaparte e Christopher, 1987)...12

Figura 2-5 Exemplos de utilização de reforços em aterros sobre solos moles ....13

Figura 2-6 Aplicação do reforço nos aterros sobre solos moles e nos taludes (Jewell, 1988)...................................................................... 14

Figura 2-7 Tipos de ruptura de aterros sobre solos moles (Jewell (1982) ...........16

Figura 2-8 Distribuição das tensões cisalhantes na base de um aterro não reforçado (Jewell, 1988) ..........................................................17

Figura 2-9 Influência das tensões cisalhantes na redução da capacidade de carga para uma sapata (Jewell, 1988).......................................18

Figura 2-10 A função do reforço frente às tensões cisalhantes, (Jewell, 1988)....18

Figura 2-11 A influência da resistência crescente com a profundidade na capacidade de carga, Jewell (1982) .............................................19

Figura 2-12 Fator de Capacidade de Carga para solo não homogêneo, Rowe e Söderman (1987, sintetizado dos resultados de David e Booker, e Matar e Salencon) .................................................................20

Figura 2-13 Definição das variáveis usadas para estimar a altura de colapso para um aterro perfeitamente reforçado (Rowe e Soderman, 1987) .21

Figura 2-14 Efeito da não - homogeneidade na profundidade da área da ruptura embaixo da sapata rígida, Rowe e Soderman (1987, modificado de Matar e Salencon 1977) .22

Figura 2-15 Altura Liquida Máxima e Deformação Admissível de Compatibilidade do Reforço (Rowe e Hinchberger 2003).........................................27

Figura 2-16 Geometria do aterro e estratigrafia da fundação. (Hinchberger e Rowe 2003). 29

Figura 2-17 Influência da rigidez do reforço no comportamento do aterros por elementos finitos e análise de escorregamento circular (Modificado de Hinchberger \& Rowe 2003) 30

Figura 2-18 Ábaco para determinação da deformação admissível de compatibilidade (Hinchberger \& Rowe 2003).................................32

Figura 2-19 Efeito da largura da crista do aterro nas deformações máximas do reforço na ruptura (Hinchberger \& Rowe 2003). 
Figura 2-20 Comparação dos vetores deslocamento na ruptura para $B=20$ e 40 $\mathrm{m}$ e rigidez do reforço, $\mathrm{J}=600 \mathrm{kN} / \mathrm{m}$ (Hinchberger \& Rowe 2003) ....36

Figura 2-21 O efeito de $S_{u 0}$ na deformação do reforço na ruptura para $\rho_{c}=1,5$ $\mathrm{kPa} / \mathrm{m}$. (Modificado de Hinchberger \& Rowe 2003) .........................37

Figura 2-22 Zonas de plastificação do solo na ruptura para $S_{\mathrm{u} 0}=5 \mathrm{kPa}$ e $16 \mathrm{kPa}$. (Modificado de Hinchberger \& Rowe 2003).....................................38

Figura 2-23 Efeito do aumento da resistência com a profundidade $S_{u 0}=10 \mathrm{kPa}$. (Modificado de Hinchberger \& Rowe 2003). 39

Figura 2-24 Deformação de compatibilidade admissível do reforço (Hinchberger e Rowe, 2003 apud Futai, 2010) 40

Figura 2-25 Deformação de compatibilidade admissível do reforço para Jo e J=12 $\mathrm{MN} / \mathrm{m}$ (Futai, 2010). 41

Figura 2-26 Variação das deformações de compatibilidade com a espessura da camada superficial de areia (Futai, 2010). 42

Figura 2-27 Fator de correção devido à presença da camada de areia aa (Futai, 2010). 43

Figura 2-28 Geometria da seção reforçada na linea de referencia I (Rowe \& Söderman,1984) 44

Figura 2-29 Comparação da deformação no reforço observada e calculada (Rowe \& Söderman, 1984) 45

Figura 2-30 Perfil de resistência não drenada no silte orgânico (Rowe e Mylleville, 1996). 46

Figura 2-31 Deformações da geogrelha observadas no estagio I da construção (Rowe e Mylleville, 1996). 47

Figura 2-32 Esforço de tração no geotêxtil no momento da ruptura (Chai, Miura e Shen, 2002) 48

Figura 2-33 Geometria do aterro experimental AE2 com reforço sobre solo moles (Oliveira, 2006) 49

Figura 2-34 Resultados dos ensaios de campo (piezocone e palheta) para os aterros experimentais AE1 e AE2 (Oliveira, 2006). .50

Figura 2-35 Resultados do ensaio cisalhamento direto da areia fina silicosa branca (Oliveira, 2006).

Figura 2-36 Esforços de tração máximos medidos nos reforços como função do tempo e relacionado ás espessuras de aterros (Oliveira,2006).........51

Figura 2-37 Seção do talude do aterro (Souza Pinto 1966) ................................52

Figura 2-38 Ábaco de Souza Pinto para aterros sobre solos moles (Massad, 2003)

Figura 3-1 Altura de ruptura na modelagem do aterro experimental. .59 
Figura 3-2 Deformações máximas do reforço da modelagem do aterro experimental. ......................................................................59

Figura 3-3 Deslocamentos horizontais para o aterro experimental AE2, Oliveira et al (2009).

Figura 3-4 Deslocamentos horizontais para o aterro experimental AE2, obtido pelo PHASE 2 61

Figura 3-5 Desvios da vertical para o aterro experimental AE2, Oliveira (2006).

Figura 3-6 Desvios da vertical para o aterro experimental AE2 obtido pelo PHASE 2.

Figura 3-7 Variação de deslocamentos horizontais máximos com a elevação do aterro AE2, Oliveira (2006)...................................................63

Figura 3-8 Variação de deslocamentos horizontais máximos com a elevação do aterro AE2 obtido pelo PHASE 2 63

Figura 3-9 Comparação das alturas atingidas pelo aterro empregando o método de Souza Pinto e mediante o PHASE 2. ........................................65

Figura 3-10 Geometria do aterro e estratigrafia da fundação. (Adaptado de Hinchberger e Rowe 2003) ........................................................67

Figura 4-1 Resultados de altura liquida do aterro e deformação de compatibilidade admissível do reforço ........................................72

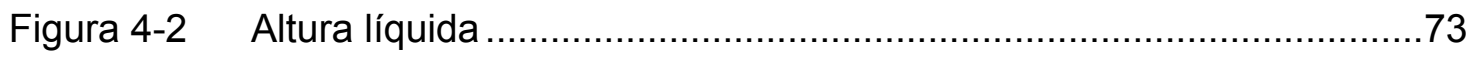

Figura 4-3 Deformação de compatibilidade do reforço..................................74

Figura 4-4 Ponto 1 - Estado da fundação num estagio anterior à plastificação. .74

Figura 4-5 Ponto 2 - Estado da fundação no inicio da plastificação....................75

Figura 4-6 Ponto 3 - Estado da fundação num estagio anterior à ruptura. .........75

Figura 4-7 Ponto 4 - Estado da fundação num estagio posterior á ruptura.........76

Figura 4-8 Influência da areia nos vetores deslocamentos do mecanismo de ruptura no aterro com Suo $=2 \mathrm{kPa}, \rho=2,0 \mathrm{kPa} / \mathrm{m}, \mathrm{J}=600 \mathrm{kN} / \mathrm{m}$ e $A=0$ (a), $2 \mathrm{~m}$ (b) e $4 \mathrm{~m}$ (c) ............................................................ 77

Figura 4-9 Alturas de ruptura (a) e deformações máximas do reforço com o aumento da rigidez do reforço $\mathrm{J}(\mathrm{b})$, para uma fundação sem areia. .79

Figura 4-10 Alturas de ruptura (a) e deformações máximas do reforço com o aumento da rigidez do reforço $\mathrm{J}$ (b) para uma fundação com $2 \mathrm{~m}$ de areia.

80

Figura 4-11 Alturas de ruptura (a) e deformações máximas do reforço com o aumento da rigidez do reforço $\mathrm{J}(\mathrm{b})$ para uma fundação com $4 \mathrm{~m}$ de areia. 81

Figura 4-12 Resultados da variação da altura do aterro com o aumento da 
espessura da camada de areia e da rigidez do reforço $\mathrm{J} \mathrm{kN/m}$

Figura 4-13 Ganho de altura em função da rigidez à tração do reforço para Suo = $2 \mathrm{kPa}$ e $\rho=1,0 \mathrm{kPa} / \mathrm{m}$. 84

Figura 4-14 Ganho de altura em função da rigidez à tração do reforço para Suo = $2 \mathrm{kPa}$ e $\rho=1,5 \mathrm{kPa} / \mathrm{m}$.

Figura 4-15 Ganho de altura em função da rigidez à tração do reforço para Suo = $2 \mathrm{kPa}$ e $\rho=2,0 \mathrm{kPa} / \mathrm{m}$.

Figura 4-16 Resultados da variação da altura do aterro com o aumento da rigidez do reforço $\mathrm{J} \mathrm{kN/m}$. 86

Figura 4-17 Influência da areia na altura do aterro não reforçado .86

Figura 4-18 Variação da deformação de compatibilidade do reforço com a rigidez do reforço e com a espessura da camada de areia até $4 \mathrm{~m}$.

Figura 4-19 Variação da deformação de compatibilidade do reforço com a rigidez do reforço e com a espessura da camada de areia até $6 \mathrm{~m}$. .89

Figura 4-20 Efeito do $\rho$ na deformação de compatibilidade do reforço na ruptura para $A=0 m(a), A=2 m(b)$ e $S_{u o}=2 \mathrm{kPa}$.

Figura 4-21 Efeito do $\rho$ na deformação de compatibilidade do reforço na ruptura para $A=4 \mathrm{~m}$ e $S_{\mathrm{uo}}=2 \mathrm{kPa}$.

Figura 4-22 Efeito do $\rho$ na deformação de compatibilidade do reforço na ruptura para $A=0 m$ e $S_{u o}=3,6 \mathrm{kPa}$.

Figura 4-23 Efeito do $\rho$ na deformação de compatibilidade do reforço na ruptura para $A=2 \mathrm{~m}(\mathrm{a})$ e $A=4 \mathrm{~m}(\mathrm{~b})$ e $S_{\text {uo }}=3,6 \mathrm{kPa}$.

Figura 4-24 Efeito do $\rho$ nas deformações de compatibilidade do reforço na ruptura para $A=0 m, A=2 m$ e $S_{u o}=5,0 \mathrm{kPa}$.

Figura 4-25 Efeito do $\rho$ nas deformações de compatibilidade do reforço na ruptura para $A=4 m$ e $S_{u o}=5,0 \mathrm{kPa}$.

Figura 4-26 Efeito do $S_{u 0}$ na deformação de compatibilidade do reforço na ruptura para $A=0 \mathrm{~m}$ e $\rho=1,0 \mathrm{kPa} / \mathrm{m}$.

Figura 4-27 Efeito do $S_{u 0}$ na deformação de compatibilidade do reforço na ruptura para $A=2 m(a), A=4 m(b)$ e $\rho=1,0 \mathrm{kPa} / \mathrm{m}$.

Figura 4-28 Efeito do $S_{u 0}$ na deformação de compatibilidade do reforço na ruptura para $A=0$ e $\rho=1,5 \mathrm{kPa} / \mathrm{m}$.

Figura 4-29 Efeito do $S_{u 0}$ na deformação de compatibilidade do reforço na ruptura para $A=0 m(a), A=2 m(b)$ e $\rho=1,5 \mathrm{kPa} / \mathrm{m}$. 100

Figura 4-30 Recalques imediatos na base do aterro reforçado para $A=0 \mathrm{~m}$ e $S_{u o}=$ $2 \mathrm{kPa}$ e $\rho=1,5 \mathrm{kPa} / \mathrm{m}$. 101

Figura 4-31 Recalques imediatos na base do aterro reforçado para $A=2 \mathrm{~m}$ e $\mathrm{S}_{\mathrm{uo}}=$ $2 \mathrm{kPa}$ e $\rho=1,5 \mathrm{kPa} / \mathrm{m}$. 102 
Figura 4-32 Recalques imediatos na base do aterro reforçado para $A=4 \mathrm{~m}$ e $\mathrm{S}_{\mathrm{uo}}=$ $2 \mathrm{kPa}$ e $\rho=1,5 \mathrm{kPa} / \mathrm{m}$. 103

Figura 4-33 Deslocamentos horizontais no pé do aterro reforçado para $A=0 \mathrm{~m} \mathrm{e}$ $\mathrm{S}_{\mathrm{uo}}=2 \mathrm{kPa}$ e $\rho=1,5 \mathrm{kPa} / \mathrm{m}$ 104

Figura 4-34 Deslocamentos horizontais no pé do aterro reforçado para $A=2 \mathrm{~m}$ e $\mathrm{S}_{\mathrm{uo}}=2 \mathrm{kPa}$ e $\rho=1,5 \mathrm{kPa} / \mathrm{m}$ 105

Figura 4-35 Deslocamentos horizontais no pé do aterro reforçado para $A=4 \mathrm{~m} \mathrm{e}$ $\mathrm{S}_{\mathrm{uo}}=2 \mathrm{kPa}$ e $\rho=1,5 \mathrm{kPa} / \mathrm{m}$. 106

Figura 4-36 Efeito da espessura da camada de areia e rigidez do reforço nos deslocamentos horizontais do aterro na ruptura. 107

Figura 5-1 Deformação admissível de compatibilidade ....................................109

Figura 5-2 Curvas normalizadas ...........................................................109

Figura 5-3 Definição dos pontos de interseção $\alpha$ e $\beta$.....................................110

Figura 5-4 Correlação a para $S_{\text {uo }}=2 \mathrm{kPa}$ diferentes valores de $\rho . \ldots \ldots \ldots \ldots \ldots \ldots . . . . . .111$

Figura 5-5 Correlação a para $S_{u o}=3,6 \mathrm{kPa}$ diferentes valores de $\rho . \ldots \ldots \ldots \ldots \ldots . . . . .112$

Figura 5-6 Correlação $\alpha$ para $S_{\text {uo }}=5 \mathrm{kPa}$ diferentes valores de $\rho . . . . . . . . . . . . . . . . .112$

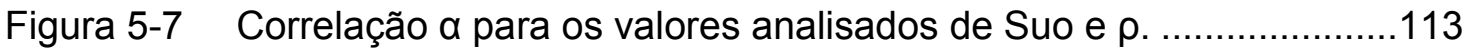

Figura 5-8 Valores $\beta$ para $S_{\text {uo }}=2 \mathrm{kPa}(\mathrm{a}) ; 3,6 \mathrm{kPa}$ (b); $5 \mathrm{kPa}$ (c) e diferentes

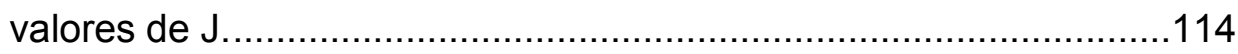

Figura 5-9 Correlação de a para os valores analisados de Suo e $\rho$. ................115

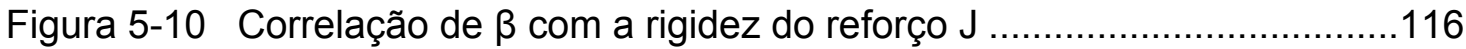

Figura 5-11 Correlação $\beta$ para $S_{\text {uo }}=2,0 \mathrm{kPa}$ diferentes valores de $\rho . \ldots \ldots \ldots \ldots \ldots . . . . .116$

Figura 5-12 Correlação $\beta$ para $S_{\text {uo }}=3,6 \mathrm{kPa}$ diferentes valores de $\rho . . . \ldots \ldots \ldots \ldots . . . . .117$

Figura 5-13 Correlação $\beta$ para $S_{\text {uo }}=5,0 \mathrm{kPa}$ diferentes valores de $\rho \ldots \ldots \ldots \ldots \ldots . . . .117$

Figura 5-14 Correlação do b para os valores analisados de Suo e $\rho$. .................118

Figura 5-15 Sequência de utilização da metodologia apresentada.....................120

Figura 5-16 Validação do modelo pelo caso de Rowe \& Söderman (1984).........122

Figura 5-17 Comparação entre as forças de tração do reforço calculadas e medidas. 123

Figura 5-18 Variação das deformações de compatibilidade com a espessura da

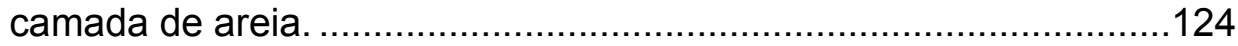

Figura 5-19 Fator de correção devido à presença da camada de areia $\alpha_{a}$.........125

Figura 5-20 Comparação entre as forças de tração do reforço calculadas e medidas. 126

Figura 5-21 Variação do fator de segurança com o aumento da rigidez do reforço J. 129

Figura 5-22 Variação do fator de segurança com o aumento da rigidez do reforço $\mathrm{J}$ para um aterro Suo $=3,6 \mathrm{kPa}$ e $\rho=1,5 \mathrm{kPa} / \mathrm{m}$ 132 
Figura 5-23 Força no reforço pelo MEF para uma rigidez de $\mathrm{J}=8800 \mathrm{kN} / \mathrm{m}$.

Figura l-1 Alturas de ruptura e deformações máximas do reforço com o aumento da rigidez do reforço $\mathrm{J} \mathrm{kN/m}$ para uma fundação sem areia de Suo=2 $\mathrm{kPa}$ e $\rho=1,5 \mathrm{kPa} / \mathrm{m}$.

Figura l-2 Alturas de ruptura e deformações máximas do reforço com o aumento da rigidez do reforço $\mathrm{J} \mathrm{kN/m}$ para uma fundação de Suo=2 $\mathrm{kPa} e$ $\rho=1,5 \mathrm{kPa} / \mathrm{m}$ com $2 \mathrm{~m}$ de areia

Figura l-3 Alturas de ruptura e deformações máximas do reforço com o aumento da rigidez do reforço $\mathrm{J} \mathrm{kN/m}$ para uma fundação de Suo=2 $\mathrm{kPa} e$ $\rho=1,5 \mathrm{kPa} / \mathrm{m}$ com $4 \mathrm{~m}$ de areia.

146

Figura l-4 Alturas de ruptura e deformações máximas do reforço com o aumento da rigidez do reforço $\mathrm{J} \mathrm{kN/m}$ para uma fundação sem areia de Suo=2 $\mathrm{kPa}$ e $\rho=2,0 \mathrm{kPa} / \mathrm{m}$.

Figura l-5 Alturas de ruptura e deformações máximas do reforço com o aumento da rigidez do reforço $\mathrm{J} \mathrm{kN/m}$ para uma fundação de Suo=2 $\mathrm{kPa} e$ $\rho=2,0 \mathrm{kPa} / \mathrm{m}$ com $2 \mathrm{~m}$ de areia. 148

Figura l-6 Alturas de ruptura e deformações máximas do reforço com o aumento da rigidez do reforço $\mathrm{J} \mathrm{kN} / \mathrm{m}$ para uma fundação Suo $=2 \mathrm{kPa}$ e $\rho=2,0$ $\mathrm{kPa} / \mathrm{m}$ com $4 \mathrm{~m}$ de areia.

Figura l-7 Alturas de ruptura e deformações máximas do reforço com o aumento da rigidez do reforço $\mathrm{J} \mathrm{kN/m}$ para uma fundação sem areia de Suo $=3,6 \mathrm{kPa}$ e $\rho=1,0 \mathrm{kPa} / \mathrm{m}$.

Figura l-8 Alturas de ruptura e deformações máximas do reforço com o aumento da rigidez do reforço $\mathrm{J} \mathrm{kN} / \mathrm{m}$ para uma fundação de Suo=3,6 $\mathrm{kPa} e$ $\rho=1,0 \mathrm{kPa} / \mathrm{m}$ com $2 \mathrm{~m}$ de areia.

Figura I-9 Alturas de ruptura e deformações máximas do reforço com o aumento da rigidez do reforço $\mathrm{J} \mathrm{kN} / \mathrm{m}$ para uma fundação Suo $=3,6 \mathrm{kPa}$ e $\rho=1,0$ $\mathrm{kPa} / \mathrm{m}$ com $4 \mathrm{~m}$ de areia.

Figura l-10 Alturas de ruptura e deformações máximas do reforço com o aumento da rigidez do reforço $\mathrm{J} \mathrm{kN/m}$ para uma fundação sem areia de Suo $=3,6 \mathrm{kPa}$ e $\rho=1,5 \mathrm{kPa} / \mathrm{m}$.

Figura l-11 Alturas de ruptura e deformações máximas do reforço com o aumento da rigidez do reforço $\mathrm{J} \mathrm{kN} / \mathrm{m}$ para uma fundação de Suo=3,6 $\mathrm{kPa} e$ $\rho=1,5 \mathrm{kPa} / \mathrm{m}$ com $2 \mathrm{~m}$ de areia. 154

Figura l-12 Alturas de ruptura e deformações máximas do reforço com o aumento da rigidez do reforço $\mathrm{J} \mathrm{kN} / \mathrm{m}$ para uma fundação $\mathrm{Suo}=3,6 \mathrm{kPa}$ e $\rho=1,5$ $\mathrm{kPa} / \mathrm{m}$ com $4 \mathrm{~m}$ de areia. 155

Figura l-13 Alturas de ruptura e deformações máximas do reforço com o aumento 
da rigidez do reforço $\mathrm{J} \mathrm{kN} / \mathrm{m}$ para uma fundação sem areia de Suo=3,6 kPa e $\rho=2,0 \mathrm{kPa} / \mathrm{m}$. 156

Figura l-14 Alturas de ruptura e deformações máximas do reforço com o aumento da rigidez do reforço $\mathrm{J} \mathrm{kN} / \mathrm{m}$ para uma fundação de Suo=3,6 $\mathrm{kPa}$ e $\rho=2,0 \mathrm{kPa} / \mathrm{m}$ com $2 \mathrm{~m}$ de areia.

Figura l-15 Alturas de ruptura e deformações máximas do reforço com o aumento da rigidez do reforço $\mathrm{J} \mathrm{kN} / \mathrm{m}$ para uma fundação Suo=3,6 kPa e $\rho=2,0$ $\mathrm{kPa} / \mathrm{m}$ com $4 \mathrm{~m}$ de areia.

Figura l-16 Alturas de ruptura e deformações máximas do reforço com o aumento da rigidez do reforço $\mathrm{J} \mathrm{kN/m}$ para uma fundação sem areia de Suo=5 $\mathrm{kPa}$ e $\rho=1,0 \mathrm{kPa} / \mathrm{m}$.

Figura l-17 Alturas de ruptura e deformações máximas do reforço com o aumento da rigidez do reforço $\mathrm{J} \mathrm{kN} / \mathrm{m}$ para uma fundação de Suo $=5 \mathrm{kPa}$ e $\rho=1,0$ $\mathrm{kPa} / \mathrm{m}$ com $2 \mathrm{~m}$ de areia. 160

Figura l-18 Alturas de ruptura e deformações máximas do reforço com o aumento da rigidez do reforço $\mathrm{J} \mathrm{kN} / \mathrm{m}$ para uma fundação Suo $=5 \mathrm{kPa}$ e $\rho=1,0$ $\mathrm{kPa} / \mathrm{m}$ com $4 \mathrm{~m}$ de areia.

161

Figura l-19 Alturas de ruptura e deformações máximas do reforço com o aumento da rigidez do reforço $\mathrm{J} \mathrm{kN/m}$ para uma fundação sem areia de Suo=5 $\mathrm{kPa}$ e $\rho=1,5 \mathrm{kPa} / \mathrm{m}$.

Figura l-20 Alturas de ruptura e deformações máximas do reforço com o aumento da rigidez do reforço $\mathrm{J} \mathrm{kN} / \mathrm{m}$ para uma fundação de Suo $=5 \mathrm{kPa}$ e $\rho=1,5$ $\mathrm{kPa} / \mathrm{m}$ com $2 \mathrm{~m}$ de areia.

Figura I-21 Alturas de ruptura e deformações máximas do reforço com o aumento da rigidez do reforço $\mathrm{J} \mathrm{kN} / \mathrm{m}$ para uma fundação Suo=5 kPa e $\rho=1,5$ $\mathrm{kPa} / \mathrm{m}$ com $4 \mathrm{~m}$ de areia. 164

Figura l-22 Alturas de ruptura e deformações máximas do reforço com o aumento da rigidez do reforço $\mathrm{J} \mathrm{kN/m}$ para uma fundação sem areia de Suo=5 $\mathrm{kPa}$ e $\rho=2,0 \mathrm{kPa} / \mathrm{m}$. 165

Figura l-23 Alturas de ruptura e deformações máximas do reforço com o aumento da rigidez do reforço $\mathrm{J} \mathrm{kN/m}$ para uma fundação de Suo $=5 \mathrm{kPa}$ e $\rho=2,0$ $\mathrm{kPa} / \mathrm{m}$ com $2 \mathrm{~m}$ de areia. 166

Figura II-1 Ganho de altura em função da rigidez à tração do reforço para Suo = $3,6 \mathrm{kPa}$ e $\rho=1,0 \mathrm{kPa} / \mathrm{m}$. 167

Figura II-2 Ganho de altura em função da rigidez à tração do reforço para Suo = $3,6 \mathrm{kPa}$ e $\rho=1,5 \mathrm{kPa} / \mathrm{m}$. 167

Figura II-3 Ganho de altura em função da rigidez à tração do reforço para Suo = $3,6 \mathrm{kPa}$ e $\rho=2,0 \mathrm{kPa} / \mathrm{m}$. 168 
Figura II-4 Ganho de altura em função da rigidez à tração do reforço para Suo = $5 \mathrm{kPa}$ e $\rho=1,0 \mathrm{kPa} / \mathrm{m}$. 168

Figura II-5 Ganho de altura em função da rigidez à tração do reforço para Suo = $5 \mathrm{kPa}$ e $\rho=1,5 \mathrm{kPa} / \mathrm{m}$. 169

Figura II-6 Ganho de altura em função da rigidez à tração do reforço para Suo = $5 \mathrm{kPa}$ e $\rho=2,0 \mathrm{kPa} / \mathrm{m}$. 169

Figura III-1 Variação da deformação de compatibilidade do reforço com a rigidez do reforço e com a espessura da camada de areia para Suo $=2 \mathrm{kPa} e$ $\rho=1$ a $1,5 \mathrm{kPa} / \mathrm{m}$.

Figura III-2 Variação da deformação de compatibilidade do reforço com a rigidez do reforço e com a espessura da camada de areia para Suo $=2 \mathrm{kPa} e$ $3,6 \mathrm{kPa}$ e $\rho=1$ a $1,5 \mathrm{kPa} / \mathrm{m}$.

Figura III-3 Variação da deformação de compatibilidade do reforço com a rigidez do reforço e com a espessura da camada de areia para Suo $=3,6 \mathrm{kPa}$ e $\rho=1,5$ a $2,0 \mathrm{kPa} / \mathrm{m}$.

Figura III-4 Variação da deformação de compatibilidade do reforço com a rigidez do reforço e com a espessura da camada de areia para Suo $=5,0 \mathrm{kPa}$ e $\rho=1$ a $1,5 \mathrm{kPa} / \mathrm{m}$.

Figura IV-1 Efeito do $\rho c$ nas deformações do reforço na ruptura para A $=0 \mathrm{~m}$ e $\mathrm{S}_{\mathrm{uo}}$ $=2 \mathrm{kPa}$ 175

Figura IV-2 Efeito do $\rho c$ nas deformações do reforço na ruptura para $A=2 \mathrm{~m}$ e $\mathrm{S}_{\text {uo }}$ $=2 \mathrm{kPa}$. 175

Figura IV-3 Efeito do pc nas deformações do reforço na ruptura para $A=4 \mathrm{~m}$ e $\mathrm{S}_{\mathrm{uo}}$ $=2 \mathrm{kPa}$. 176

Figura IV-4 Efeito do $\rho c$ nas deformações do reforço na ruptura para $A=6 \mathrm{~m}$ e $\mathrm{S}_{\mathrm{uo}}$ $=2 \mathrm{kPa}$. 


\section{LISTA DE TABELAS}

Tabela 2-1 Funções dos vários geossintéticos nos projetos de engenharia (Souza Bueno e Monje Vilar, 2004).

Tabela 2-2 Quadro comparativo de alguns geossintéticos existentes no mercado..

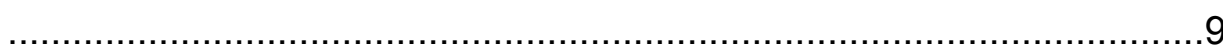

Tabela 2-3 Fatores de correção do reforço (Hinchberger \& Rowe 2003)............34

Tabela 2-4 Expressões propostas para deformações de compatibilidade (Futai,

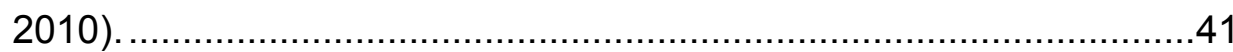

Tabela 2-5 Dados os três aterros experimentais (Oliveira, 2006).......................50

Tabela 3-1 Resumo dos resultados do aterro experimental AE2 de Oliveira (2006) e do PHASE 2

Tabela 3-2 Resumo dos resultados da altura de ruptura obtida pelo método de Souza Pinto (1966) e do PHASE 2 ..............................................65

Tabela 3-3 Resumo dos parâmetros de material utilizados nas análises no PHASE 2 68

Tabela 4-1 Parâmetros utilizados nas análises numéricas ..................................71

Tabela 4-2 Resumo de alturas da ruptura do aterro, com $\mathrm{S}_{\mathrm{uo}}=2 \mathrm{kPa}$ e diferente $\rho$ $=1,0 \mathrm{kPa} / \mathrm{m} ; 1,5 \mathrm{kPa} / \mathrm{m}$ e 2,0 kPa/m com diferentes $\mathrm{J}$ e espessura de areia 82

Tabela 4-3 Resumo de alturas da ruptura do aterro, com $\mathrm{S}_{\mathrm{uo}}=3,6 \mathrm{kPa}$ e diferente $\rho=1,0 \mathrm{kPa} / \mathrm{m} ; 1,5 \mathrm{kPa} / \mathrm{m}$ e $2,0 \mathrm{kPa} / \mathrm{m}$ com diferentes $\mathrm{J}$ e espessura de areia. .82

Tabela 4-4 Resumo de alturas da ruptura do aterro, com $\mathrm{S}_{\mathrm{uo}}=5,0 \mathrm{kPa}$ e diferente $\rho=1,0 \mathrm{kPa} / \mathrm{m} ; 1,5 \mathrm{kPa} / \mathrm{m}$ e $2,0 \mathrm{kPa} / \mathrm{m}$ com diferentes $\mathrm{J}$ e espessura de areia.

Tabela 5-1 Valores médios de $\alpha$ para diferentes correlações $S_{\text {uo }}+7,5 \rho \ldots \ldots \ldots \ldots .113$

Tabela 5-2 Dados de aterros reforçados sobre solos moles levados à ruptura e sem romper. 121

Tabela 5-3 Valores de deformação de compatibilidade e altura na ruptura........123

Tabela 5-4 Resultados do fator de segurança aplicando o modelo proposto.....129

Tabela 5-5 Resultados do fator de segurança aplicando o modelo proposto.....132 


\section{SUMÁRIO}

PÁGINA

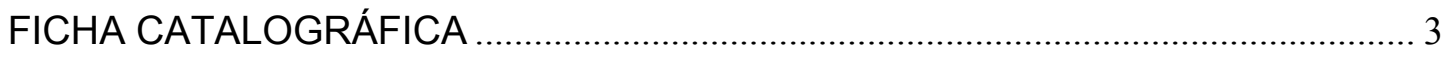

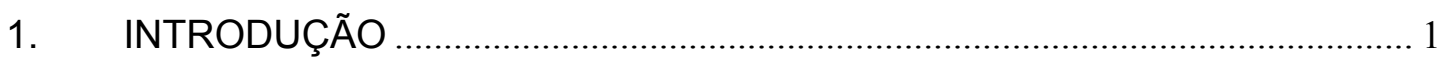

1.1 Relevância do Tema .............................................................................. 1

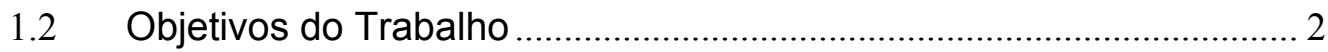

1.3 Organização da Dissertação................................................................... 2

2. REVISÃO BIBLIOGRÁFICA DE ATERROS NÃO REFORÇADOS E

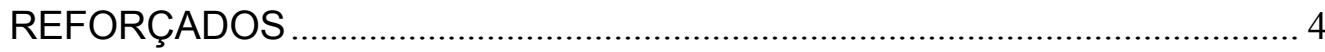

2.1 Introdução ..................................................................................... 4

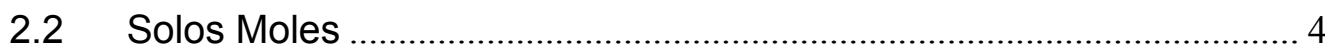

2.3 Breve descrição dos Geossintéticos......................................................... 6

2.3.1 Propriedades dos Geossintéticos ................................................ 7

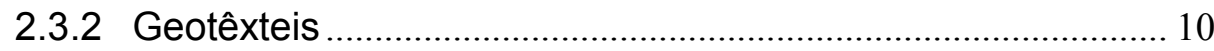

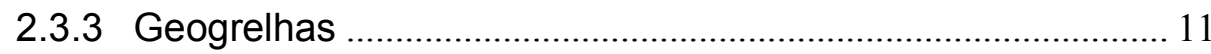

2.4 Aplicações do Solo Reforçado................................................................. 12

2.5 Ruptura em Aterros Reforçados sobre Solos Moles.............................. 15

2.6 Análise de Aterros Reforçados pela Teoria da Plasticidade............... 17

2.7 Análise por Elementos Finitos .............................................................. 24

2.7.1 Procedimento de Rowe e Soderman (1987) para determinar a altura da ruptura do aterro pelo MEF ...................................... 25

2.7.2 Estudo de Rowe e Hinchberger (2003): Fatores que afetam a deformação do reforço na ruptura do aterro .............................. 28

a) Efeito da Rigidez do Reforço ................................................... 30

b) Efeito da Largura da Crista do Aterro, B ...................................... 34

c) Efeito da Resistência não drenada na Superfície, $S_{\text {uo }}$............. 36

d) Efeito do Aumento da Resistência com a Profundidade, $\rho_{c} . .38$

2.8 Método para definir a deformação de compatibilidade do reforço (Futai, 2010) 
2.9 Casos históricos de aterros reforçados.................................................... 43

2.9.1 Aterro Almere, Rowe \& Söderman (1984) …………………..... 44

2.9.2 Aterro em Hubrey Road, Rowe e Mylleville (1996) .................. 45

2.9.3 Aterro em Lian-Yun-Gang, Chai, Miura e Shen (2002) .......... 47

2.9.4 Aterro reforçado com uma camada de areia na fundação

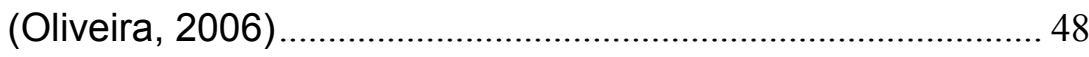

2.9.5 Aterro não reforçado de coesão crescente com a profundidade 52

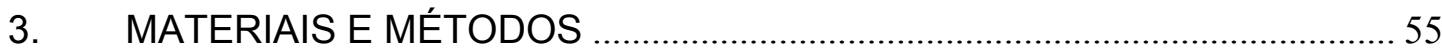

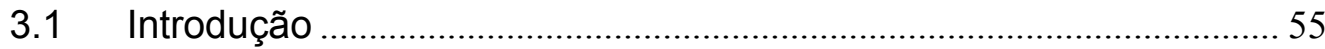

3.2 Método de Análise por Modelagem Numérica - Abordagem do

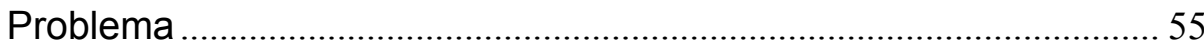

3.3 O Programa de Elementos Finitos .......................................................... 56

3.4 Modelagem do Aterro por Elementos Finitos ………………………….... 56

3.5 Validação e Calibração do Programa ........................................................ 57

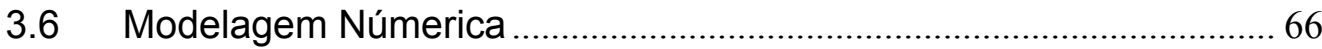

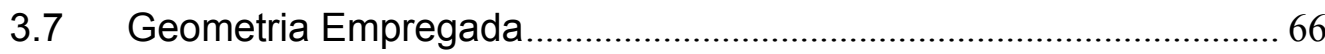

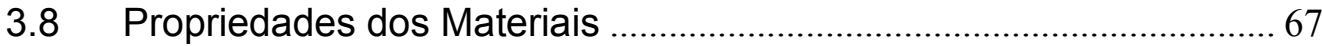

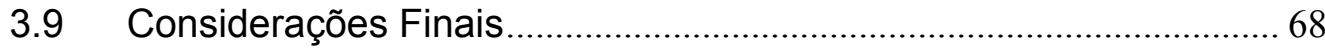

4. APRESENTAÇÃO E ANÁLISES DOS RESULTADOS …………………....... 70

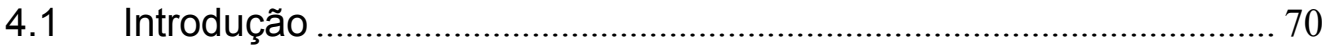

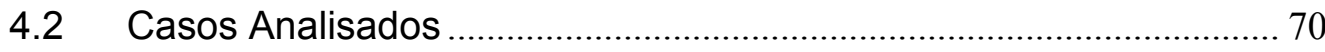

4.3 Resultados das Análises pelo MEF ..................................................... 72

4.3.1 Altura de ruptura e deformação do reforço .................................. 72

4.3.2 Definição das áreas de plastificação .......................................... 73

4.3.3 Influência da camada superficial de areia ................................. 76

4.3.4 Resultados da altura de ruptura do aterro e deformação do

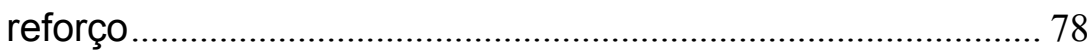


4.3.5 Efeito do aumento da resistência com a profundidade, $\rho$...... 90

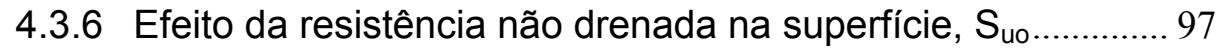

4.3.7 Variação dos recalques na base do aterro ............................ 101

4.3.8 Influência nos deslocamentos horizontais ............................ 103

5. MODELO PARA O CÁLCULO DA DEFORMAÇÃO DO REFORÇO .......... 108

5.1 Aterros reforçados sobre solos moles ........................................... 108

5.2 Aplicação da metodologia proposta................................................. 121

5.3 Aterros reforçados sobre solos moles com uma camada superficial de

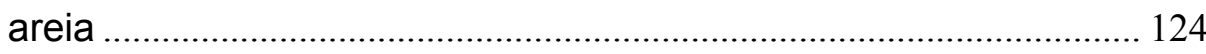

5.4 Comparação dos resultados .......................................................... 127

5.4.1 Procedimento proposto para determinar a rigidez do reforço127

5.4.2 Procedimento de Rowe e Hinchberger (2003) para determinar a rigidez do reforço. 129

5.4.3 Procedimento de Low et al. (1990) para verificar a estabilidade.

6. CONCLUSÕES E SUGESTÔES PARA TRABALHOS FUTUROS............. 135

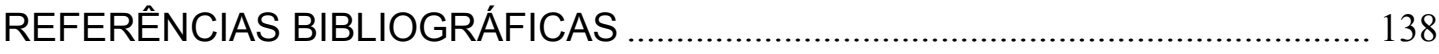

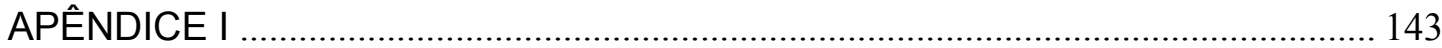

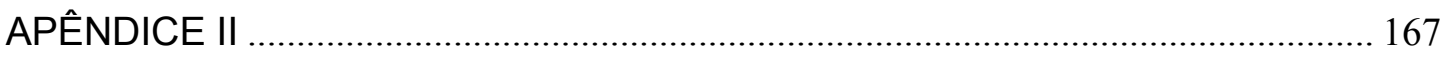

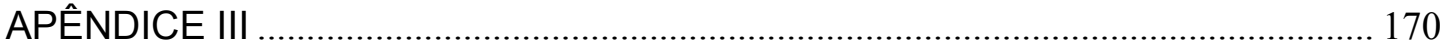

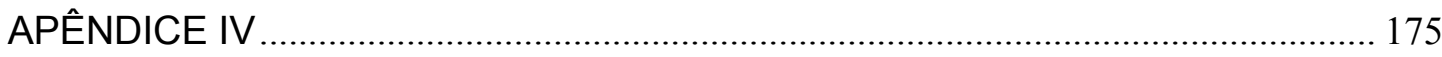




\section{INTRODUÇÃO}

\subsection{Relevância do Tema}

O crescimento das cidades brasileiras se deu à costa, onde há presença de depósitos flúvio-marinhos de espessura considerável, a característica desses depósitos de solo mole é a ocorrência de baixas resistências e de grandes deformações. Os mais conhecidos são os depósitos da Baixada Fluminense, e da Baixada Santista; assim como, as argilas de Pernambuco, Santa Catarina, Paraná, Rio Grande do Sul, Bahia e Sergipe.

A consequência da expansão urbana trouxe consigo um aumento na demanda de obras de terra, e assim foi necessário construir sobre áreas consideradas inadequadas por apresentar grandes espessuras de solo mole. A necessidade de ocupar essas áreas acarretou a construção de aterros sobre solos moles, tornando-se um desafio a ser enfrentado pelos engenheiros geotécnicos.

Embora os aterros sobre solos moles tenham sido muito estudados, eles ainda apresentam características e comportamentos por pesquisar com respeito à rupturas e aos recalques inesperados. Um dos principais problemas se apresenta durante o processo construtivo, onde o risco de ruptura durante a construção pode afetar à obra e provocar danos aos equipamentos, atrasos nos cronogramas e o aumentos dos custos.

Neste contexto surgiram técnicas para garantir a estabilidade do aterro durante e após a construção. Uma das alternativas que apresenta uma solução econômica e permite um processo de construção mais controlado é o uso de geossintéticos como elementos de reforço.

$\mathrm{Na}$ prática da engenharia, os aterros reforçados são projetados pelos métodos convencionais de equilíbrio limite, mas na aplicação desse método é preciso incluir a força de tração do reforço. O que normalmente se faz é a aplicação de fatores de redução sobre a resistência do reforço para obter a força nele, a qual depende da interação aterro-reforço-solo de fundação e que pode ser obtido mediante os métodos numéricos.

Além disso, a análise pode ser complementada com resultados baseados na teoria de plasticidade, para estimar a altura de colapso de um aterro perfeitamente reforçado. 
Neste trabalho pretende-se mostrar que uma boa análise de aterros reforçados sobre solo moles pode ser feita integrando os três tipos de análise: o método baseado na teoria da plasticidade, o método de elementos finitos e o método de equilíbrio limite. Além de ampliar o estudo dos aterros com uma camada superficial de areia, o que é uma situação possível na prática.

\subsection{Objetivos do Trabalho}

O estudo tem como objetivo avaliar o comportamento de aterros reforçados com geossintéticos sobre solo mole na condição não drenada e de resistência crescente com a profundidade, aplicando uma nova metodologia introduzida por Rowe e Soderman em 1987 para o calculo das deformações na ruptura, que leva em conta os recalques imediatos.

Analisar numericamente a influência da rigidez do reforço e da espessura de uma camada de areia na superfície, observando as variações na deformação do reforço quando esses parâmetros são variados.

Propor um método analítico para o cálculo das deformações do reforço nas condições de trabalho e assim avaliar a estabilidade do aterro pelos métodos de equilíbrio limite, conhecendo a força mobilizada no reforço, calculada mediante o método dos elementos finitos.

\subsection{Organização da Dissertação}

Esta dissertação encontra-se dividida em cinco capítulos. Apresenta-se a seguir a descrição dos próximos capítulos:

O Capítulo 2 será destinado a uma revisão bibliográfica sobre aterros reforçados, os conceitos e métodos de análise para calcular a altura da ruptura em aterros reforçados sobre solo mole. Incluindo uma breve descrição dos solos do litoral brasileiro e do aterro experimental tomado da literatura para validar o programa de elementos finitos utilizado.

No Capítulo 3 apresenta a metodologia utilizada para desenvolver a presente pesquisa, tanto o referente à modelagem como os parâmetros geotécnicos analisados. Além disso, são apresentados os resultados da validação do programa para casos de aterro reforçado e não reforçado. 
O Capítulo 4 é dedicado à analise dos resultados das alturas de ruptura, deslocamentos verticais e horizontais e deformações no reforço. Apresenta-se o efeito dos parâmetros do solo nas deformações e comparações entres os resultados obtidos para diferentes tipos de fundação, com e sem areia.

No Capítulo 5 apresenta-se um modelo numérico que permite dimensionar o reforço para uma altura dada de um aterro reforçado, sendo possível calcular as deformações produzidas no reforço e conhecer a força mobilizada. O modelo proposto foi testado satisfatoriamente com casos de aterros in situ tomados da literatura. Adicionalmente e apresentada um fator de ajuste das deformações no reforço devido à presença da areia.

O Capítulo 6 apresenta as conclusões alcançadas na presente pesquisa e as sugestões para futuras pesquisas.

Finalmente são apresentados quatro apêndices contendo os resultados das alturas de ruptura e deformações máximas do reforço (Apêndice I), os ganhos em altura dos aterros para diferentes dados de fundação e rigidez do reforço (Apêndice II), a variação das deformações do reforço com o aumento da camada de areia e a rigidez (Apêndice III), o efeito nas deformações do aumento da resistência com a profundidade (Apêndice IV) e o efeito da resistência não drenada na superfície Suo (Apêndice V). 


\section{REVISÃO BIBLIOGRÁFICA DE ATERROS NÃO REFORÇADOS E REFORÇADOS}

\subsection{Introdução}

Nesse capítulo será apresentada uma breve revisão bibliográfica sobre os aterros reforçados sobre solos moles, com uma breve explicação sobre as características dos solos moles do litoral brasileiro. Além disso, são apresentados os conceitos e aplicações do solo reforçado, geossintéticos, o mecanismo de interação solo-reforço e métodos de análises numéricas de aterros.

\subsection{Solos Moles}

Os solos moles têm baixa capacidade de suporte, baixa permeabilidade e elevada compressibilidade. A construção sobre este tipo de solo requer cuidados quanto à definição dos parâmetros geotécnicos, á luz de sua origem geológica, tipo de análise e sequência construtiva adotada.

Esse tipo de solo apresenta-se no litoral brasileiro, em forma de depósitos marinhos e aluviais de argila mole. Os solos moles de origem fluvial se apresentam nas várzeas dos rios, e podem estar intercalados com camadas de areias finas; os solos de origem marinha foram formados em dois ciclos de sedimentação devido a dois episódios de ingressão do mar no Quaternário.

No Estado de São Paulo encontra-se os terrenos constituídos por sedimentos argilosos da Baixada Litorânea. Massad (2003) mostrou de forma esquemática os estágios da gênese dos sedimentos argilosos da Baixada Santista Figura 2-1.

O conhecimento da origem dos solos auxilia na compreensão das propriedades e das suas condições de adensamento. As argilas sedimentares devem sua resistência ao seu adensamento devido ao próprio peso, ao efeito de rebaixamentos do nível do mar e eventualmente a ação de dunas de areia. Desta forma elas são especialmente moles na superfície, aumentando a consistência conforme a profundidade (Pinto, 1994). Segundo Massad (2003), os ensaios de palheta executados nessa argila têm indicado um crescimento linear da resistência não-drenada com a profundidade devido a essa adensamento do solo. 
1ำ Estagío: máximo da transgressão - Cananéia (Pleistoceno)

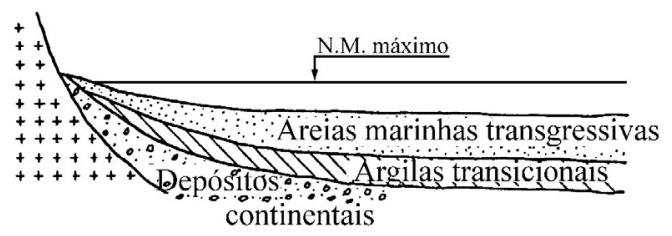

$2^{\circ}$ Estagío: Regressão e formação de cordões de areia

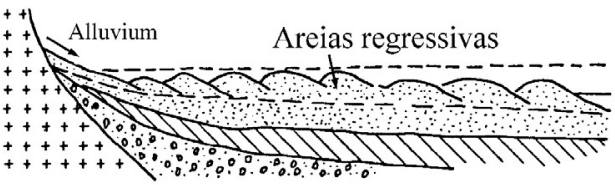

3ำ Estagío: Erosão parcial dos sedimentos marinhos

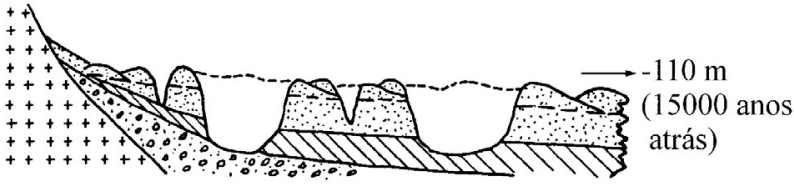

4 Estagío: Máximo da transgressão - Santos (Holoceno)

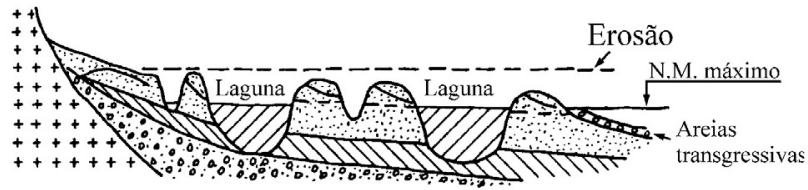

Figura 2-1 llustração dos possíveis estágios da gênese das Planícies Sedimentares Paulistas (Suguio e Martin, 1981 apud Massad, 2003).

Os solos moles abordados nesta pesquisa têm a característica de apresentar um aumento da resistência não drenada com a profundidade, além de encontrar, em alguns casos, a presença de alternâncias de camadas de argilas e areias, assim como camadas de areias argilosas ou argilas muito arenosas. Dentro dos principais problemas envolvidos nos solos moles, estão os recalques diferenciais e a construção rápida dos aterros, que podem causar a ruptura do solo mole sob condições não drenadas.

Frente a esses problemas, uma das técnicas mais usadas nas últimas décadas foi o uso dos geossintéticos no solo como elementos de reforço, por oferecer soluções econômicas e tecnicamente avançadas. 


\subsection{Breve descrição dos Geossintéticos}

A procura por formas de melhorar a resistência do solo data de tempos préhistóricos. A utilização de elementos resistentes à tração para reforçar o solo, tais como palha, bambu e mato, tem sido feita há milhões de anos nos solos moles com o objetivo de melhorar a resistência.

Mas o emprego de materiais sintéticos produzidos pela indústria foi possível com o desenvolvimento dos polímeros tais como PVC, poliamida, poliéster, polietileno, polipropileno. E o grande passo no desenvolvimento dos materiais geossintéticos foi na metade dos anos 1960 quando foi fabricado o geotêxtil nãotecido de filamentos contínuos na França, na Inglaterra e nos Estrados Unidos. Em quanto isso as indústrias de embalagens inglesas desenvolviam a tecnologia de fabricação de malhas sintéticas, ou geogrelha.

No Brasil as primeiras aplicações de geotêxteis em obras rodoviárias, foram em 1971.

Dentro das principais funções dos geossintéticos, de acordo com a norma brasileira NBR 12.553, e apresentadas no Manual Brasileiro de Geossintéticos (Vertematti, 2004).

- Controle de erosão superficial, prevenção de erosão superficial de partículas de solo devido a escoamento superficial de um fluido.

- Drenagem, coleta e condução de um fluido pelo corpo de um geossintético.

- Filtração, retenção de um solo ou de outras partículas permitindo a passagem livre do fluido em movimento.

- Impermeabilização, bloqueio ou desvio de fluidos.

- Proteção, limitação ou prevenção de danos a elementos de obras geotécnicas.

- Reforço, utilização das propriedades mecânicas de uma geossintético para a melhoria do comportamento mecânico de uma estrutura geotécnica.

- Separação, ação de impedir a mistura ou interação entre materiais adjacentes.

A Tabela 2-1 mostra o emprego de vários geossintéticos de acordo às funções nos projetos. 
Tabela 2-1 Funções dos vários geossintéticos nos projetos de engenharia (Souza Bueno e Monje Vilar, 2004).

\begin{tabular}{l|c|c|c|c|c|c|c}
\hline Geossintético & Separação & Proteção & Filtração & Drenagem & Erosão & Reforço & $\begin{array}{c}\text { Impermeabili- } \\
\text { zação }\end{array}$ \\
\hline Geotêxtil & $\mathrm{X}$ & $\mathrm{X}$ & $\mathrm{X}$ & $\mathrm{X}$ & $\mathrm{X}$ & $\mathrm{X}$ & $\mathrm{X}$ \\
\hline Geogrelha & $\mathrm{X}$ & - & - & - & - & $\mathrm{X}$ & - \\
\hline Geomembrana & $\mathrm{X}$ & - & - & - & - & - & $\mathrm{X}$ \\
\hline Georrede & - & $\mathrm{X}$ & - & $\mathrm{X}$ & - & - & - \\
\hline $\begin{array}{l}\text { Geocomposto } \\
\text { argiloso }\end{array}$ & - & - & - & - & - & - & $\mathrm{X}$ \\
\hline Geocélula & - & $\mathrm{X}$ & - & - & $\mathrm{X}$ & $\mathrm{X}$ & - \\
\hline Geotubo & - & - & - & $\mathrm{X}$ & - & - & - \\
\hline Geofibras & - & - & - & - & - & $\mathrm{X}$ & - \\
\hline
\end{tabular}

*Quando impregnado de material asfáltico

Entre os diferentes tipos geossintéticos encontramos: geotêxteis, geogrelha georrede, geomembrana e geotubos. Suas aplicações são das formas mais variadas e diversas na engenharia.

As duas categorias principais dos geossintéticos para reforço são os geotêxteis e as geogrelhas, e as matérias-primas mais utilizadas na fabricação deles são: a poliamida (náilon) PA, poliéster PET, polietileno PE, polipropileno PP.

\subsubsection{Propriedades dos Geossintéticos}

As propriedades dos geossintéticos necessárias para atender as exigências da obra onde serão empregados, são determinadas a partir de ensaios de campo ou, mais comumente, de laboratório as quais para serem realistas precisam reproduzir os aspectos importantes da interação do geossintético com o meio em que será inserido e devem apresentar vida útil compatível com a da obra.

O comportamento dos geossintéticos se deve aos seus componentes polímeros básicos e aditivos, e ao processo de fabricação. O conhecimento das propriedades dos materiais empregados na confecção pode permitir inferir sobre possível degradação e envelhecimento precoce do material em contato com os vários produtos e agentes de meio. Os principais ensaios executados são para determinar as propriedades físicas e as propriedades mecânicas.

As propriedades Físicas dos geossintéticos de maior interesse são massa 
por unidade de área ou gramatura $\left(\mu_{\mathrm{A}}\right)$, espessura nominal $\left(\mathrm{t}_{\mathrm{GT}}\right)$, porosidade $\left(\mathrm{n}_{\mathrm{GT}}\right) \mathrm{e}$ porcentagem de área aberta.

Nas propriedades mecânicas expressam relações entre carregamento e deformações. A resistência à tração unidirecional pode ser determinada em tiras (faixa larga) ou em faixa restrita (grab test), cada qual buscando reproduzir uma condição de campo. O ensaio consiste em prender as extremidades do corpo de prova e sujeito a uma máquina universal é aplicada uma carga de tração crescente registrando-se as deformações correspondentes até a ruptura.

Koerner (2004) apresentou num gráfico a resposta típica de diferentes geotêxteis segundo os processos de fabricação. A força de tração por unidade de largura do geotêxtil $(\mathrm{kN} / \mathrm{m})$ versus deformação axial. No eixo vertical, para obter as unidades de resistência convencionais o valor deve ser dividido pela espessura do material. No eixo horizontal esta indicado a deformação axial.

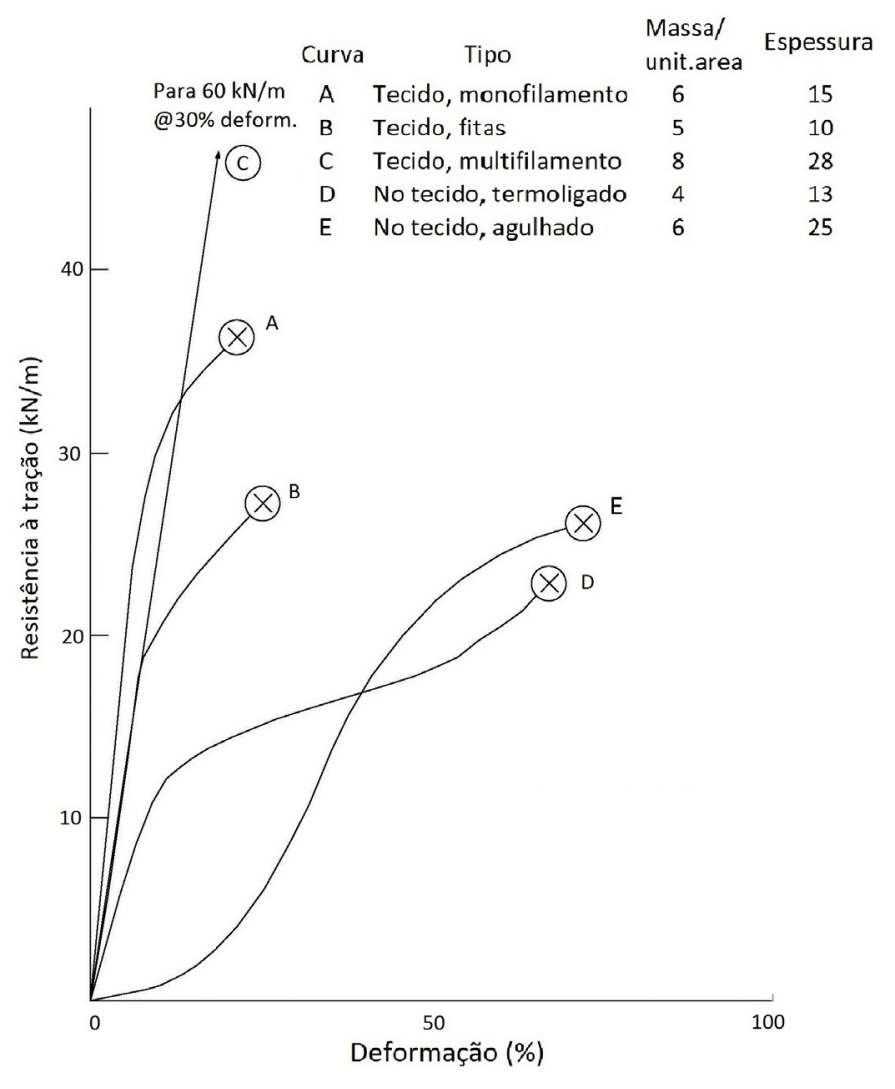

Figura 2-2 Resultados de ensaios de tração de geotêxteis de diferentes processos de fabricação (Koerner, 1994).

A seguir é mostrada uma tabela comparativa de diversos tipos de geossintéticos comerciais existentes. 
Tabela 2-2 Quadro comparativo de alguns geossintéticos existentes no mercado.

\begin{tabular}{|c|c|c|c|c|c|c|c|}
\hline & \multirow[t]{2}{*}{ Polímero } & \multirow[t]{2}{*}{ Tipo } & \multicolumn{2}{|c|}{$\begin{array}{c}\text { Resistência } \\
\text { à tração (kN/m) }\end{array}$} & \multirow{2}{*}{$\begin{array}{c}\text { Módulo } \\
\text { Mód. Rigidez } \\
5 \% \text { deformação } \\
\text { Dir. L (kN/m) }\end{array}$} & \multicolumn{2}{|c|}{$\begin{array}{l}\text { Deformação } \\
\text { máxima } \\
\text { máxima na } \\
(\%)\end{array}$} \\
\hline & & & Dir. L & Dir. T & & Dir. L & Dir. T \\
\hline Stabilenka 150/45 & PET & Geotêxtil tec. & $\geq 150$ & $\geq 45$ & $\geq 1,500$ & $\leq 10$ & \\
\hline Stabilenka 1000/100 & PET & Geotêxtil tec. & $\geq 1000$ & $\geq 100$ & $\geq 10,000$ & $\leq 10$ & \\
\hline MacGrid WG150 & PET & Geogrelha & 150 & 30 & & 12 & \\
\hline Hate $25 / 25$ UV & PP & Geotêxtil tec. & $\geq 25$ & $\geq 25$ & & $\leq 15$ & $\leq 15$ \\
\hline Engefort & PET & Geogrelha & 85 & 35 & & 12 & 14 \\
\hline Fortrac 3D-90 & PET & Geogrelha & $\geq 90$ & & $\geq 675$ & $\leq 12,5$ & \\
\hline Tenax TT 120SAMP & HDPE & Geogrelha & 120 & & & 13 & \\
\hline Pavco T2400 & $\mathrm{PP}$ & Geotêxtil & 40 & & & 22 & \\
\hline Fortrac $400 / 50-30 \mathrm{~A}$ & PET & Geogrelha & $\geq 400$ & $\geq 50$ & $\geq 13,600$ & $\leq 3,5$ & \\
\hline Fortrac $1000 / 100 \mathrm{~A}$ & PET & Geogrelha & $\geq 1000$ & $\geq 100$ & $\geq 34,000$ & $\leq 3,6$ & \\
\hline
\end{tabular}

Valores obtidos da literatura publicada e comercial.

Esse ensaio define a chamada resistência nominal do geossintético, cujo valor é o que normalmente se utiliza em catálogo para caracterizá-lo. Além disso, é importante definir o parâmetro rigidez $(\mathrm{J})$, que é a resistência à tração pela deformabilidade.

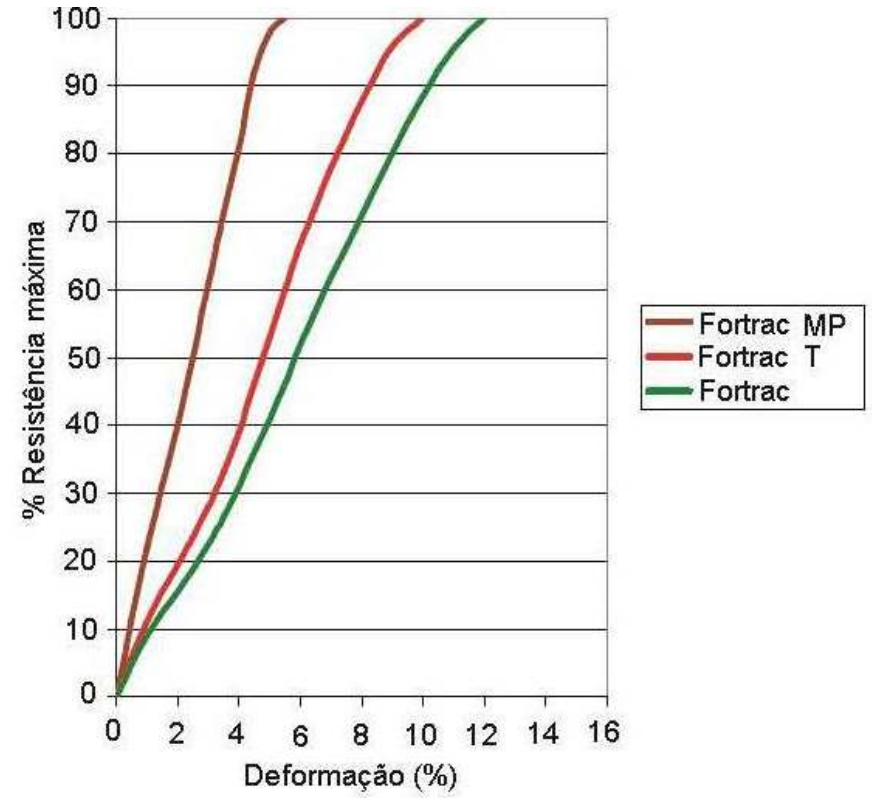

Figura 2-3 Curvas de Resistencia x Deformabilidade (Batista, 2007). 
A Figura 2-3, mostra três curvas de resistência por deformação para diferentes produtos de geossintéticos.

Um outro ensaio para medir a resistência mecânica é a resistência ao puncionamento, esse ensaio é uma descrição da resistência ao impacto provocado pela queda de materiais, os esforços de compressão gerados por grãos isolados podem ser de tal monta que causam sua perfuração. Para realizar o ensaio o geossintético e fixado às bordas de um cilindro rígido e submetendo-o a uma força estática ou dinâmica. O ensaio por puncionamento estático é feito numa máquina universal que aplica uma força vertical crescente na superfície do corpo de prova até sua perfuração, e medida a força máxima e o deslocamento correspondente.

No puncionamento dinâmico o ensaio busca representar o lançamento de materiais granulares sobre o geotêxtil, um cone padrão cai em queda livre a $50 \mathrm{~mm}$ sobre o geossintético provocando um furo cujo diâmetro é medido por um outro cone padronizado.

Dentro dos geotêxteis mais empregados como reforço estão as geogrelhas e os geotêxteis tecidos por ser bastante rígidos, a seguir será apresentada uma pequena definição deles.

\subsubsection{Geotêxteis}

Produto têxtil bidimensional permeável. Composto de fibras cortadas, filamentos contínuos, monofilamentos, laminetes ou fios; formando estruturas tecidas, não tecidas ou tricotadas.

Nos geotêxteis não tecidos, os filamentos 0 as fibras cortadas estão dispostas numa rede frouxa e são ligadas usando um ou a combinação dos seguintes processos: ligação química, ligação térmica ou ligação mecânica.

Geotêxteis são os geossintéticos mais versáteis, dentre muitas aplicações nas obras geotécnicas. Além do reforço de solos pode-se utilizá-los com funções de drenagem, filtração, separação entre camadas ou barreira (quando é impregnado com algum material impermeabilizante). Conforme o seu processo de fabricação podem ser divididos nos grupos de geotêxteis tecidos e não tecidos.

$\mathrm{Na}$ aplicação como reforço, o geotêxtil interactua com o solo a través de forças friccionais ou de adesão para resistir às tensões de cisalhamento. Para 
prover o reforço da estrutura, o geotêxtil deve ter a suficiente resistência para suportar as tensões geradas, e aquela resistência deve ser desenvolvida com pequenas deformações (modulo alto) para prevenir o movimento excessivo da estrutura.

O Technical Manual da US ARMY (1995) recomenda o uso de geotêxtil tecido como reforço de aterros e estruturas de contenção por prover grandes resistências e pequenas deformações.

Dentro dos geossintéticos existentes no mercado para o reforço de aterros sobre solos moles temos:

Um geotêxtil tecido com resistência à tração de até $1,000 \mathrm{kN} / \mathrm{m}$ na direção principal podendo ser fabricado com uma resistência maior, com a característica de mobilizar altas tensões com deformações baixas, esse geotêxtil pode produzir deformações menores a $10 \%$ no sentido longitudinal. $E$ outro geotêxtil tecido de PVA, pode ser produzido com módulos até e além de $36,000 \mathrm{kN} / \mathrm{m}$, resistência à tração até 2,200 kN/m (uniaxial) e $500 \mathrm{kN} / \mathrm{m}$ (biaxial) nas duas direções; e deformações menores a $6 \%$.

Outros geotêxteis disponíveis tem-se os tecido de PP os quais apresentam uma resistência à tração de $28 \mathrm{kN} / \mathrm{m}$ com deformação de $18 \%$, e o outros com resistência de $110 \mathrm{kN} / \mathrm{m}$ e deformação $10 \%$.

\subsubsection{Geogrelhas}

As geogrelhas consistem em grelhas de plástico com aberturas de diferentes formatos que permitem a interação do meio no qual estão confinadas, possuindo a função principal de reforço de solo. É considerado unidirecional quando apresenta elevada resistência à tração apenas em uma direção e bidirecional quando apresenta elevada resistência à tração nas duas direções principais (ortogonais). Em função do processo de fabricação, as geogrelhas podem ser extrudadas, soldadas ou tecidas.

Dentro dos geogrelhas existentes no mercado para o reforço de aterros sobre solos moles tem-se:

Uma geogrelha flexível de PET presenta resistência à tração entre $20 \mathrm{kN} / \mathrm{m}$ e $400 \mathrm{kN} / \mathrm{m}$ tendo a opção ser fabricada para atingir resistências de até $1,000 \mathrm{kN} / \mathrm{m}$ 
para aplicações especiais, a deformação na resistência ultima é menor a $10 \%$ no sentido longitudinal.

Ou uma geogrelha que apresenta uma resistência à tração máxima de 121 $\mathrm{kN} / \mathrm{m}$ com deformações de 10\%. E as geogrelhas tecidas de PET que mobilizam elevadas resistências com baixos valores de alongamento, resistências últimas de até $150 \mathrm{kN} / \mathrm{m}$ e alongamento na resistência ultima de $12 \%$.

\subsection{Aplicações do Solo Reforçado}

Nas estruturas de solo reforçado, os elementos colocados no solo para reforçar e aumentar sua resistência, também apresenta vantagens em quanto aos custos e facilidade na construção.

As aplicações da técnica dos solos reforçados são múltiplas, podem se encontrar em muros reforçados, em taludes reforçados e aterros reforçados sobre solos moles. Esta revisão não pretende esgotar o tema, mas coletar informações relacionadas ao tema de pesquisa.

O aterro reforçado é um sistema composto com três componentes: o solo de fundação (argila moles), o reforço e o aterro, como é apresentado na Figura 2-4. Num aterro sobre solo mole, o reforço pode ser colocado para: reforçar o talude do aterro ou atingir maiores taludes envolvendo o corpo do aterro

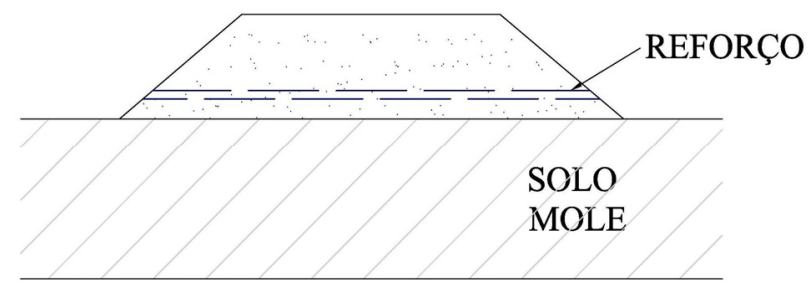

Figura 2-4 Estrutura típica de solo reforçado (Bonaparte e Christopher, 1987)

$\mathrm{Na}$ construção dos aterros reforçados o reforço pode ser colocado em toda a extensão da interface aterro-fundação, em única camada ou em camadas múltiplas compreendendo toda a altura ou posicionado próximo à base do aterro. O reforço também pode ser colocado na base dos aterros estaqueados para minimizar os recalques, além de otimizar a espessura do aterro, o espaçamento entre estacas e a redução ou até eliminação dos capitéis normalmente empregados. Na Figura 2-5, 
são apresentados alguns exemplos de aterros reforçados.

(a)

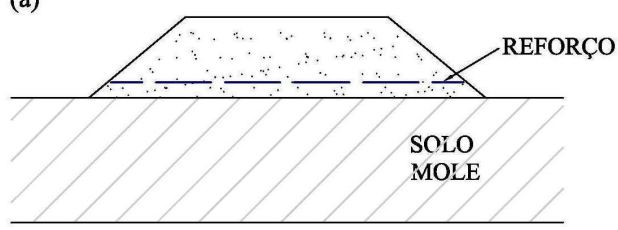

(c)

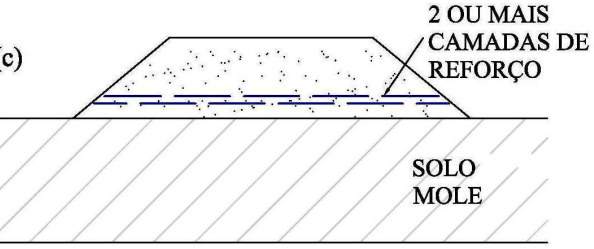

(b)

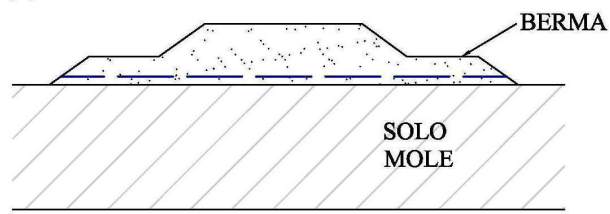

(d)

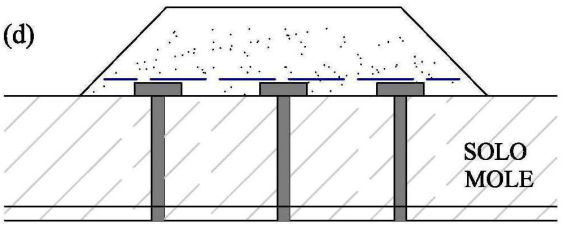

Figura 2-5 Exemplos de utilização de reforços em aterros sobre solos moles

Os aterros construídos sobre solos moles tem a tendência de espalhar-se lateralmente devido às tensões horizontais atuando no corpo do aterro. Essas tensões de terra causam tensões cisalhantes na base do aterro, o qual deve ser suportado pelo solo de fundação. Se o solo de fundação não tiver a resistência adequada, pode acorrer a ruptura. Os reforços de geossintético ou geogrelhas fornecem o incremento da resistência que garante a estabilidade (Christopher et al. 2001).

O reforço reduz os deslocamentos horizontais e verticais, o que faz reduzir o recalque imediato. Deve-se notar que o reforço não reduz a magnitude dos recalques por adensamento primário e secundário do aterro, mas pode uniformizálo.

Christopher et al. (2001), citaram as contribuições do uso do reforço na construção dos aterros sobre solos moles, tais como:

- O incremento do fator de segurança;

- O incremento na altura do aterro;

- A redução nos deslocamentos do aterro durante a construção;

- A melhora no comportamento do aterro devido ao aumento da uniformidade dos recalques pós-construção.

Uma diferença importante no uso do reforço, segundo Jewell (1988), está mostrada na Figura 2-6, onde se pode observar como varia o fator de segurança 
com relação à estabilidade global, para um aterro e um talude reforçado e um não reforçado.

Para aterros sobre solos moles, Figura 2-6 (a), o reforço é requerido para manter a estabilidade do aterro durante o período construtivo, que é a condição mais critica de estabilidade, pois o solo mole ainda não adensou e não teve ganho de resistência. O adensamento aumenta a resistência do solo até que se torna suficiente para manter a estabilidade sem os benefícios do reforço.

O reforço ajuda a manter o fator de segurança acima da unidade Figura 2-6 (b), para ser estável em comparação do caso de aterro não reforçado, onde o fator de segurança vai diminuindo durante a construção.

Segundo Almeida (1996), o reforço melhora a estabilidade durante o periodo construtivo e durante o adensamento da argila da fundação, até que a resistência ao cisalhamento da fundação tenha aumentado suficientemente para prescindir o efeito benéfico do reforço.

(a)

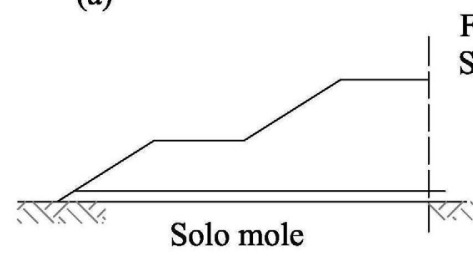

Carregamento sobre o solo mole

(c)

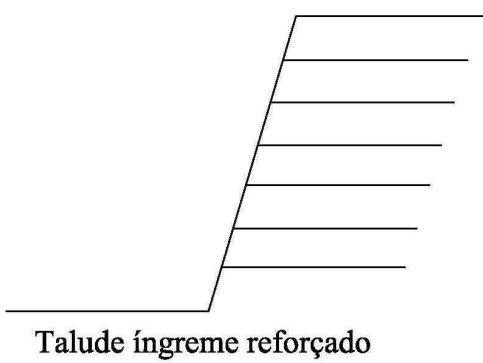

(b)

Fator de

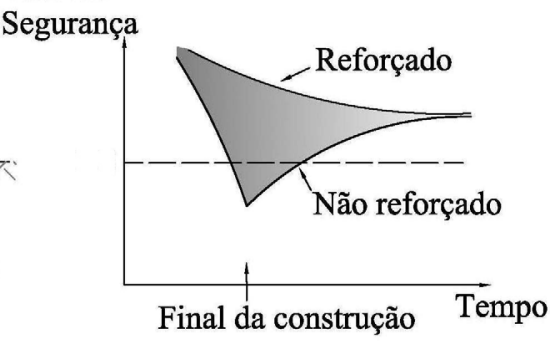

(d)

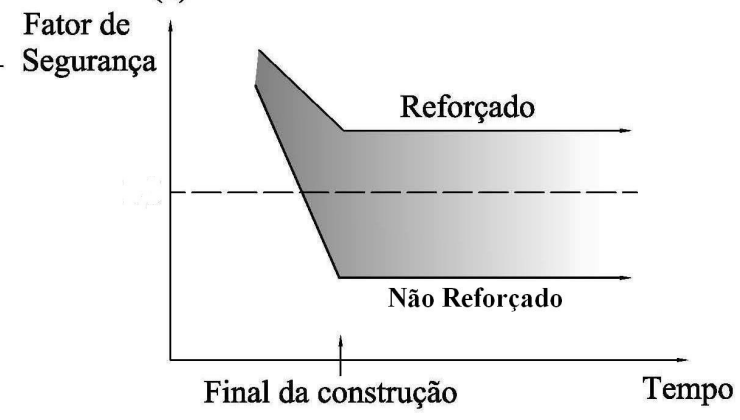

Figura 2-6 Aplicação do reforço nos aterros sobre solos moles e nos taludes (Jewell, 1988)

A Figura 2-6 (c), mostra o caso onde o reforço é colocado ao longo de um talude, com o fim de construir taludes íngremes, é preciso que a força de tração do 
reforço se mantenha constante por um longo período de tempo, então o reforço é requerido durante toda a vida útil da estrutura.

Nas Figura 2-6 (d), observa-se como é necessário o reforço para manter a estabilidade do talude no tempo.

\subsection{Ruptura em Aterros Reforçados sobre Solos Moles}

Para projetar aterros é necessário realizar uma série de análises numéricas e nelas devem-se considerar os estados limites últimos e estado limite de utilização do aterro.

O estado limite último está relacionado com a ruptura, quando o aterro perde a capacidade resistente como um todo ou em parte. Segundo a British Standard (BS8006 1995), considera-se como estados limites:

- estabilidade local;

- escorregamento rotacional;

- movimento lateral do aterro;

- extrusão da fundação;

- estabilidade global.

O estado limite de utilização é o estado no qual o aterro não rompeu, mas começou a ter um comportamento diferente para o qual foi projetado. Nesse caso é imposto um limite às deformações para a boa funcionalidade da obra.

Para os estados limites de utilização, a BS8006 considera:

- deformação excessiva do reforço;

- recalque da fundação.

A construção rápida de aterros sobre solos moles constitui um problema comum de instabilidade e a utilização dos reforços melhora as condições, aumentando o fator de segurança. Para realizar uma análise de estabilidade, devem-se verificar os possíveis mecanismos de ruptura desse tipo de estrutura.

Jewell (1988) descreveu os mecanismos pelos quais os reforços poderiam melhorar o desempenho dos aterros sobre solos moles. A tensão lateral imposta pelo aterro sobre o solo mole gera tensões cisalhantes, que por sua vez reduzem a capacidade de suporte. O reforço colocado na base do aterro pode resistir a uma parte ou a todo o empuxo promovido pelo aterro e resistir às deformações laterais 
da fundação, aumentando, desse modo, a capacidade de suporte.

Usualmente, são identificados três modos de ruptura (Jewell, 1982; Bonaparte \& Christopher, 1987) em aterros sobre solos moles:

- Instabilidade da fundação - recalques ou deformações excessivas; extrusão do solo de fundação sob o aterro intacto, com perda de geometria e recalques significativos. Ocorre devido à baixa capacidade de carga da fundação (Figura 2-7 a)

- Instabilidade interna - envolve somente o deslizamento lateral do material do aterro por sobre o reforço. (Figura 2-7 b)

- Instabilidade global - ruptura do aterro e da fundação com superfície de ruptura bem definida, a qual pode ser rotacional ou translacional. (Figura 2-7 c)

Segundo Futai (2010), na instabilidade de fundação (Figura 2-7 a), quando o solo mole tem espessura limitada em relação à dimensão do aterro, as tensões cisalhantes geradas pelo aterro podem induzir a extrusão (ou expulsão) do solo mole de fundação.

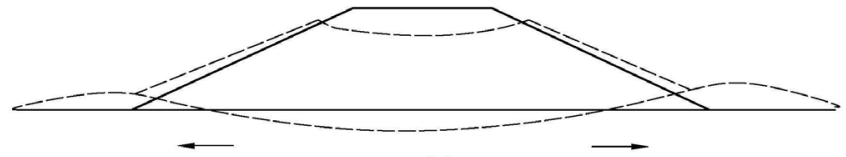

(a)

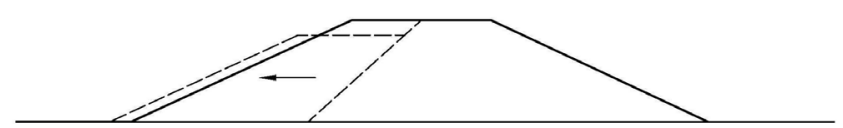

(b)

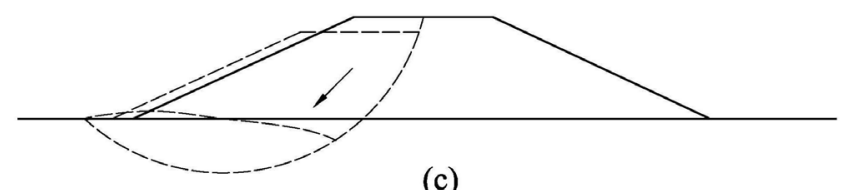

(c)

Figura 2-7 Tipos de ruptura de aterros sobre solos moles (Jewell (1982) (a) instabilidade da fundação, (b) instabilidade interna, (c) instabilidade global.

$\mathrm{Na}$ instabilidade interna, se os esforços cisalhantes entre o reforço e o material do aterro são inadequados, a tensão ativa dentro do aterro pode causar o deslizamento horizontal do corpo do aterro por cima do reforço. Na prática, este 
raramente é o caso crítico. Os parâmetros-chave para controlar estes mecanismos de ruptura são a resistência ao cisalhamento na fundação e na interface reforçosolo.

Existem várias propostas para projetar aterros reforçados sobre argilas moles, a seguir é apresentada algumas das soluções baseadas na teoria da plasticidade e do método de elementos finitos.

\subsection{Análise de Aterros Reforçados pela Teoria da Plasticidade}

Para os aterros reforçados sobre uma camada continua de solo mole, a estabilidade pode ser analisada como um problema de capacidade de carga da fundação.

O aterro aplica cargas verticais à superfície da fundação em combinação com as tensões cisalhantes causadas pelo empuxo horizontal do aterro (Figura 2-8).

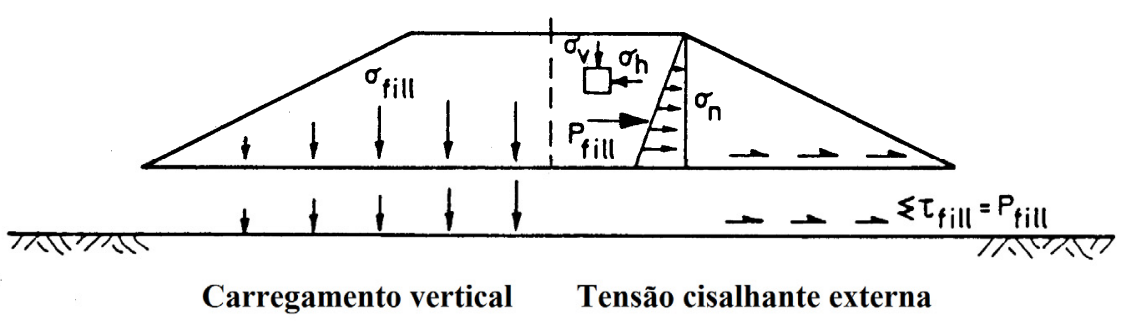

Figura 2-8 Distribuição das tensões cisalhantes na base de um aterro não reforçado (Jewell, 1988)

Nesse caso, o reforço é utilizado para melhorar a capacidade de carga da fundação. A estabilidade é critica durante a construção, devido ao carregamento rápido das camadas do material de aterro antes de se produzir a drenagem da fundação (condição não-drenada da fundação). Os solos argilosos podem drenar, adensar e aumentar a resistência com o tempo.

A diferença entre o caso de aterro não reforçado e o aterro reforçado é similar à diferença entre uma sapata lisa e uma sapata rugosa (Jewell, 1988). A influência das tensões cisalhantes externas é reduzir a capacidade de carga da fundação, como é mostrado na Figura 2-9. 
Capacidade de carga reduzida pela tensões cisalhantes
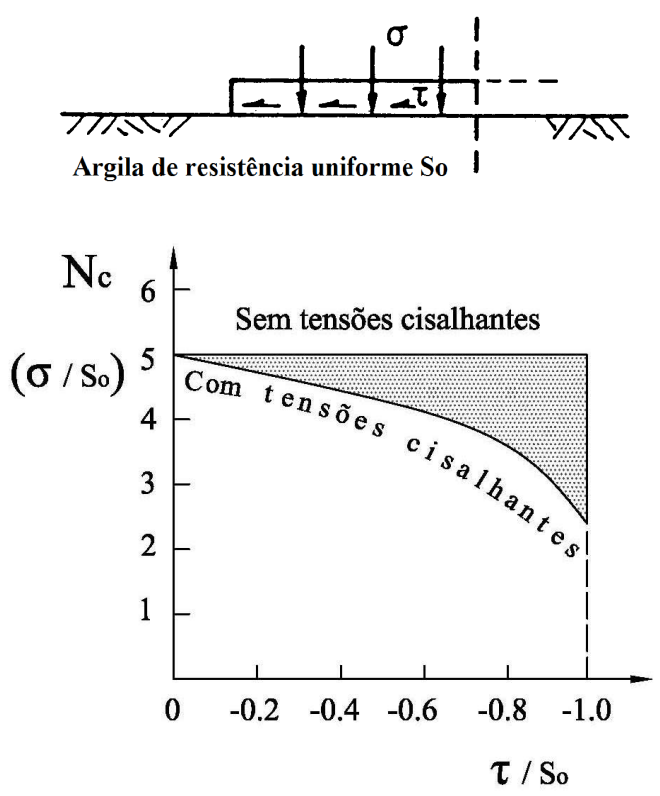

Figura 2-9 Influência das tensões cisalhantes na redução da capacidade de carga para uma sapata (Jewell, 1988).

O reforço colocado na base melhora a estabilidade do aterro, suportando as tensões cisalhantes que causam a instabilidade. Assim a fundação só tem que suportar as tensões verticais impostas pelo aterro (Figura 2-10).

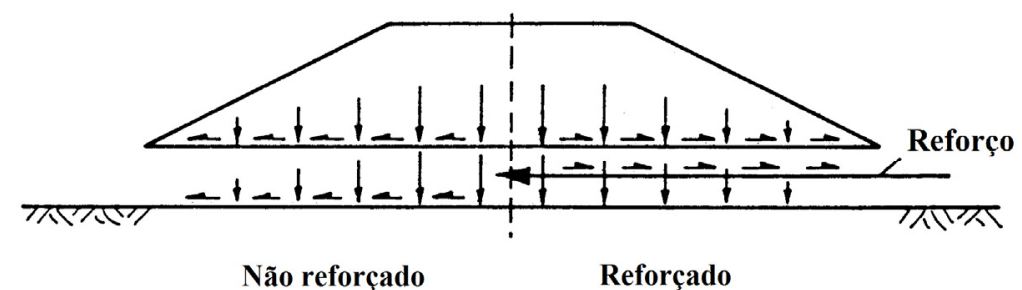

Figura 2-10 A função do reforço frente às tensões cisalhantes, (Jewell, 1988).

A teoria da plasticidade permite calcular as máximas tensões verticais que a fundação pode suportar em combinação com as tensões cisalhantes produzidas no contato fundação-aterro.

As soluções existentes para fundações de solos moles com a resistência 
crescente com a profundidade são mostradas na Figura 2-11 em termos do fator de capacidade de carga total Nc, para sapatas lisas e rugosas (Davis e Booker, 1973 apud Jewell, 1988)

As regiões sombreadas nas Figura 2-9 e Figura 2-11, indicam a magnitude da melhora da capacidade de carga que se pode esperar com o uso do reforço.

As cargas aplicadas por um aterro reforçado podem ser comparadas àquelas aplicadas a uma sapata rugosa. Rowe e Soderman (1987) apresentaram uma solução baseada na teoria da plasticidade, a qual pode ser usada para estimar a máxima altura de um aterro reforçado.

Nesta solução é considerado o incremento da resistência não drenada crescente com a profundidade, assim como o efeito da espessura relativa do solo de fundação, b/D.
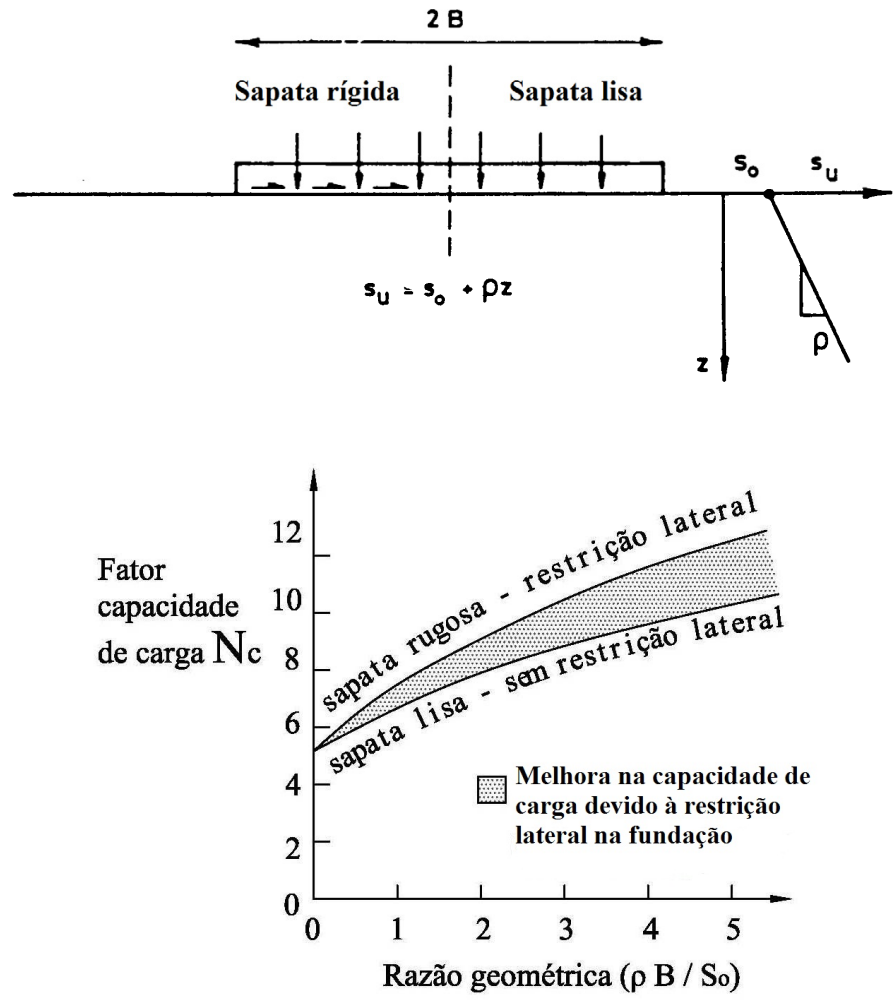

Figura 2-11 A influência da resistência crescente com a profundidade na capacidade de carga, Jewell (1982)

Os fatores da capacidade de carga, foram resumidos na Figura 2-12, em 
termos adimensionais de $\frac{\rho_{c} b}{S_{u o}}$ onde $\rho_{c}$ é a taxa de variação em $S_{u o} \operatorname{com} z, b$ é a largura efetiva da sapata e Suo a resistência não drenada abaixo da sapata.

Sabendo que um aterro reforçado nunca será reforçado ao ponto de ser rígido, estas soluções dão um limite na melhora da estabilidade, que pode ser atingida usando um reforço de elevada rigidez à tração. Segundo Rowe e Söderman (1987), estas soluções baseadas na teoria da plasticidade, junto a uma análise de elementos finitos podem ser usadas para:

- Estimar inicialmente a máxima altura que pode ser atingida pelo aterro, e usar essa informação para refinar a análise do aterro pelo MEF

- Depois de análise, essas soluções podem ser usadas para corroborar a altura da ruptura obtida pelo MEF para um aterro perfeitamente reforçado.

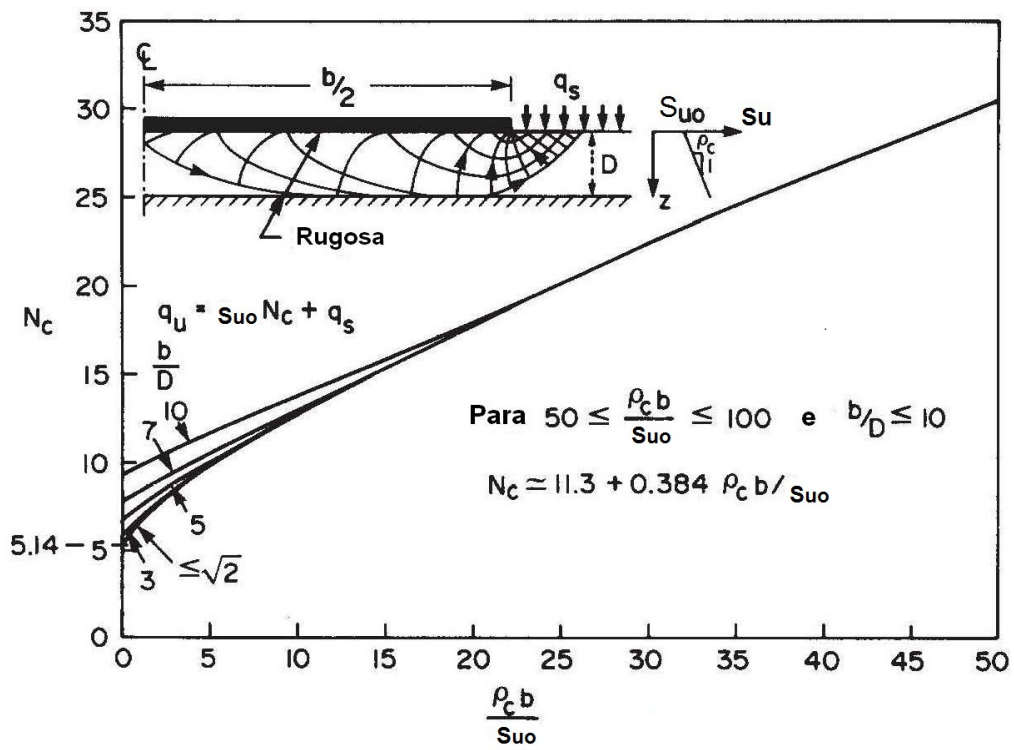

Figura 2-12 Fator de Capacidade de Carga para solo não homogêneo, Rowe e Söderman (1987, sintetizado dos resultados de David e Booker, e Matar e Salencon)

Como as soluções de plasticidade são para sapatas rígidas de largura $b$ e os aterros, geralmente, tem forma trapezoidal, deve-se fazer uma aproximação para determinar a largura equivalente do aterro. Das considerações da plasticidade, a tensão na borda da sapata rígida é $(2+\pi)$ Suo. Assumiu-se que a largura afetiva da 
sapata $b$ se estenderá entre os pontos a cada lado do aterro onde a pressão $h$ aplicada é igual a $(2+\pi) S_{u o}$. Por isto, a espessura $h$, onde a pressão aplicada é

$(2+\pi) S_{u o}$ fica: $h=\frac{(2+\pi) S_{u o}}{\gamma}$

E da Figura 2-13, tem-se:

$b=B+2 n(H-h)$

onde $B$ é a largura da crista, $H$ é a altura do aterro e $n$ é a cotangente do ângulo do talude.

A capacidade de carga $q_{u}$ da sapata rígida de largura $b$ é dada por:

$q_{u}=N_{c} S_{u o}+q_{s}$

Onde $q_{s}$ é a pressão de sobrecarga aplicada na superfície do solo fora da largura da sapata e $N_{c}$ é o fator da capacidade de carga obtida da Figura 2-12.

Observando a Figura 2-13, note-se que a borda triangular do aterro promove uma sobrecarga que vai incrementar a estabilidade. Então precisa-se de uma estimativa de $q_{s}$ em termos da pressão aplicada por essa distribuição triangular.

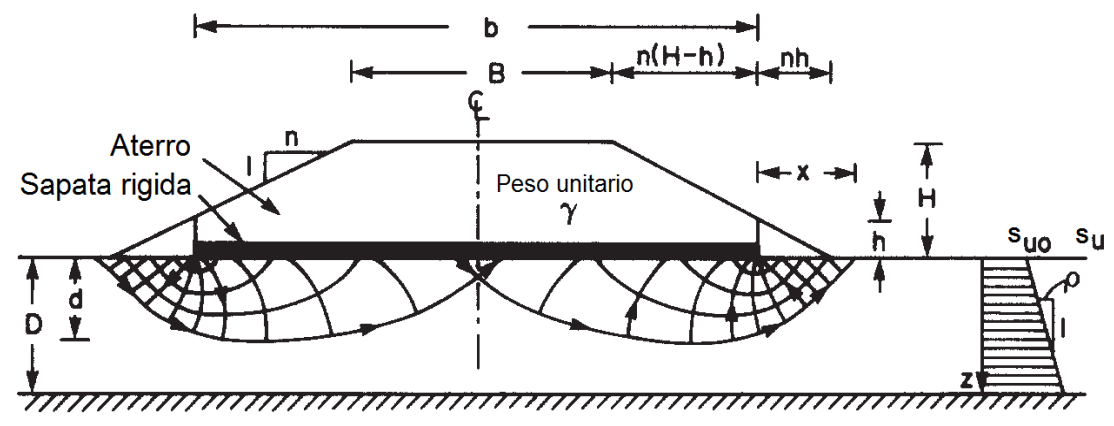

Figura 2-13 Definição das variáveis usadas para estimar a altura de colapso para um aterro perfeitamente reforçado (Rowe e Soderman, 1987)

A Figura 2-14, mostra a profundidade $d$ por onde se espera que 0 mecanismo da ruptura se desenvolva (Matar e Salencon 1977). 
Nos solos típicos, nota-se que a extensão lateral da região plástica envolvida na ruptura, estende-se uma distância $x$ desde a sapata até o pé do aterro (ver Figura 2-13), onde $x$ é aproximadamente igual ao mínimo de $d$ (que pode ser determinado a partir da Figura 2-14) e a espessura atual do depósito $D$. $x=\min (d, D)$

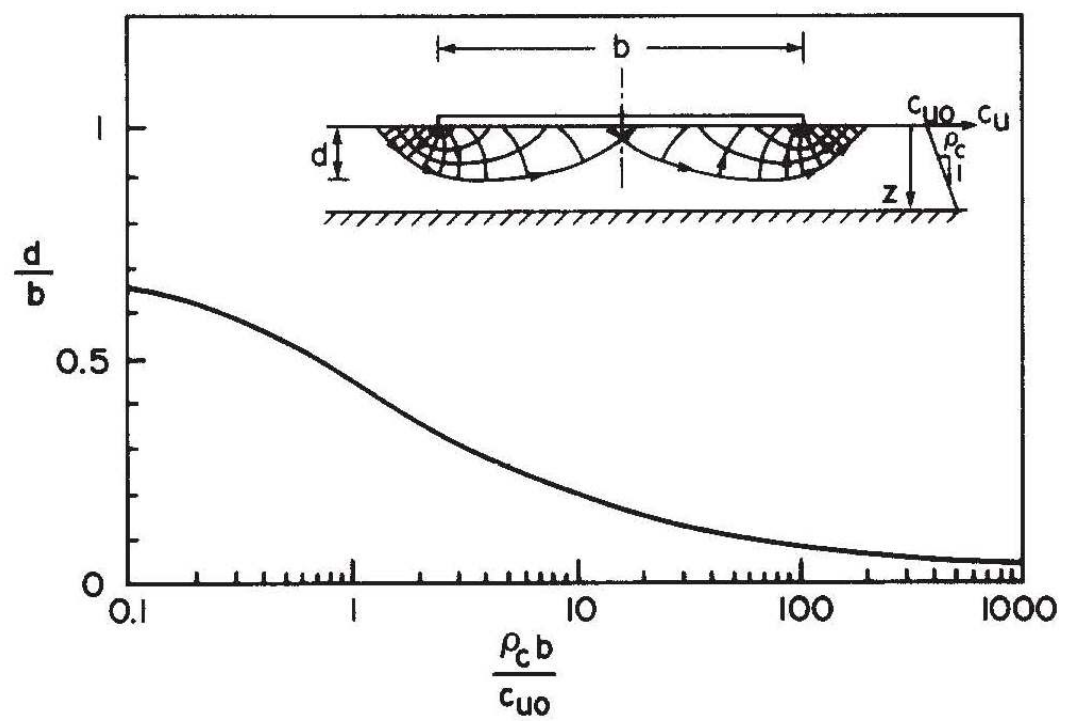

Figura 2-14 Efeito da não - homogeneidade na profundidade da área da ruptura embaixo da sapata rígida, Rowe e Soderman (1987, modificado de Matar e Salencon 1977)

Assim distribuindo a tensão aplicada devido à distribuição triangular sobre a distância $x$ é dada por:

$q_{s}=\frac{n \gamma h^{2}}{2 x}$

para $x>n h$

e

$q_{s}=\frac{(2 n h-x) \not h}{2 n h}$

para $x \leq n h$

Com os valores de $q_{s}$, pode-se calcular o valor para $q_{u}$ mediante a expressão $q_{u}=N_{c} S_{u o}+q_{s}$. Esse valor $q_{u}$, pode ser comparado com a tensão média aplicada $q_{a}$ devido ao aterro sobre a largura $b$, como é apresentado a seguir: 


$$
q_{a}=\gamma\left[\frac{B H+n\left(H^{2}-h^{2}\right)}{b}\right]
$$

No colapso, a taxa $\frac{q_{u}}{q_{a}}$ deve ser igual à unidade. Assim, para determinar a altura de colapso, $H_{c}$, para uma largura de crista, ângulo de inclinação e perfil de resistência dado, é necessário adotar um procedimento no qual $H$ é assumido, $q_{u}$ e $q_{a}$ são calculados e a razão de $\frac{q_{u}}{q_{a}}$ determinada. Se $\frac{q_{u}}{q_{a}}$ é maior que a unidade, então $H$ deve ser aumentada (se é menor que a unidade, então $H$ é reduzida) até que a altura crítica $H=H_{c}$ é atingida onde $\frac{q_{u}}{q_{a}}=1$.

Rowe e Söderman (1987) deram esta proposta para ser complementada com uma analises pelo MEF, Este é o procedimento adotado inicialmente para determinar a altura máxima do aterro, se for o caso, para fazer uma modelagem.

Para propósitos de estimar o possível fator de segurança máximo (definido anteriormente como $F S=\frac{q_{u}}{q_{a}}$ ), para uma dada geometria de aterro e determinado perfil de solo ou conferir a altura do colapso pelo método de elementos finitos, $q_{u}$ e $q_{a}$ podem ser determinados diretamente das equações (2.1) a (2.6), portanto a razão $\frac{q_{u}}{q_{a}}$ pode ser determinada.

No caso onde a análise de elementos finitos indica o colapso, a razão $\frac{q_{u}}{q_{a}}$ calculada para a geometria do aterro no colapso, deve ser aproximadamente igual a unidade para um aterro perfeitamente reforçado (dado que a ruptura não é controlada pela ruptura do reforço).

O uso das soluções baseadas na teoria da plasticidade para estimar a máxima contribuição do reforço, foi mostrado anteriormente. Os resultados das análises pelo método de elementos finitos são usados para demostrar que embora a carga de colapso calculada da teoria da plasticidade pode ser atingida por aterros reforçados de maior altura, em muitas situações a ruptura pode acontecer antes.

Por outro lado, as soluções baseadas na teoria da plasticidade são úteis 
porque provêem soluções que podem servir como base e ser comparadas com outras obtidas em diferentes análises, mas não pode ser usada para projetar aterros, porque não define a força de tração ou a rigidez do reforço.

É possível definir a essa força no reforço mediante uma análise pelo método de elementos finitos (MEF), conhecendo os dados da interação aterro-reforço-solo mole.

\subsection{Análise por Elementos Finitos}

A inclusão do reforço de geossintético num aterro construído sobre solos moles pode melhorar substancialmente a estabilidade e permitir a construção de aterros de maior altura em comparação aos casos de aterros sem reforço. Numerosos métodos para projetar aterros têm sido propostos baseados no método de equilíbrio limite e método de elementos finitos, além da teoria da plasticidade (Rowe e Söderman, 1987), para saber a melhora no comportamento que o aterro pode ter com o reforço.

O método do equilíbrio limite é o método mais usado para avaliação da estabilidade dos aterros reforçados sobre solos moles na condição não drenada (Haliburton, 1981; Jewell, 1982; Milligan e La Rochelle, 1984; Rowe e Soderman 1985; Bergado et al.,1994; Palmeira et al., 1998, etc.). Mas nem o método de equilíbrio limite ou soluções de plasticidade fornecem informação sobre deformações ou tensões que se desenvolvem no reforço num aterro reforçado.

Estas limitações, podem ser superadas pelo método dos elementos finitos, que possibilita o estudo adequado de estruturas de solo reforçado, e além de analisar as deformações, conhecer as zonas de plastificação do solo mole, também permite identificar o mecanismo da ruptura.

O aterro reforçado é um sistema composto, que envolve três componentes: a fundação, o material do aterro e o reforço. A maior vantagem da análise de elementos finitos em relação aos métodos convencionais é que pode ser simulada uma completa interação do aterro, além de modelar os estágios de construção.

O desempenho do aterro reforçado depende da interação entre estes componentes. Diante isto, surge a pergunta de qual a importância das considerações de interação do desempenho do aterro em relação às deformações 
do reforço. Essa pergunta pode ser resolvida mediante a construção e monitoramento de aterros experimentais. Mas, infelizmente, o custo de se realizar e monitorar um número suficiente de aterros reforçados é tão grande que não é prático. O uso do método de elementos finitos é uma alternativa mais efetiva em relação ao custo de construir aterros experimentais, porque permite realizar simulações numéricas da construção de aterros para diferentes condições.

O método de elementos finitos (MEF) é, atualmente, um dos mais importantes métodos numéricos utilizados. Além de ser conhecido por ser uma ferramenta poderosa para o uso na avaliação de comportamento de aterros, podem-se encontrar exemplos de modelagem de aterros reforçados na literatura. Muitos pesquisadores já empregaram a técnica do MEF para interpretar o comportamento de campo de aterros reforçados (Andrawes et al., 1980; Rowe, 1982; Boutrop e Holtz, 1983; Rowe, 1984; Monnet et al., 1986; Duncan et al., 1987; Schaefer e Duncan, 1988; Humphrey e Holtz, 1989; Hird e Kwok, 1990; Mylleville e Rowe, 1991; Chai e Bergado, 1993; Litwinowicz et al., 1994; Rowe et al., 1996; Varadarajan et al., 1997; Hinchberger e Rowe, 1998).

Na sequência apresenta-se o procedimento de Rowe e Soderman (1987), o qual aborda uma série de análises pelo MEF, realizados em aterros reforçados com o fim de mostrar o estudo da interação no reforço, considerando a magnitude das deformações produzidas nele, antes de ocorrer a ruptura do aterro.

\subsubsection{Procedimento de Rowe e Soderman (1987) para determinar a altura da ruptura do aterro pelo MEF}

A teoria da plasticidade (anteriormente descrita) pode ser usada para determinar a máxima altura que o aterro pode atingir com o uso do reforço, mas não define as características do reforço e não considera as magnitudes das deformações que podem desenvolver-se no reforço antes da ruptura.

Para interpretar os resultados obtidos nas análises por elementos finitos, Rowe e Söderman (1987), definiram o termo "plasticidade contígua" para assim identificar os eventos que se produzem durante a construção do aterro até a ruptura. O termo "plasticidade contígua" esta relacionado à situação onde ocorre uma plastificação geral do solo que compõe a região do mecanismo de ruptura. 
Nessa condição, as tensões cisalhantes do solo estão mobilizadas ao longo da superfície potencial de ruptura.

Para um aterro não reforçado, a ruptura e o escorregamento coincidem com o desenvolvimento da plasticidade contígua e o mecanismo de ruptura, mas para um aterro reforçado o desenvolvimento das áreas de plasticidade contígua é o primeiro estagio frente à ruptura e ao escorregamento, Rowe e Soderman (1987).

A seguir, apresenta-se uma breve descrição dos modelos utilizados na analise realizada pelos autores.

Entre os modelos constitutivos existentes na literatura, um dois mais simples é o critério da ruptura de Mohr-Coulomb, este modelo tem sido aplicado com sucesso na análise de aterros reforçados (Rowe e Söderman, 1984; Rowe, 1982; Rowe, MacLean e Söderman, 1985).

Para modelar o comportamento do solo do aterro foi considerada a variação da rigidez do solo com aumento do nível de tensão durante a construção, porque influencia nos esforços e deslocamentos desenvolvidos no aterro reforçado. Um método simples foi adotar o modelo não-linear baseado na equação do Janbu (1963).

$$
\frac{E}{P_{a}}=K_{E}\left(\frac{\sigma_{3}^{\prime}}{P_{a}}\right)^{M}
$$

Onde:

$E$ - é o modulo de Young

$P_{a}$ - é a pressão atmosférica

$\sigma_{3}^{\prime}$ - é a tensão efetiva menor

$K_{E}-$ é constante do material (250)

$M$ - é constante do material $(0,5)$

Essa não linearidade está inclusa no modelo "hiperbólico" e pode ser incluída nos modelos elástico-plásticos. O reforço pode ser modelado usando um elemento de barra unidimensional.

\section{Conceito de Altura Líquida e Deformação Admissível do Reforço}

Segundo Rowe e Soderman (1987), a importância de considerar as deformações para analisar a ruptura, pode ser demostrada mediante um gráfico na forma de altura liquida do aterro versus a espessura do aterro, conforme mostrado 
na Figura 2-15

A altura líquida do aterro é a espessura do aterro sobre o nível do terreno, ou seja, é a altura com a qual aterro foi executado menos o recalque imediato, e é apresentado no eixo vertical. A ruptura é definida pelo ponto máximo que atinge a curva no gráfico e a altura de ruptura esta indicada no eixo horizontal, assim como é mostrado na Figura 2-15 (a).
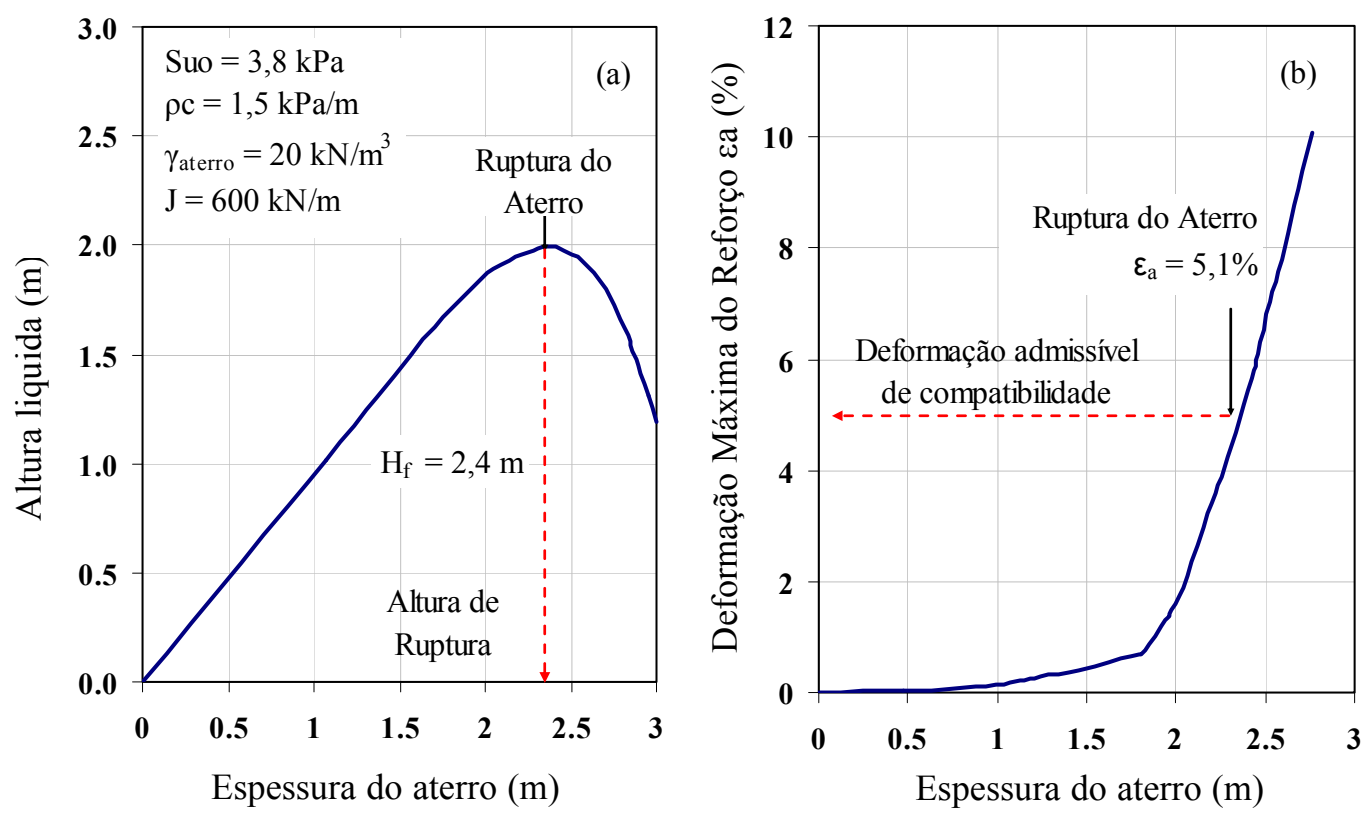

\section{Figura 2-15 Altura Liquida Máxima e Deformação Admissível de Compatibilidade do Reforço (Rowe e Hinchberger 2003).}

As deformações no reforço são suscetíveis à altura do aterro onde se apresenta a plasticidade contígua, devido ao fato que tensões cisalhantes do solo estão sendo mobilizadas. É assim que as deformações começam a desenvolver-se com o incremento da plastificação do solo de fundação.

Esse conceito é importante para definir a deformação admissível de compatibilidade do reforço correspondente à altura máxima (espessura) da ruptura do aterro reforçado (Figura 2-15 b). A máxima deformação que ocorre no geossintético no momento da ruptura do sistema será denominada de deformação admissível de compatibilidade. Esta deformação de compatibilidade é a deformação referente à altura líquida máxima. A deformação desenvolvida no reforço para uma 
altura de aterro especifica, vão depender da altura do aterro onde ocorre a plasticidade continua (Rowe e Söderman, 1987).

Qualquer tentativa de colocar uma camada (material de aterro) adicional depois de ter atingido a altura máxima, só diminui o desempenho do aterro sem incrementar a altura dele, porém só vai resultar na perda da altura líquida.

Para aterros reforçados, o colapso envolve a ruptura do solo e do sistema solo-reforço. É claro que a ruptura solo-reforço pode tomar a forma de ruptura da interface solo-geossintético (escorregamento do geossintético em relação ao solo) ou a ruptura do geossintético. Não obstante, o geossintético pode atingir a deformação máxima (item 2.3 .2 e 2.3.3) antes de romper. Por isso, é comum que a ruptura do aterro (decorrente da plastificação do solo de fundação) aconteça antes da ruptura do geossintético.

Num projeto de aterros reforçados, é considerado que a superfície de ruptura e nos casos em que o geossintético rompe, a interface solo-reforço rompe ou a deformação máxima do geossintético atinge a "deformação admissível de compatibilidade" (Figura 2-15 b).

O procedimento apresentado anteriormente foi aplicado com sucesso por Rowe (1982) no estudo do aterro Pinto Pass nos Estados Unidos e por Rowe e Söderman (1984) no estudo do aterro Almere na Holanda.

\subsubsection{Estudo de Rowe e Hinchberger (2003): Fatores que afetam a deformação do reforço na ruptura do aterro}

Como é sabido, o método de equilíbrio limite é o mais aceito para avaliar a estabilidade de um aterro reforçado sobre solos moles, mas nesse método a força mobilizada no reforço é assumida como conhecida (Rowe e Soderman, 1985, 1987).

Para projetar aterros, os engenheiros baseiam-se na experiência ou em métodos de análise para estimar a deformação no reforço a usar nos cálculos da análise de equilíbrio limite (Bonaparte e Christopher, 1987).

Rowe e Hinchberger (2003) elaboraram um artigo, baseados nos conceitos de Rowe e Söderman (1987) de altura líquida de deformação admissível do reforço; mediante série de análises e resumindo os resultados pelo MEF, criaram um ábaco para estimar a deformação admissível de compatibilidade do reforço $\varepsilon_{a}$ para o caso 
de aterros que rompem devido aos deslocamentos excessivos. O método é aplicado nos solos moles com a resistência não drenada crescente com a profundidade.

Os autores estudaram o comportamento dos aterros e a influência nas deformações dos parâmetros do solo de fundação, a geometria do aterro é a rigidez do reforço.

\section{Abordagem do Estudo}

Para realizar uma estimativa aproximada da deformação admissível do reforço na ruptura do aterro foram modelados aterros típicos com altura $h$; crista de largura $B$; inclinação do talude $n H: 1 \mathrm{~V}$, sobre uma camada de argila mole de profundidade $D$, apresentado na Figura 2-16

A resistência não drenada do solo mole é igual a $S_{\text {uo }}$ na superfície $e$ aumenta $\rho_{c}$ com a profundidade. Os detalhes quanto aos procedimentos de elementos finitos, os modelos constitutivos e a modelagem foram baseados no estudo de Rowe e Söderman (1987), Rowe e Mylleville (1993).

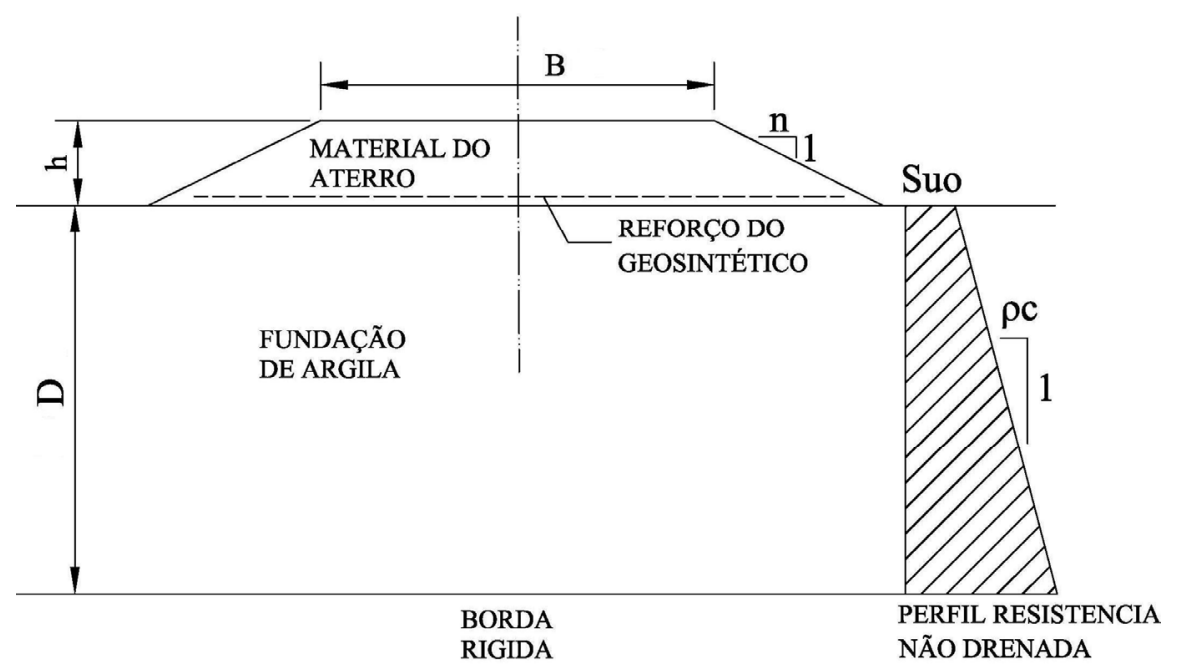

Figura 2-16 Geometria do aterro e estratigrafia da fundação. (Hinchberger e Rowe 2003)

Apresentam-se, a seguir os fatores estudados por esses autores, que influenciam nas deformações do reforço de aterros reforçados sobre solo mole. 


\section{a) Efeito da Rigidez do Reforço}

A construção de vários aterros levados à ruptura foi simulada numericamente por Hinchberger \& Rowe (2003), para aterros sobre solo mole de uma espessura tal que não tivessem influência na cinemática ou geometria do mecanismo de ruptura. Essa profundidade da camada de fundação $D$ foi selecionada com base nos cálculos de equilíbrio limite e confirmada com os vetores de deslocamento. Assim, a profundidade da base rígida variou entre 2 e 2,5 vezes a profundidade de plastificação.

O efeito do aumento da rigidez do reforço, foi resumido na Figura 2-17 os autores fizeram várias análises com variação da rigidez para um solo mole com $\mathrm{S}_{\mathrm{uo}}$ $=11,5 \mathrm{kPa}$ e $\rho c=1,5 \mathrm{kPa} / \mathrm{m}$.

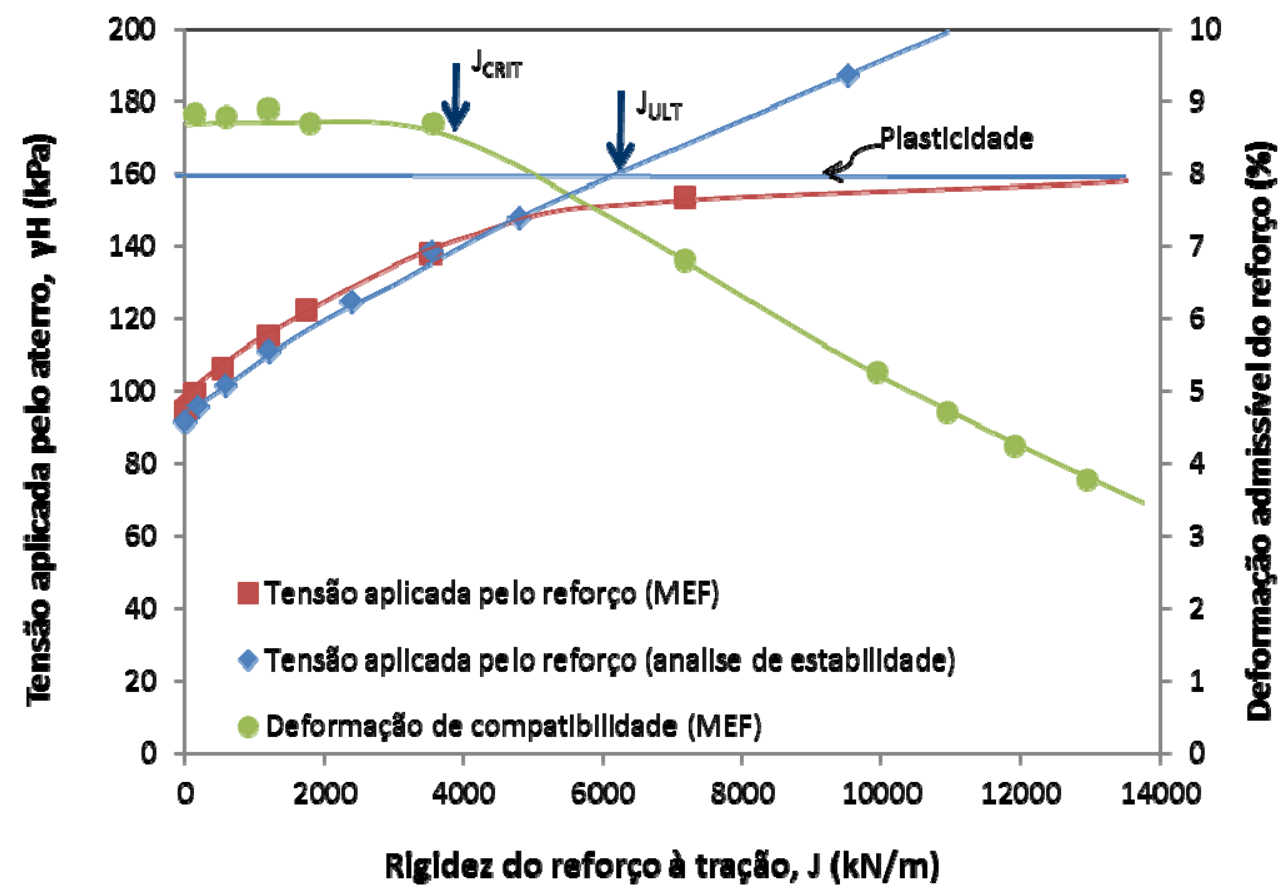

Figura 2-17 Influência da rigidez do reforço no comportamento do aterros por elementos finitos e análise de escorregamento circular (Modificado de Hinchberger \& Rowe 2003)

A Figura 2-17 mostra as tensões induzidas pelo aterro na ruptura e as deformações de compatibilidade correspondentes. Para baixos valores de rigidez até um valor de rigidez crítico $\mathrm{J}_{\text {crit, }}$ a deformação do reforço na ruptura; determinada 
usando o conceito de altura líquida máxima é constante denominada deformação crítica, $\varepsilon_{\mathrm{o}}\left(8,8 \%\right.$ neste caso). A partir de esse valor de $\mathrm{J}_{\text {crit, }}$ a deformação reduz com o aumento da rigidez.

Nessa faixa de rigidez, abaixo de $\mathrm{J}_{\text {crit }}\left(\mathrm{J}_{0}<\mathrm{J}_{\text {crit }}\right)$, verificou-se que a rigidez do reforço tem pouca influência na espessura do aterro que causa a plastificação da fundação. O peso adicional do aterro depois de produzida a plastificação é suportado pelo reforço. Os aterros cuja rigidez do reforço está abaixo do $\mathrm{J}_{\text {crit }}$ foram definidos por Hinchberger \& Rowe (2003) como sub-reforçados.

Nos casos de aterros com rigidez acima de $J_{\text {crit., a rigidez do reforço }}$ influencia na cinemática da ruptura. Uma elevada rigidez do reforço faz que o mecanismo de ruptura seja deslocado para uma profundidade maior dentro da fundação.

Os autores simplificaram as análises para realizar uma análise de estabilidade por equilíbrio limite, assumindo a força no reforço $T_{a}=J^{*} \varepsilon_{a}$ e a deformação constante e igual a $\varepsilon_{0}\left(\varepsilon_{0}=8,8 \%\right)$. Na Figura 2-17, pode-se ver que os resultados pelo equilíbrio limite são compatíveis com os obtidos pelo MEF até o limite de altura estabelecido pela solução da teoria da plasticidade.

Após todo esse estudo, Hinchberger \& Rowe (2003), desenvolveram um ábaco para estimar a deformação admissível de compatibilidade do reforço $\varepsilon_{a}$, para aterros na condição sub-reforçada, ou seja, quando $\mathrm{J}<\mathrm{J}_{\text {crit. }}$ A correlação para definir a deformação admissível de compatibilidade foi feita com base na altura de ruptura de aterros não reforçados, $\mathrm{H}_{\mathrm{C}}$; porque é um valor que deve ser calculado como no primeiro lugar para projetar o aterro, e representa a altura a partir da qual o reforço começa a ser mobilizado na condição sub-reforçado.

Os resultados de uma série de análises de elementos finitos foram sintetizados no gráfico mostrado na Figura 2-18.

No projeto de aterros sobre solos moles, o projetista pode escolher o uso de geossintético como reforço para garantir a estabilidade não-drenada no fim da construção. Hinchberger \& Rowe (2003) propõem um método simplificado para estimar o reforço necessário para conseguir a estabilidade do aterro, o qual é mostrado a seguir.

I. Parâmetros fatorizados da resistência do solo.

Assumindo uma determinada a resistência não drenada da fundação, se 
obtém os parâmetros fatorizados $S_{\mathrm{uo}}{ }^{*}$ e $\rho^{*}$, aplicando um fator parcial PF o

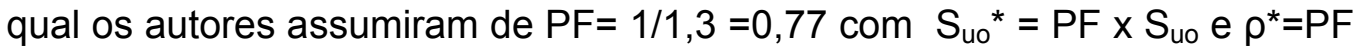
$x \rho$.

Adoptando um fator parcial $\mathrm{PF}=0,77$ para um aterro no reforçado, é equivalente a adoptar um fator de segurança de 1,3.

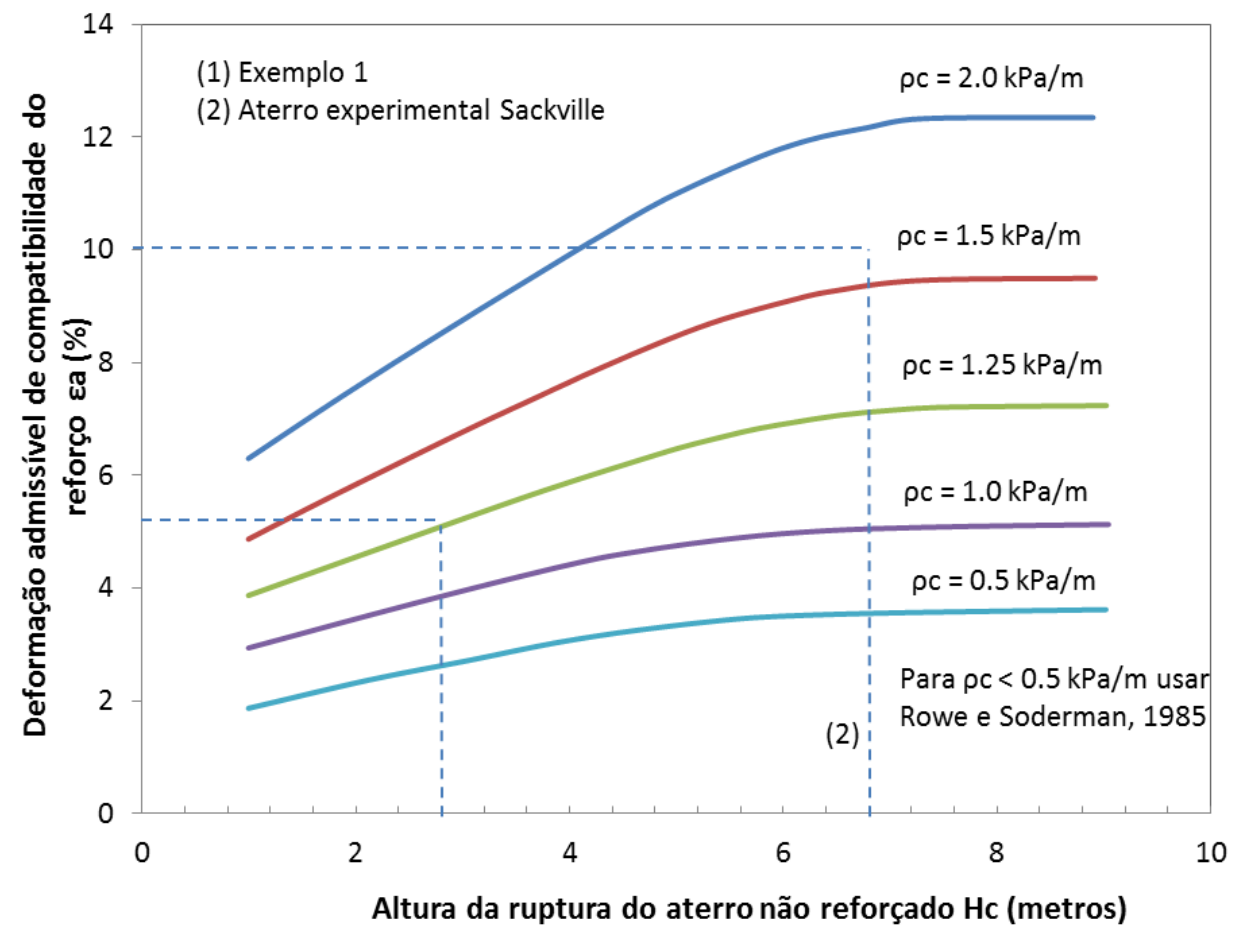

\section{Figura 2-18 Ábaco para determinação da deformação admissível de compatibilidade (Hinchberger \& Rowe 2003).}

II. Altura de colapso de um aterro não reforçado

Efetuar uma analise de equilibrio limite (slip circle), empregando os parâmetros fatorizados para avaliar se o reforço é requerido. Se a altura de colapso calculada do aterro não reforçado, $\mathrm{H}_{\mathrm{c}}$, é igual o maior do que a altura desejada $\mathrm{H}$, o projeto não requer reforço. Caso contrário, pode ser considerado permitir o aumento de altura do aterro. No contexto de estado limite, a altura de colapso $\mathrm{H}_{\mathrm{c}}$ para $\mathrm{o}$ aterro não reforçado corresponde à altura na qual o momento instabilizador é igual ao momento estabilizador

III. Altura de colapso de um aterro perfeitamente reforçado 
Se o reforço é requerido para atingir à altura desejada deve-se calcular a altura máxima teórica $\mathrm{H}_{\cup}$ para um aterro perfeitamente reforçado descrito por Rowe e Soderman (1987). São adotados os parâmetros fatorizados e assume-se que há suficiente reforço para que o aterro se comporte como uma sapata rígida, e a altura $\mathrm{H}_{U}$ é calculada usando as soluções de capacidade de carga para sapatas rígidas adaptadas para a analise de aterros.

Se a altura desejada $\mathrm{H}$, excede à altura máxima para um aterro perfeitamente reforçado $\left(H>H_{U}\right)$, o reforço só não vai fornecer a estabilidade e é necessário usar alternativas para estabilizar.

Se a altura desejada $\mathrm{H}$, excede $\mathrm{H}_{\mathrm{c}}$ mas é menor que $\mathrm{H}_{U}$, é preciso selecionar um reforço para fornecer a força estabilizadora.

IV. Forças do Reforço na Estabilidade de um Aterro Reforçado

A estabilidade de um aterro reforçado pode ser avaliada realizando uma análise de equilíbrio limite (por exemplo, Rowe e Soderman, 1985; Rowe e Mylleville, 1993; Palmeira et al., 1998), onde há um adicional no momento resistente devido à força $T$ mobilizada pela inclusão do reforço. A força do reforço, $T$; pode ser considerada como o mínimo de:

i. a força necessária para suportar a resistência ao cisalhamento na interface argila-aterro abaixo do aterro e acima da fundação (Jewell, 1988);

ii. a força capaz de resistir ao arrancamento (por exemplo, Fowler e Koerner, 1987);

iii. a força admissível do reforço.

$T_{a}=m J \varepsilon_{a}$

Onde $m$ é o número de camadas de reforço (tipicamente $m$ é igual a 1 ou 2; $J$ é a rigidez secante do reforço para uma deformação entre 0 até $\varepsilon_{a} ; \varepsilon_{a}$ é a deformação admissível do reforço.

Os cálculos feitos pelo método de equilíbrio limite utilizando $\varepsilon_{0}$ tendem a superestimar o efeito de reforço para $\mathrm{J}>\mathrm{J}_{\text {crit }}$. Consequentemente, foi introduzido um fator de correção, $\alpha_{r}$, apresentado na Tabela 2-3, para ser usado nos projetos. O fator de correção, $\alpha_{r}$, pode ser entendido da Figura 2-17 e representa a relação da $J_{F E}$ (resultados dos elementos finitos) para $J_{L E}$ (resultado de equilíbrio limite) para 
um determinado carregamento.

Tabela 2-3 Fatores de correção do reforço (Hinchberger \& Rowe 2003).

\begin{tabular}{c|c}
\hline$\left(H-H_{c}\right) /\left(H_{u}-H_{c}\right)$ & Fator de correção, $\alpha_{r}$ \\
\hline$\leq 0,7$ & 1,0 \\
0,8 & 1,15 \\
0,9 & 1,4 \\
1,0 & 2,0 \\
\hline
\end{tabular}

Sendo:

$\mathrm{H}$ : altura do aterro reforçado

$\mathrm{H}_{\mathrm{C}}$ : altura de ruptura do aterro não reforçado

$\mathrm{H}_{\mathrm{u}}$ : altura de um aterro perfeitamente reforçado, cujo valor é obtido pela solução da teoria de plasticidade.

A força no reforço junto com a deformação admissível de compatibilidade $\varepsilon_{a}$ da Figura 2-18, podem ser usadas para especificar a rigidez mínima requerida do reforço.

$$
J=\frac{\alpha_{r} T_{r}}{\varepsilon_{a}}
$$

O valor $\alpha_{r}$ corrige os valores obtidos pela analise por equilíbrio limite que ficam acima do valor obtido pela teoria da plasticidade.

\section{b) Efeito da Largura da Crista do Aterro, B}

Para analisar os efeitos da largura da crista, foram modelados aterros com larguras B, com $20 \mathrm{~m}$ e $40 \mathrm{~m}$. Os parâmetros de resistência do solo usados foram $S_{\text {uo }}=7,5 \mathrm{kPa}$ e $\rho_{\mathrm{c}}=1,25 \mathrm{kPa} / \mathrm{m}$ e a profundidade da fundação foi escolhida para que não ocorresse plastificação limitada pela profundidade. Usando o mesmo procedimento descrito na seção anterior, a profundidade da fundação foi selecionada com base em cálculos de equilíbrio limite e que variam entre 2 e 2,5 vezes a profundidade afetada pelo círculo crítico.

O cálculo indica que ambos os aterros estão bem definido na faixa subreforçada e a diferença entre a máxima deformação do reforço na ruptura não apresenta diferença prática significativa. Uma deformação admissível de compatibilidade $\varepsilon_{a}$ de cerca de $5 \%$ ( Figura 2-19) seria adequada para se projetar 
ambos os aterros.

Observa-se na Figura 2-19, que quando o reforço se torna muito rígido (superior a $8000 \mathrm{kN} / \mathrm{m}$ ), o cálculo da deformação do reforço na ruptura para $B=$ $40 \mathrm{~m}$ começa a exceder os valores calculados da deformação do reforço na ruptura para $B=20 m$.

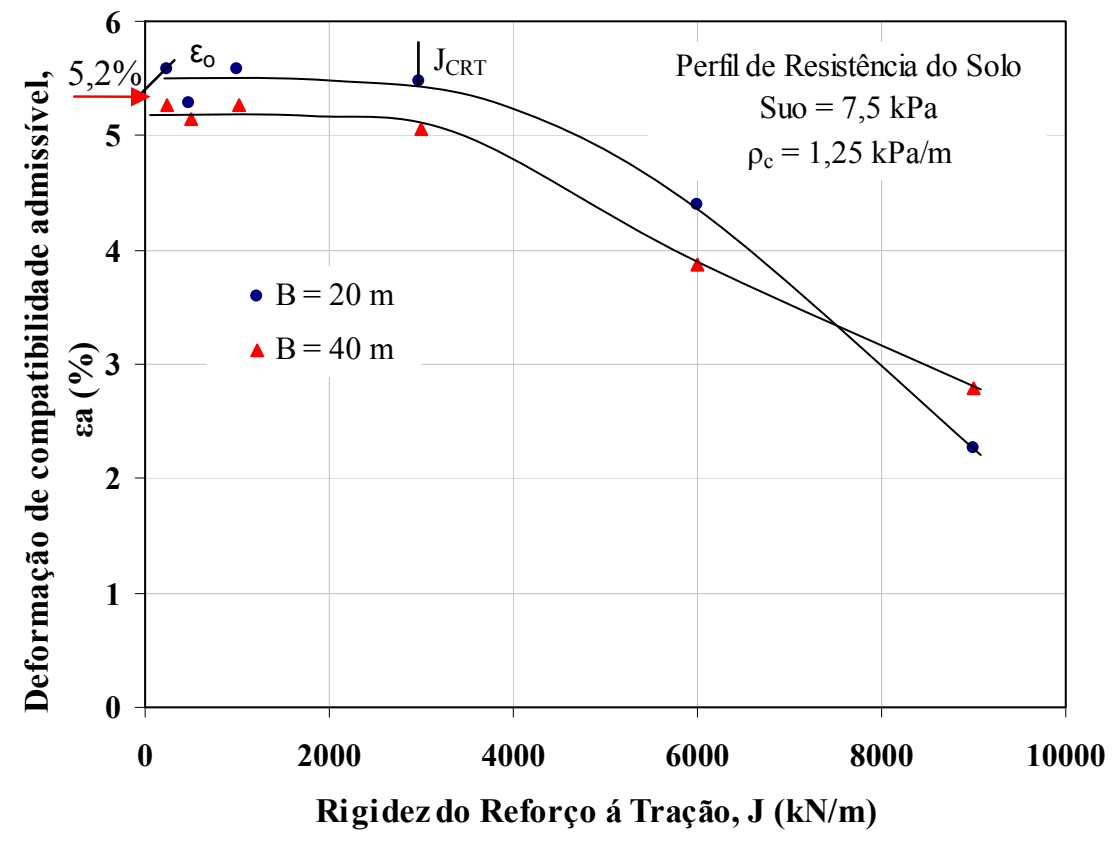

\section{Figura 2-19 Efeito da largura da crista do aterro nas deformações máximas do reforço na ruptura (Hinchberger \& Rowe 2003).}

Para reforço com rigidez maior que $\mathrm{J}_{\text {crit }} \mathrm{O}$ carregamento aplicado na ruptura tende a se aproximar da solução de capacidade de carga de uma função rígida e a relação $D / B$ possa a influenciar tanto a cinemática da ruptura como também 0 resultado da deformação do reforço na ruptura.

Foi considerado em geral, que para outras geometrias e perfis de solo, a largura da crista do aterro teve um impacto insignificante sobre o cálculo da deformação do reforço na ruptura, desde que a profundidade do solo não tenha influenciado na geometria e cinemática da ruptura.

A Figura 2-20 mostra o campo de velocidade na ruptura de dois aterros analisados na Figura 2-19 e para $\mathrm{J}=600 \mathrm{kN} / \mathrm{m}$.

Tanto a geometria e a forma do mecanismo de ruptura são essencialmente os mesmos e por isso, a largura da crista não tem um impacto significativo sobre o 
comportamento do aterro no âmbito dos aterros sub-reforçados. Então se pode notar que a largura da crista do aterro não tem qualquer impacto sobre a altura ou a geometria do mecanismo de ruptura para aterros não reforçados similares com $B=$ 20 e $40 \mathrm{~m}$.

(a)
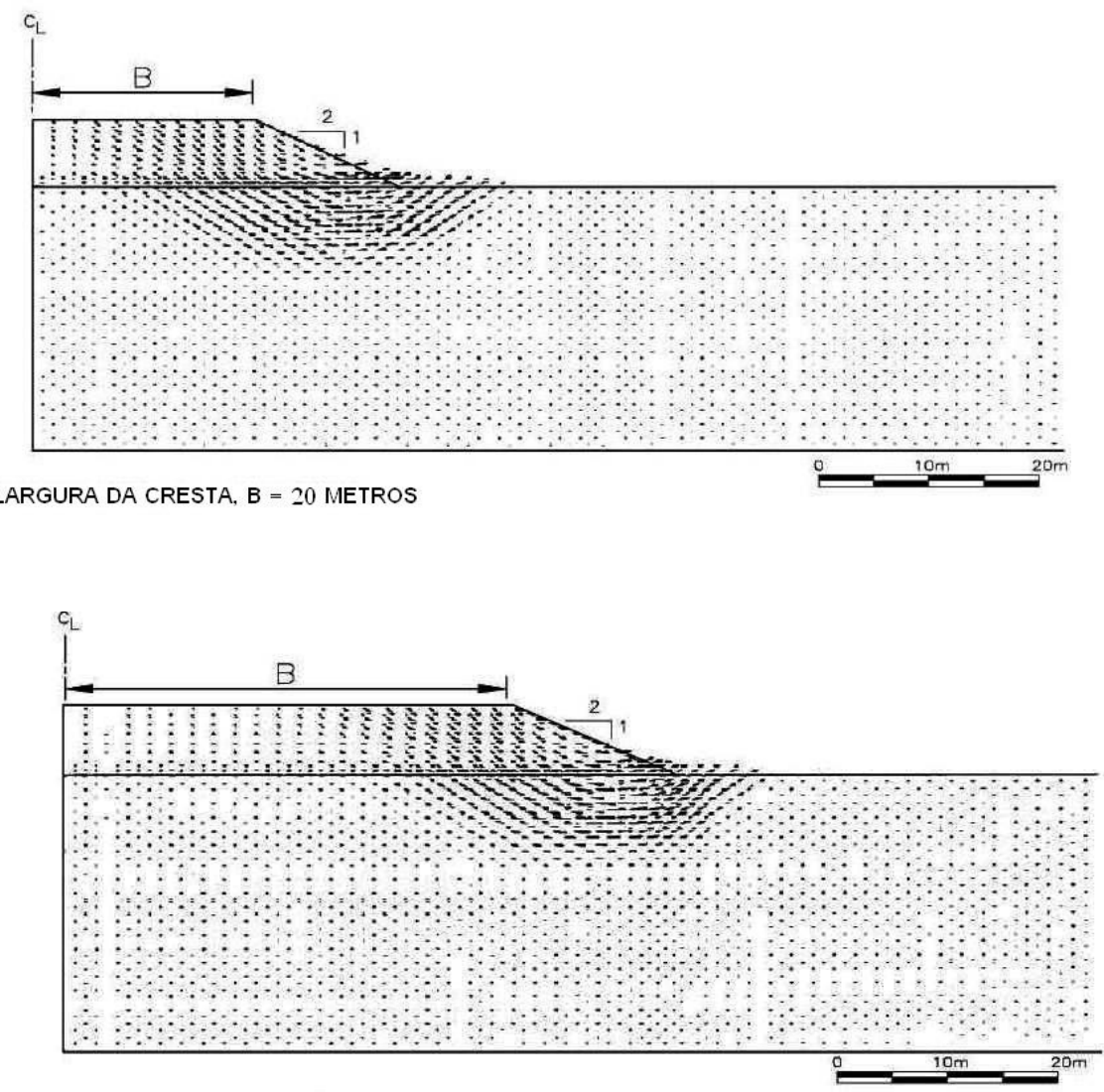

(b)

Figura 2-20 Comparação dos vetores deslocamento na ruptura para $B=20 \mathrm{e}$ $40 \mathrm{~m}$ e rigidez do reforço, $\mathrm{J}=600 \mathrm{kN} / \mathrm{m}$ (Hinchberger \& Rowe 2003)

O efeito insignificante da largura da crista do aterro sobre a deformação do reforço na ruptura foi também confirmado por Rowe e Söderman (1987) e Rowe e Mylleville (1990) para aterros com largura de crista de 30 e $18 \mathrm{~m}$, respectivamente.

\section{c) Efeito da Resistência não drenada na Superfície, $\mathbf{S}_{\mathrm{uo}}$}

A influência da resistência não drenada na superfície do solo mole, $S_{u 0}$ esta mostrada na Figura 2-21 para $\rho_{\mathrm{c}}$ igual a $1,5 \mathrm{kPa} / \mathrm{m}$. Para $S_{u 0}$ inferior a $11,5 \mathrm{kPa}$, apresenta o comportamento do aterro sub-reforçado. 


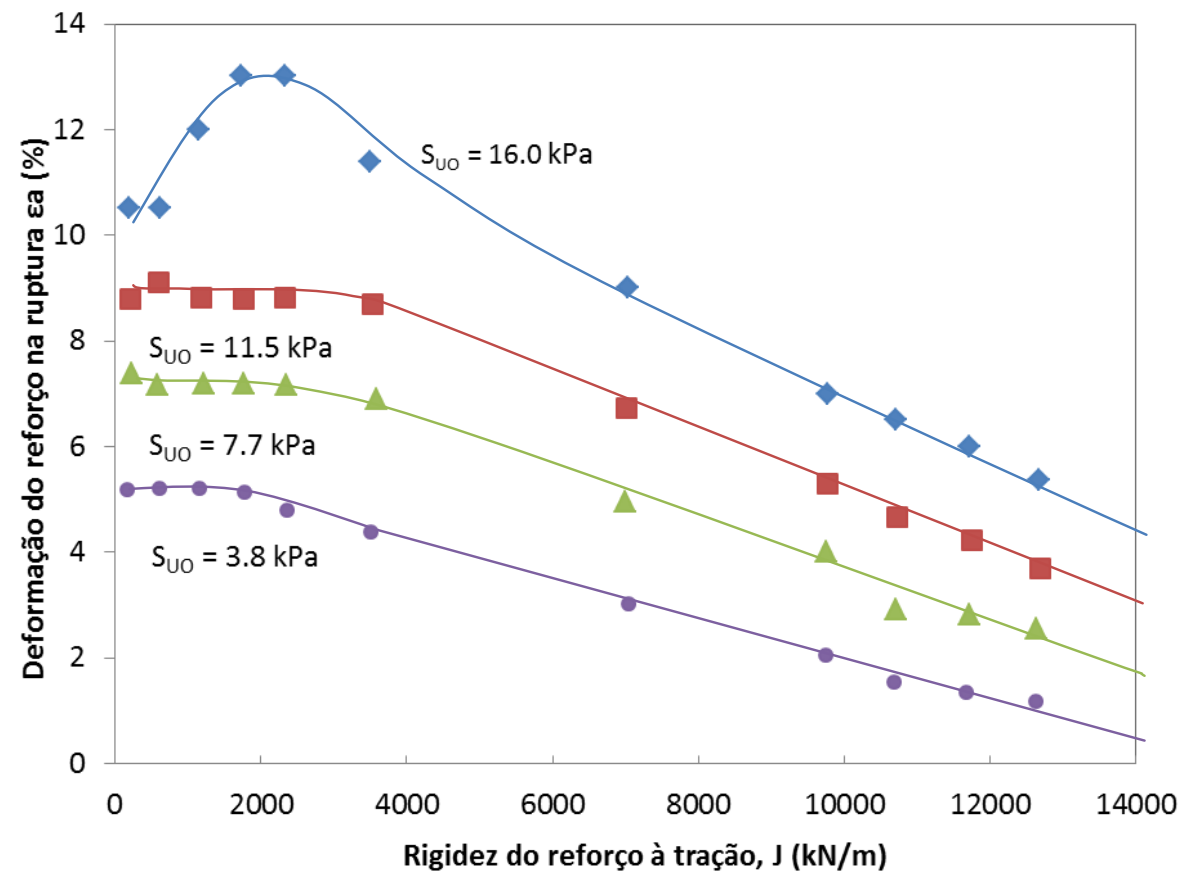

Figura 2-21 0 efeito de $S_{u 0}$ na deformação do reforço na ruptura para $\rho_{c}=$ 1,5 kPa/m. (Modificado de Hinchberger \& Rowe 2003)

Inicialmente, com o aumento da rigidez do reforço $\mathrm{J}$, a deformação do reforço apresenta valores relativamente constante para $\varepsilon_{0}$. A deformação do reforço na ruptura aumenta na medida em que aumenta a resistência não drenada na superfície de 3,8 para $11,5 \mathrm{kPa}$. Esse comportamento reflete a influência de $S_{u 0}$ na deformação crítica do reforço, $\varepsilon_{0}$.

Assim como o valor de $S_{u 0}$, também há aumento da altura do aterro e a mudança do mecanismo da ruptura associados. Isto leva a um aumento da deformação do reforço. Para $S_{u 0}$ superior a $16 \mathrm{kPa}$, não fica bem definido a faixa na qual o comportamento é sub-reforçado. Como a espessura do aterro na ruptura aumenta a interação entre o reforço, aterro e fundação se tornam mais complexas. $\mathrm{Na}$ ruptura do aterro reforçado, existem zonas que ficam com uma tensão abaixo da condição de ruptura e isso tem algum efeito sobre a deformação do reforço calculado.

A Figura 2-22 mostra as zonas de plastificação do solo para os dois valores de $S_{u 0}$ (isto é, $5 \mathrm{kPa}$ e $16 \mathrm{kPa}, \rho_{\mathrm{c}}=1,5 \mathrm{kPa} / \mathrm{m}$ e J $=2000 \mathrm{kN} / \mathrm{m}$. Observa-se que 
para valores de $S_{u 0}$ menores, as áreas de plastificação se apresentam mais perto da superfície.

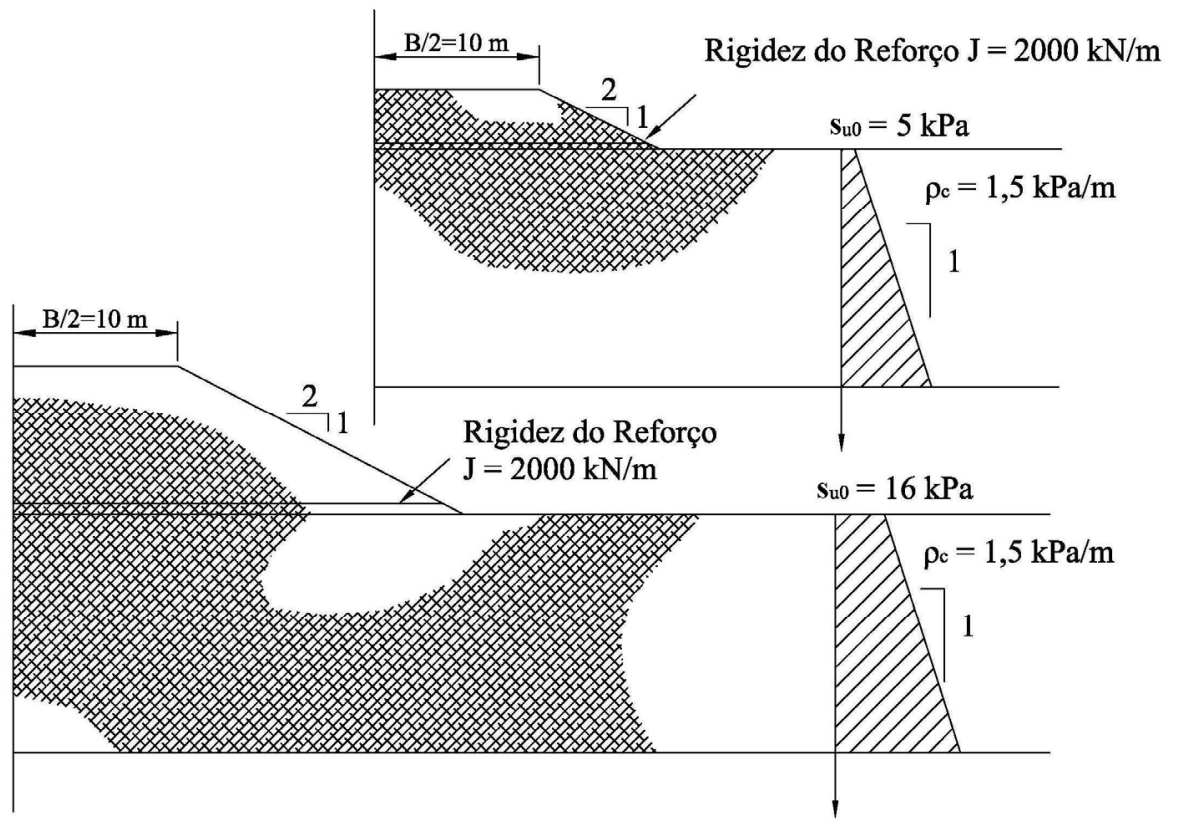

Figura 2-22 Zonas de plastificação do solo na ruptura para $S_{\mathrm{u} 0}=5 \mathrm{kPa}$ e 16 kPa. (Modificado de Hinchberger \& Rowe 2003)

Com base nos resultados numéricos apresentados na Figura 2-21, percebese que, na ruptura de aterros mais altos, existe potencial para arqueamento do aterro (Terzaghi et al., 1996). Este arqueamento causa um comportamento diferente ao comportamento ideal dos aterros reforçados.

\section{d) Efeito do Aumento da Resistência com a Profundidade, $\rho_{c}$}

A Figura 2-23, mostra o impacto do $\rho_{c}$ sobre a deformação de ruptura do aterro usando um valor constante de $S_{u 0}$ igual a $10 \mathrm{kPa}$. A espessura do solo mole foi selecionada para que ela não tenha qualquer influência sobre a cinemática de ruptura. A deformação máxima do reforço na ruptura aumenta à medida em que a taxa de ganho de resistência com a profundidade aumenta $(0,5$ a $1,5 \mathrm{kPa} / \mathrm{m})$. Como $\rho_{c}$ aumenta, a profundidade do mecanismo de ruptura que se desenvolve no solo diminui (Hinchberger, 1996). Assim, a componente de deformação plástica horizontal do solo de fundação aumenta em relação à componente vertical e, consequentemente, aumenta a deformação do reforço e a espessura do aterro. 


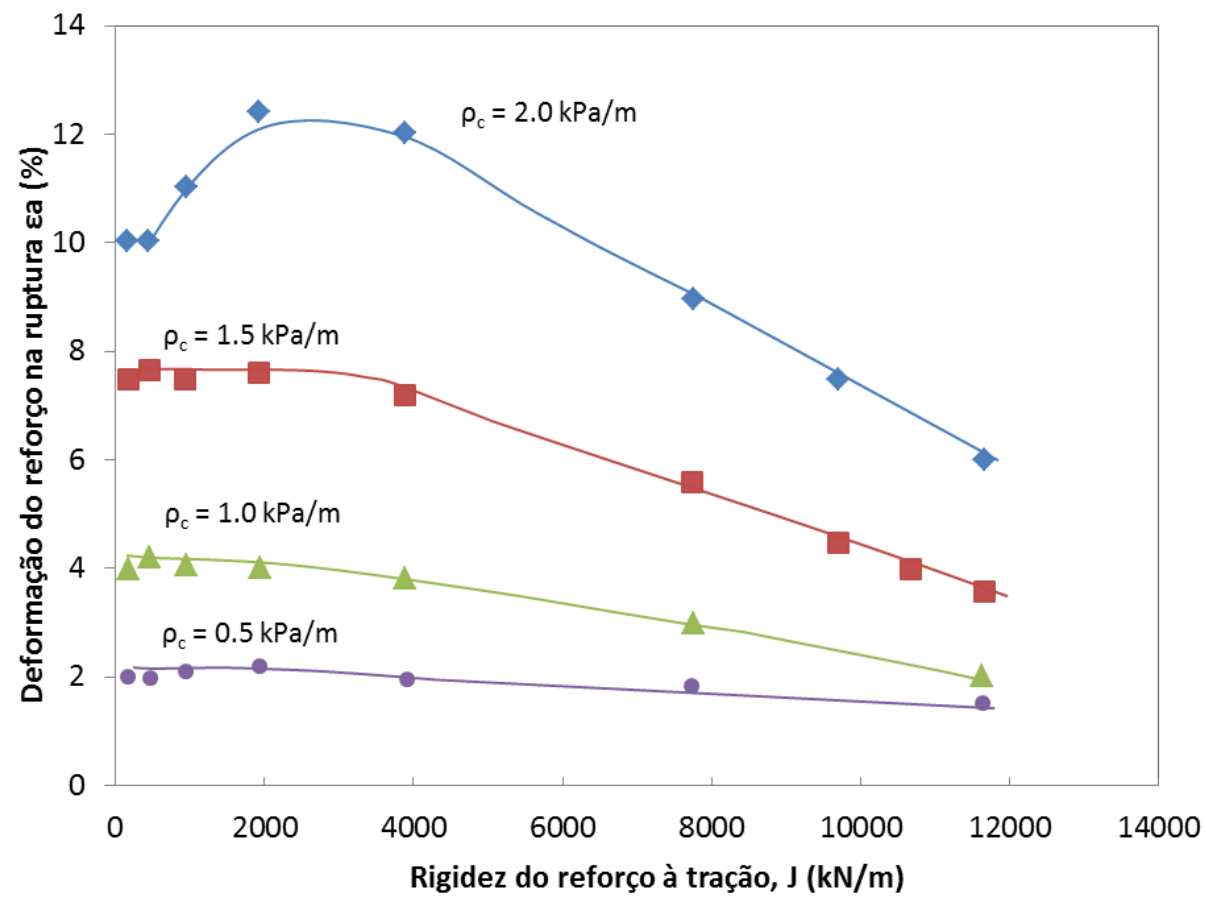

Figura 2-23 Efeito do aumento da resistência com a profundidade $S_{\mathrm{u} 0}=10$ kPa. (Modificado de Hinchberger \& Rowe 2003)

Para o caso em que $\rho_{c}=2,0 \mathrm{kPa} / \mathrm{m}$, a faixa de comportamento no qual ocorre sub-reforço não fica bem definida. Conforme discutido anteriormente, este tipo de resposta ocorre devido ao arqueamento do aterro. Neste caso e nos outros semelhantes, a deformação crítica no reforço $\varepsilon_{o}$, limitou-se para um baixo valor de rigidez do reforço (por exemplo, $\varepsilon_{o}=10 \%$ no caso de $S_{u o}=10 \mathrm{kPa}$ e $\rho_{\mathrm{c}}=2 \mathrm{kPa} / \mathrm{m}$ ).

O artigo de Hinchberger \& Rowe (2003) apresentou esse método para estimar as deformações no reforço e avaliar a estabilidade do aterro sobre solo mole em condições não-drenadas.

\subsection{Método para definir a deformação de compatibilidade do reforço (Futai, 2010)}

Futai (2010) buscou estabelecer uma correlação entre a deformação admissível em função de Suo, $\rho$ e $J$, baseando-se nos resultados pelo MEF de Hinchberger e Rowe (2003) e Fuertes et al. (2010) e em algumas análises complementares. 

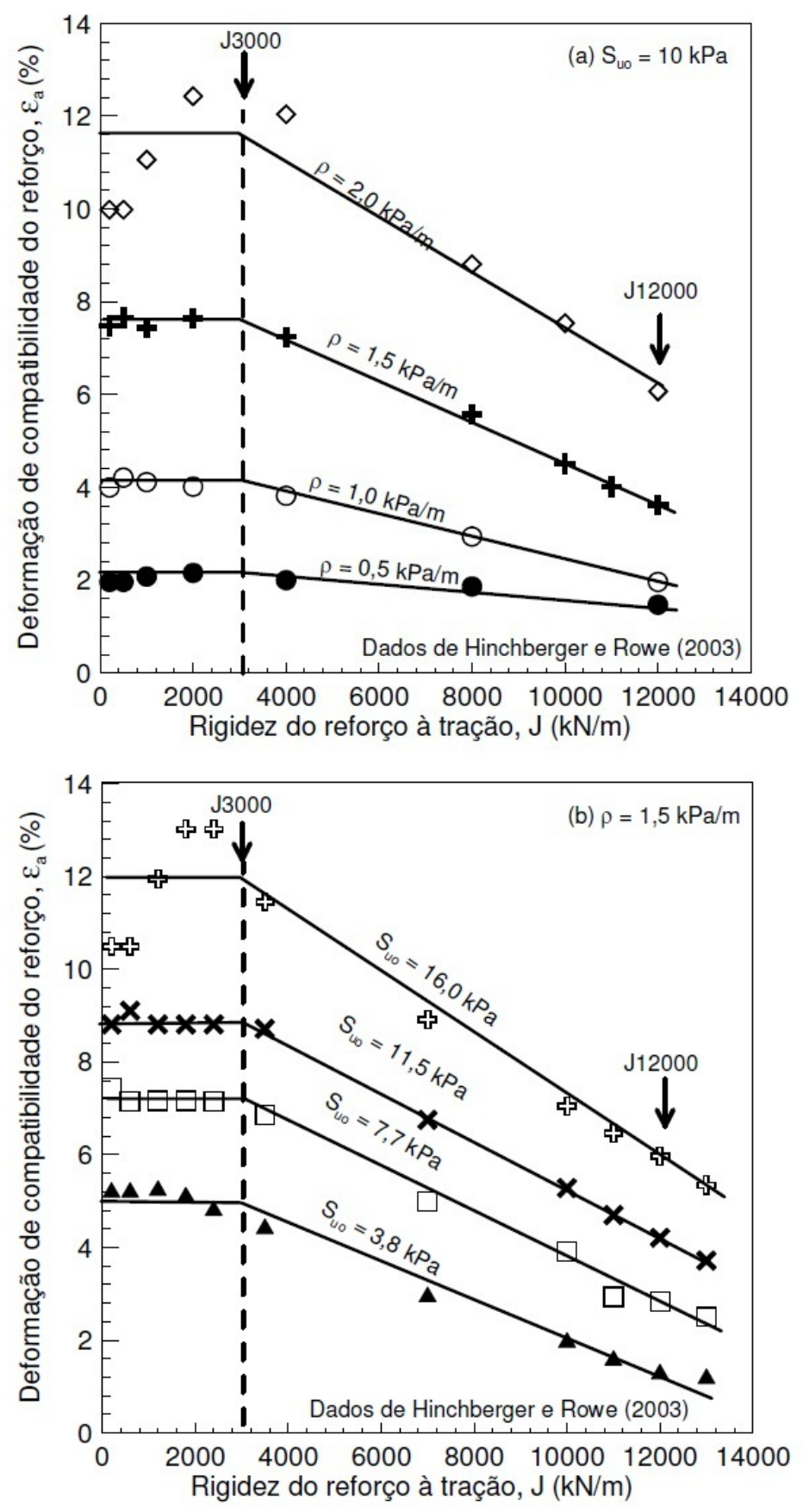

Figura 2-24 Deformação de compatibilidade admissível do reforço (Hinchberger e Rowe, 2003 apud Futai, 2010)

O autor interpretou os dados de Hinchberger e Rowe (2003), e dos gráficos

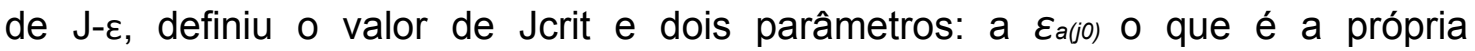
deformação admissível e a deformação de compatibilidade para $\mathrm{J}=12000 \mathrm{kN} / \mathrm{m}$, 
denominado de $\varepsilon_{a(j 12000)}$

A Figura 2-24, mostra os ajuste dos dados de Hinchberger e Rowe (2003) às duas retas, a primeira uma reta horizontal até $\mathrm{J}_{\text {crit }}=3000 \mathrm{kN} / \mathrm{m}$, e outra com valores decrescentes para deformação de compatibilidade com o aumento da rigidez do reforço. Esses dados foram correlacionados com relação dos parâmetros da fundação (Suo+7,5 $\rho$ ), e foram apresentados num gráfico (Figura 2-25).

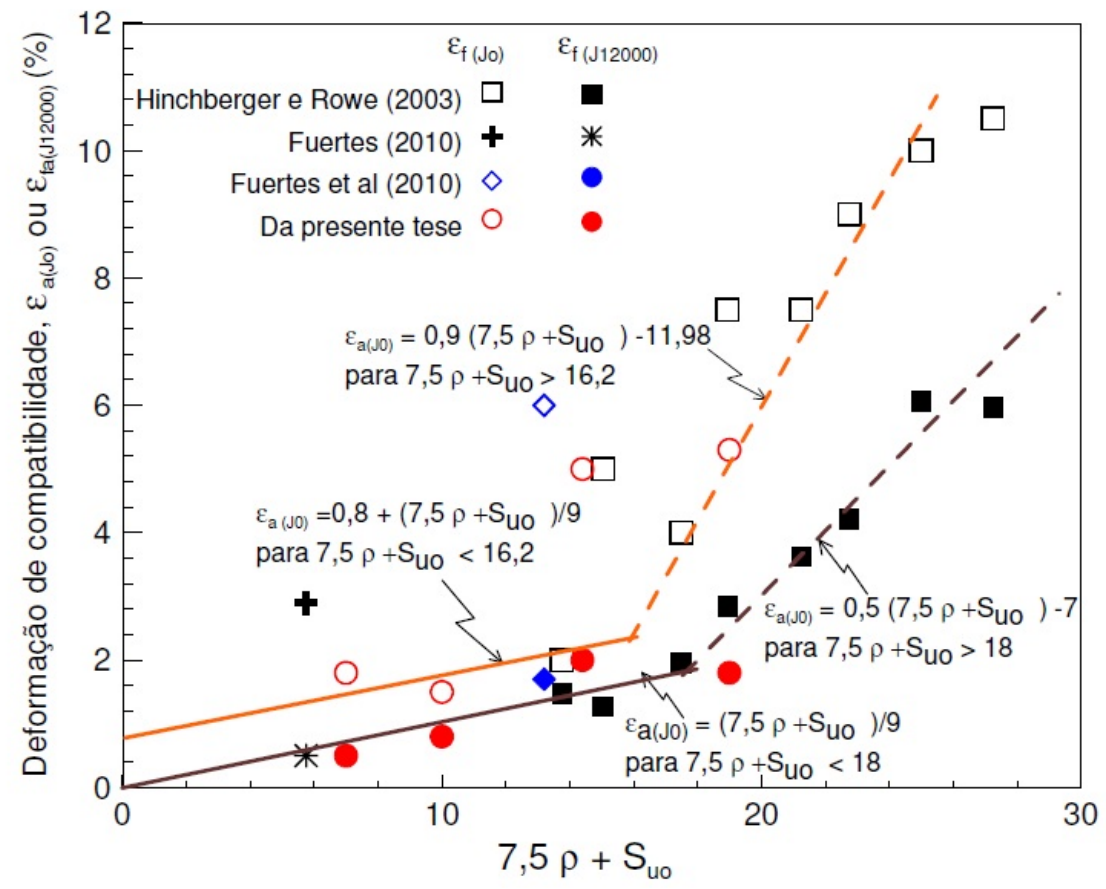

Figura 2-25 Deformação de compatibilidade admissível do reforço para Jo e $\mathrm{J}=12 \mathrm{MN} / \mathrm{m}$ (Futai, 2010)

Do gráfico, o autor gerou expressões para correlacionar $\varepsilon_{a(j 0),} \varepsilon_{a(j 12000)} e$ (Suo $+7,5 \rho)$, as quais estão listadas na Tabela 2-4.

Tabela 2-4 Expressões propostas para deformações de compatibilidade (Futai, 2010).

\begin{tabular}{c|ll|ll}
\hline Trechos & \multicolumn{2}{|c|}{$\varepsilon_{a(J 0)}$} & \multicolumn{2}{|c}{$\varepsilon_{a(112000)}$} \\
\hline \multirow{2}{*}{ Primeiro } & $\mathrm{S}_{\mathrm{uo}}+7,5 \rho_{\mathrm{c}}<16,2 \mathrm{kPa}$ & $(2.10 \mathrm{a})$ & $\mathrm{S}_{\mathrm{uo}}+7,5 \rho_{\mathrm{c}}<18 \mathrm{kPa}$ & $(2.10 \mathrm{~b})$ \\
& $\varepsilon_{a(J 0)}=0,8+\left(c_{o}+7,5 \rho_{c}\right) / 9$ & $(2.11 \mathrm{a})$ & $\varepsilon_{a(J 0)}=\left(c_{o}+7,5 \rho_{c}\right) / 9$ & $(2.11 \mathrm{~b})$ \\
\hline \multirow{2}{*}{ Segundo } & $\mathrm{S}_{\mathrm{uo}}+7,5 \rho_{\mathrm{c}}>16,2 \mathrm{kPa}$ & $(2.12 \mathrm{a})$ & $\mathrm{S}_{\mathrm{uo}}+7,5 \rho_{\mathrm{c}}>18 \mathrm{kPa}$ & $(2.12 \mathrm{~b})$ \\
& $\varepsilon_{a(J 0)}=0,9\left(c_{o}+7,5 \rho_{c}\right)-11,98$ & $(2.13 \mathrm{a})$ & $\varepsilon_{a(J 0)}=0,5\left(c_{o}+7,5 \rho_{c}\right)-7$ & $(2.13 \mathrm{~b})$ \\
\hline
\end{tabular}


Normalizando a deformação de compatibilidade, se deram duas condições:

a) Para $\mathrm{J}<3000 \mathrm{kN} / \mathrm{m}$ a deformação de compatibilidade é a própria deformação de compatibilidade admissível e é equivalente a proposta de Hinchberger e Rowe (2003).

$$
\varepsilon a=\varepsilon a(J 0)
$$

b) Para $\mathrm{J}>3000 \mathrm{kN} / \mathrm{m}$ a deformação de compatibilidade deve ser calculada pela expressão:

$$
\varepsilon_{a}=\varepsilon_{a}(J 0)-\left(\varepsilon_{a}(J 0)-\varepsilon_{a}(J 12000)\right)(0,00011 J-0,3)
$$

Os valores de $\varepsilon_{a(J 0)}$ e $\varepsilon_{a(J 12000)}$ podem ser calculados mediante as expressões apresentadas na Tabela 2-4. A metodologia proposta não pode ser aplicada diretamente nos casos em que a fundação apresenta uma camada superior de areia sobreposta ao solo mole. Porém, Futai (2010) corrigiu o efeito da camada superficial de areia na deformação de compatibilidade, observando que as deformações reduzem-se com o aumento da espessura da camada de areia, mostrado na Figura 2-26.

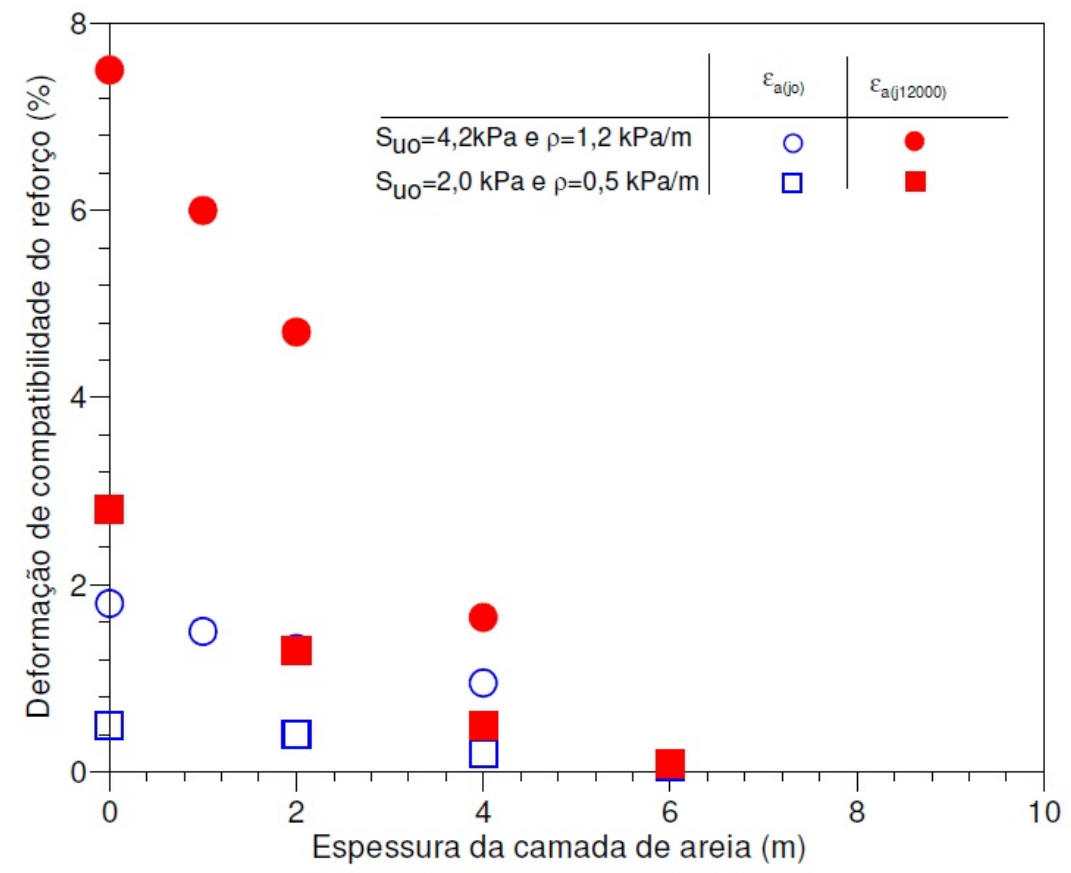

Figura 2-26 Variação das deformações de compatibilidade com a espessura da camada superficial de areia (Futai, 2010).

Verificou a proporção da redução da deformação, calculando a relação entre 
as deformações de compatibilidade para aterros com e sem uma camada de areia. Com os dados de $\varepsilon_{a(j 0)}$ e $\varepsilon_{a(j 12000)}$ foram traçadas duas retas, conforme está mostrado na Figura 2-27, encontrando um Fator de correlação devido à presença

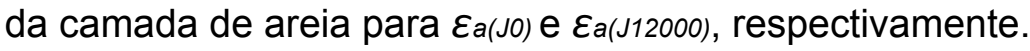

$$
\begin{aligned}
& \alpha_{a 0}=1-0,19 A \\
& \alpha_{a 12000}=1-0,14 A
\end{aligned}
$$

Sendo A, a espessura da camada de areia, e a correlação só vale para espessuras de areia até $6 \mathrm{~m}$.

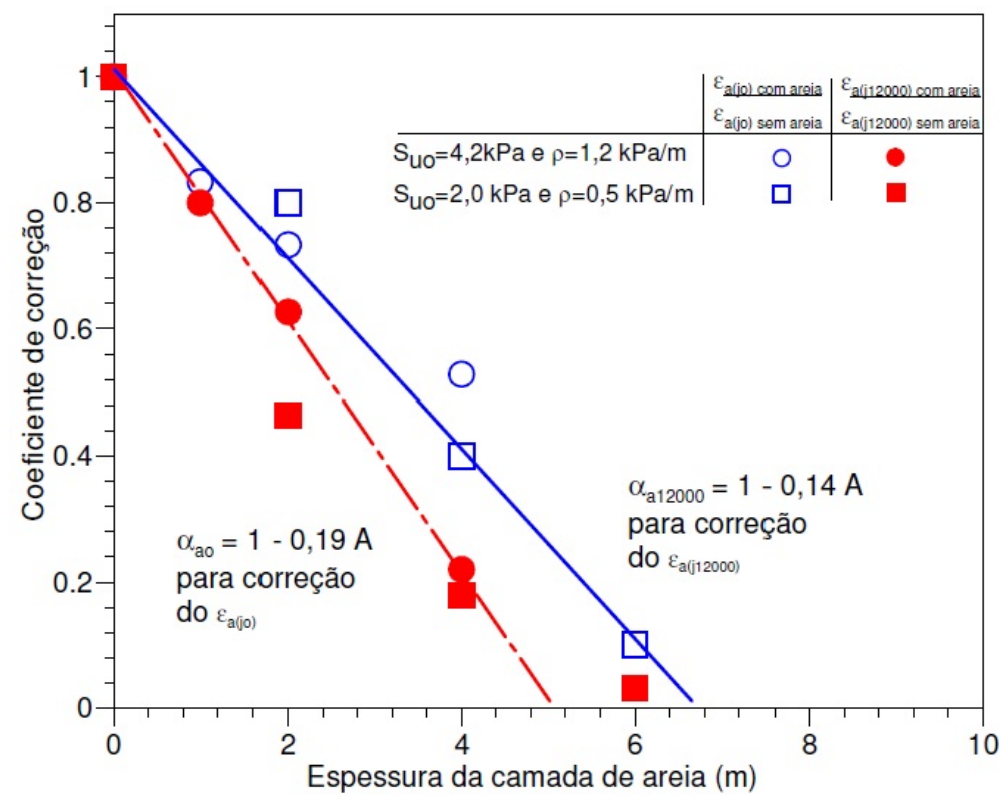

Figura 2-27 Fator de correção devido à presença da camada de areia $\alpha$ a (Futai, 2010).

\subsection{Casos históricos de aterros reforçados}

Numerosos casos de estudo têm sido apresentados para avaliar a influencia do uso do reforço nos aterros sobre solos moles, durante a construção e na estabilidade. Para fazer uma comparação do comportamento in situ e o comportamento esperado mediante simplificações numéricas.

A seguir são apresentados alguns casos de aterros que serão mencionados ao longo da presente dissertação. 


\subsubsection{Aterro Almere, Rowe \& Söderman (1984)}

Rowe \& Söderman (1984), fizeram um artigo sobre dois aterros experimentais que foram construídos na comunidade de Almere na Holanda em 1979, um deles com reforço e o outro sem, com o objetivo de avaliar o efeito do geotêxtil na estabilidade do aterro em solo mole. Foi feito uma analises do MEF para fazer uma comparação no comportamento obtido na análise e o observado dos aterros.

O aterro reforçado foi construído com uma vala para induzir ao colapso do aterro. Além disso, foi construída uma barragem de retenção de argila antes de colocar o material de aterro, o qual induziu uma ligeira deformação do reforço de $1 \%$ em excesso. A Figura 2-28 ilustra a geometria do aterro.

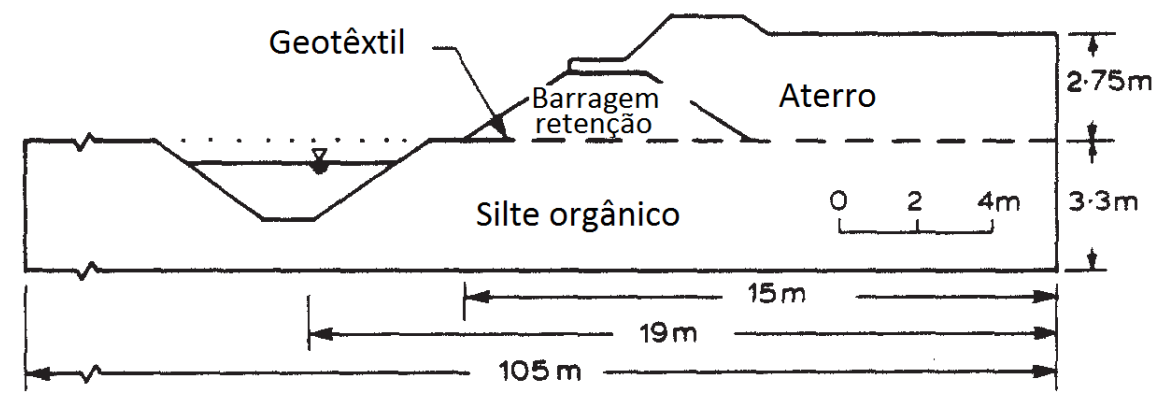

Figura 2-28 Geometria da seção reforçada na linea de referencia I (Rowe \& Söderman,1984)

O perfil da resistência não drenada para à argila orgânica é Suo $=8 \mathrm{kPa}$. Os valores calculados e os medidos in situ da deformação do reforço no aterro são mostrados Figura 2-29.

Os valores da deformação do reforço apresentam se constantes até uma altura do aterro de $1 \mathrm{~m}$, depois tem um aumento gradual até os $2 \mathrm{~m}$ e após esse valor as deformações aumentam rapidamente até atingir a altura de ruptura de $2,75 \mathrm{~m}$. Os resultados demostraram boa concordância entre as alturas de ruptura calculadas pelo MEF e as observadas no aterro, além de corroborar o efeito do geotêxtil no aumento da estabilidade. 


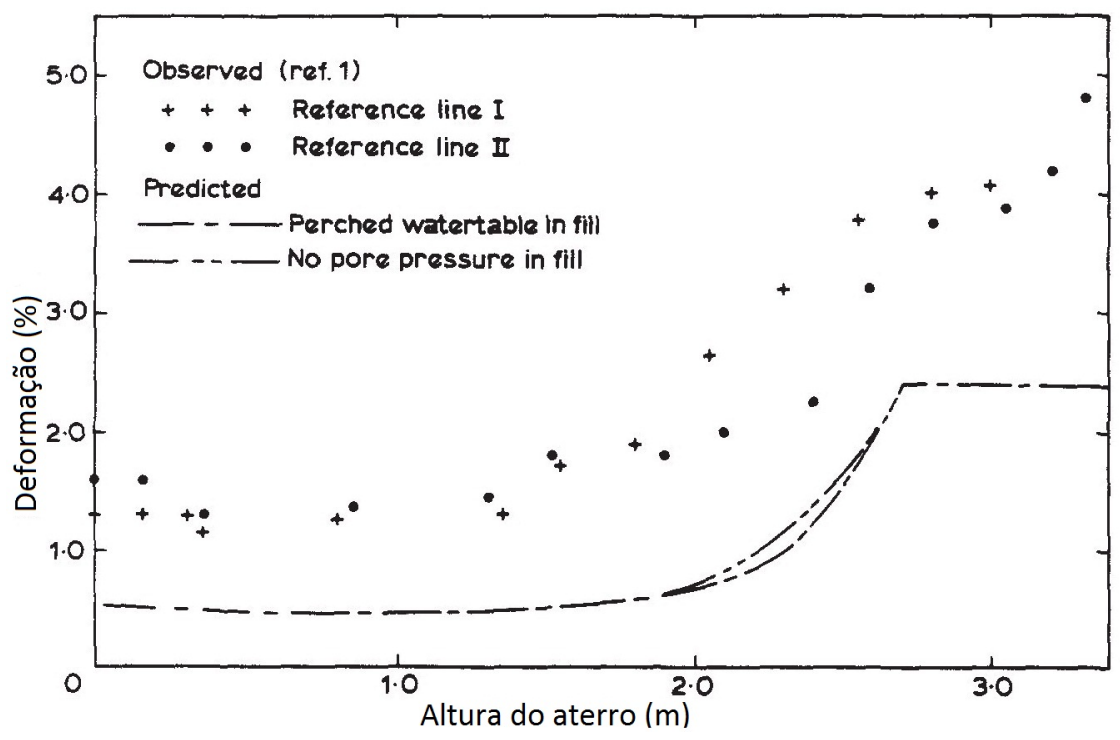

Figura 2-29 Comparação da deformação no reforço observada e calculada (Rowe \& Söderman, 1984)

\subsubsection{Aterro em Hubrey Road, Rowe e Mylleville (1996)}

Rowe e Mylleville (1996) tiveram a oportunidade de monitorar o comportamento de um aterro reforçado com geogrelha construído sobre um depósito de turfa sobreposta ao silte orgânico, Hubrey Road. Onde os engenheiros geotécnicos decidiram construir o corpo do aterro em estágios para permitir a dissipação da pressão de poros e o ganho de resistência da fundação antes de colocar a seguinte camada. Além de construir em estágios, foi colocado o reforço de geogrelha na interface do aterro e o solo orgânico.

O artigo mostra o Estagio I da construção, onde foi colocado $1,5 \mathrm{~m}$ de material de aterro. O perfil da resistência não drenada para o silte orgânico é Suo $=4 \mathrm{kPa} e$ $\rho=2 \mathrm{kPa} / \mathrm{m}$, como apresentado na Figura 2-30. 


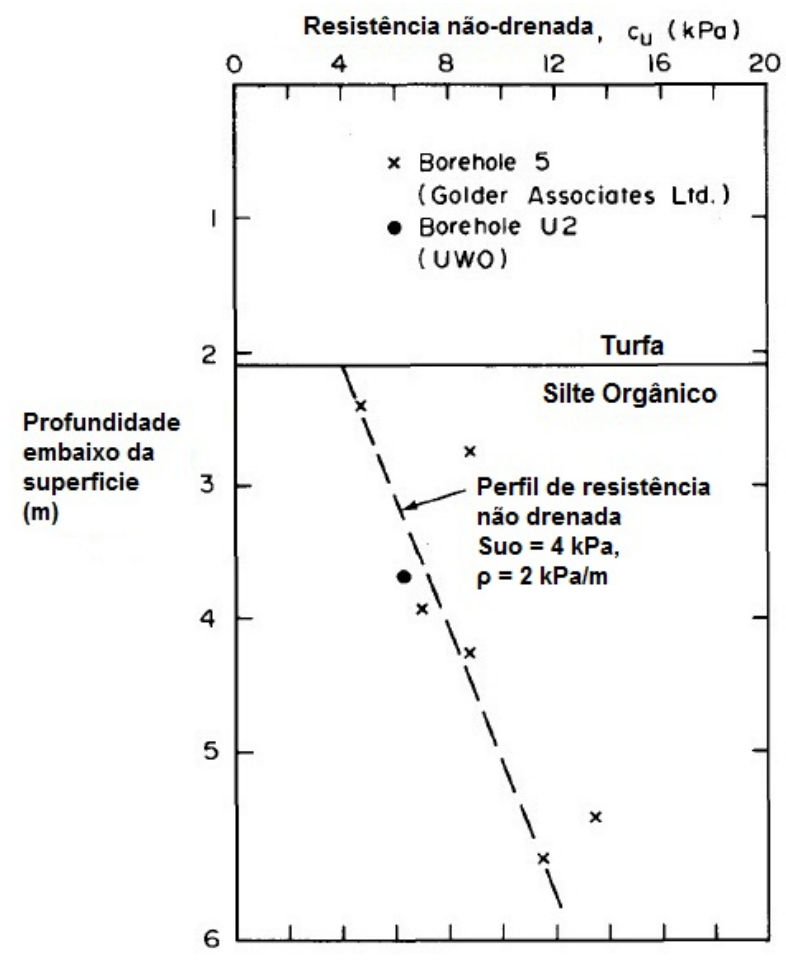

Figura 2-30 Perfil de resistência não drenada no silte orgânico (Rowe e Mylleville, 1996)

O aterro foi instrumentado e a Figura 2-31 mostra as deformações medidas em diversos pontos na geogrelha, para os primeiros 60 dias do Estagio I.

As deformações atingiram os valores máximos nos primeiros dez dias após a colocação das camadas e foram se reduzindo com o tempo. A diferença nas medidas em diversos pontos é devido à natureza variável do deposito orgânico e a diferença nos lugares onde foi colocado o material do aterro; os pontos que apresentam valores maiores estão situados no centro do aterro.

Nesse caso de estudo, a ruptura do aterro aconteceu no Estagio II; o artigo mostra uma sequência de construção diferente e uma analise do comportamento utilizando ferramentas do MEF, os autores apresentaram esse estudo para ser usado pelos futuros pesquisadores na validação dos próprios modelos. 


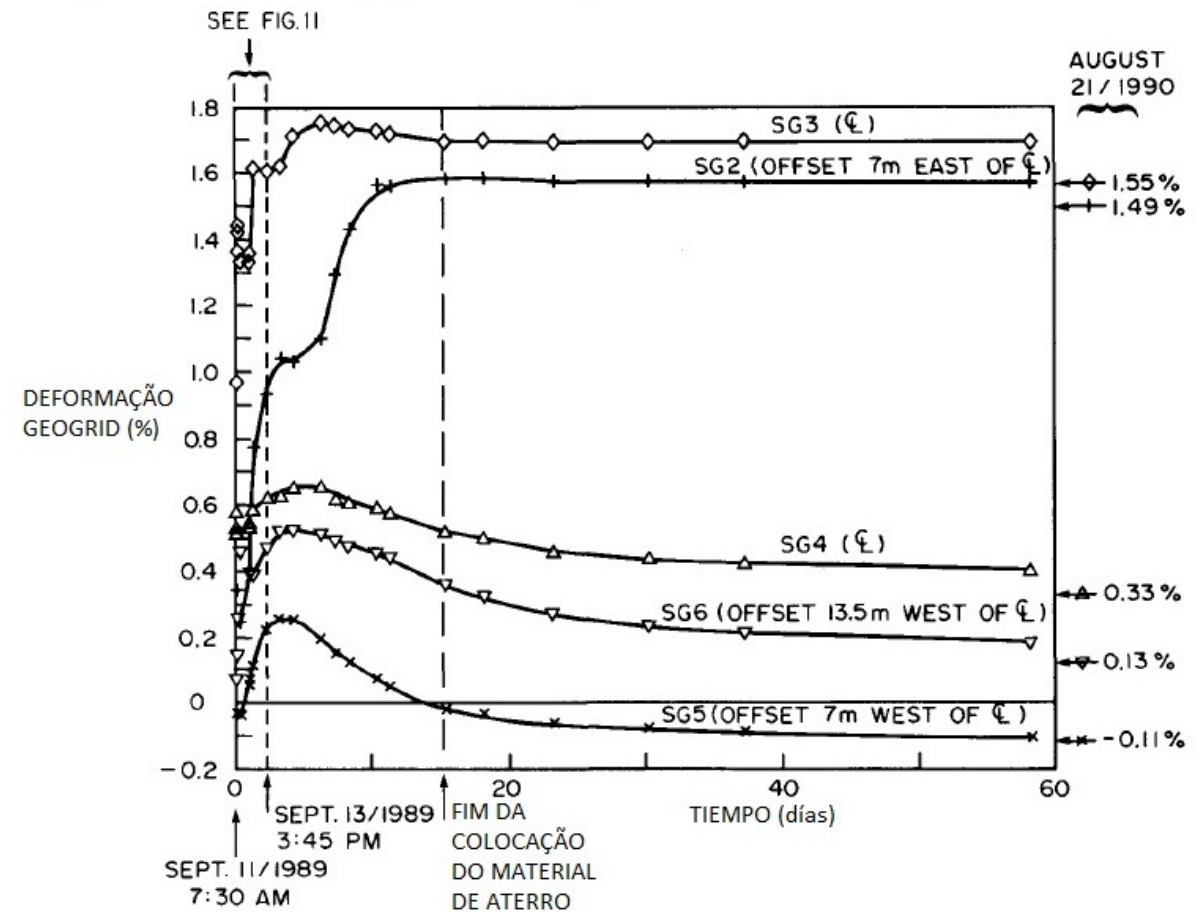

Figura 2-31 Deformações da geogrelha observadas no estagio I da construção (Rowe e Mylleville, 1996).

\subsubsection{Aterro em Lian-Yun-Gang, Chai, Miura e Shen (2002)}

Os aterros experimentais analisados nesse artigo foram construídos para serem levados à ruptura nos depósitos argilosos de Lian-Yun-Gang, ao oeste de China; um deles foi construído diretamente na fundação e outro com uma camada de geotêxtil na base do aterro. O objetivo desse estudo foi analisar o efeito no reforço no fator de segurança e a resposta da fundação.

A fundação consistia numa crosta de $2 \mathrm{~m}$ sobrejacente a uma camada de argila mole de $8,5 \mathrm{~m}$. O perfil da resistência não drenada para a argila foi de Suo = $4,25 \mathrm{kPa}$ e $\rho=1,7 \mathrm{kPa} / \mathrm{m}$. Na construção dos aterros foram colocados instrumentos para medir os recalques, piezômetros e medidores do deslocamento horizontal. A altura da ruptura para o aterro reforçado foi de $4,35 \mathrm{~m}$.

A analise MEF foi realizada para avaliar o comportamento do aterro e foram utilizados dois valores para a rigidez do reforço: 800 e 1600 kN/m. As tensões no reforço são mostrados na Figura 2-32. 


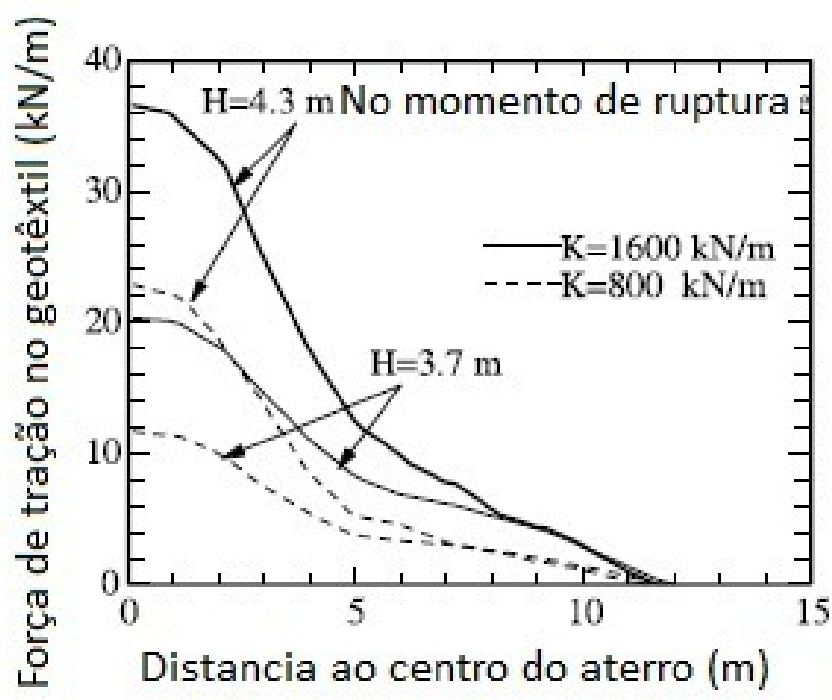

Figura 2-32 Esforço de tração no geotêxtil no momento da ruptura (Chai, Miura e Shen, 2002)

Os resultados encontrados pelos autores mostram que o reforço pode aumentar o fator de segurança, devido à tensão mobilizada no reforço e à geometria do aterro; e os excessos de pressão de poros e os aumentos na taxa de deslocamentos são indicadores da estabilidade no aterro.

\subsubsection{Aterro reforçado com uma camada de areia na fundação (Oliveira, 2006)}

Em alguns casos os solos moles podem apresentar lentes de areia ou camadas superficiais, que podem influenciar no comportamento do aterro e na interação solo-reforço.

Nos capítulos posteriores serão apresentados os resultados dos estudos realizados nos aterros, considerando uma fundação de solo mole com uma camada superficial de areia.

Para realizar este estudo com o programa PHASE 2, um dos casos empregados para validar o programa utilizado é dos aterros levados à ruptura, apresentado por Oliveira (2006) e que será descrito a seguir.

Oliveira (2006) apresentou a construção de três aterros experimentais reforçados sobre solo mole com uma camada superficial de areia em Santa Catarina. As forças mobilizadas no reforço foram monitoradas durante a construção 
mediante células de carga com o objetivo de fazer uma comparação dos resultados. Os aterros apresentavam as seguintes características:

- Aterro Experimental com drenos verticais e com reforço AE1

- Aterro Experimental sem drenos e com reforço AE2

- Aterro Experimental sem drenos verticais e sem reforços AE3, para servir como referência para o comportamento dos aterros reforçados.

Os aterros $A E 1$ e $A E 2$ foram posicionados de forma que estivessem assentes sobre camadas de areia de um antigo aterro hidráulico, o qual apresentava uma ligeira inclinação na superfície embaixo do corpo do aterro, material que depois foi usado para construir os aterros. O aterro AE3 foi construído sobre uma camada de areia fina com espessura ligeiramente superior à dos demais.

Para o presente estudo, o aterro de interesse foi o AE2, por ser reforçado e sem drenos. Os três aterros possuíam a mesma geometria e instrumentação. A seguir é mostrada na Figura 2-33, a seção do aterro AE2, antes e depois de produzida a ruptura.

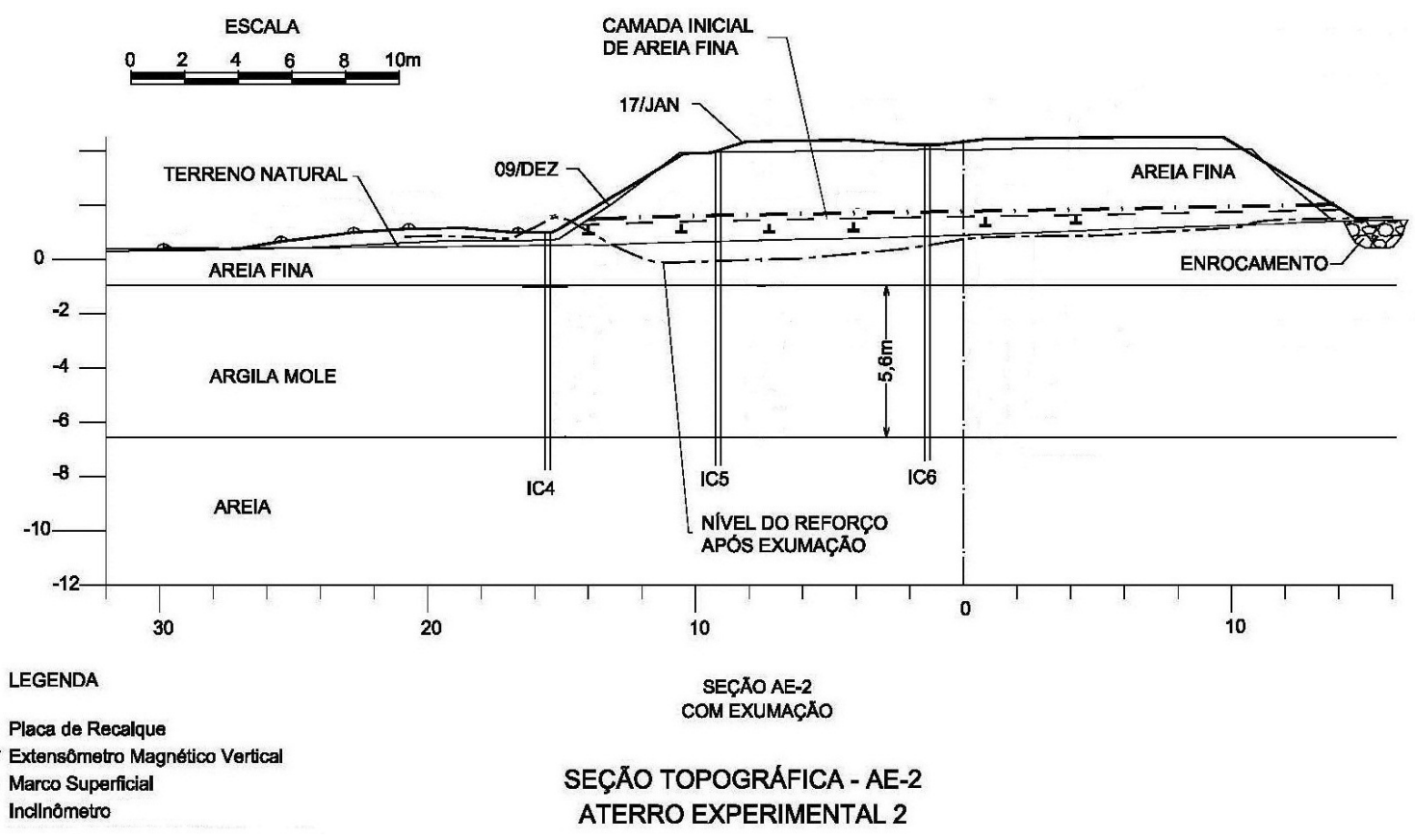

Figura 2-33 Geometria do aterro experimental AE2 com reforço sobre solo moles (Oliveira, 2006) 
A fundação dos aterros apresentava diferenças na espessura de camada de argila e da camada de areia superficial. Estas diferencias são apresentadas na Tabela 2.5.

Tabela 2-5 Dados os três aterros experimentais (Oliveira, 2006).

\begin{tabular}{l|c|c|c}
\hline \multirow{2}{*}{ Dados } & \multicolumn{3}{c}{ Aterros Experimentais } \\
\cline { 2 - 4 } & AE1 & AE2 & AE3 \\
\hline Espessura da areia superficial & 1.7 & $\mathbf{1 . 8}$ & 2.1 \\
\hline Espessura da argila & 8.2 & $\mathbf{5 . 6}$ & 4.5 \\
\hline
\end{tabular}

O aterro AE3 apresentava uma lente de areia de $0.7 \mathrm{~m}$ a uma profundidade de 2.8 até $3.5 \mathrm{~m}$ de profundidade.

Os perfis da resistência não drenada da argila obtidos mediante ensaios de piezocone e palheta são mostrados na Figura 2-34.
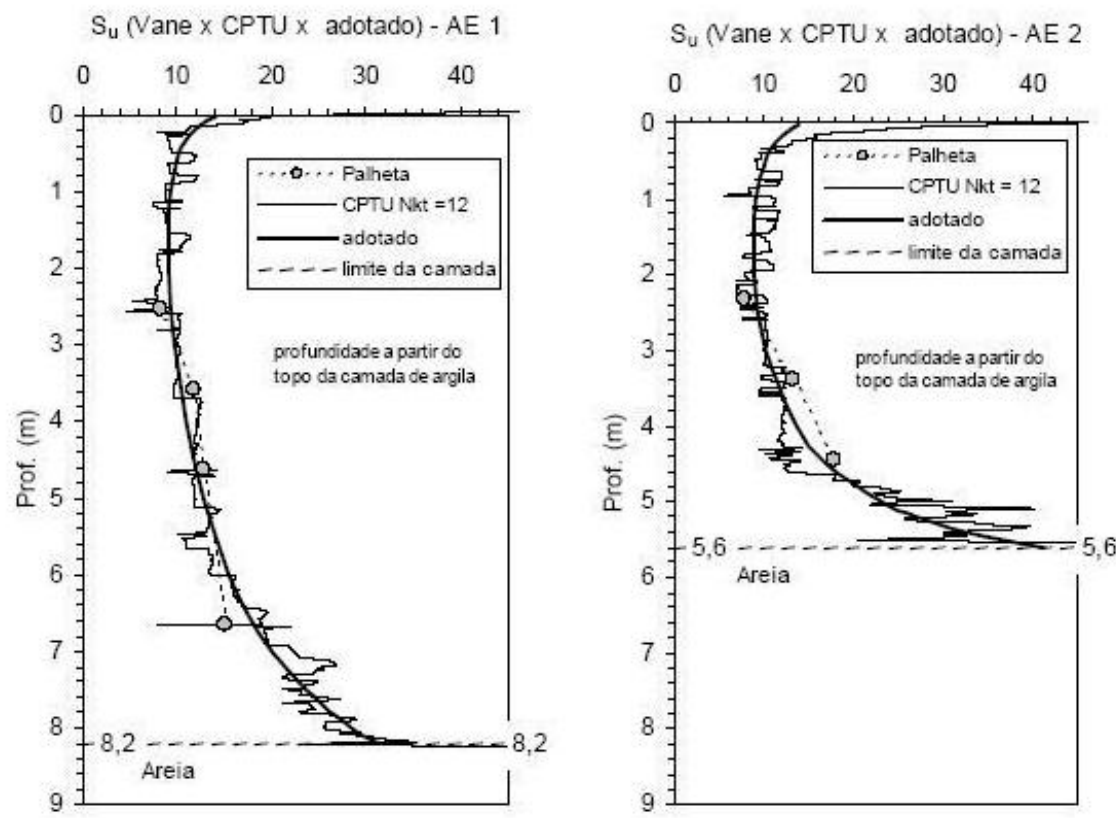

\section{Figura 2-34 Resultados dos ensaios de campo (piezocone e palheta) para os} aterros experimentais AE1 e AE2 (Oliveira, 2006).

Os materiais granulares envolvidos na construção dos aterros experimentais são a areia fina resultante da execução do aterro hidráulico e que cobre a argila. Esse material foi utilizado na construção dos aterros. 


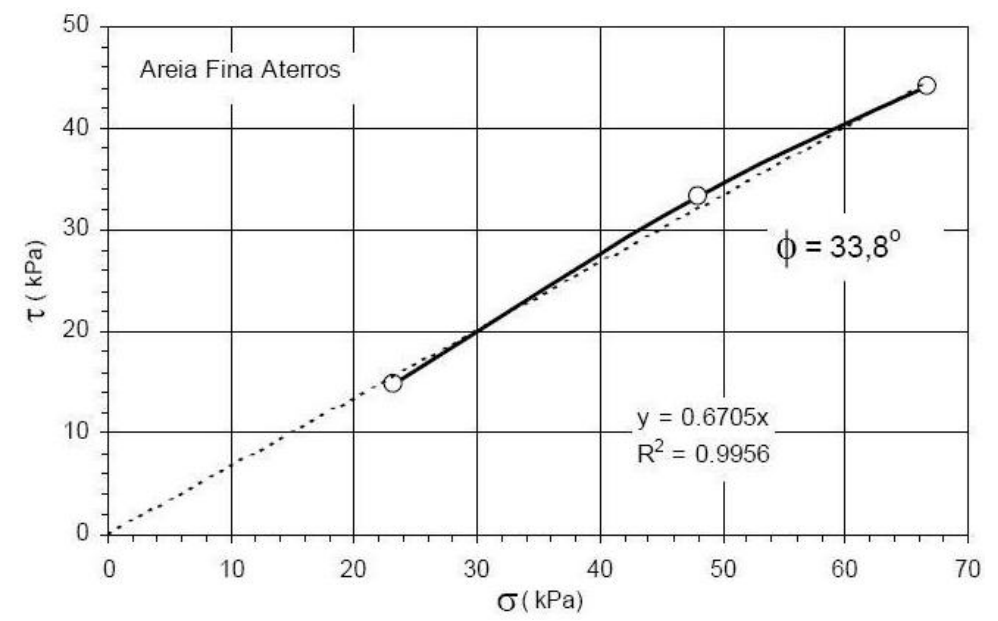

Figura 2-35 Resultados do ensaio cisalhamento direto da areia fina silicosa branca (Oliveira, 2006).

A areia fina de coloração branca foi ensaiada para determinar os parâmetros geotécnicos. Realizaram-se ensaios de cisalhamento direto e se mediu um ângulo de atrito de $33.8^{\circ}$ (Figura 2-35). Resistência nominal do reforço tecido de poliéster empregado era de $200 \mathrm{kN} / \mathrm{m}$ na direção principal, e de $45 \mathrm{kN} /$ na direção secundária. Foi utilizado reforço tecido de poliéster com resistência $200 \times 45 \mathrm{kN} / \mathrm{m}$ e rigidez à tração de $1700 \mathrm{kN} / \mathrm{m}$ à $5 \%$ de deformação.

A Figura 2-36, apresenta o aumento das forças no reforço ao longo do tempo e o aumento da altura do aterro para AE1 e AE2.

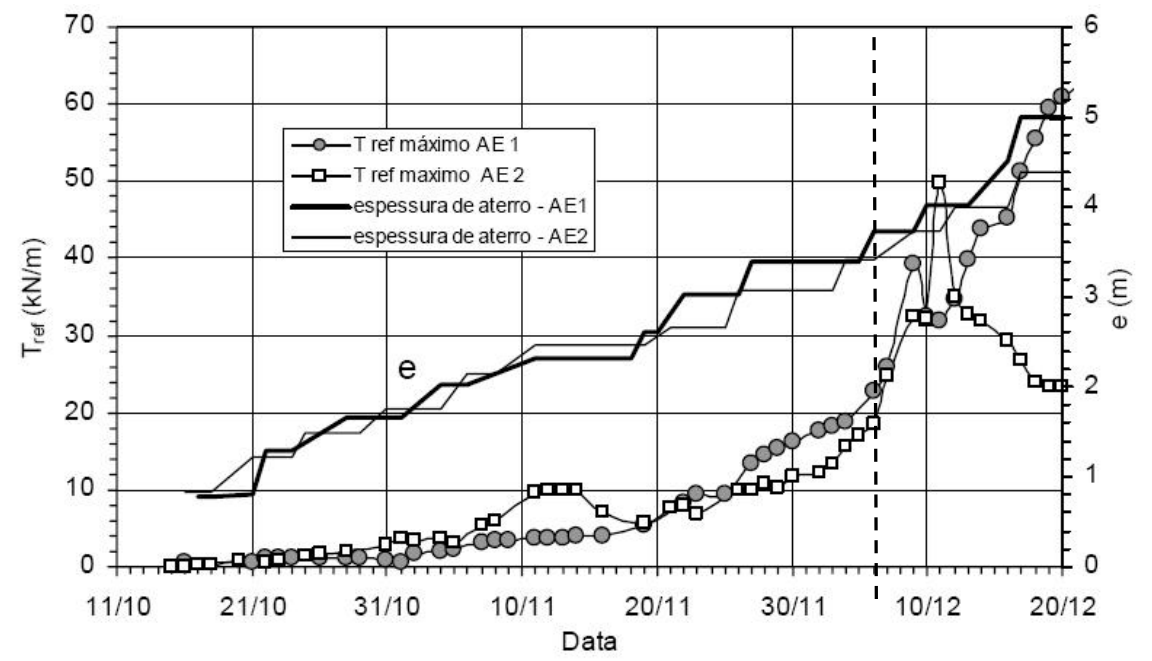

Figura 2-36 Esforços de tração máximos medidos nos reforços como função do tempo e relacionado ás espessuras de aterros (Oliveira,2006) 
Os valores da força aumentam com a altura do aterro depois da nona camada (a linha vertical), o que pode ser considerado o momento da ruptura para ambos os aterros, nesse ponto os valores da força no reforço apresentam uma taxa de incremento maior.

Num artigo posterior, Oliveira et al. (2010) concluíram na pesquisa que a importância da camada superficial de areia foi maior que a contribuição do reforço. A camada superficial restringiu os movimentos laterais da fundação e a mobilização do reforço,

A metodologia apresentada nesse item será utilizada na validação do programa de elementos finitos. Além disso, será ampliado o estudo da camada superficial de areia para diferentes espessuras da camada e também para diferentes parâmetros do solo.

\subsubsection{Aterro não reforçado de coesão crescente com a profundidade}

Sousa Pinto (1966) propôs um método para avaliar a estabilidade de aterros não reforçados sobre solo mole com a coesão linearmente crescente com a profundidade.

Uma breve explicação da metodologia será apresentada a seguir.

Para um aterro de altura $H$ e com a projeção do talude na horizontal $d$ como é indicado na Figura 2-37.

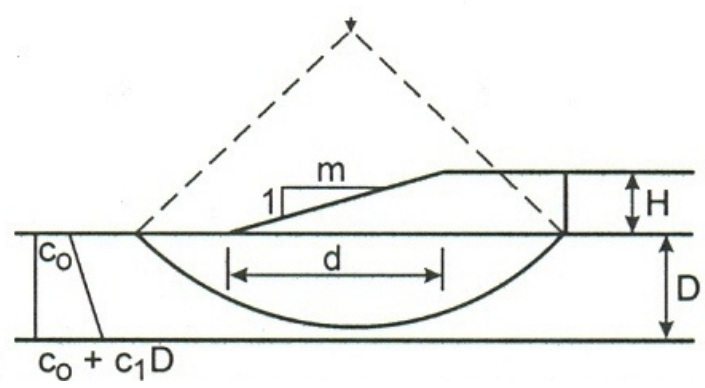

Figura 2-37 Seção do talude do aterro (Souza Pinto 1966)

A pressão que leva o terreno à ruptura vale: 


$$
q_{r}=N_{c o}{ }^{*} C_{o}
$$

Onde $\mathrm{N}_{\mathrm{co}}$ é o fator de carga e, co a resistência não-drenada na superfície do terreno. $O$ fator de carga é apresentado na forma de ábacos, como ilustrado na Figura 2-38, onde se constata que:

A solução de Fellenius é um caso particular dessa solução mais geral. De fato, se $c_{1}=0$ (coesão constante) tem-se $N_{c o}=5$

Quanto menor o valor de $D$, a espessura da camada de argila mole, maior o valor de $N_{c o}$ e maior a altura de aterro que se pode lançar sem que o solo se rompa, corroborando a afirmação acima.

Outra forma de analisar é mediante expressões matemáticas aproximadas, que se pode empregar para o cálculo dos fatores de carga $N_{c o}$, utilizando o computador, e são as seguintes:

a) Para camadas de solos moles muito espessas $(D=\infty)$, tem-se:

$$
\begin{aligned}
& N_{c o} \cong 6,1+2,1 * \frac{c_{1} d}{c_{o}} \Rightarrow \text { para }: \ldots . .0 \leq \frac{c_{1} d}{c_{o}} \leq 2 \\
& N_{c o} \cong 7,0+1,4 * \frac{c_{1} d}{c_{o}} \Rightarrow \text { para }: \ldots . .2 \leq \frac{c_{1} d}{c_{o}} \leq 20
\end{aligned}
$$




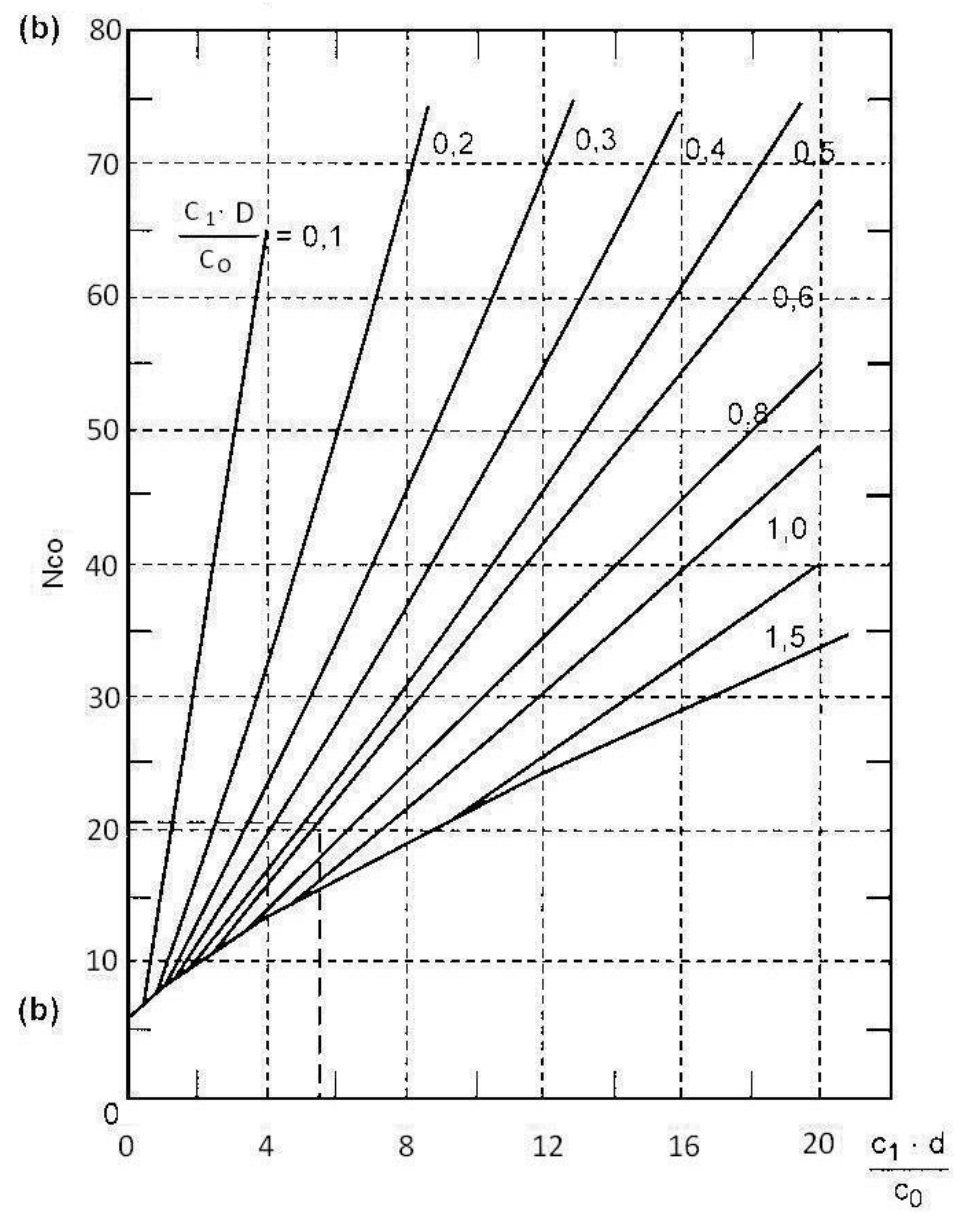

Figura 2-38 Ábaco de Souza Pinto para aterros sobre solos moles (Massad, 2003) 


\section{MATERIAIS E MÉTODOS}

\subsection{Introdução}

Apresentam-se neste capítulo os procedimentos para a validação do software de elementos finitos que será usado para estimar as deformações no reforço no momento da ruptura mediante a aplicação da modelagem numérica. Os resultados serão usados para elaborara um modelo analítico que sirva para definir a deformação do reforço na condição de trabalho. Descreve-se o método utilizado, a modelagem, os modelos constitutivos que simulam o comportamento tensãodeformação do solo, calibração do modelo, os parâmetros utilizados e o software de elementos finitos empregado no estudo.

\subsection{Método de Análise por Modelagem Numérica - Abordagem do Problema}

Hinchberger e Rowe (2003) estudaram a deformação mobilizada no reforço para solos moles de resistências não drenada crescentes com a profundidade. Mas existem solos moles que podem apresentar lentes ou camadas de materiais mais resistentes como a areia, os quais podem alterar o comportamento do aterro.

Nesse trabalho busca-se analisar a contribuição de uma camada de areia na superfície, baseando as análises no estudo realizado por Hinchberger e Rowe (2003) para aterros sobre solos moles com resistência crescente com a profundidade, mas adicionando uma camada homogênea de areia na superfície. Empregando os conceitos de altura da ruptura do aterro devido à plastificação do solo da fundação e a deformação de compatibilidade associada a essa altura.

Das análises realizadas, enfocaram-se os resultados na elaboração de um modelo para estimar a deformação do reforço para uma determinada altura. Conhecendo a tensão mobilizada é possível determinar o fator de segurança do aterro, adicionalmente empregado o modelo é possível dimensionar o reforço calculando a rigidez necessária conhecendo o fator de segurança. A avaliação do modelo foi feita empregando casos de aterros da literatura.

Nessa dissertação a calibração do programa de elementos finitos foi realizada com casos de aterros apresentados por Hinchberger e Rowe (2003) e de Oliveira (2006). Apresenta-se a seguir o procedimento utilizado para a modelagem numérica e validação do software utilizado. 


\subsection{O Programa de Elementos Finitos}

$\mathrm{Na}$ presente dissertação foi utilizado o programa PHASE 2 (Rockscience, 2001), que é um programa desenvolvido na Universidade de Toronto, Canadá, para modelagem bidimensional (deformação plana ou assimétrica) do comportamento de maciços rochosos, taludes e aterros dentre outros.

O programa permite realizar as simulações computacionais, fazendo uma análise elasto-plástica bidimensional (2D) baseada no método dos elementos finitos. O programa é capaz de gerar a malha de elementos finitos automaticamente e, além disso, conta com opção de realizar refinamentos em toda a malha ou em regiões. Também é possível escolher o número de nós.

Outra funcionalidade importante do PHASE 2 é a simulação em múltiplos estágios, em que, para cada etapa, se tem resultados distintos representados em um mesmo arquivo de trabalho; o número de estágios deve ser definido no início do processo. Além disso, permite a inclusão de diferentes litologias, sendo necessário conhecer os dados de entrada, parâmetros de resistência e deformabilidade dos materiais envolvidos na análise. Esse programa de elementos finitos não considera o adensamento da fundação.

O programa oferece diferentes opções, podem ser usados os modelos para solos e rochas: Mohr-Coulomb, Drucker-Prager, Hoek-Brown generalizado, CamClay. Na opção Mohr-Coulomb é necessário definir as propriedades elásticas dos materiais: coeficiente de Poisson e modulo de Young, assim como selecionar o tipo desejado para o comportamento dos materiais: elástico ou elasto-plástico.

Este programa pode ser usado para uma grande variedade de projetos de engenharia, os que incluem análise de taludes por elementos finitos e análise de percolação de água subterrânea.

\subsection{Modelagem do Aterro por Elementos Finitos}

Para realizar a análise numérica foi escolhida uma seção típica do aterro reforçado e considerou-se a espessura de solo mole de $20 \mathrm{~m}$. Sendo possível escolher o número de nós, o presente estudo foi realizado com uma malha triangular de três nós de integração.

Com a finalidade de testar a malha, foi feito um estudo de refinamento de 
malha, incrementando o número de elementos. Este refinamento foi manual nas áreas de interesse. Testando diferentes tipos de malha, começando por uma simples até uma complexa, observou-se que, quanto mais refinada a malha, maior o tempo de processamento.

O número de iterações foi analisado testando seis malhas no programa, observando que os resultados não diferem muito quando se varia o número de iterações entre 30 e 100. A característica principal foi a diminuição na altura da ruptura do aterro em alguns centímetros. Quanto maior é o número de iterações há um aumento no tempo de processamento e a altura é menor. Adotou-se o valor de 100 iterações para as análises.

Foram consideradas as seguintes restrições de deslocamentos:

- a base da seção foi fixada para impedir os deslocamentos horizontais e verticais;

- as fronteiras laterais foram fixadas aproximadamente a $20 \mathrm{~m}$ do pé do talude e os deslocamentos horizontais foram impedidos, sendo possível somente a ocorrência de deslocamentos verticais e na superfície sem restrições.

Modelou-se o reforço a través de um elemento típico "geossintético", que exibe um comportamento elástico e resiste apenas a esforços de tração, inserindo a rigidez como dado do reforço. Foi usada uma camada simples de reforço, situada na interface solo de fundação - material do aterro. No presente estudo foi simulada a seção completa do aterro.

A modelação numérica permitiu modelar de uma forma mais realista toda a sequência construtiva do aterro, em diferentes estágios de construção.

Nos cálculos efetuados, admitiu-se que os solos apresentavam um comportamento elasto-plástico isotrópico com critério de ruptura de Mohr-Coulomb, porque permite modelar o comportamento do solo até o momento da ruptura, assim como conhecer a magnitude das deformações esperadas antes da ruptura.

\subsection{Validação e Calibração do Programa}

Com o objetivo de validar a metodologia adotada nessa pesquisa e calibrar o programa utilizado, buscou-se reproduzir no programa casos de aterros estudados 
anteriormente. Nesse caso foi empregado um dos casos de aterros experimentais, apresentados por Oliveira (2006).

Além disso, para avaliar as analises dos casos de aterros não reforçados, os resultados foram comparados com a metodologia proposto por Sousa Pinto (1966) para aterros não reforçados, com o fim de verificar os resultados de forma numérica e analítica.

\section{Aplicação do caso de Aterro experimental AE2, Oliveira (2006) na calibração do programa}

Encontra-se na literatura o caso de um aterro experimental com reforço sobre solo mole executados por Oliveira (2006) o que for apresentado no item 2.9.4. Tentou-se reproduzir no PHASE 2 o comportamento do aterro experimental $\mathrm{AE}$ 2, que apresentava uma camada de areia na superfície e reforço na base do aterro.

Os estágios de construção representam a sequência construtiva, o que quer dizer que o primeiro estágio representa o início da construção, e a partir do segundo em diante corresponde à execução de uma camada de terraplenagem. A modelagem foi realizada em estágios com alteamentos de $0,30 \mathrm{~m}$ de espessura do aterro.

Os materiais foram analisados usando o modelo elasto-plástico com critério de ruptura de Mohr-Coulomb, com peso especifico igual a $17,5 \mathrm{k} \mathrm{N} / \mathrm{m}^{3}$, ângulo de atrito de $33,8^{\circ}$, coeficiente de Poisson $v=0,3$ e com um módulo de deformação típico para material dos aterros de $\mathrm{E}=15000 \mathrm{kPa}$.

O solo de fundação foi modelado com coeficiente de Poisson $v=0,5$, isotrópico e perfeitamente plástico. O módulo de deformação (Eu) foi definido em função da resistência não drenada $S_{u}$, através da relação $E_{u} / S_{u o}$ igual a 300 .

O solo de fundação foi modelado de maneira tal que, considere o aumento da resistência não drenada com a profundidade, com Suo $=4,8 \mathrm{kPa}$ e $\rho_{c}=0,6$ $\mathrm{kPa} / \mathrm{m}$, sendo-lhes atribuídos os valores da relação linear:

$$
S u=4,8+0,6 z
$$

O aterro AE2 foi construído com uma ligeira inclinação na base do corpo do aterro para induzir à ruptura, detalhe que também foi reproduzido na modelagem numérica. 
A Figura 3-1 e Figura 3-2, apresentam-se os resultados obtidos aplicando a metodologia da altura liquida e deformação de compatibilidade de Rowe e Soderman (1987). A altura de ruptura nesse caso é de 3,0 m (Figura 3-1).

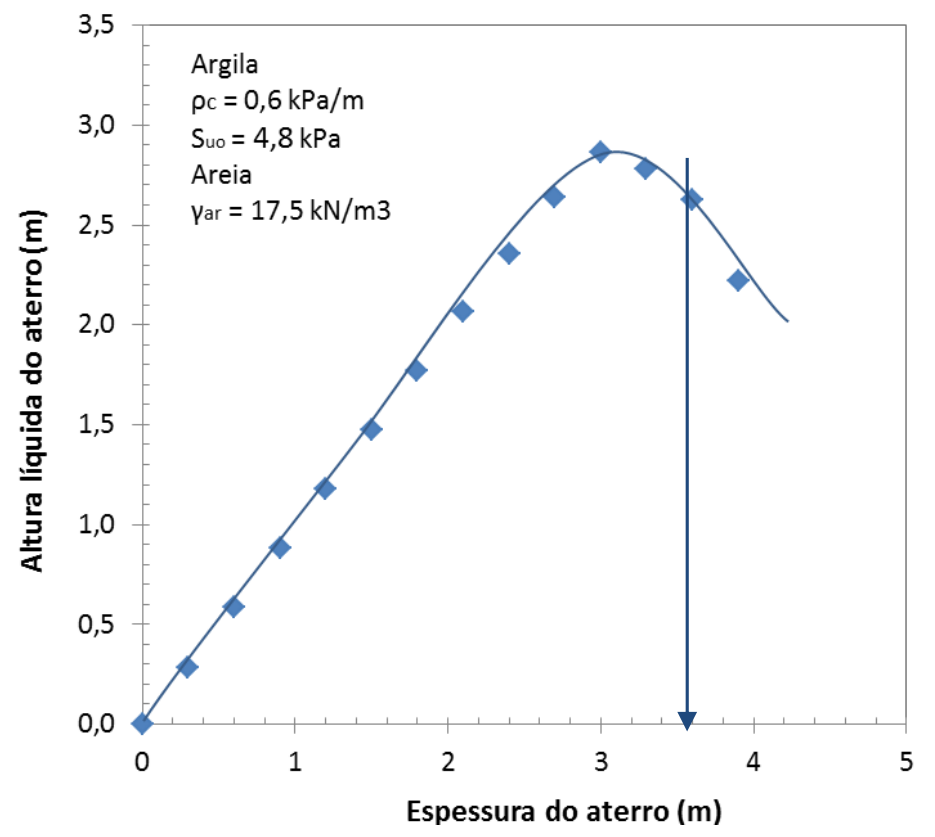

Figura 3-1 Altura de ruptura na modelagem do aterro experimental.

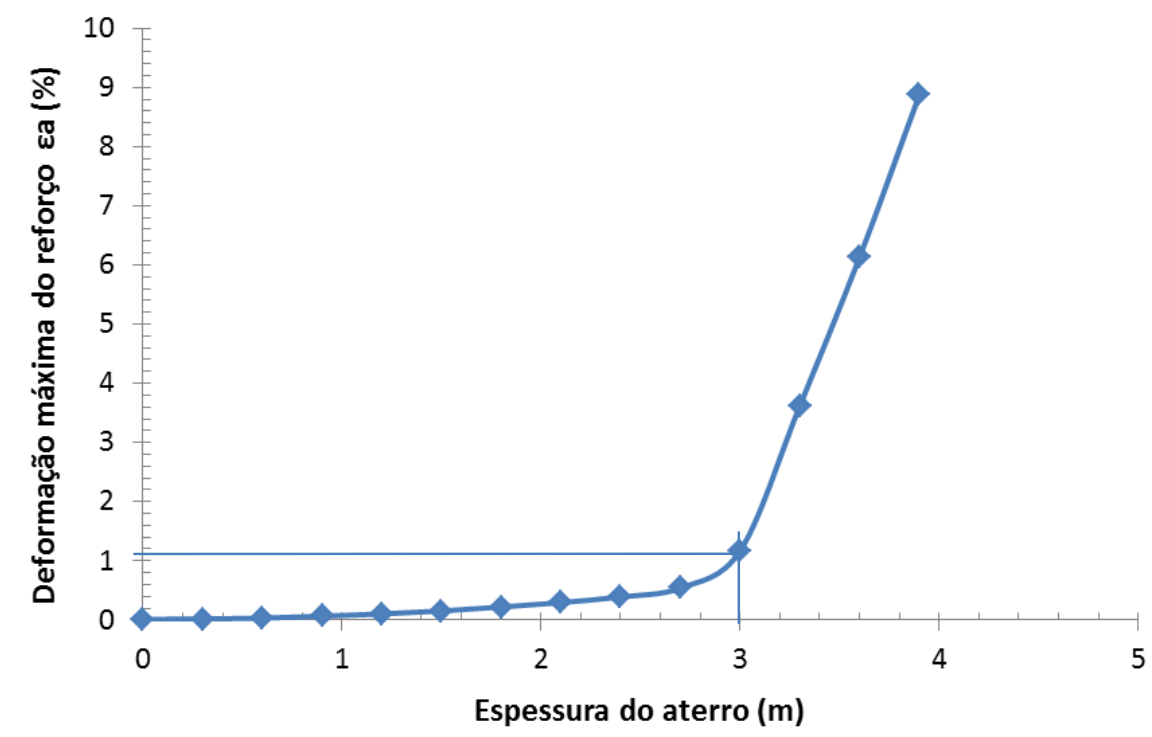

Figura 3-2 Deformações máximas do reforço da modelagem do aterro experimental. 
No PHASE 2, o aumento de deslocamentos ocorre entre a $9^{\mathrm{a}}$ e $10^{\mathrm{a}}$ camada; sendo representado na calibração pelos $10^{\circ}$ e $11^{\circ}$ estágios. A deformação de compatibilidade associada à altura de ruptura foi de $1,16 \%$, e está mostrado na Figura 3-2.

Oliveira (2006) descreveu que a $8^{a}$ camada de material de aterro colocada foi a última camada estável e a partir da $9^{a}$ camada, os incrementos de deslocamentos foram bastante acentuados em relação ás camadas anteriores, caracterizando o início da ruptura por plastificação.

A seguir são apresentados os resultados do inclinômetro IC4 na Figura 3-3, instalado junto ao pé do talude do aterro, as medidas foram feitas em profundidade ao longo de uma vertical. Na Figura 3-3, não está inclusa a camada superficial de areia, e a camada de argila tem uma espessura de 5,6 $\mathrm{m}$ de profundidade.

Segundo Oliveira (2006), os valores de deslocamentos horizontais foram obtidos por integração a partir dos desvios da vertical medidos a cada $0,5 \mathrm{~m}$, os valores de deslocamentos são apresentados em milímetros e os dos ângulos de desvio da vertical em porcentagem.

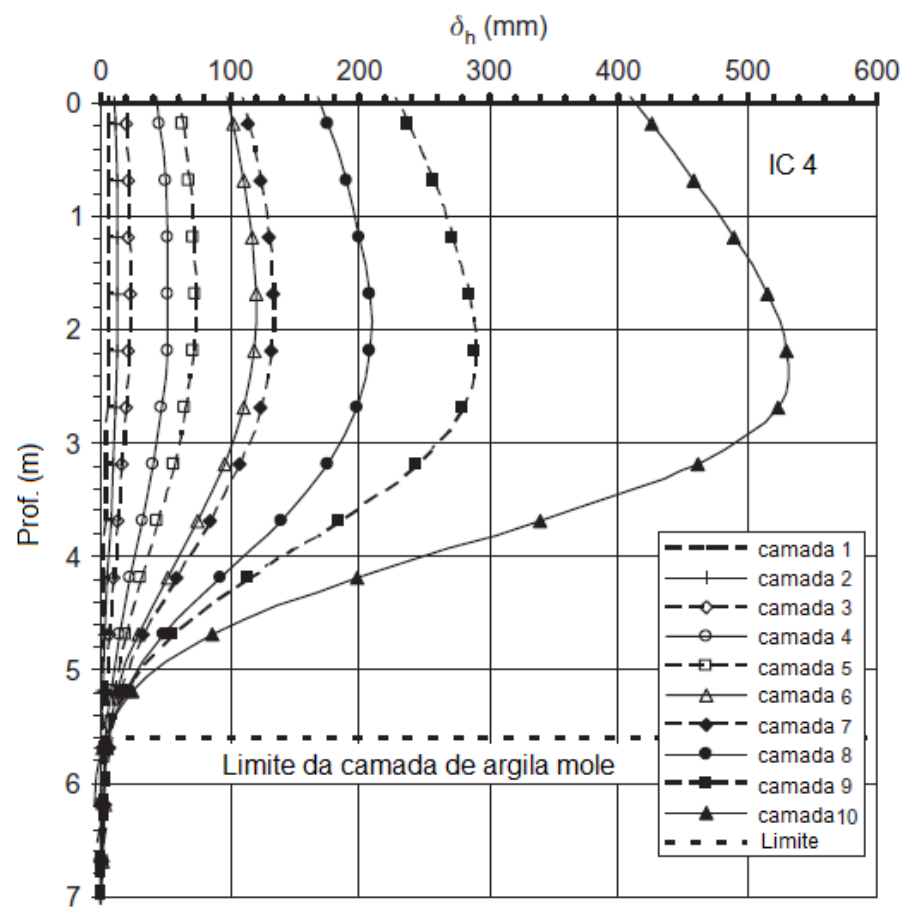

Figura 3-3 Deslocamentos horizontais para o aterro experimental AE2, Oliveira et al (2009). 
A Figura 3-4, apresenta os resultado por estágio de construção para deslocamentos horizontais obtidos no PHASE 2, numa linha vertical no pé do aterro. A camada de areia esta inclusa na estratigrafia da fundação a $1.8 \mathrm{~m}$ de profundidade, o limite inferior da camada de argila esta situada a 7,4 m no eixo vertical da figura.

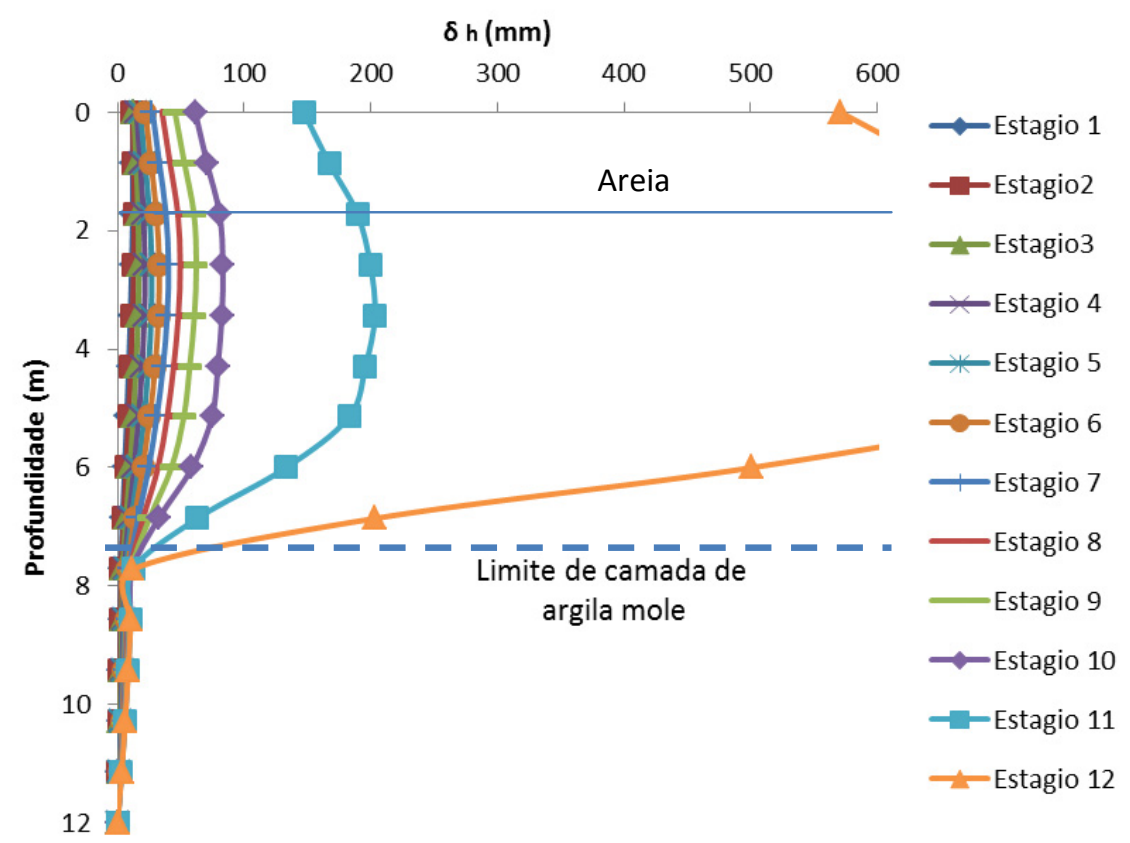

\section{Figura 3-4 Deslocamentos horizontais para o aterro experimental AE2, obtido pelo PHASE 2}

Observa-se uma boa concordância na distribuição das curvas, na Figura 3-3 os máximos deslocamentos horizontais produzem-se aproximadamente a $2 \mathrm{~m}$ do inicio da camada de argila assim como na Figura 3-4.

$\mathrm{Na}$ Figura 3-5, observa-se que os desvios da vertical máximos encontram-se aproximadamente na profundidade das máximas deformações cisalhantes, associadas às superfícies de ruptura, e essa profundidade não varia com o carregamento. O mesmos acontece com os resultados obtido no PHASE 2, apresentados na Figura 3-6. 


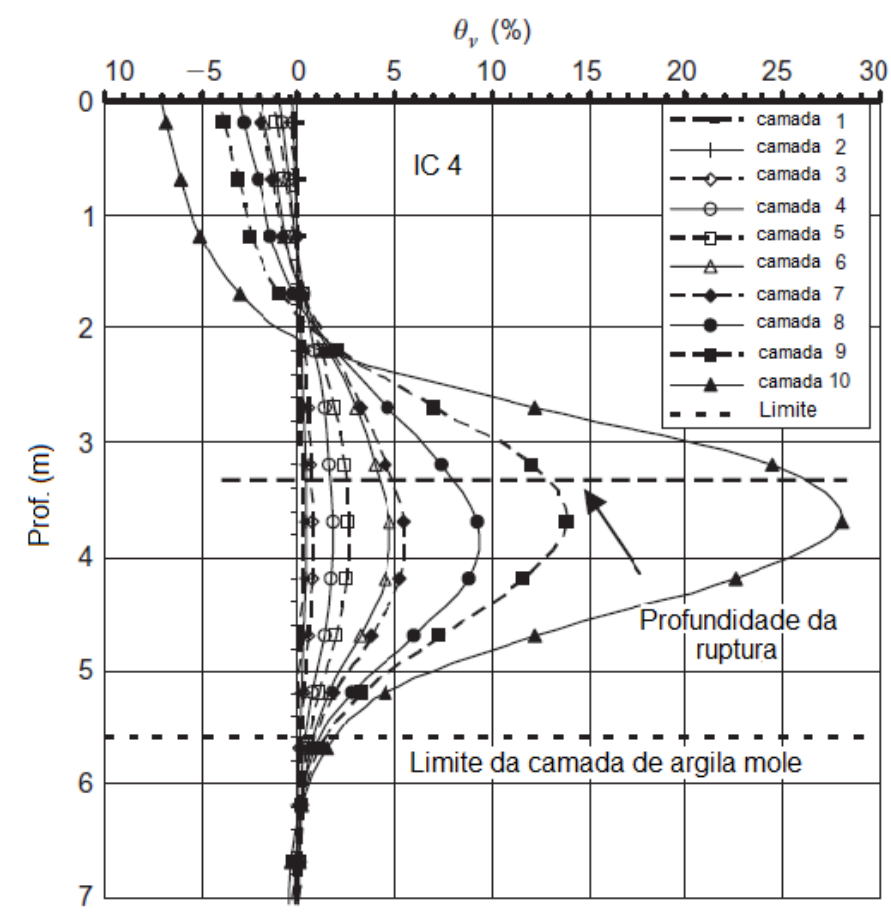

Figura 3-5 Desvios da vertical para o aterro experimental AE2, Oliveira (2006).

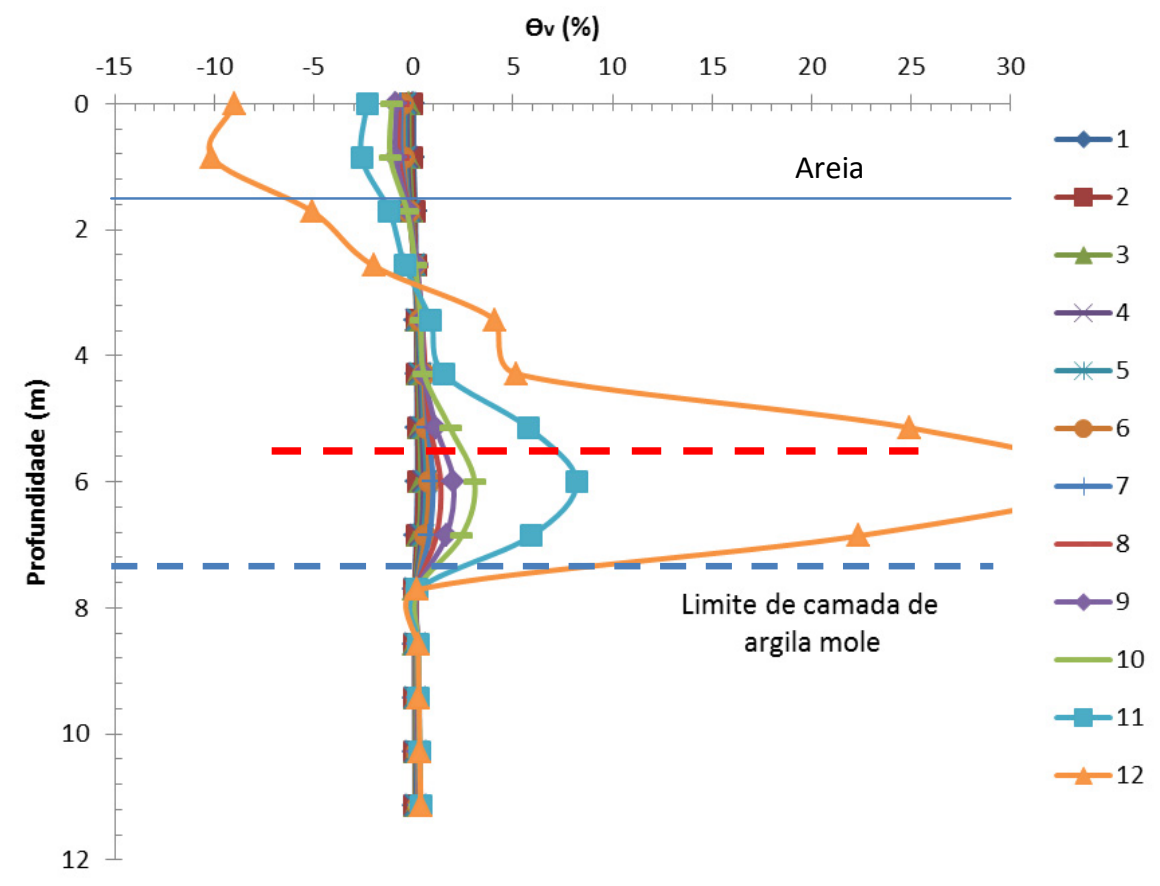

Figura 3-6 Desvios da vertical para o aterro experimental AE2 obtido pelo PHASE 2 
Para analisar a variação dos deslocamentos horizontais e os desvios da vertical com o carregamento, foram plotados os gráficos de seus valores máximos em cada vertical, em cada data de leitura, desde o início do carregamento até a ruptura, Oliveira (2006), como é mostrada na Figura 3-7.

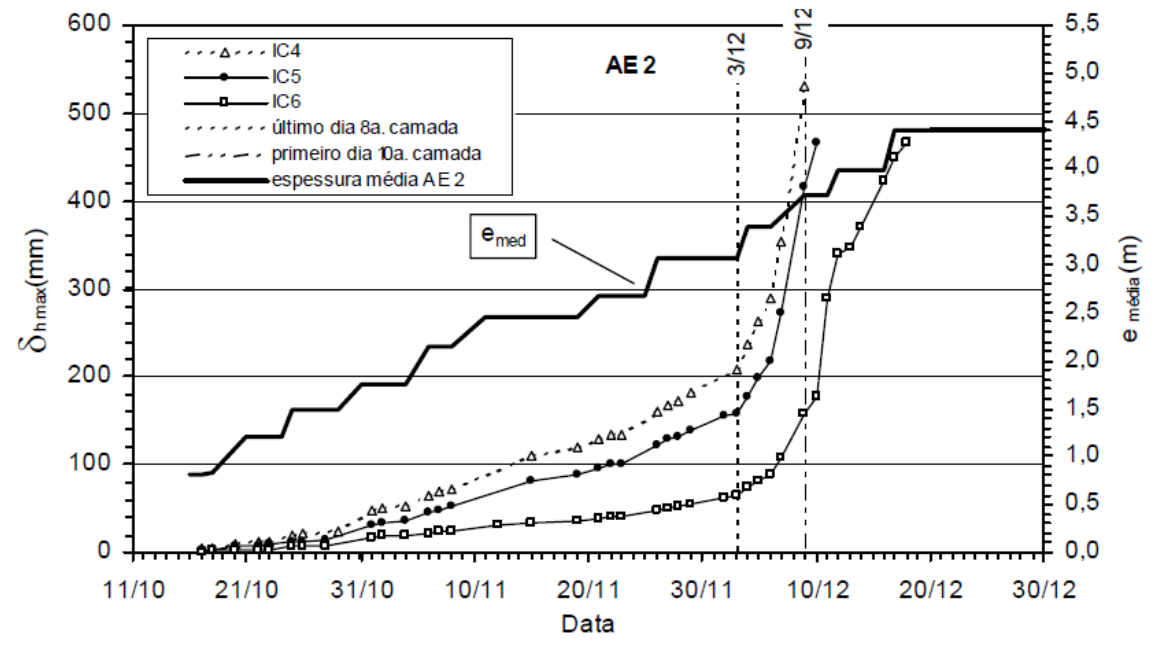

Figura 3-7 Variação de deslocamentos horizontais máximos com a elevação do aterro AE2, Oliveira (2006).

$\mathrm{Na}$ Figura 3-8, os resultados dos deslocamentos máximos obtidos do software foram plotados para cada estagio da construção, que simula a colocação de uma camada de terraplenagem.

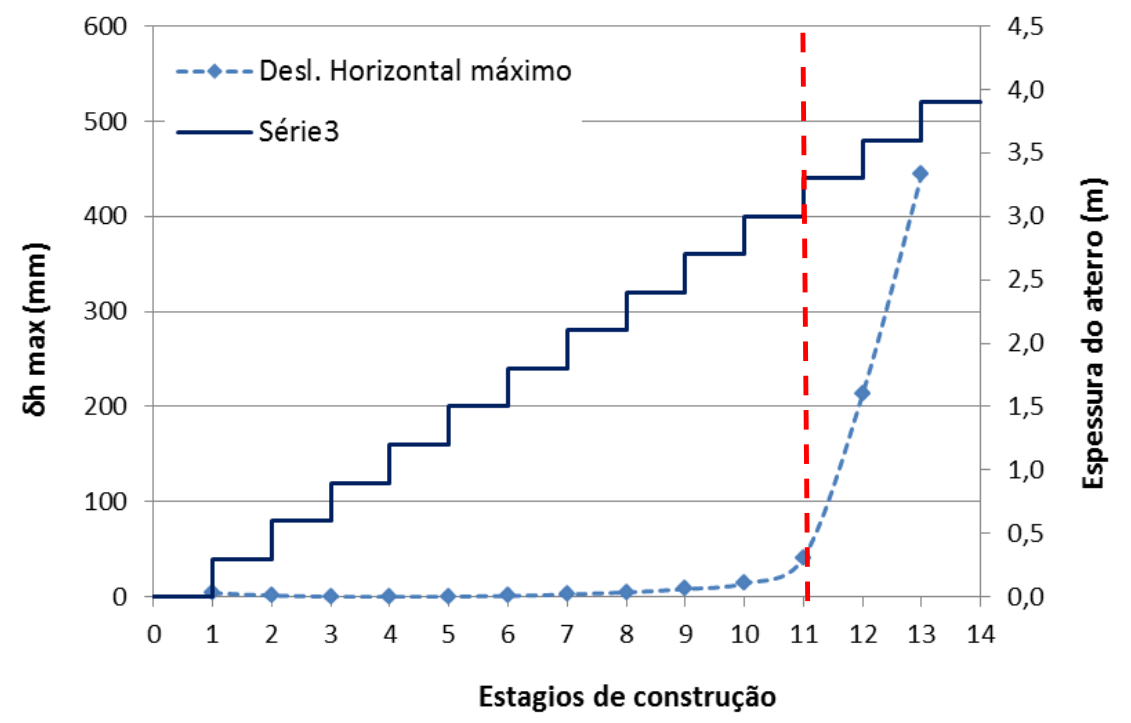

Figura 3-8 Variação de deslocamentos horizontais máximos com a elevação do aterro AE2 obtido pelo PHASE 2 
Observa-se que os deslocamentos se incrementam a partir do $11^{\circ}$ estagio, caracterizado como o inicio da ruptura.

Os valores das alturas e os respectivos valores das forças do reforço estão compilados na Tabela 3,1.

Tabela 3-1 Resumo dos resultados do aterro experimental AE2 de Oliveira (2006) e do PHASE 2.

\begin{tabular}{l|c|c}
\hline \multicolumn{1}{c|}{ Dados } & Aterro Experimental & PHASE 2 \\
\hline Espessura da areia superficial & 1,8 & 1,8 \\
\hline Altura de ruptura & 3,71 & 3 \\
\hline Força de tração máxima na ruptura & $18,5 \mathrm{kN} / \mathrm{m}$ & $19,8 \mathrm{kN} / \mathrm{m}$ \\
\hline Deslocamento horizontal-sob pé $(\mathrm{mm})$ & 289 & 203,2 \\
\hline Desvio da vertical $(\%)$ & 13,9 & 8,5 \\
\hline
\end{tabular}

Observa-se os valores aproximados dos resultados no PHASE2 e dos medidos in situ, alguns dos valores podem diferir devido ao fato que o programa não leva em consideração o adensamento que pode se produzir durante a construção.

\section{Aplicação da proposta Sousa Pinto (1966) para aterros não reforçados}

Para calibrar o programa analisando aterros não reforçados sobre solo mole foi realizada uma comparação de resultados empregando o método proposto por Sousa Pinto (1966), para depósitos em que a resistência não-drenada cresce linearmente com a profundidade e o programa PHASE 2.

A Tabela 3.2 mostra os resultados das alturas atingidas pelo aterro calculadas mediante o PHASE 2 o e os resultados com base no método de Souza Pinto. Os parâmetros do solo Suo e $\rho$ são as variáveis.

Observa-se que as alturas obtidas empregando os dois métodos, diferem em alguns centímetros, para ilustrar melhor isto foi colocado num gráfico comparativo mostrado na Figura 3-9. 
Tabela 3-2 Resumo dos resultados da altura de ruptura obtida pelo método de Souza Pinto (1966) e do PHASE 2.

\begin{tabular}{c|c|c|c}
\hline \multirow{2}{*}{ Suo $(\mathrm{kPa})$} & $\rho(\mathrm{kPa} / \mathrm{m})$ & Souza Pinto 1966 $(\mathrm{m})$ & PHASE 2 $(\mathrm{m})$ \\
\hline \multirow{3}{*}{2,00} & 1,00 & 1,28 & 1,125 \\
\cline { 2 - 4 } & 1,50 & 2,04 & 1,875 \\
\cline { 2 - 4 } & 2,00 & 2,70 & 3,00 \\
\hline \multirow{3}{*}{3,60} & 1,00 & 1,44 & 1,80 \\
\cline { 2 - 4 } & 1,50 & 2,51 & 2,40 \\
\cline { 2 - 4 } & 2,00 & 3,22 & 3,60 \\
\hline \multirow{3}{*}{5,00} & 1,00 & 2,59 & 2,25 \\
\cline { 2 - 4 } & 1,50 & 3,56 & 3,30 \\
\cline { 2 - 4 } & 2,00 & 4,27 & 4,00 \\
\hline
\end{tabular}

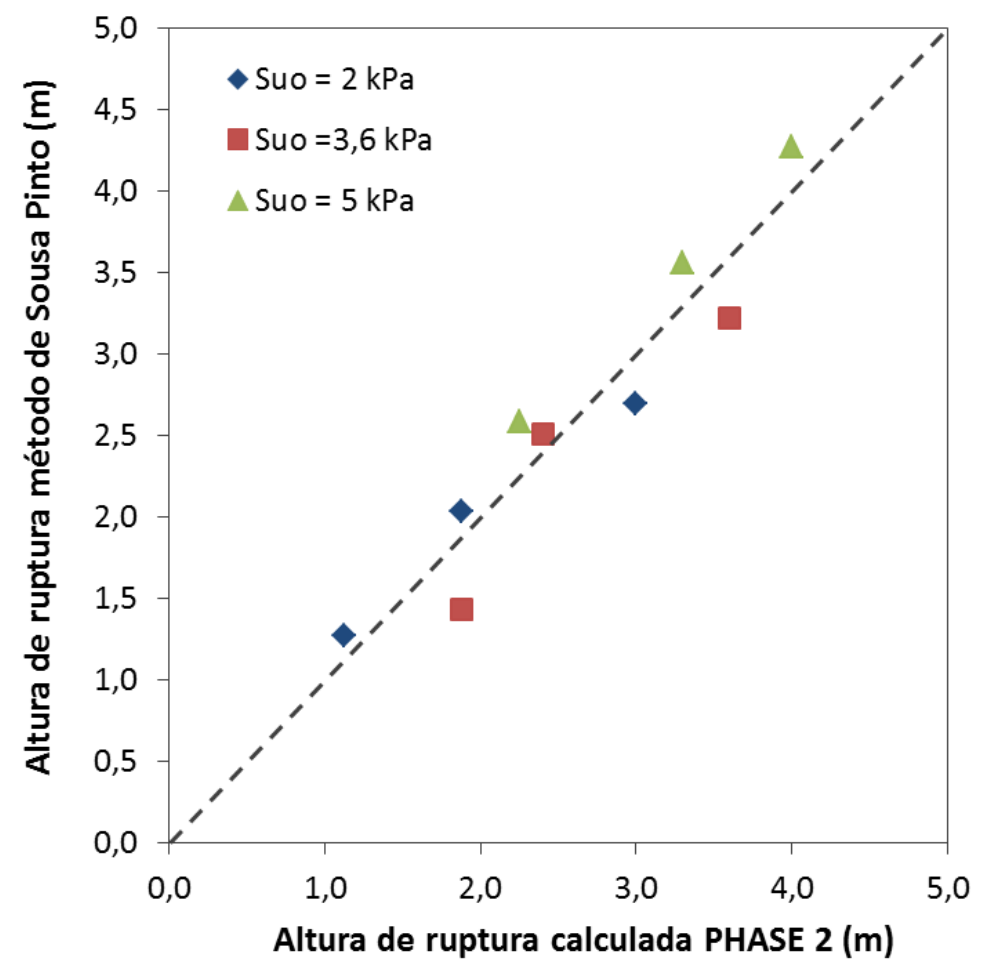

Figura 3-9 Comparação das alturas atingidas pelo aterro empregando o método de Souza Pinto e mediante o PHASE 2.

Os resultados obtidos a fim de calibrar o modelo utilizado estão bem próximo dos valores teóricos, as diferenças na modelagem usada podem influenciar nos resultados. 


\subsection{Modelagem Númerica}

Objetivou-se, com o estudo numérico, estender o estudo realizado por Hinchberger e Rowe (2003) verificando as deformações do reforço nos aterros sobre solos moles com uma camada superficial de areia, sob diferentes condições de geometria e propriedades dos materiais.

Variou-se a resistência não drenada na superfície, o aumento da resistência com a profundidade e o módulo de elasticidade do solo de fundação, além da rigidez do reforço e da espessura da camada de areia.

Detalham-se, a seguir, a modelagem e os parâmetros dos materiais envolvidos nas análises.

\subsection{Geometria Empregada}

Inicialmente, foram analisados aterros com altura inicial de $1,5 \mathrm{~m}$ e aumentando conforme se incrementavam os parâmetros do solo até uma altura máxima de 8 a $9 \mathrm{~m}$ de sobrecarga; a base do aterro aproximadamente de $46 \mathrm{~m}$ de largura, sendo a inclinação do talude de $1 \mathrm{H}: 2 \mathrm{~V}$, sobrejacentes a uma camada de 20 $m$ de solo de fundação.

$\mathrm{Na}$ modelagem numérica, o corpo do aterro foi analisado em múltiplos estágios de construção alteados cada um de $37,5 \mathrm{~cm}$ de espessura; para o solo de fundação foram modelados dois casos com diferente tipo de estratigrafia da fundação: solo mole com e sem areia, no caso sem areia foi analisado considerando-se uma camada total de argila não drenada simulando o incremento da resistência com a profundidade; para os casos com presença da camada de areia o procedimento foi o mesmo adicionando uma espessura de areia variável.

O reforço foi colocado em toda a extensão da base do aterro, e com fins de comparação foram analisados casos de aterros sem reforço. Colocou-se a linha piezométrica na superfície da fundação. Na Figura 3-10, apresentam-se as características geométricas dos aterros considerados nas análises. 


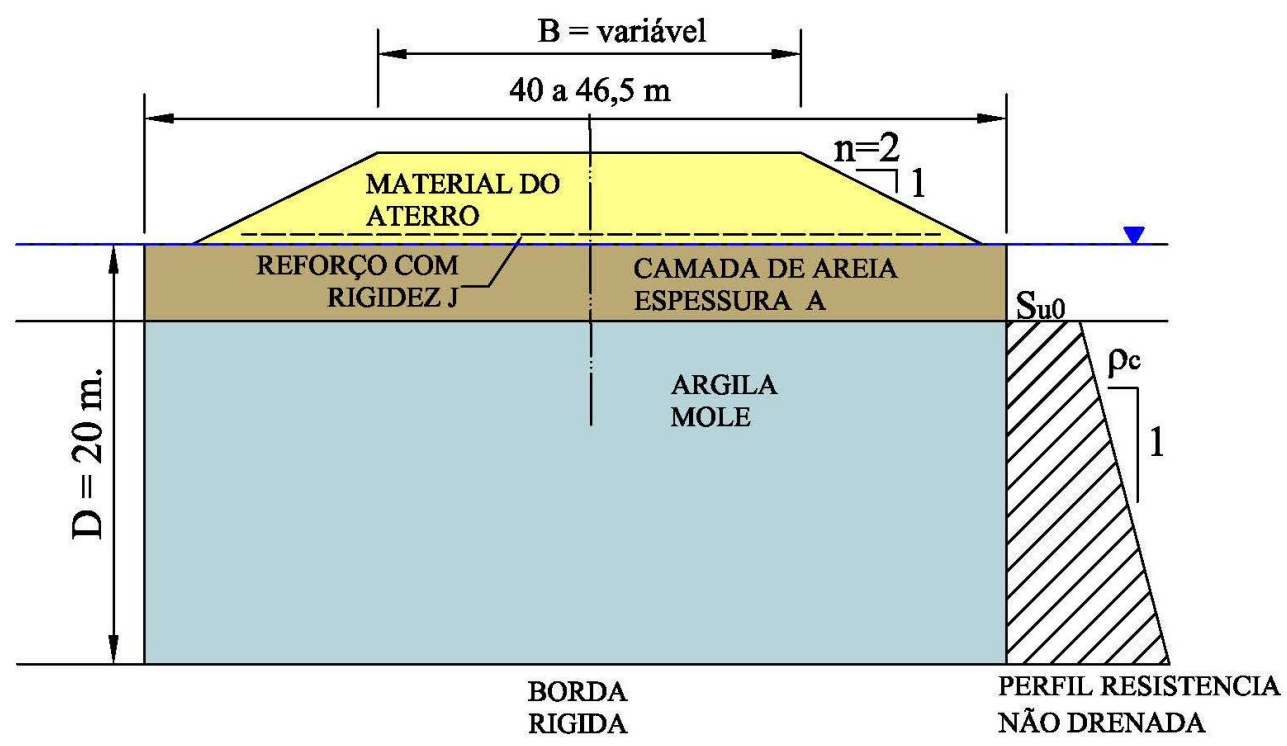

Figura 3-10 Geometria do aterro e estratigrafia da fundação. (Adaptado de Hinchberger e Rowe 2003)

\subsection{Propriedades dos Materiais}

Os parâmetros geotécnicos utilizados na modelagem numérica foram estimados a partir dos dados de Hinchberger e Rowe (2003).

O material do aterro foi modelado em tensões efetivas, com um módulo de elasticidade $\mathrm{E}=10 \mathrm{MPa}$, isotrópico e perfeitamente plástico; um coeficiente de Poisson $v=0,3$; peso específico igual a $20 \mathrm{kN} / \mathrm{m}^{3}$ e ângulo de atrito $\phi=30^{\circ}$.

A areia foi modelada com parâmetros drenados (tensões efetivas) e utilizouse um modulo de elasticidade $\mathrm{E}=20 \mathrm{MPa}$, isotrópico e perfeitamente plástico; um coeficiente de Poisson $v=0,3$; ângulo de atrito $\phi=30^{\circ}$ e peso específico saturado igual a $21 \mathrm{kN} / \mathrm{m}^{3}$.

O solo mole de fundação foi modelado em condições não-drenadas (tensões totais), utilizado um coeficiente de Poisson $v=0,5$, isotrópico e perfeitamente plástico, o módulo de deformação, $E_{u}$, foi definido em função da resistência não drenada $S_{u}$, a través da relação adotada $E_{u} / S_{u}$ igual a 125 e varia com a profundidade $z$.

O resumo dos parâmetros utilizados nas análises são mostrados na Tabela 3-3. 
Tabela 3-3 Resumo dos parâmetros de material utilizados nas análises no PHASE 2.

\begin{tabular}{cccc}
\hline Parâmetros & Material Aterro & Argila Mole & Areia \\
\hline$\gamma(\mathrm{kN} / \mathrm{m})$ & 20 & - & 21 (saturado) \\
$\mathrm{E}(\mathrm{MPa})$ & 10 & - & 20 \\
$v$ & 0.3 & 0.5 & 0.3 \\
$\phi\left({ }^{\circ}\right)$ & 30 & - & 30 \\
$\mathrm{Eu} / \mathrm{Su}$ & - & 125 & - \\
\hline
\end{tabular}

A resistência não drenada $\left(S_{u}\right)$ dos solos moles num exemplo de caso são as argilas da Baixada Santista, as que mostram uma tendência sempre crescente com a profundidade (Sousa Pinto e Massad, 1978). Então para considerar a variação de resistência não drenada com a profundidade, foi escolhida no programa a opção de parâmetros de resistência dependentes da profundidade mediante a relação linear:

$S_{u}=S_{u o}+\rho_{c} z$

Variando os valores para $S_{u}$ e $\rho_{c}$.

Ao longo do desenvolvimento da pesquisa, foram realizadas análises preliminares em aterros com alturas de $2 \mathrm{~m}$ até $8 \mathrm{~m}$, com inclinação de talude de $1 \mathrm{H}: 2 \mathrm{~V}$, sobre uma camada de areia com diferente espessura sobrejacente a uma camada de solo mole. As análises foram efetuadas em um número de etapas variável dependendo do número de camadas do aterro.

Estudou-se a influência nas deformações do reforço da espessura da camada de areia na fundação e da variação da rigidez do reforço.

O presente estudo analisou a ruptura produzida pelos recalques imediatos durante a construção, não sendo estudada a influência do recalque por adensamento nestas análises.

\subsection{Considerações Finais}

Esse capítulo descreveu as principais características e propriedades adotadas nas simulações numéricas do aterro reforçado.

Foram apresentados os parâmetros geotécnicos, a geometria da seção de estudo, os modelos constitutivos adotados e a descrição da modelagem do processo construtivo. 
A descrição da modelagem do aterro contemplou o primeiro passo das análises, o que é a validação do programa. Que resultou numa boa aproximação dos resultados obtidos com os da literatura.

A seqüência construtiva foi simulada mediante estágios, representando cada estágio a colocação de uma camada de material de aterro. 


\section{APRESENTAÇÃO E ANÁLISES DOS RESULTADOS}

\subsection{Introdução}

Neste capitulo, são apresentados e discutidos os resultados das análises efetuadas utilizando o programa de elementos finitos PHASE $2 \vee 6$.

Serão apresentados os resultados obtidos, aplicando a metodologia das alturas liquidas e a deformação de compatibilidade do reforço, e será mostrado um caso onde se indica o como age o mecanismo de ruptura na fundação.

Foi analisada a influência nas deformações do reforço, nas alturas atingidas e nos deslocamentos da fundação devido as seguintes fatores:

- os parâmetros do solo mole de fundação,

- a rigidez do reforço,

- a presença da camada de areia na superfície da fundação.

A espessura da camada de areia foi incluída nas análises por se apresentar na natureza em forma de camadas superficiais nos depósitos de solos moles, podendo alterar substancialmente a interação solo-reforço. Neste sentido, serão analisados aterros reforçados sobre fundações que incluam esta camada natural de areia superficial, visando identificar os efeitos dela no mecanismo de ruptura.

E foi mediante uma variedade de simulações, com diferentes combinações dos parâmetros do solo e rigidez do reforço, que se avaliaram os fatores que afetam à deformação de compatibilidade do reforço.

\subsection{Casos Analisados}

Observando os estudos executados nos solos moles brasileiros, especificamente na Baixada Santista, onde há presença de camadas de areia e a resistência tem em aumento com a profundidade, as resistências das argilas obtidas nos ensaios de palheta executados oscilam em torno nos valores de $3 \mathrm{kPa}$ para os Mangues aumentando para os Sedimentos flúvio-lagunares (SFL) na faixa de 10 a $60 \mathrm{kPa}$. Os resultados do aumento da resistência com a profundidade para os solos de Cubatão apresentaram um valor de $\rho=2,0 \mathrm{kPa} / \mathrm{m}$, na llha de Santo Amaro de 2,1 kPa/m, no Vale do R. Quilombo 2,3 kPa/m e no Vale do R. Diana 1,0 
$\mathrm{kPa} / \mathrm{m}$ entre outros valores nessa faixa (Massad, 1999).

Em vista disso, os valores da fundação na presente dissertação, empregada para executar as analises foram de $\mathrm{S}_{\mathrm{uo}}=2 \mathrm{kPa}, 3,6 \mathrm{kPa}$ e $5 \mathrm{kPa}$, e as respectivas combinações de $\rho$ na faixa de valores apresentados anteriormente para reproduzir valores de $\rho$ existentes.

Os valores da rigidez do reforço $(\mathrm{J})$ foram tomados de $300 \mathrm{kN} / \mathrm{m}$ até o valor de $10.000 \mathrm{kN} / \mathrm{m}$, cabe ressaltar que nos catálogos de geossintéticos as empresas oferecem a fabricação de rigidez maior a $10,000 \mathrm{kN} / \mathrm{m}$ segundo o requerimento da obra, chegando até os $36.000 \mathrm{kN} / \mathrm{m}$ em casos especiais.

A camada de areia foi analisada simulando o caso de uma fundação sem areia até uma fundação com espessura de $4 \mathrm{~m}$.

Na Tabela 4-1 apresentam-se os parâmetros utilizados e as combinações deles utilizadas nas análises numéricas.

\section{Tabela 4-1 Parâmetros utilizados nas análises numéricas}

\begin{tabular}{|c|c|c|c|c|}
\hline \multicolumn{4}{|c|}{ FUNDACC̃O } & \multirow{2}{*}{$\begin{array}{c}\text { REFORÇO } \\
\\
\text { Variação da Rigidez } \\
\text { do Reforço } \\
\mathbf{J}(\mathbf{k N} / \mathrm{m})\end{array}$} \\
\hline $\mathrm{Eu} / \mathrm{Cu}$ & $\begin{array}{l}\text { Suo } \\
\text { (kPa) }\end{array}$ & $\begin{array}{c}\rho \\
(k P a / m)\end{array}$ & $\begin{array}{c}\text { Espessura da } \\
\text { Camada de Areia } \\
\text { (m) }\end{array}$ & \\
\hline \multirow{9}{*}{125} & \multirow{3}{*}{2,0} & 1,0 & \multirow{4}{*}{0} & \multirow{4}{*}{$\begin{array}{c}300 \\
600 \\
1000\end{array}$} \\
\hline & & 1,5 & & \\
\hline & & 2,0 & & \\
\hline & \multirow{3}{*}{3,6} & 1,0 & & \\
\hline & & 1,5 & \multirow[t]{3}{*}{2} & 2000 \\
\hline & & 2,0 & & 4000 \\
\hline & \multirow{3}{*}{5,0} & 1,0 & & 8000 \\
\hline & & 1,5 & \multirow[t]{2}{*}{4} & 10000 \\
\hline & & 2,0 & & \\
\hline
\end{tabular}

A apresentação dos resultados será organizada em gráficos, os quais incluem dados de fundações com diferentes espessuras de camada de areia superficial e com diferentes valores de rigidez do esforço à tração, assim como os resultados obtidos da deformação do reforço para cada condição analisada. Os deslocamentos verticais foram obtidos na horizontal ao longo da base do aterro, e os deslocamentos horizontais obtidos a través de uma linha vertical no pé do talude 
do aterro que atravessa a camada de fundação.

\subsection{Resultados das Análises pelo MEF}

As análises com o MEF permitiram avaliar as deformações do reforço e as alturas atingidas, tendo em conta o estado de carregamento inicial e final, além disso, permitiu analisar a evolução da ruptura à medida que a plastificação se expande pela fundação.

Neste item apresentam-se as análises para aterros reforçados sobre uma fundação composta por duas camadas, areia superficial e argila.

\subsubsection{Altura de ruptura e deformação do reforço}

Mostram-se os resultados obtidos com o programa Phase2 empregando a metodologia proposta por Hichberger \& Rowe (2003), o que considera os recalques imediatos.

Os gráficos de altura líquida obtidas para um aterro reforçado, são os mostrados na Figura 4-1 (a).

(a)

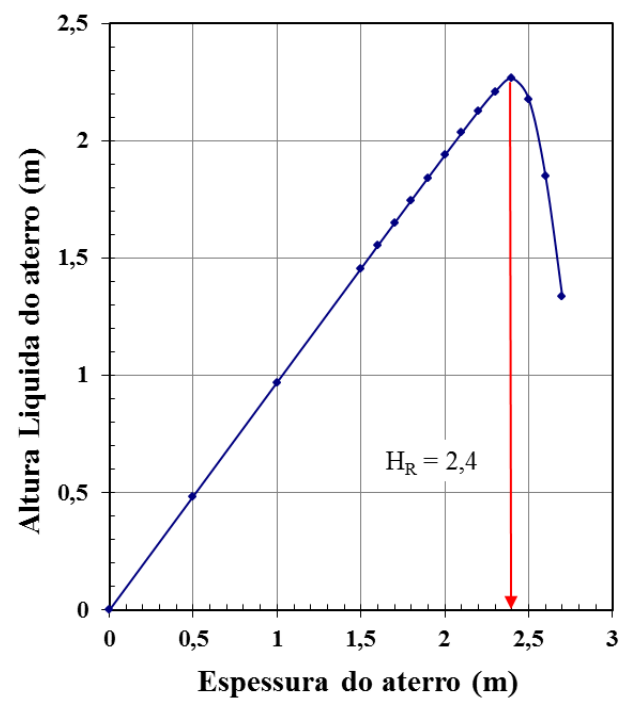

(b)

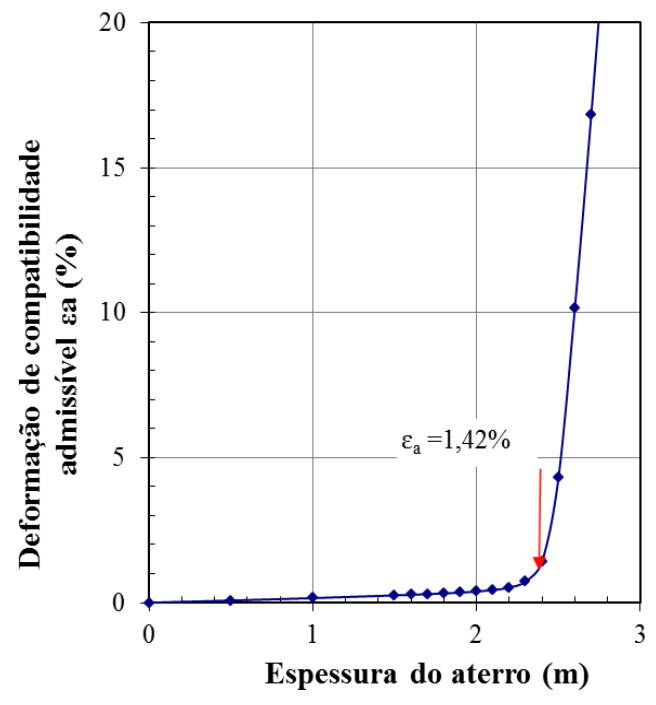

Figura 4-1 Resultados de altura liquida do aterro e deformação de compatibilidade admissível do reforço 
A altura líquida máxima no eixo das ordenadas é representada pelo ponto máximo da curva, a altura da ruptura obtida traçando uma linha vertical ao eixo das abaixas, é neste caso $\mathrm{H}_{\mathrm{R}}=2,4 \mathrm{~m}$.

A essa altura de ruptura do aterro está associada uma deformação de compatibilidade do reforço $\varepsilon_{a}$ de 1,42 , que é o valor da deformação de compatibilidade que corresponde à altura de ruptura $\mathrm{H}_{R}$, como é indicado na Figura 4-1 (b).

\subsubsection{Definição das áreas de plastificação}

Para mostrar as áreas de plastificação do solo serão empregados os gráficos de altura liquida e deformação de compatibilidade. Na Figura 4-2 esta indicada a numeração dos estágios onde começou a plastificar o solo.

Nesse caso o aterro atingiu uma altura de $1,75 \mathrm{~m}$, a essa altura de ruptura do aterro está associada uma deformação de compatibilidade do reforço $\varepsilon_{a}$ de $5,8 \%$ como é indicado na Figura 4-3.

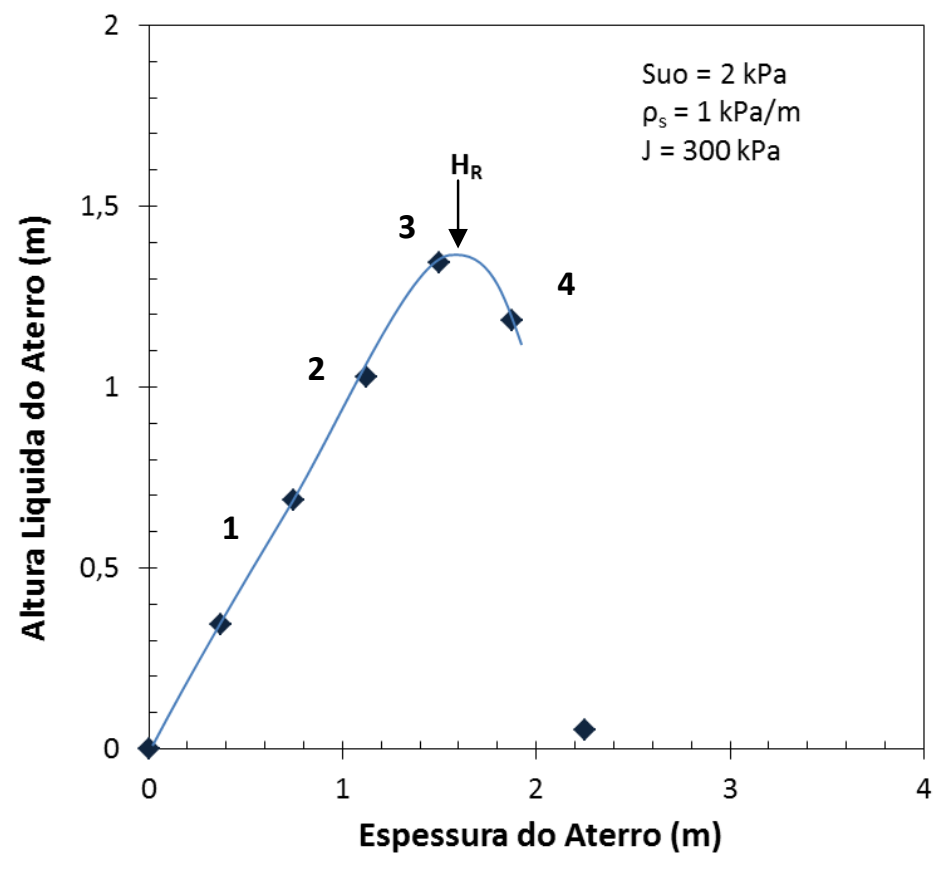

Figura 4-2 Altura líquida 


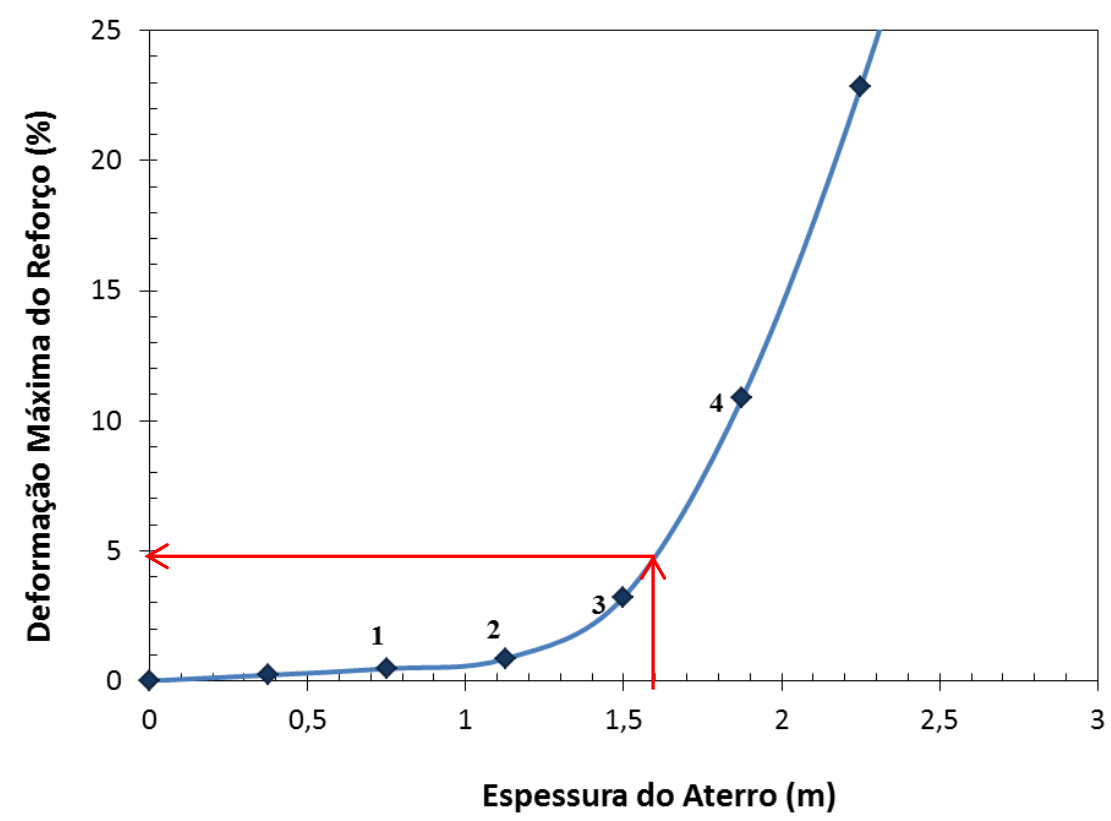

Figura 4-3 Deformação de compatibilidade do reforço

Os pontos da curva numerados serão apresentados adiante nas Figura 4-4 a Figura 4-7, eles indicam os estágios de construção onde se produz a plastificação do solo.

Nos seguintes perfis, as áreas vermelhas indicam plastificação do solo, onde apresenta uma maior concentração de deformações cisalhantes ao longo da potencial superfície de ruptura.

A Figura 4-4, representa o Ponto 1 e mostra o estado da fundação antes do solo começar a plastificar.

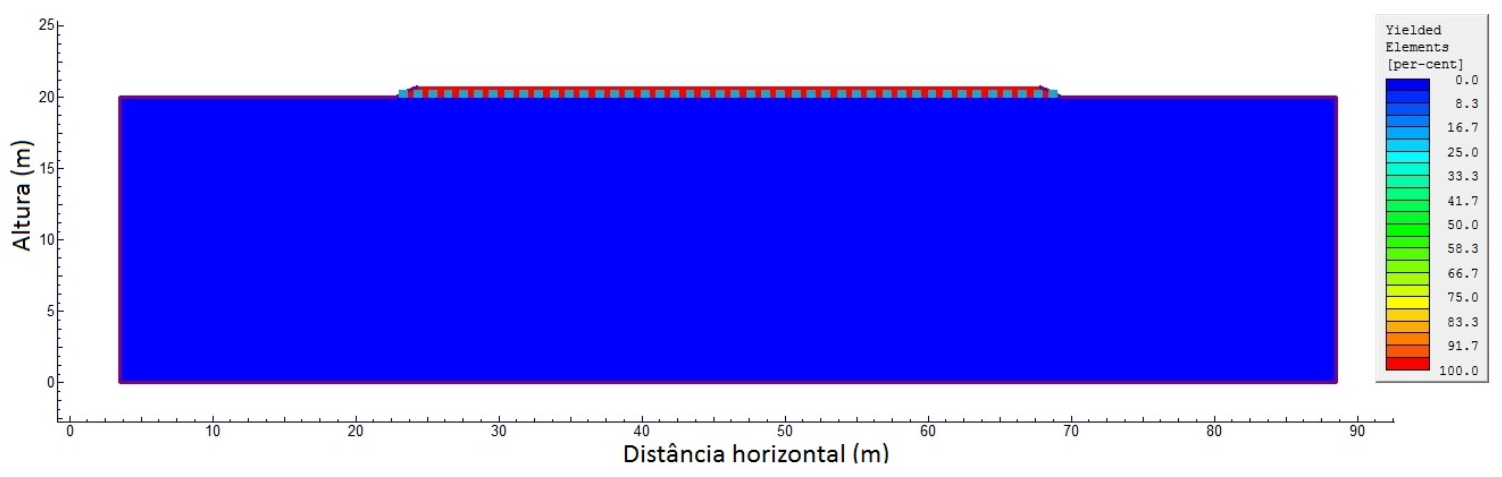

Figura 4-4 Ponto 1 - Estado da fundação num estagio anterior à plastificação. 
A Figura 4-5 mostra o inicio da plastificação do solo e começa perto ao pé do talude do aterro. Nesse estágio há aumento das taxas dos deslocamentos e deformações e uma plastificação parcial das áreas próximas à superfície de ruptura.

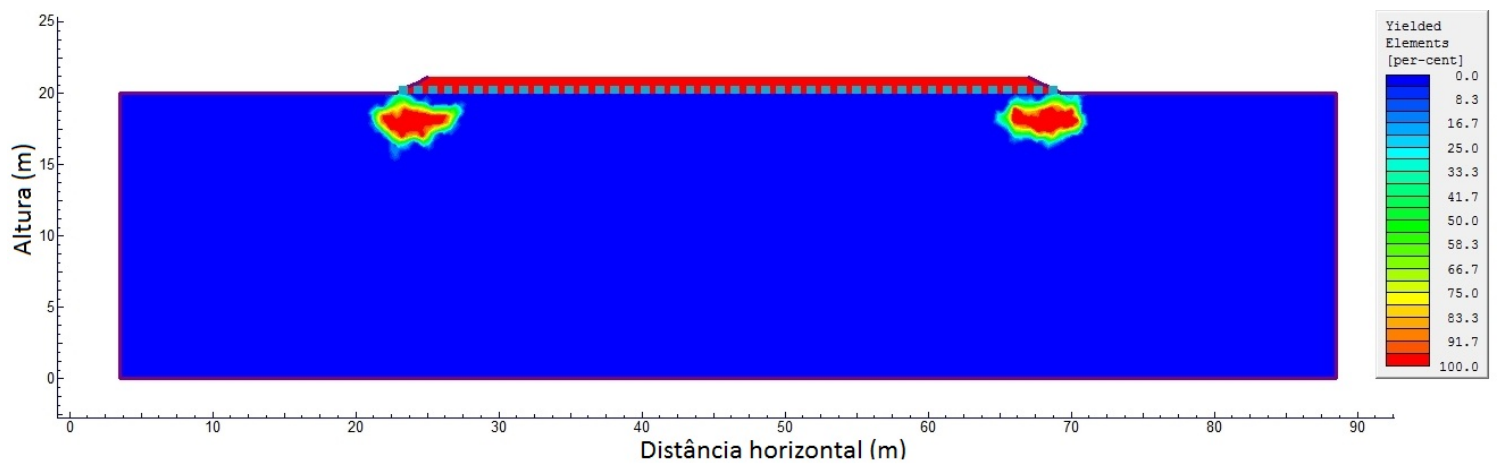

Figura 4-5 Ponto 2 - Estado da fundação no inicio da plastificação.

A Figura 4-6 mostra o estado da fundação em um estágio do aterro anterior à ruptura da fundação. Os deslocamentos são maiores devido às tensões cisalhantes produzidas ao longo da superfície de ruptura e a plastificação ocorre ao longo e próximas dessa superfície; nesse caso mostra-se uma superfície circular de ruptura.

Observa-se o aumento das áreas em vermelho ao longo do aterro.

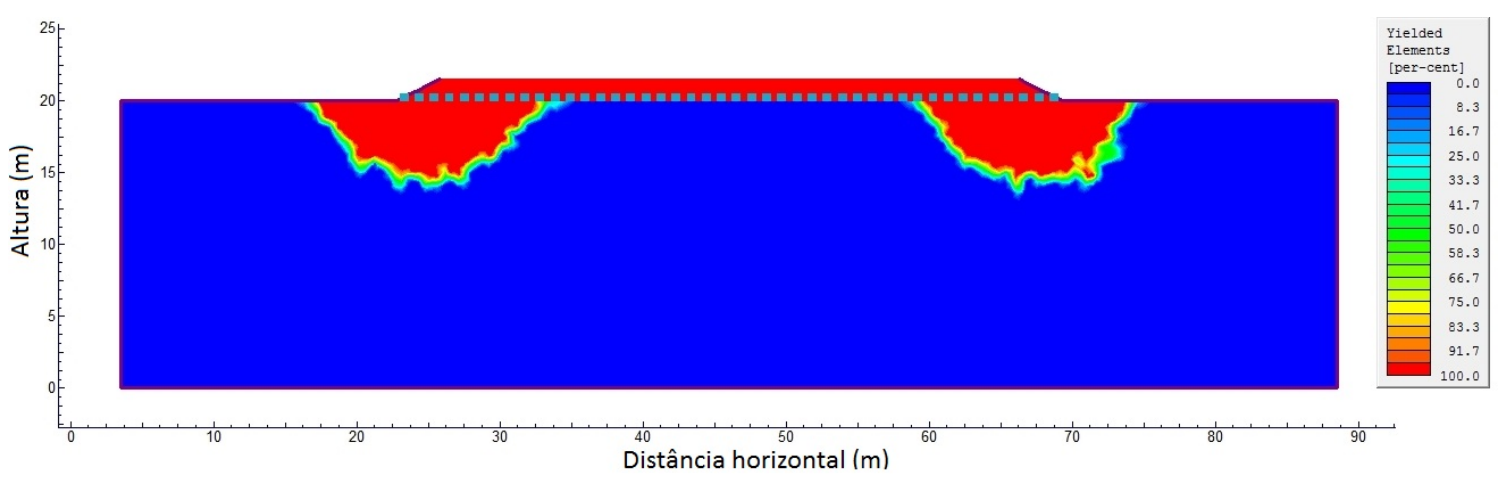

Figura 4-6 Ponto 3 - Estado da fundação num estagio anterior à ruptura.

A Figura 4-7 mostra o estado da fundação após de ocorrida à ruptura, onde há queda de altura liquida. Os deslocamentos ocorrem de forma generalizada em toda a fundação e são muito elevados. Segundo Rowe \& Soderman (1985) este 
estágio é denominado de "ruptura controlada" onde a altura útil do aterro cai à medida que se executam novas camadas; para suportar os esforços impostos pelas camadas adicionadas são produzidas grandes deformações no reforço e no solo de fundação.

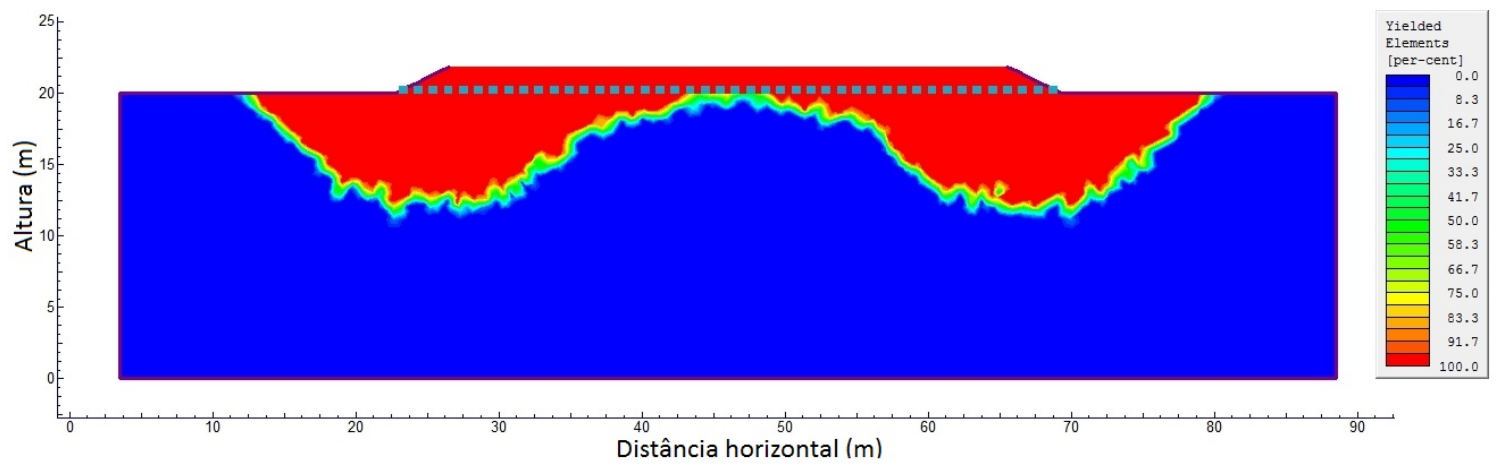

Figura 4-7 Ponto 4 - Estado da fundação num estagio posterior á ruptura.

Nota-se a plastificação de toda a extensão da camada de fundação ao longo da base do aterro reforçado.

Os resultados mostram concordância com os modos de ruptura para aterros reforçados sobre solos moles descritos por Oliveira (2006) que correspondem ao modo de ruptura por plastificação.

\subsubsection{Influência da camada superficial de areia}

Para visualizar a influência da areia no mecanismo de ruptura foram obtidos os vetores deslocamento em cada nó da malha, no momento da ruptura para um J $=600 \mathrm{kN} / \mathrm{m}$ e Suo $=2 \mathrm{kPa}$ e $\rho=1 \mathrm{kPa} / \mathrm{m}$.

Os vetores deslocamento indicam a direção e a magnitude relativa dos movimentos do solo no início da ruptura. Os vetores deslocamentos diminuem com a profundidade, assim como as deformações no solo, conforme o aumento da resistência com a profundidade.

O aterro construído sobre solo mole e sem a camada areia (Figura 4-8 a) atinge uma altura de ruptura de $\mathrm{H}_{\mathrm{R}}=4,2 \mathrm{~m}$ e os vetores indicam que o mecanismo de ruptura começa próximo ao talude, no pé do aterro, e se estende até uma profundidade de aproximadamente $7 \mathrm{~m}$. 


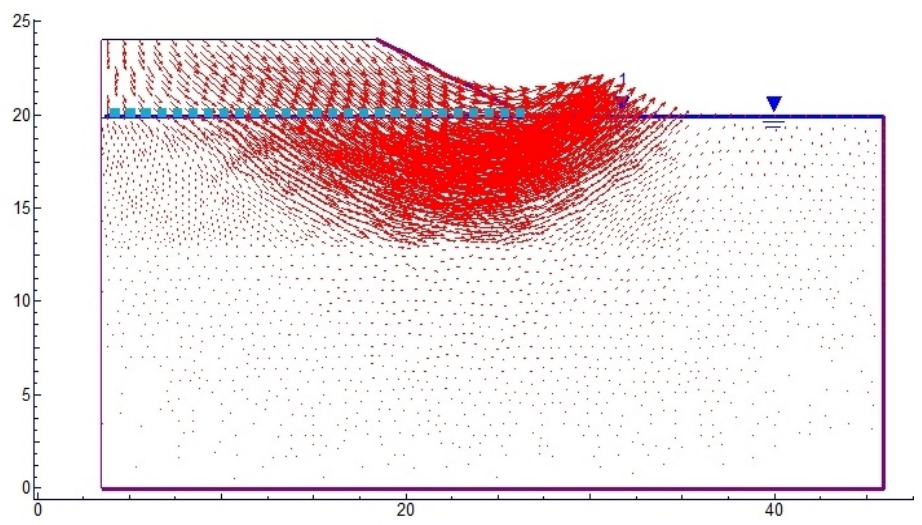

(a) sem areia

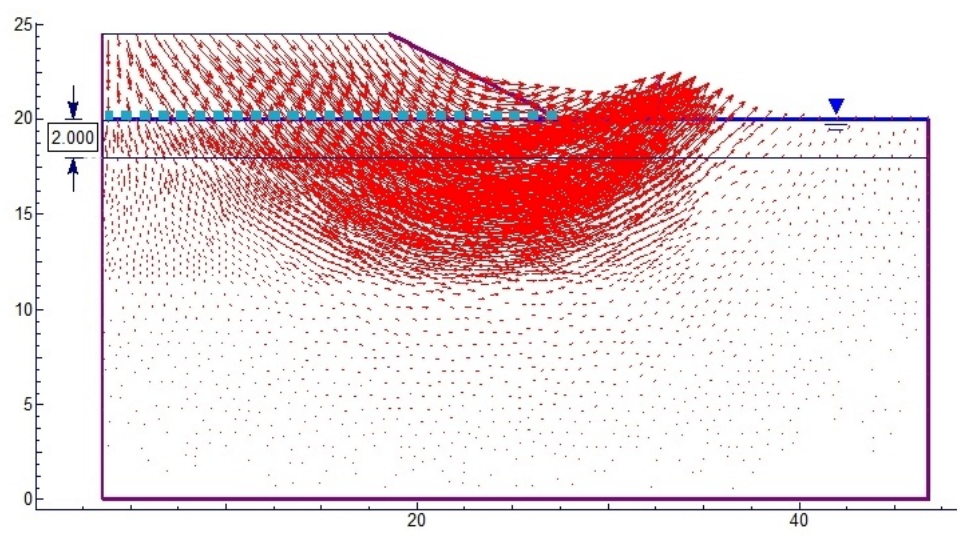

(b) com $2 \mathrm{~m}$ de areia

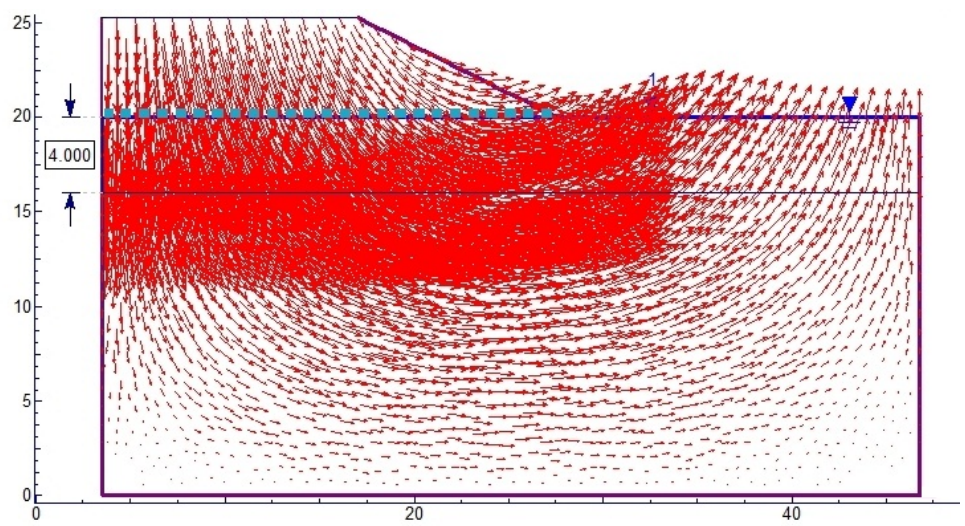

(c) com $4 \mathrm{~m}$ de areia

Figura 4-8 Influência da areia nos vetores deslocamentos do mecanismo de ruptura no aterro com $S_{u o}=2 \mathrm{kPa}, \rho=2,0 \mathrm{kPa} / \mathrm{m}, \mathrm{J}=600 \mathrm{kN} / \mathrm{m}$ e $A=0$ (a), $2 \mathrm{~m}$ (b) e $4 \mathrm{~m}$ (c)

Na Figura 4-8 (c), os vetores deslocamento indicam que o mecanismo de 
ruptura se desloca em direção ao centro do aterro até atingir uma profundidade de aproximadamente $10 \mathrm{~m}$ e uma altura maior de $\mathrm{H}_{\mathrm{R}}=5,5 \mathrm{~m}$.

É possível perceber da Figura 4-8(b e c) que a presença da camada de areia na superfície pode mudar significativamente o mecanismo de ruptura. No caso do aterro sobre uma camada de areia de $2 \mathrm{~m}$, o mecanismo de ruptura é deslocado verticalmente para baixo da camada de areia Figura 4-8, onde apresenta maior concentração dos vetores e, é por essa razão que o aterro rompe com uma altura de $4,5 \mathrm{~m}$ e o mecanismo de ruptura se estende até uma profundidade de $8,5 \mathrm{~m}$.

\subsubsection{Resultados da altura de ruptura do aterro e deformação do reforço}

Os resultados foram organizados em gráficos, que mostram as curvas de altura líquida e altura da ruptura do aterro, assim como as respectivas deformações do reforço, para os aterros construídos sobre uma camada de argila e sobre uma camada de areia no topo de $2 \mathrm{~m}$ e $4 \mathrm{~m}$, respectivamente. Mediante o MEF, foi obtida a força mobilizada no reforço para cada estágio e a partir dela e da rigidez do reforço se calcularam as deformações $\varepsilon$.

Nas Figura 4-9 a Figura 4-11, são apresentadas as variações das alturas de ruptura e deformações do reforço para uma fundação sem areia com Suo $=2 \mathrm{kPa} e$ $\rho=1,0 \mathrm{kPa} / \mathrm{m}$, e fundação com espessura de areia de $2 \mathrm{~m}$ e $4 \mathrm{~m}$ com diferente rigidez do reforço $\mathrm{J}$ em $\mathrm{kN} / \mathrm{m}$.

$\mathrm{Na}$ modelagem dos aterros construídos diretamente sobre argila, 0 comportamento é similar aos resultados obtidos por Hichberger \& Rowe (2003) e a altura de ruptura do aterro aumenta, na medida em que a rigidez aumenta, a deformação é menor. Nos aterros com presença da areia na superfície do terreno, verificou se um comportamento similar ao caso da fundação sem areia, mas as alturas de rupturas apresentadas são maiores, porém a deformação é menor. Quanto mais espessa a camada de areia maior poderá ser a altura do aterro.

No Apêndice I, apresentam-se os resultados destas análises para todos os casos estudados. Nesses gráficos, verifica-se o aumento das alturas e das deformações máximas do reforço em função da rigidez e da espessura da camada de areia. 


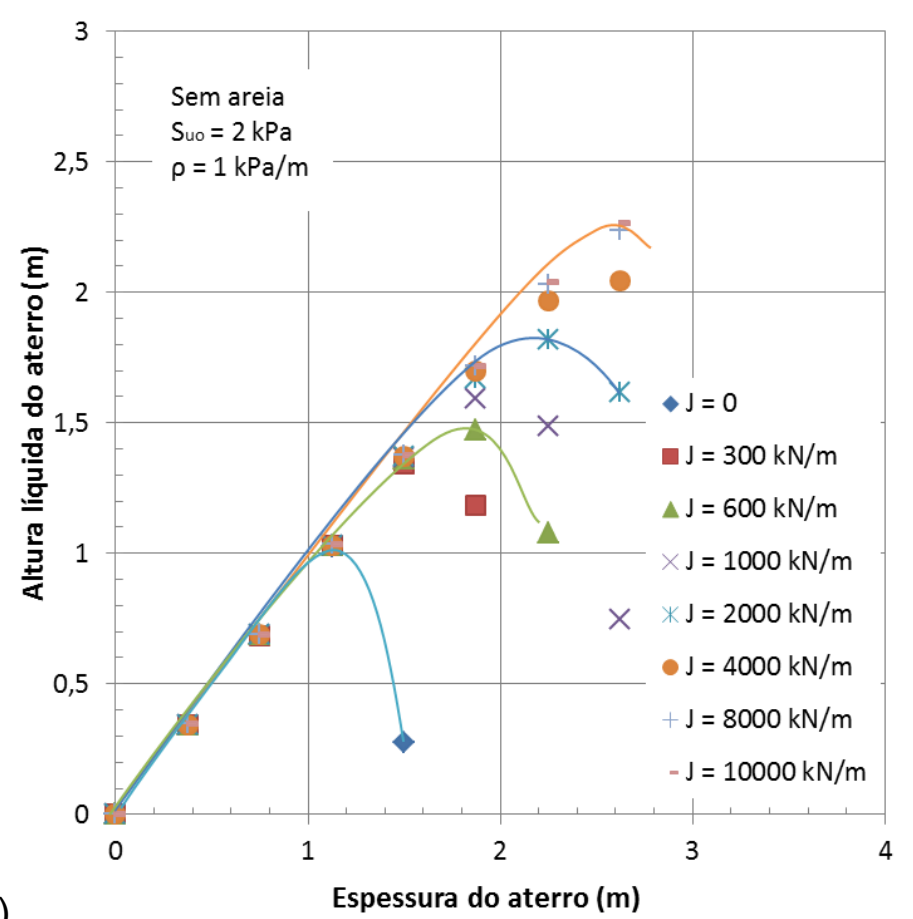

(a)

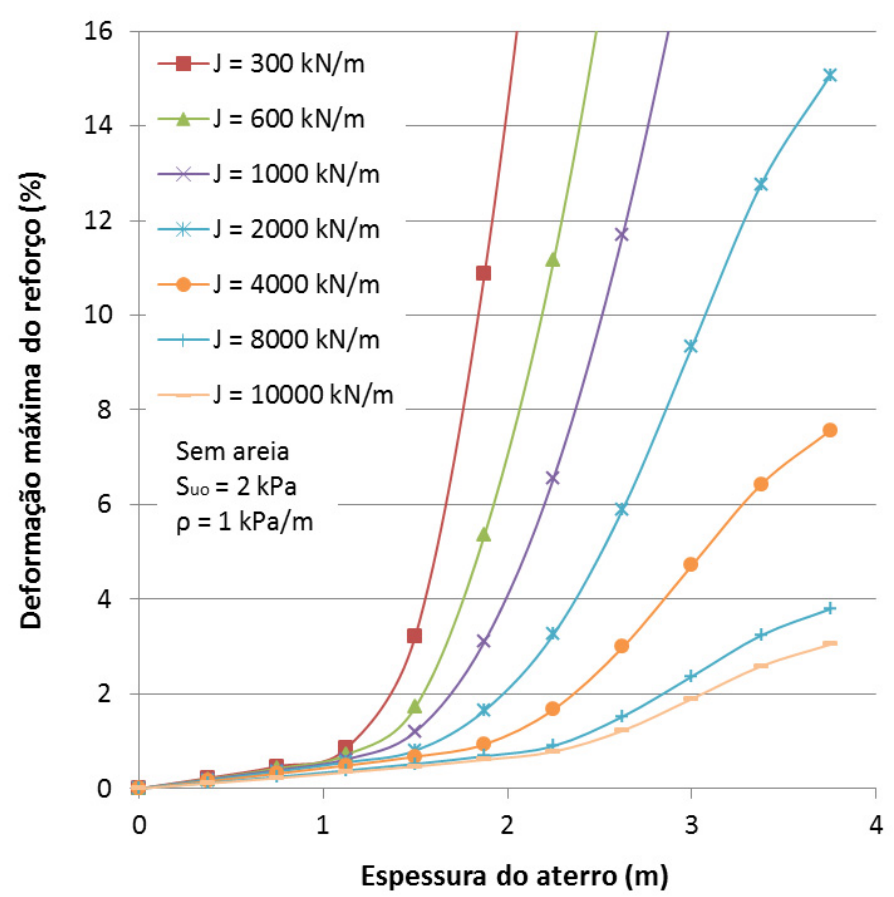

(b)

Figura 4-9 Alturas de ruptura (a) e deformações máximas do reforço com o aumento da rigidez do reforço $\mathrm{J}(\mathrm{b})$, para uma fundação sem areia. 


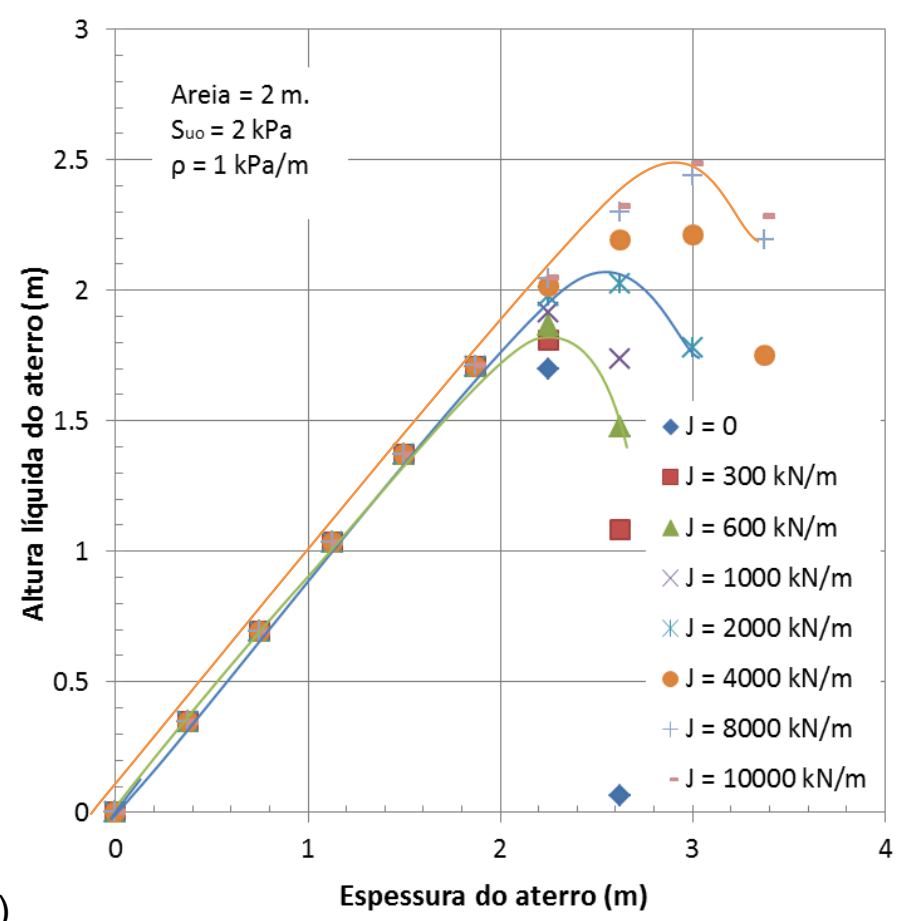

(a)

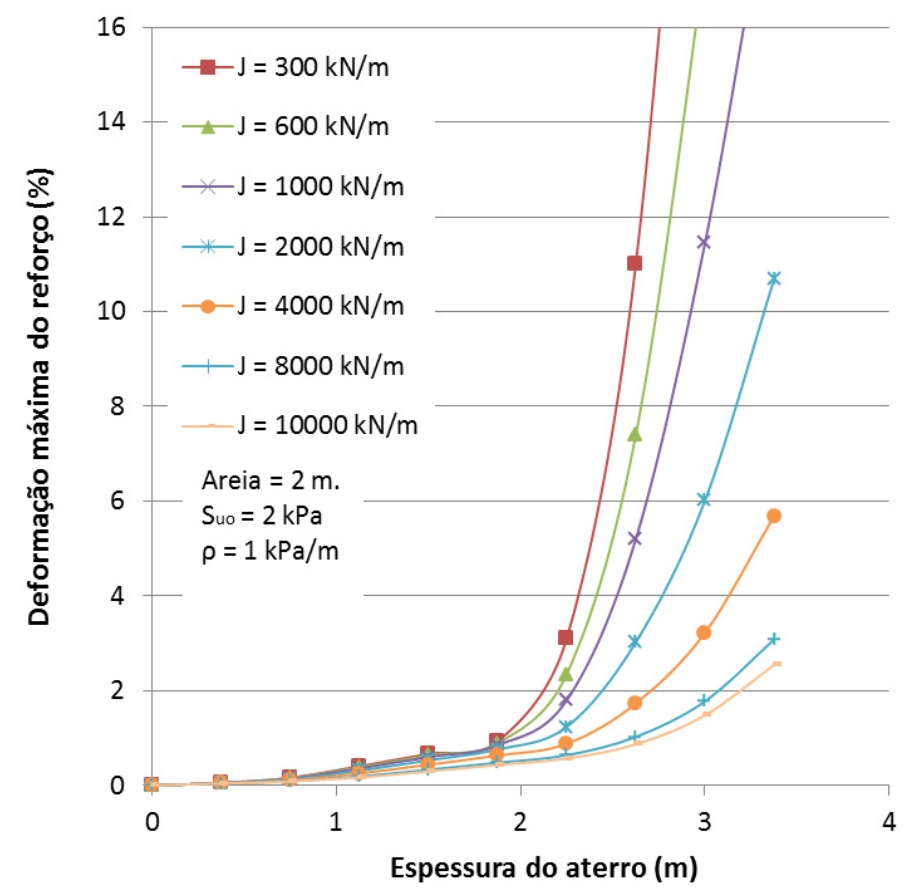

(b)

Figura 4-10 Alturas de ruptura (a) e deformações máximas do reforço com o aumento da rigidez do reforço $\mathrm{J}$ (b) para uma fundação com $2 \mathrm{~m}$ de areia. 


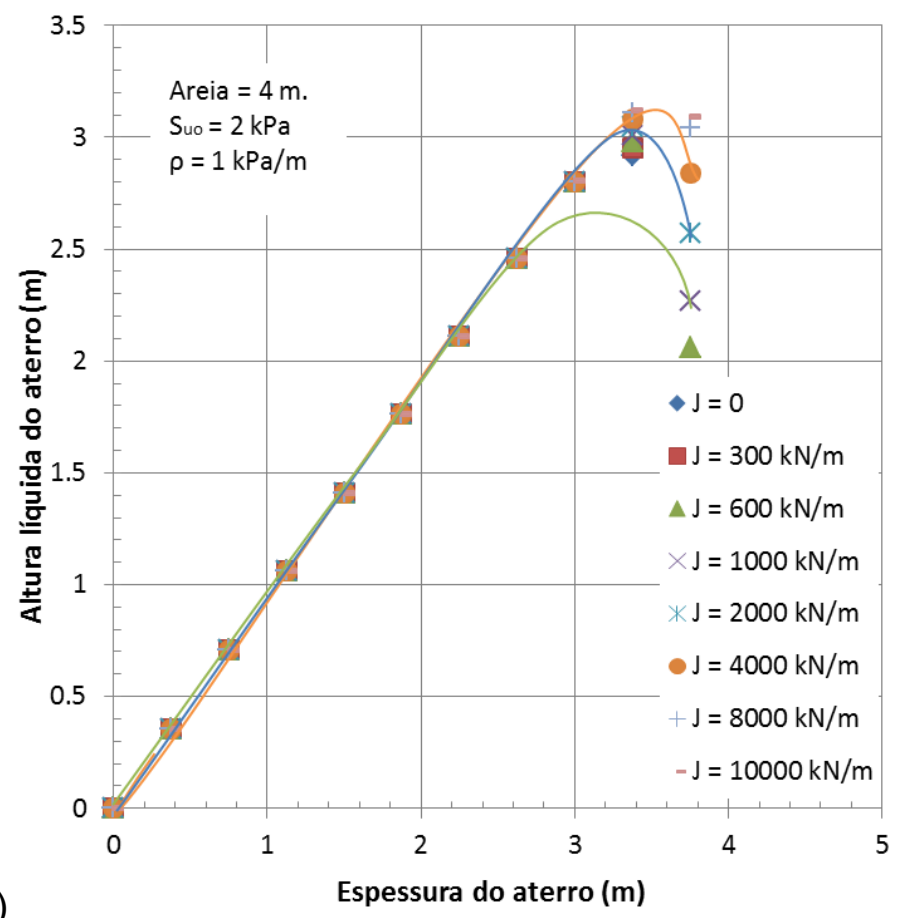

(a)

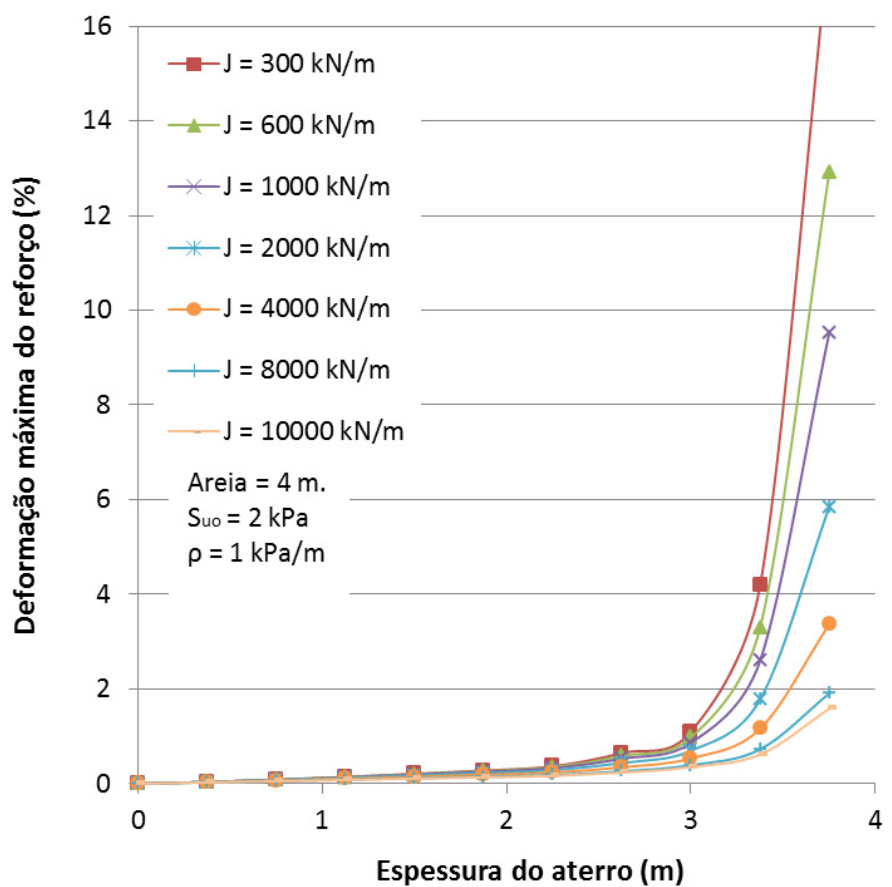

(b)

Figura 4-11 Alturas de ruptura (a) e deformações máximas do reforço com o aumento da rigidez do reforço $\mathrm{J}$ (b) para uma fundação com $4 \mathrm{~m}$ de areia. 
As alturas de ruptura dos resultados mostrados no Apêndice I, foram listados nas Tabelas 4-2, 4-3 e 4-4; em função da rigidez dos reforços à tração e das espessuras das camadas de areia.

Tabela 4-2 Resumo de alturas da ruptura do aterro, com $S_{\text {uo }}=2 \mathrm{kPa}$ e diferente $\rho=1,0 \mathrm{kPa} / \mathrm{m} ; 1,5 \mathrm{kPa} / \mathrm{m}$ e $2,0 \mathrm{kPa} / \mathrm{m}$ com diferentes $\mathrm{J}$ e espessura de areia.

\begin{tabular}{c|c|c|c|c|c|c|c|c|c}
\hline \multirow{2}{*}{$\begin{array}{c}\mathrm{S}_{\text {uo }} \\
(\mathrm{kPa})\end{array}$} & $\begin{array}{c}\text { Espessura } \\
\text { da areia } \\
(\mathrm{m})\end{array}$ & $\begin{array}{c}\text { Sem } \\
\text { Reforço }\end{array}$ & \multicolumn{7}{|c|}{ Reforço de Rigidez, J kN/m } \\
\cline { 3 - 11 } & 0 & 1,125 & 1,5 & 1,75 & 1.875 & 2,2 & 2,5 & 2,65 & 2,7 \\
\hline \multirow{4}{*}{1} & 2 & 2,1 & 2,15 & 2,2 & 2,3 & 2,5 & 2,75 & 2,9 & 3,0 \\
\cline { 2 - 11 } & 4 & 3,1 & 3,15 & 3,25 & 3,3 & 3,375 & 3,5 & 3,6 & 3,65 \\
\hline \multirow{3}{*}{1,5} & 0 & 1.875 & 2,25 & 2,8 & 3 & 3,6 & 4,1 & 4,2 & 4,3 \\
\cline { 2 - 10 } & 2 & 2,8 & 3 & 3,2 & 3,375 & 3,75 & 4,5 & 4,75 & 4,75 \\
\hline & 4 & 4,1 & 4,125 & 4,3 & 4,4 & 4,5 & 4,8 & 5 & 5,1 \\
\hline \multirow{3}{*}{2} & 0 & 3 & 3,75 & 4,2 & 5,1 & 6 & 6,375 & 6,75 & 7,05 \\
\hline & 2 & 3,6 & 4 & 4,3 & 5,15 & 6 & 6,375 & 6,75 & 7,125 \\
\hline & 4 & 6,3 & 6,5 & 6,65 & 6,75 & 7 & - & - & - \\
\hline
\end{tabular}

Tabela 4-3 Resumo de alturas da ruptura do aterro, com $S_{\mathrm{uo}}=3,6 \mathrm{kPa} e$ diferente $\rho=1,0 \mathrm{kPa} / \mathrm{m} ; 1,5 \mathrm{kPa} / \mathrm{m}$ e $2,0 \mathrm{kPa} / \mathrm{m}$ com diferentes $\mathrm{J}$ e espessura de areia.

\begin{tabular}{|c|c|c|c|c|c|c|c|c|c|}
\hline \multirow{2}{*}{$\begin{array}{c}\mathrm{S}_{\mathrm{uo}} \\
(\mathrm{kPa})\end{array}$} & \multirow{2}{*}{$\begin{array}{c}\text { Espessura } \\
\text { da areia } \\
\text { (m) }\end{array}$} & \multirow{2}{*}{$\begin{array}{c}\text { Sem } \\
\text { Reforço }\end{array}$} & \multicolumn{7}{|c|}{ Reforço de Rigidez, J kN/m } \\
\hline & & & 300 & 600 & 1000 & 2000 & 4000 & 8000 & 10000 \\
\hline \multirow{3}{*}{1} & 0 & 1,8 & 2,2 & 2,3 & 2,5 & 2,9 & 3,3 & 3,375 & 3,5 \\
\hline & 2 & 2,6 & 2,7 & 2,8 & 2,9 & 3,2 & 3,6 & 3,75 & 3,8 \\
\hline & 4 & 3,6 & 3,75 & 3,8 & 3,85 & 3,95 & 4 & 4,1 & 4,2 \\
\hline \multirow{3}{*}{1,5} & 0 & 2,4 & 3,2 & 3,6 & 4 & 4,6 & 5,3 & 5,625 & 5,7 \\
\hline & 2 & 3,375 & 3,55 & 3,7 & 4,05 & 4,65 & 5,3 & 5,625 & 5,8 \\
\hline & 4 & 4,75 & 4,815 & 4,9 & 5,1 & 5,2 & 5,5 & 5,8 & 6 \\
\hline \multirow{3}{*}{2} & 0 & 3,6 & 4,5 & 5,2 & 5,8 & 6,3 & 7 & 7,5 & 7,875 \\
\hline & 2 & 4,7 & 4,8 & 5,3 & 5,8 & 6,4 & 7 & - & - \\
\hline & 4 & 6,75 & 6,85 & 6,9 & 7,125 & 7,2 & - & - & - \\
\hline
\end{tabular}


Tabela 4-4 Resumo de alturas da ruptura do aterro, com $S_{\mathrm{uo}}=5,0 \mathrm{kPa} e$ diferente $\rho=1,0 \mathrm{kPa} / \mathrm{m} ; 1,5 \mathrm{kPa} / \mathrm{m}$ e $2,0 \mathrm{kPa} / \mathrm{m}$ com diferentes $\mathrm{J}$ e espessura de areia.

\begin{tabular}{|c|c|c|c|c|c|c|c|c|c|}
\hline \multirow{2}{*}{$\begin{array}{c}\mathrm{S}_{\mathrm{uo}} \\
(\mathrm{kPa})\end{array}$} & \multirow{2}{*}{$\begin{array}{c}\text { Espessura } \\
\text { da areia } \\
\text { (m) }\end{array}$} & \multirow{2}{*}{$\begin{array}{c}\text { Sem } \\
\text { Reforço }\end{array}$} & \multicolumn{7}{|c|}{ Reforço de Rigidez, J kN/m } \\
\hline & & & 300 & 600 & 1000 & 2000 & 4000 & 8000 & 10000 \\
\hline \multirow{3}{*}{1} & 0 & 2,25 & 2,9 & 3,1 & 3,2 & 3,6 & 4,2 & 4,5 & 4,8 \\
\hline & 2 & 3 & 3,3 & 3,35 & 3,4 & 3,4 & 4,3 & 4,5 & 4,8 \\
\hline & 4 & 4 & 4,25 & 4,3 & 4,4 & 4,45 & 4,6 & 4,8 & 4,9 \\
\hline \multirow{3}{*}{1,5} & 0 & 3,3 & 3,75 & 4,3 & 4,875 & 5,25 & 5,9 & 6,375 & 6,375 \\
\hline & 2 & 4 & 4,125 & 4,4 & 4,875 & 5,25 & 5,9 & 6,375 & 6,4 \\
\hline & 4 & 5,1 & 5,4 & 5,5 & 5,6 & 5,8 & 6 & 6,375 & 6,4 \\
\hline \multirow{3}{*}{2} & 0 & 4 & 4,45 & 5,15 & 6 & 6,75 & 7,875 & - & - \\
\hline & 2 & 5 & 5,3 & 5,625 & 6,1 & 6,75 & 7,875 & - & - \\
\hline & 4 & 6,3 & 6,75 & - & - & - & - & - & - \\
\hline
\end{tabular}

Os resultados indicaram que em todos os casos houve ganho de altura pelo uso do reforço. A Figura 4-12 mostra como é a variação das alturas considerando a variação da espessura de areia e rigidez do reforço J.

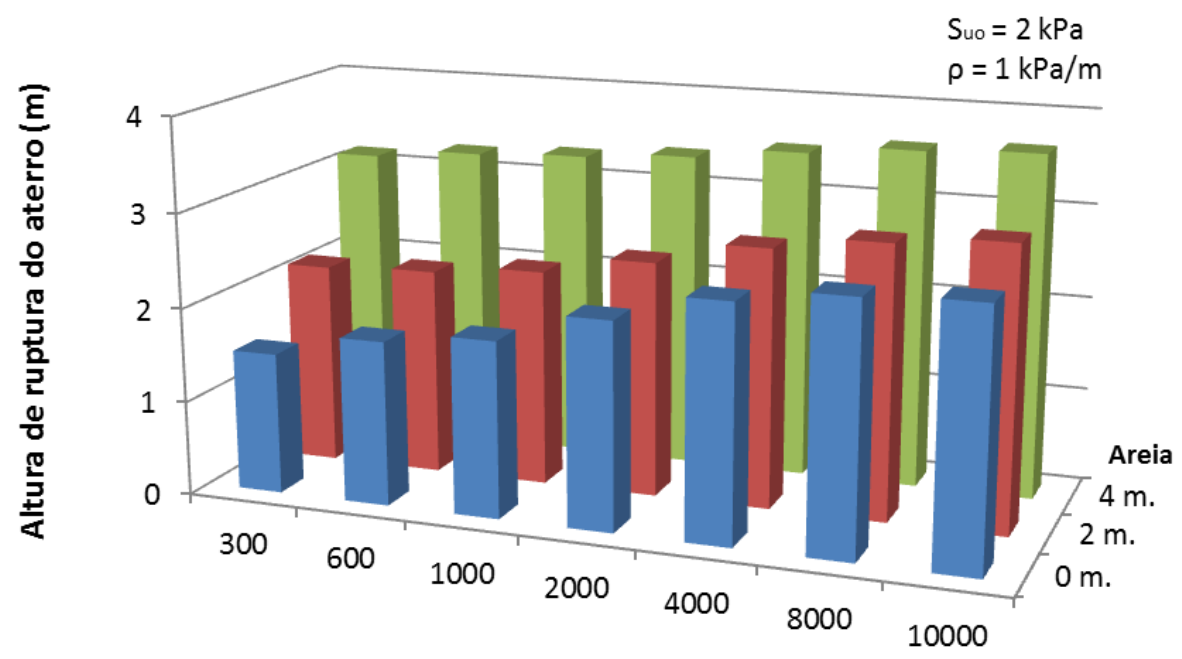

Rigidez do reforço à tração, $\mathrm{J}(\mathrm{kN} / \mathrm{m})$

Figura 4-12 Resultados da variação da altura do aterro com o aumento da espessura da camada de areia e da rigidez do reforço $\mathrm{J} \mathrm{kN/m}$. 
Com base nas Tabelas 4-2 a 4-4, calcularam-se os ganhos porcentuais de altura em relação ao aterro não reforçado para os três casos analisados: fundação sem areia, com $2 m$ e $4 m$ de areia na superfície (Figura 4-13 a Figura 4-15)

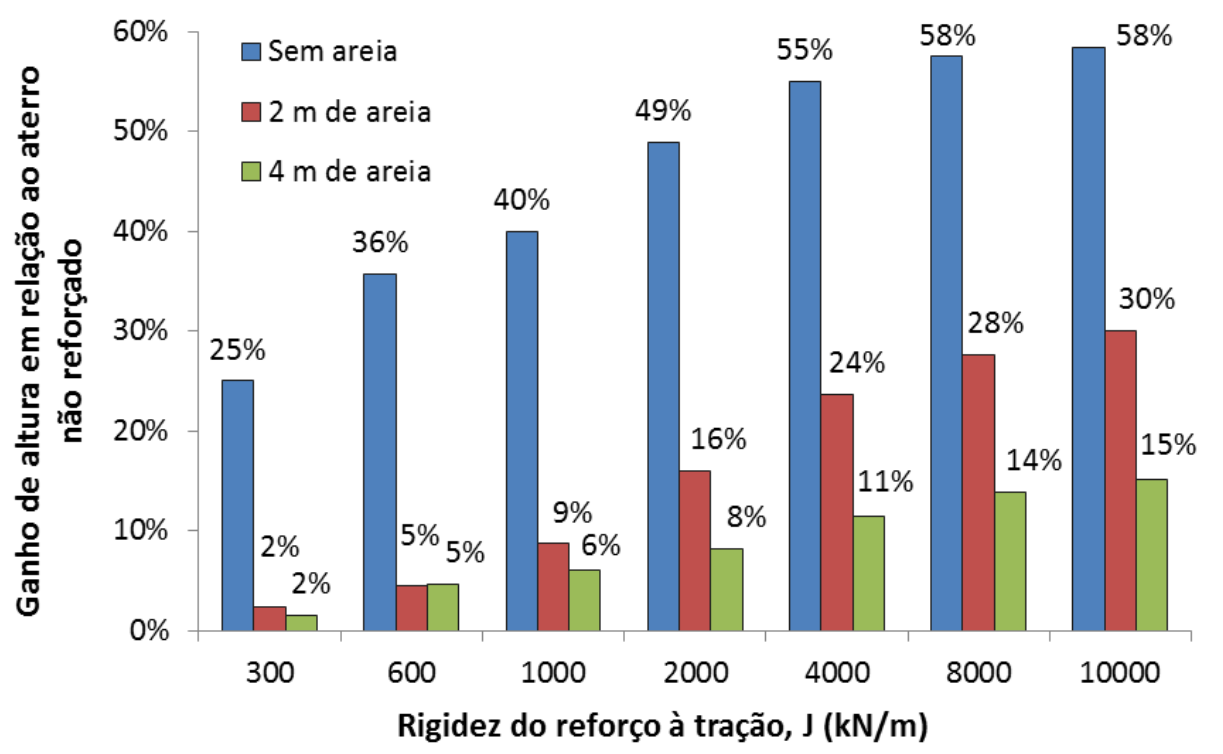

Figura 4-13 Ganho de altura em função da rigidez à tração do reforço para Suo $=2 \mathrm{kPa}$ e $\rho=1,0 \mathrm{kPa} / \mathrm{m}$.

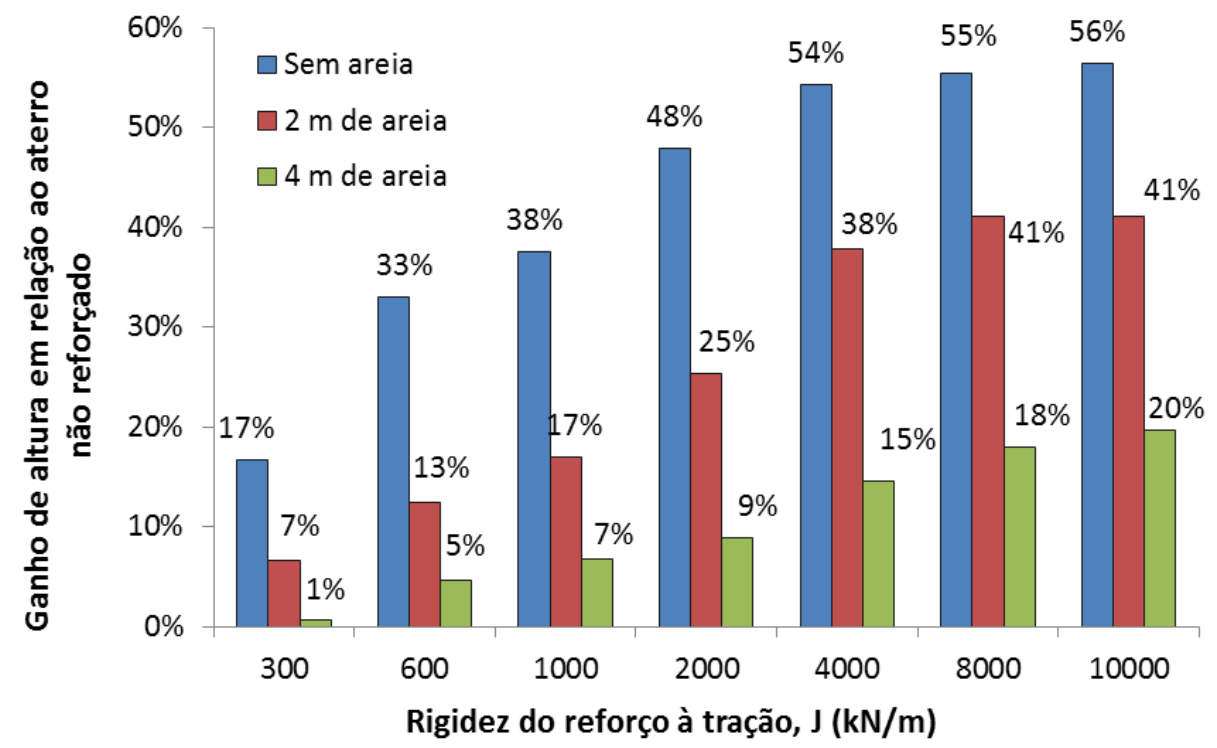

Figura 4-14 Ganho de altura em função da rigidez à tração do reforço para Suo $=2 \mathrm{kPa}$ e $\rho=1,5 \mathrm{kPa} / \mathrm{m}$. 
O ganho é maior no solo sem a camada de areia podendo atingir até $58 \%$ além da altura máxima não reforçada para $\mathrm{J}=10,000 \mathrm{kN} / \mathrm{m}$ em um solo com $\rho=2,0$ $\mathrm{kPa} / \mathrm{m}$, Figura 4-13. Também há boa eficiência com $2 \mathrm{~m}$ de areia sobreposta ao solo mole chegando a um ganho máximo de $49 \%$ para J=10,000 kN/m, Figura 4-15.

Por outro lado, o uso de reforço com camadas de areia de $4 \mathrm{~m}$ de espessura, o ganho é pequeno e até nulo para alguns casos, quer dizer que a eficiência do reforço é reduzida com a espessura da camada de areia e já não justificaria o uso do reforço pelos custos.

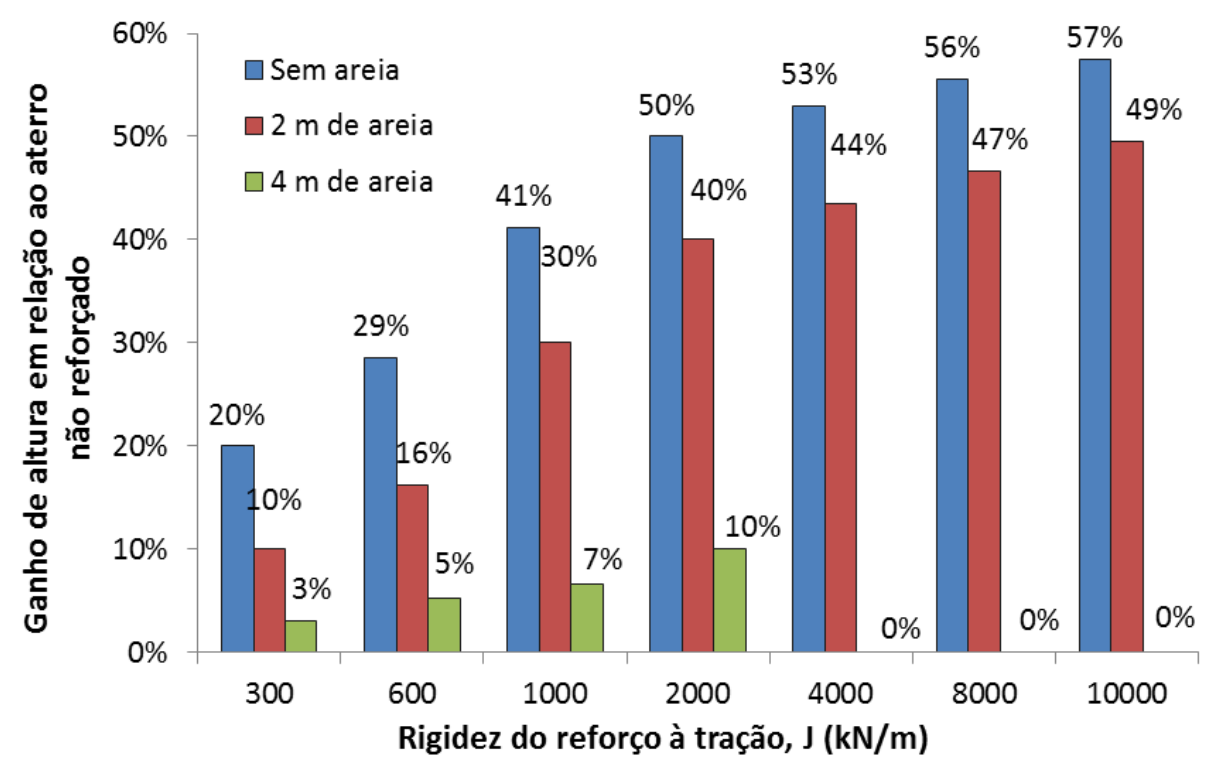

Figura 4-15 Ganho de altura em função da rigidez à tração do reforço para Suo $=2 \mathrm{kPa}$ e $\rho=2,0 \mathrm{kPa} / \mathrm{m}$.

A Figura 4-16 mostra que para uma maior espessura de areia o aumento na altura é no máximo de $1 \mathrm{~m}$, diferente dos outros casos, onde se observa que o aumento de altura é de aproximadamente $2 \mathrm{~m}$. A influencia da rigidez do reforço é mais notável na fundação com uma única camada de argila, a diferença dos casos com presença de areia, onde o aumento das alturas é mínimo após a rigidez de $4,000 \mathrm{kN} / \mathrm{m}$.

Nos casos apresentados, observa-se que alguns deles apresentam um comportamento diferente, com o aumento da rigidez há aumento da altura até certo 
limite. Pode-se explicar que para fins práticos, o uso de um reforço com maior rigidez não seria mais conveniente.

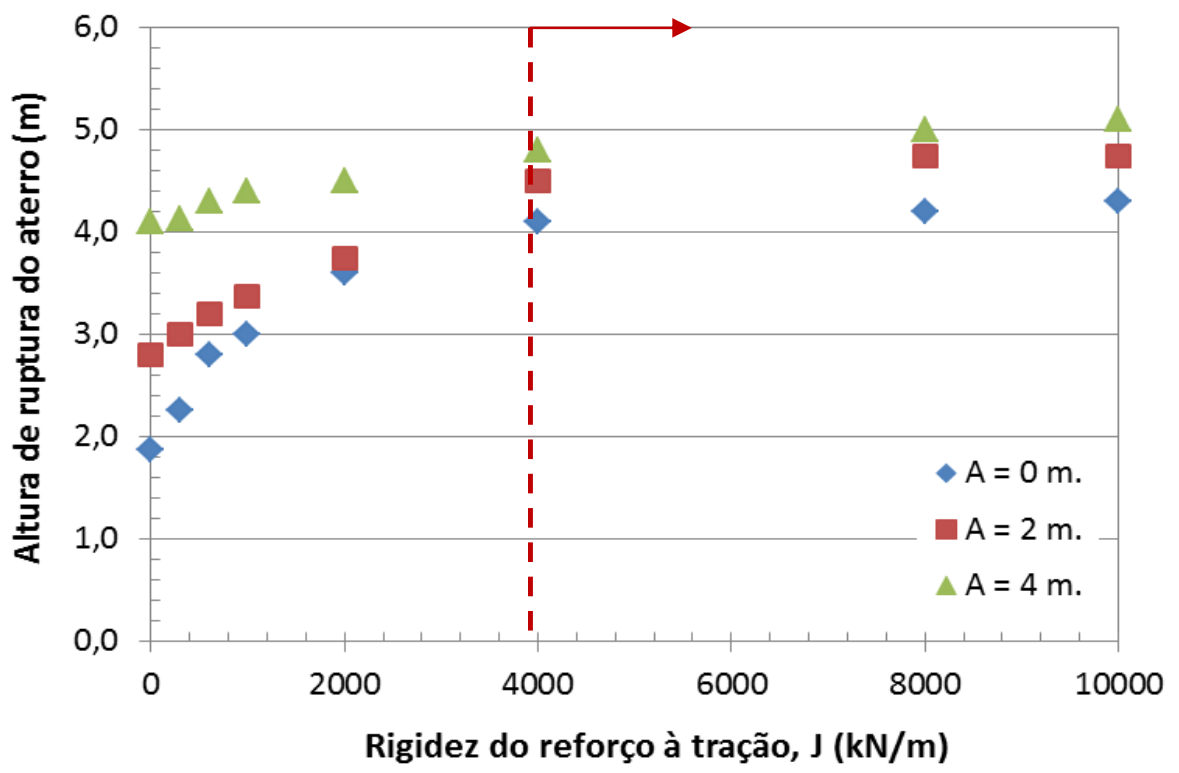

Figura 4-16 Resultados da variação da altura do aterro com o aumento da rigidez do reforço $\mathrm{J} \mathrm{kN} / \mathrm{m}$.

No Apêndice II apresenta-se os resultados dos ganhos percentuais de altura, referentes a Suo $=3,6 \mathrm{kPa}$ e 5,0 kPa respetivamente. Nota-se que os ganhos de altura são elevados para as fundações sem camada de areia.

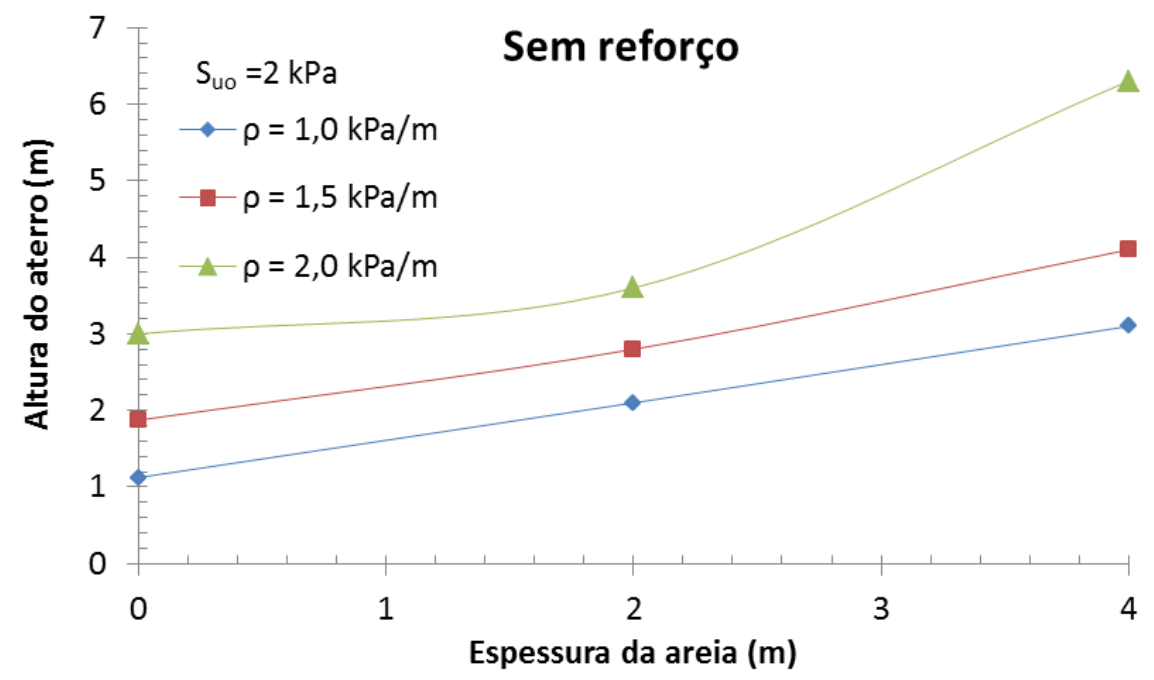

Figura 4-17 Influência da areia na altura do aterro não reforçado 
O comportamento do aterro frente à presença da areia pode ser observado na Figura 4-17, onde são apresentados os casos de aterros não reforçados. $O$ aumento da espessura da camada da areia permite ao aterro atingir maiores alturas sem precisar do uso do reforço.

A variação da deformação de compatibilidade influenciada pela camada de areia e pela rigidez do reforço está mostrada nas Figura 4-18 e Figura 4-19, para solos com diferente resistência.

A Figura 4-18, apresenta os resultados das deformações de compatibilidade para $\mathrm{Suo}=2 \mathrm{kPa}$ e $3,6 \mathrm{kPa}$ com $\rho=1 \mathrm{kPa} / \mathrm{m}$ e camada de areia até $4 \mathrm{~m}$. Na Figura 4-19 os resultados para aterros com dados de fundação de $S_{u o}=2 \mathrm{kPa}$ e $5 \mathrm{kPa}$ com $\rho=0,5 \mathrm{kPa} / \mathrm{m}$.

A deformação de compatibilidade é maior para solos sem camada de areia, a camada de areia produz uma diminuição nas deformações do reforço Figura 4-18.

Na Figura 4-19 foram analisados casos de espessura de areia de até $6 \mathrm{~m}$, e rigidez do reforço de $30.000 \mathrm{kN} / \mathrm{m}$, a diferencia e marcada para valores acima dos $\mathrm{J}$ $>10.000 \mathrm{kN} / \mathrm{m}$ as curvas convergem em valores muito baixos de deformação e nota-se que o reforço não é mais mobilizado.

No Apêndice III, são apresentadas as análises da variação das deformações do reforço, realizadas no presente trabalho, para diferentes dados de fundação e espessura da camada de areia. 

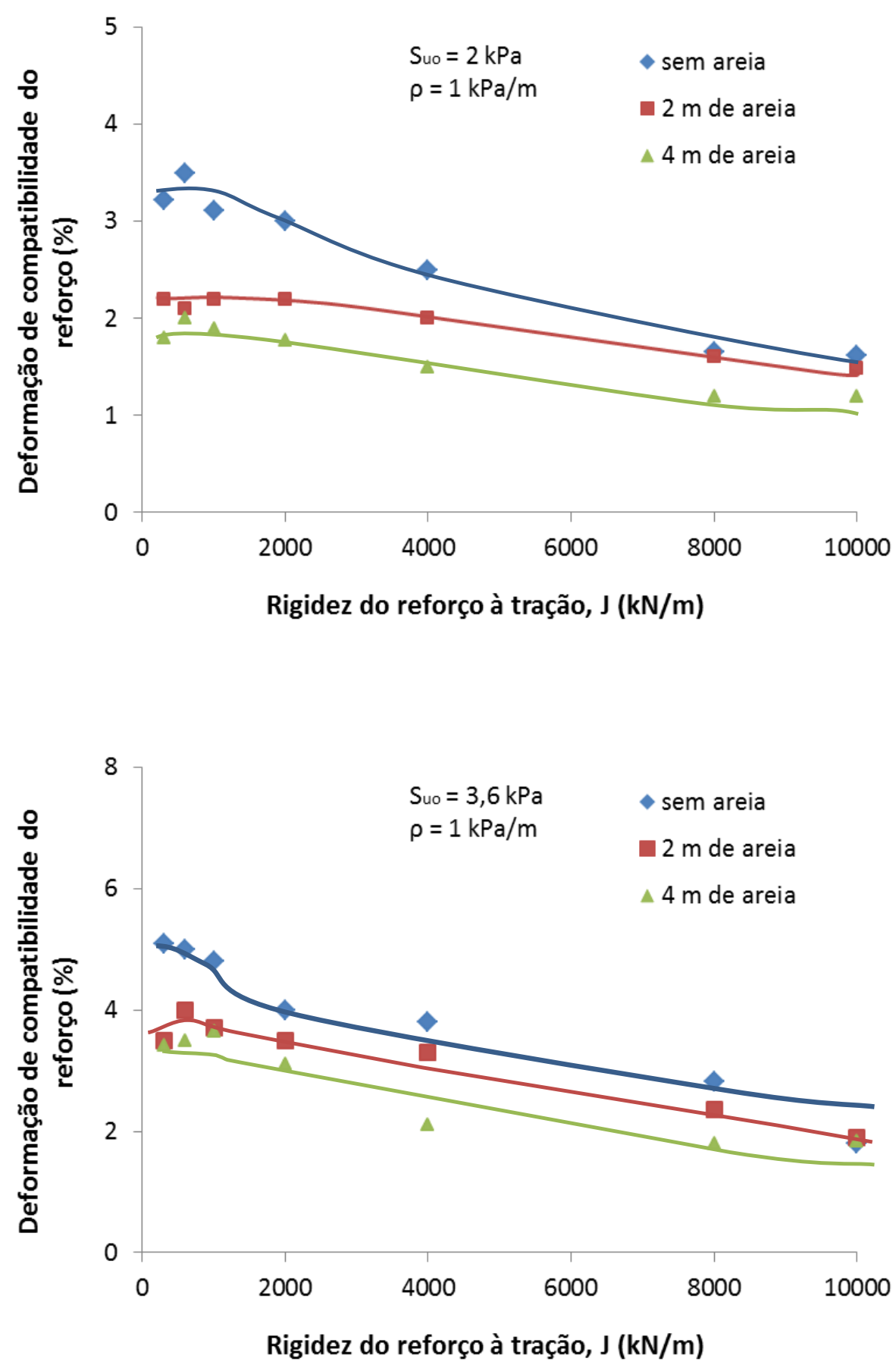

Figura 4-18 Variação da deformação de compatibilidade do reforço com a rigidez do reforço e com a espessura da camada de areia até $4 \mathrm{~m}$. 

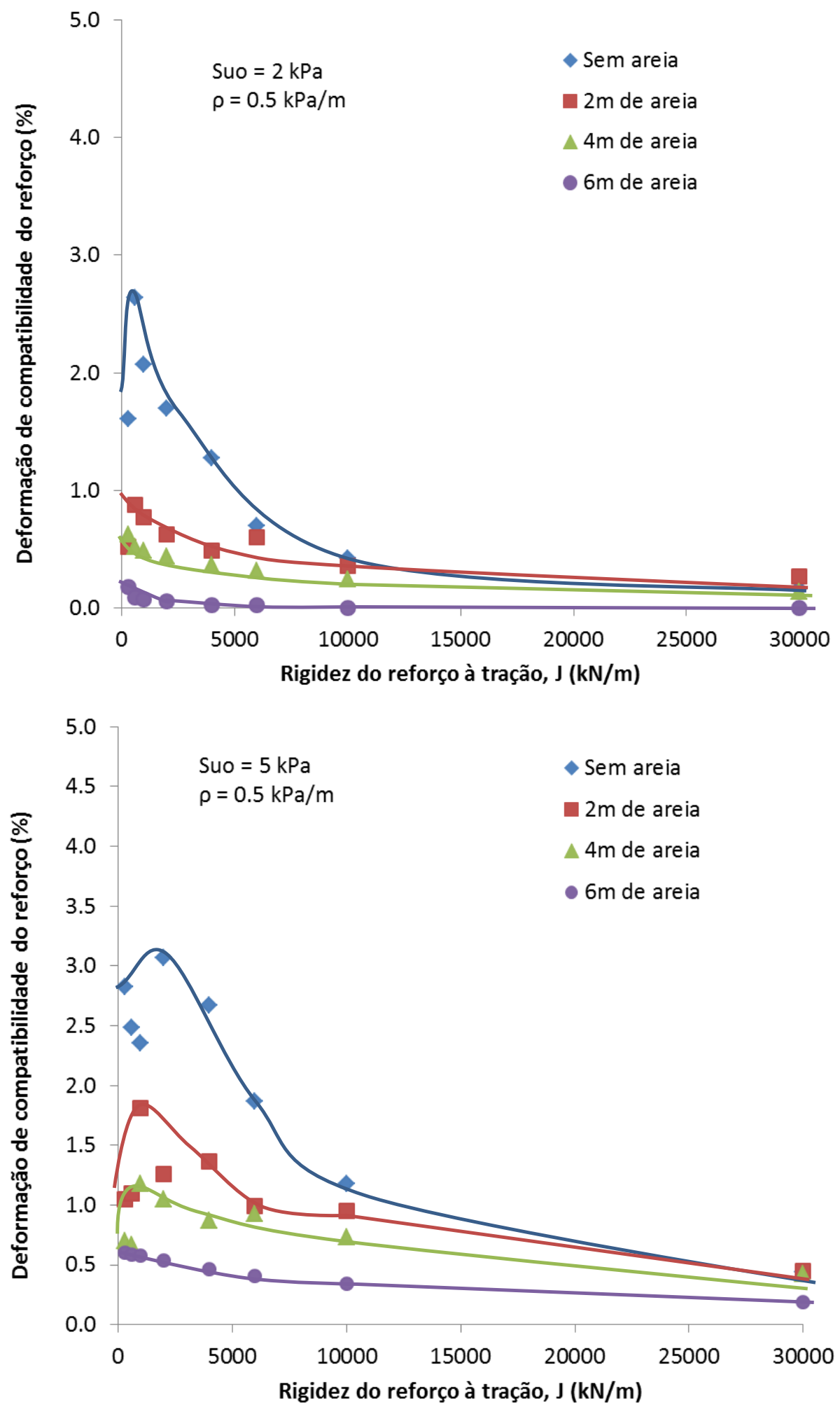

Figura 4-19 Variação da deformação de compatibilidade do reforço com a rigidez do reforço e com a espessura da camada de areia até $6 \mathrm{~m}$. 


\subsubsection{Efeito do aumento da resistência com a profundidade, $\rho$}

A variação da deformação de compatibilidade influenciada pelo aumento da resistência com a profundidade $\rho$ está mostrado nas Figura 4-20 a Figura 4-25

Foram obtidas as deformações no momento da ruptura para $S_{\text {ио }}=2 \mathrm{kPa}$ $3,6 \mathrm{kPa}$ e $5,0 \mathrm{kPa}$, e diferentes $\rho$, colocando diferentes espessura de camadas de areia, tal como é mostrado no Apêndice IV. Após obter os resultados, eles foram agrupados com o objetivo de mostrar a influência da variação de $\rho$.

Nota-se que para solos de resistência menor (valores de $\rho$ ) as deformações também são menores, porque o reforço é pouco mobilizado. As deformações de compatibilidade aumentam conforme aumenta o incremento da resistência com a profundidade.

Observa-se o comportamento das deformações frente à presença de areia Figura 4-20 (b) e Figura 4-21, as deformações de compatibilidade tendem a diminuir porque a areia inibe as deformações do reforço, e para valores muito elevados de rigidez do reforço as curvas convergem para valores de deformação muito baixos.

Cabe ressaltar que no aterro Pinto Pass, estudado por Rowe (1982), onde o autor observou que nos reforços de modulo de rigidez $\mathrm{J}$ baixos a médios, podem ocorrer grandes deformações antes de o reforço atingir a sua capacidade última, e nesses casos o colapso do aterro pode ter acontecido antes da ruptura do geossintético. A observação esta relacionada à mobilização de altos valores de tensão cisalhante na interface solo-reforço. Quando toda a resistência ao cisalhamento disponível na interface é mobilizada, o deslizamento ocorre ao longo da interface reforço-fundação e o sistema deforma sem mobilizar tensão adicional no reforço. Nos casos estudado observa-se uma maior mobilização nos casos sem presença da areia e nos casos de solo de resistência não drenada maior.

$\mathrm{Na}$ Figura 4-20 (a), os valores de deformação obtidos para $\rho$ de $2 \mathrm{kPa} / \mathrm{m}$ entre $20 \%$ a $28 \%$, são altos para rigidez $\mathrm{J}<1.000 \mathrm{kN} / \mathrm{m}$, e estão por cima dos limite estrutural dos geotêxteis e as geogrelhas. Nesse caso, o solo tem maior resistência e a mobilização do reforço é maior, mas para uma rigidez baixa as deformações produzidas são muito altas podendo chegar até a ruptura do reforço. 
(a)

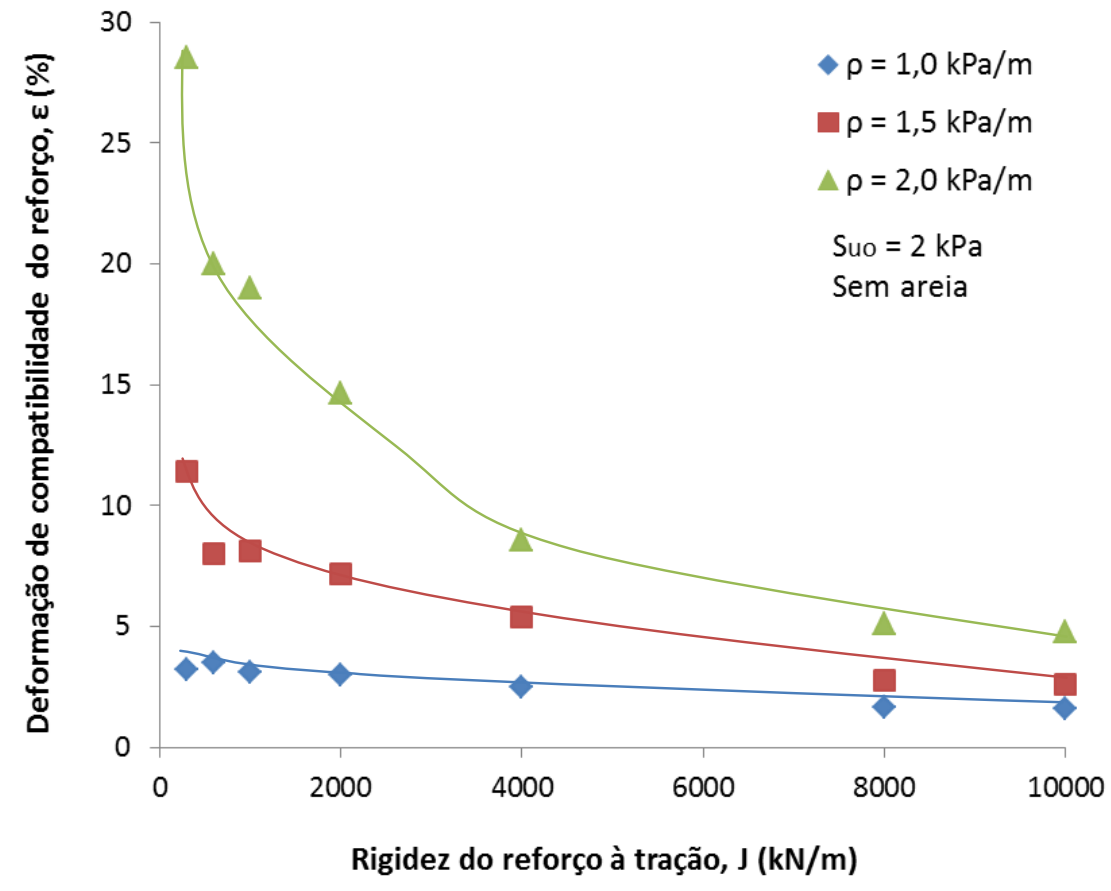

(b)

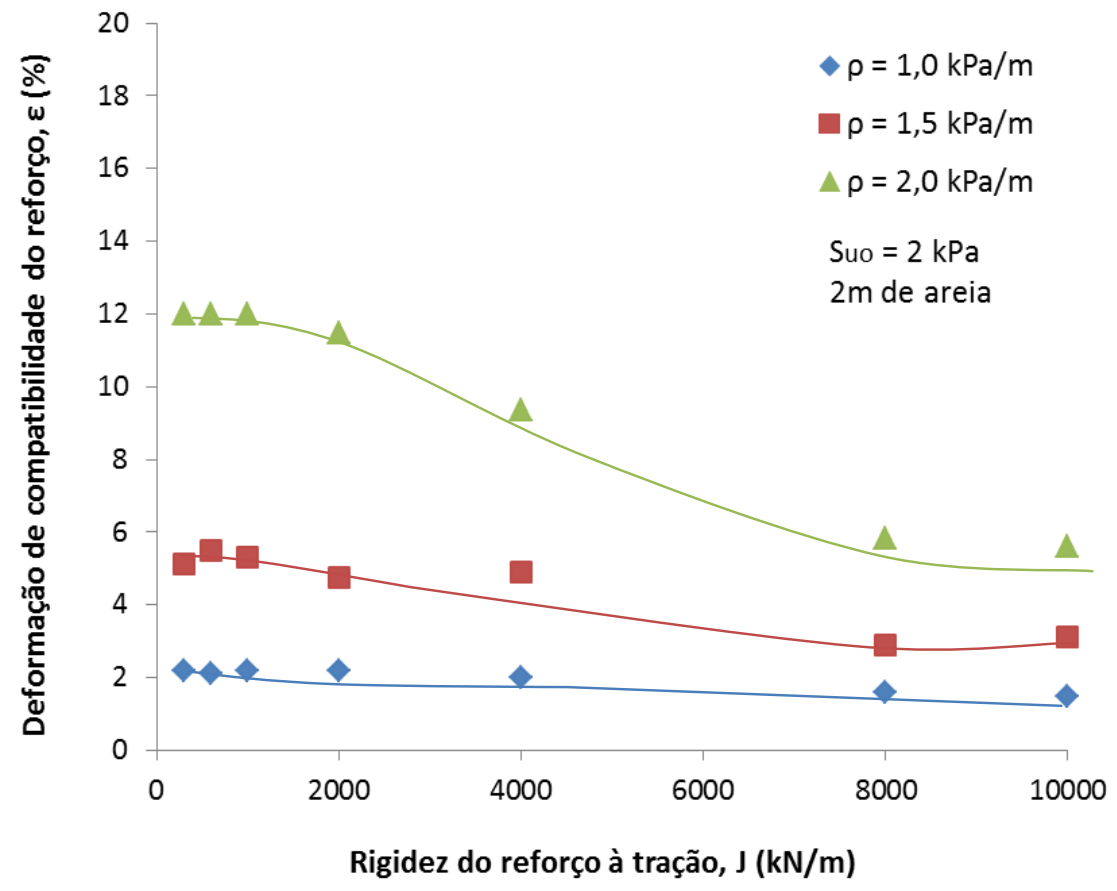

Figura 4-20 Efeito do $\rho$ na deformação de compatibilidade do reforço na ruptura para $A=0 \mathrm{~m}(\mathrm{a}), A=2 \mathrm{~m}(\mathrm{~b})$ e $S_{\mathrm{uo}}=2 \mathrm{kPa}$. 
Na Figura 4-20(a) e Figura 4-21, as deformações de compatibilidade para fundações com camadas de areia de $2 \mathrm{~m}$ e $4 \mathrm{~m}$ respectivamente, apresentam valores que se encontram dentro da faixa de deformações de geotêxteis e geogrelhas disponíveis no mercado. Citando alguns exemplos de geotêxteis no tecido de PP que pode atingir deformações até de 10\% e de PVA com deformações $<6 \%$. As deformações sofreram uma diminuição notável em comparação ao caso de uma camada só de argila.

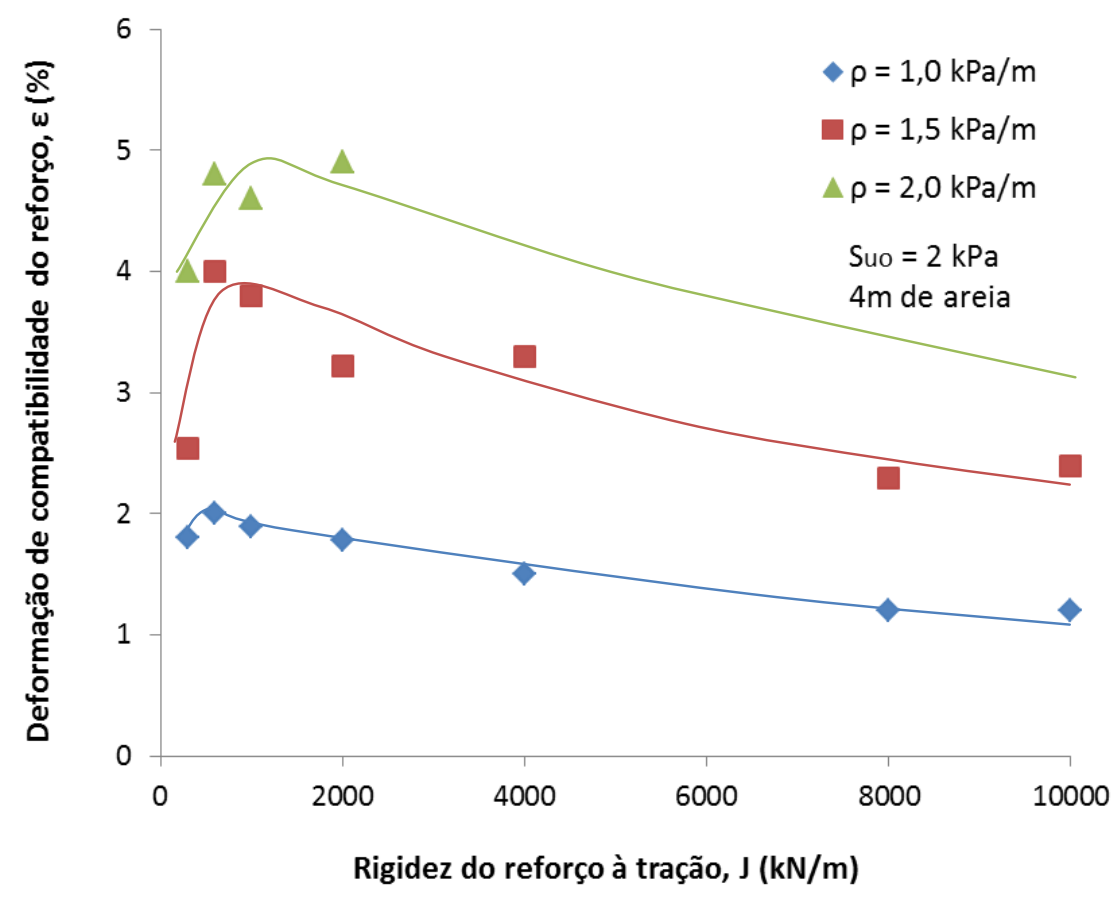

Figura 4-21 Efeito do $\rho$ na deformação de compatibilidade do reforço na ruptura para $A=4 \mathrm{~m}$ e $S_{u o}=2 \mathrm{kPa}$.

Na Figura 4-21, as curvas apresentaram um comportamento diferente aos casos anteriores, muito similar à Figura 2-23, onde Hinchberger \& Rowe (2003), baseando-se em resultados numéricos, indicaram que é provável que na ruptura de aterros maiores exista potencial para arqueamento do aterro, que causa um comportamento diferente ao ideal dos aterros reforçados.

Nesse caso, pode-se atribuir ao arqueamento do aterro os valores altos apresentados devido à necessidade de aumentar a altura, com o fim de aumentar a 
sobrecarga e conseguir a ruptura do aterro. Sendo preciso realizar este aumento na altura, nos casos onde a fundação apresentava maior resistência.

A Figura 4-22, com $\mathrm{S}_{\mathrm{uo}}=3,6 \mathrm{kPa}$, é um caso similar ao apresentado de $\mathrm{S}_{\mathrm{uo}}=$ $2 \mathrm{kPa}$. As deformações de compatibilidade do reforço nas fundações mais resistentes atingiram valores muito altos devido à maior mobilização do reforço.

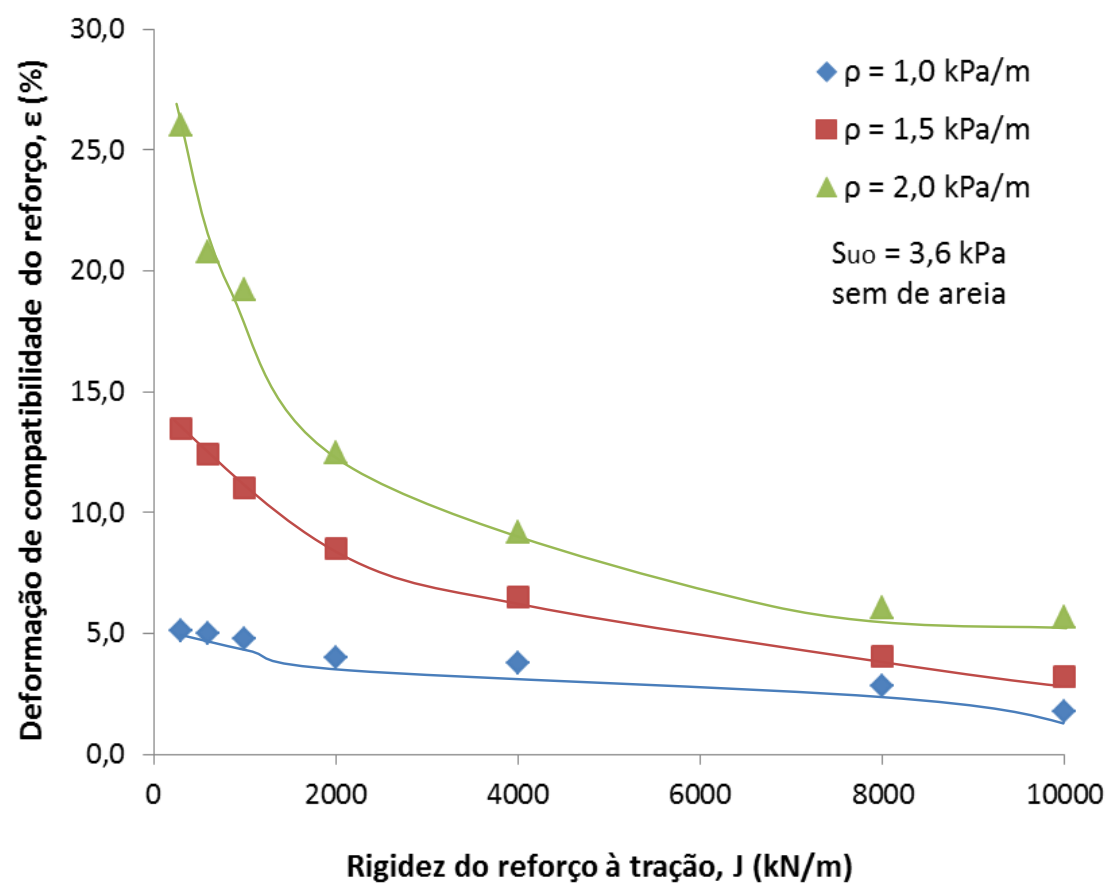

Figura 4-22 Efeito do $\rho$ na deformação de compatibilidade do reforço na ruptura para $A=0 \mathrm{~m}$ e $S_{\text {uo }}=3,6 \mathrm{kPa}$.

$\mathrm{Na}$ Figura 4-23 (a) e (b), para camadas de areia de $2 \mathrm{~m}$ e $4 \mathrm{~m}$ respectivamente, as deformações são menores devido à presença da área. Nesses casos foi necessário aumentar a altura do aterro para chegar até a ruptura, porém onde os aterros são maiores se observa que apresentaram potencial para o arqueamento do aterro.

Os casos de aterros modelados com uma fundação de resistência maior Suo = 3,6 kPa e $5 \mathrm{kPa}$ o comportamento é similar Figura 4-24 e Figura 4-25.

Observando os casos estudados, é possível dizer que o aumento da resistência da fundação promove o aumento da deformação de compatibilidade. Nos casos de fundação sem areia e $\rho=2 \mathrm{kPa} / \mathrm{m}$ as deformações continuam apresentando valores muito altos e já com a presença da areia nota-se uma 
redução nas deformações.

(a)

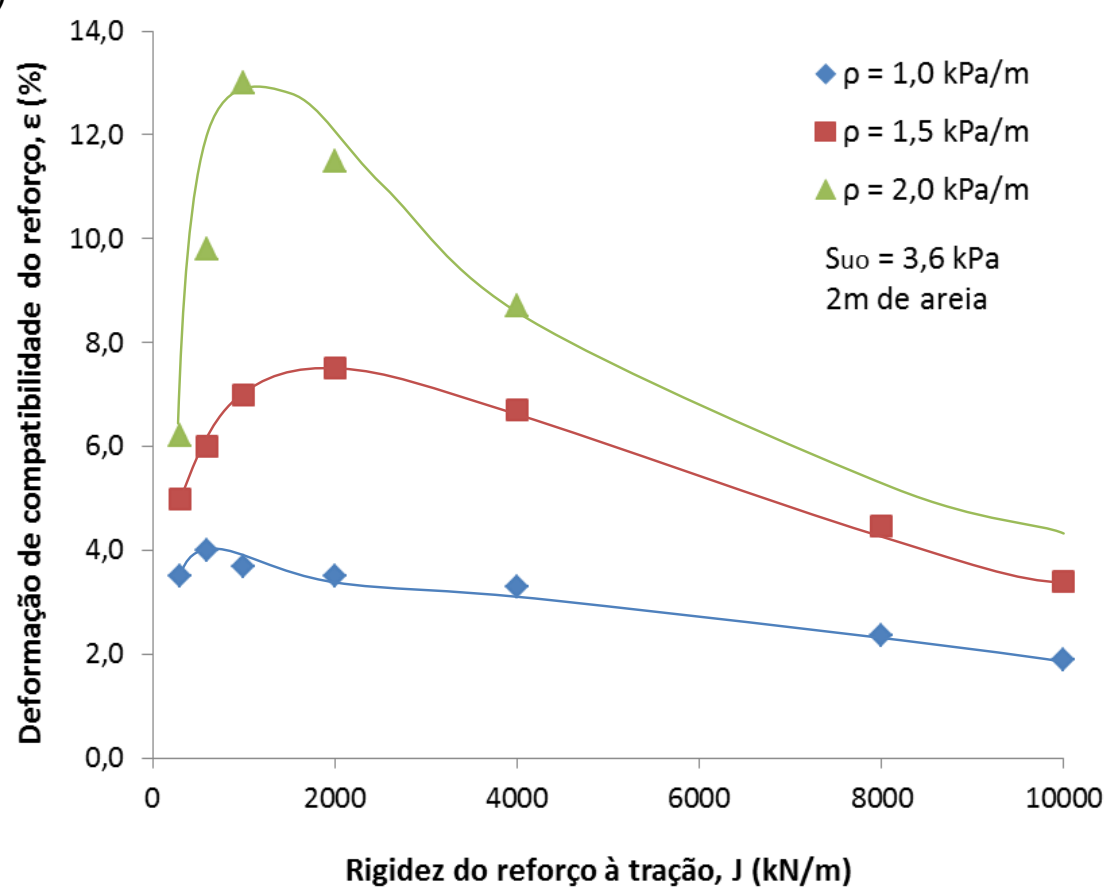

(b)

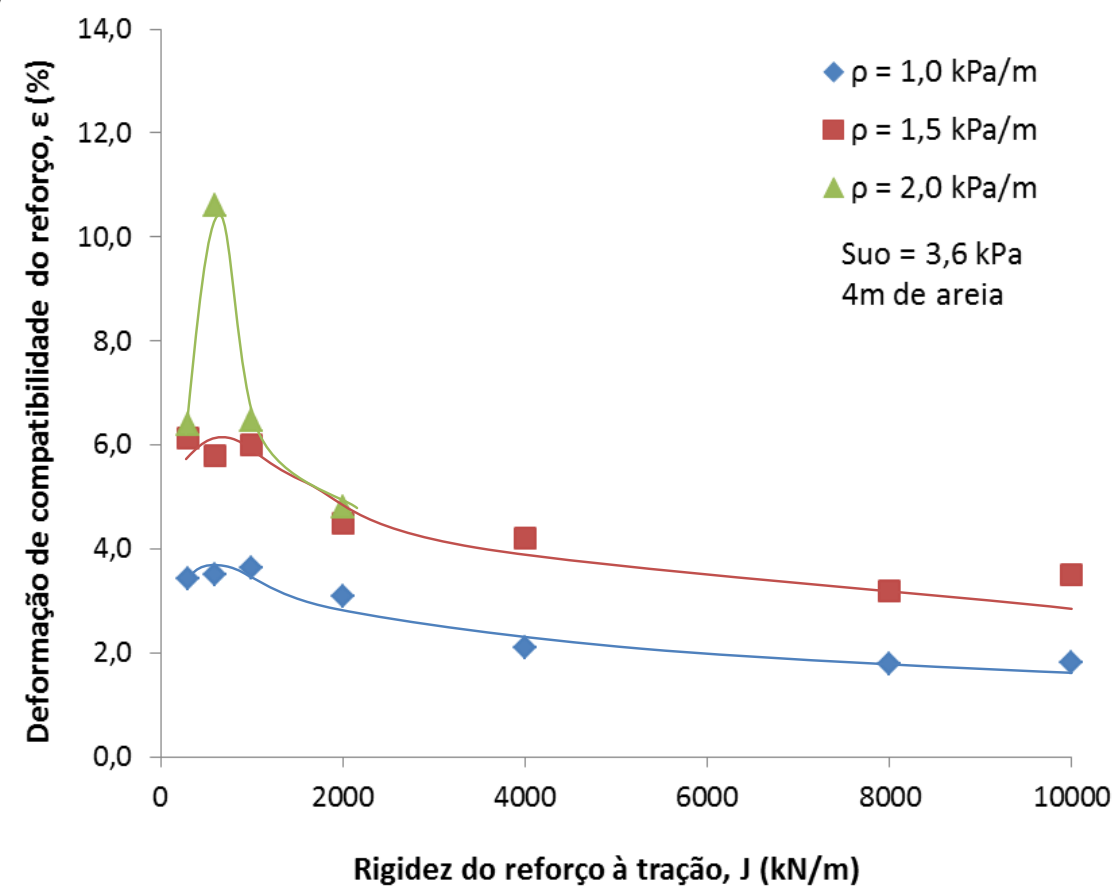

Figura 4-23 Efeito do $\rho$ na deformação de compatibilidade do reforço na ruptura para $A=2 \mathrm{~m}$ (a) e $A=4 \mathrm{~m}$ (b) e $S_{u o}=3,6 \mathrm{kPa}$. 
(a)

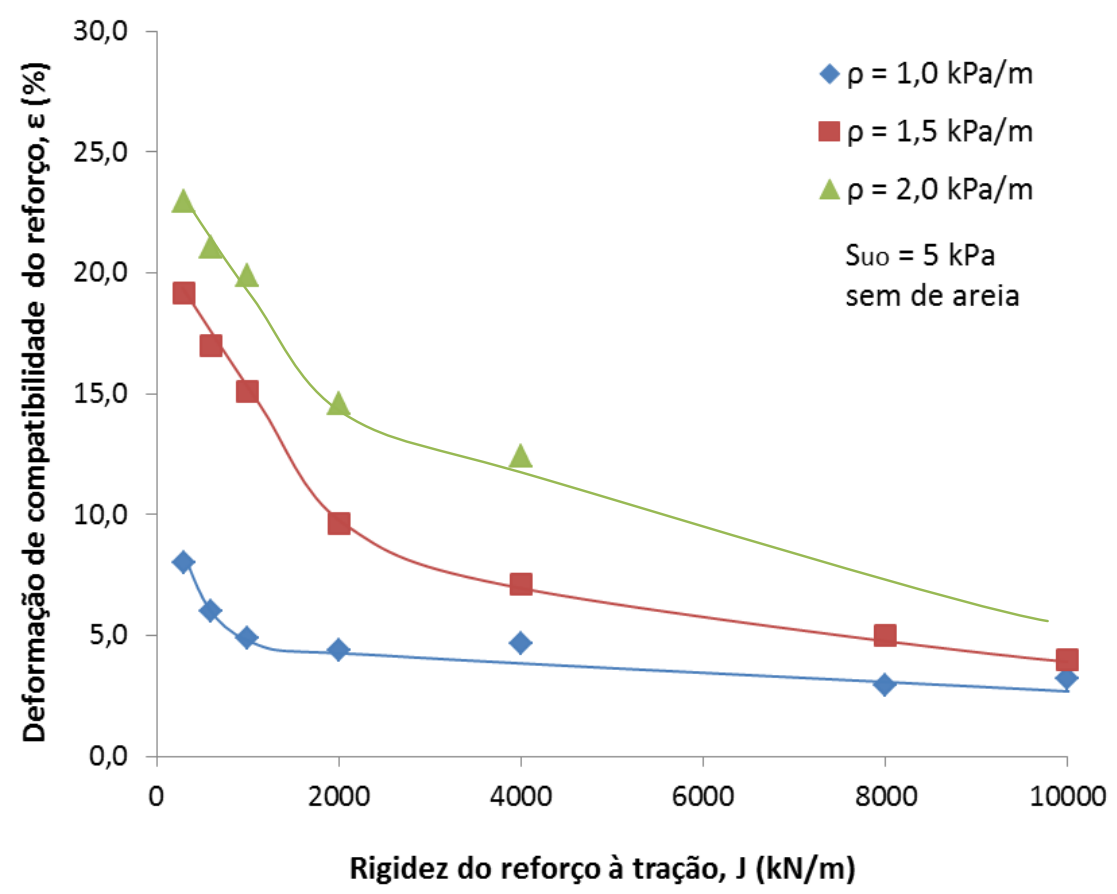

(b)

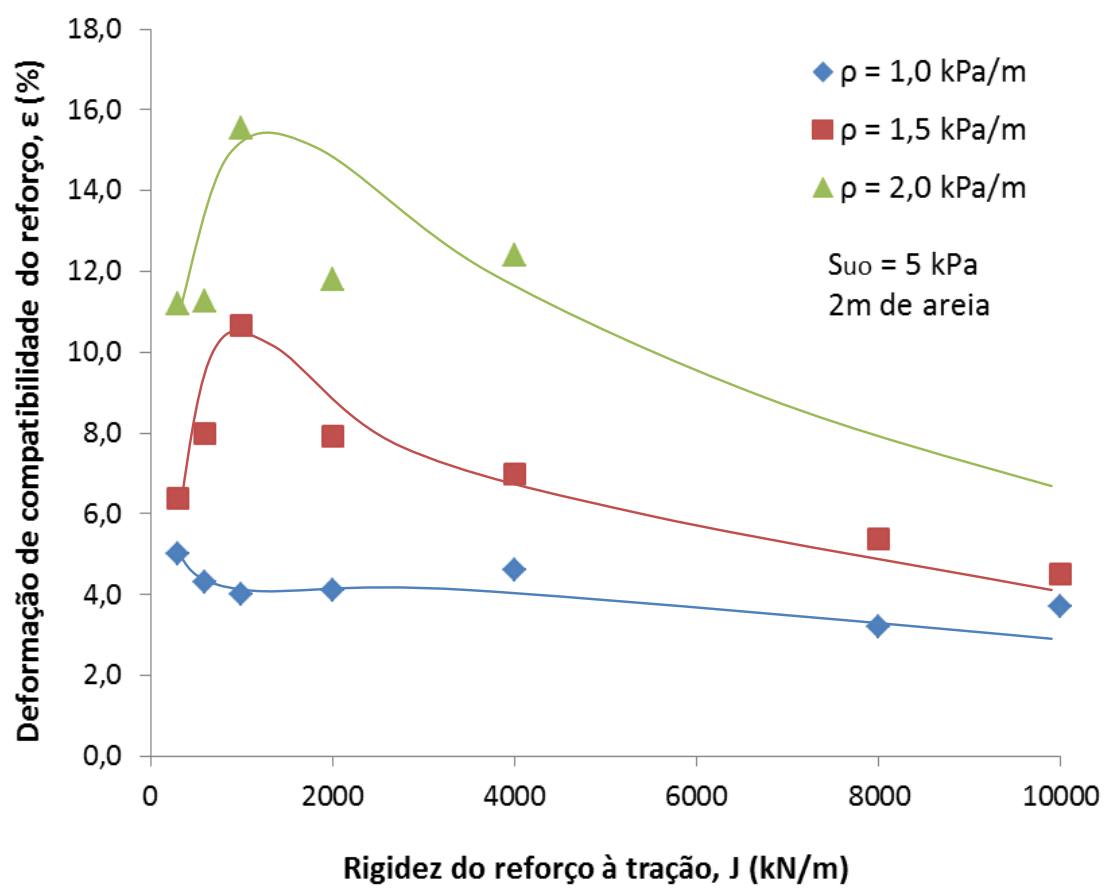

Figura 4-24 Efeito do $\rho$ nas deformações de compatibilidade do reforço na ruptura para $A=0 \mathrm{~m}, A=2 \mathrm{~m}$ e $S_{\mathrm{uo}}=5,0 \mathrm{kPa}$. 


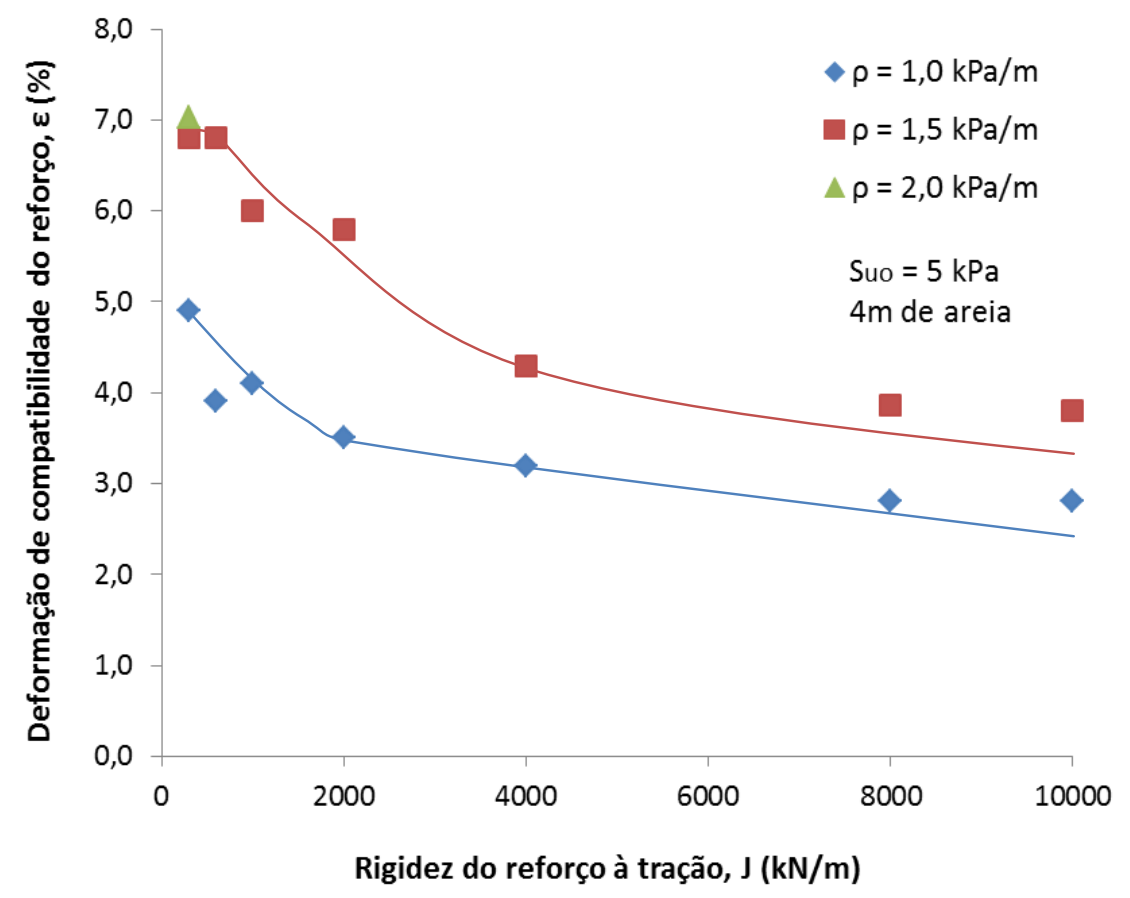

Figura 4-25 Efeito do $\rho$ nas deformações de compatibilidade do reforço na ruptura para $A=4 \mathrm{~m}$ e $S_{\mathrm{uo}}=5,0 \mathrm{kPa}$.

Os casos apresentados foram analisados para estudar a influência de $\rho$ nas deformações de compatibilidade do reforço para aterros construídos em fundações só de argila mole e com presença de areia na superfície.

Os valores obtidos para deformações do reforço nas fundações de uma camada só de argila, apresentaram valores altos e por cima dos valores de deformação do reforço em condições reais para geossintéticos, especialmente nos casos de rigidez do reforço $<1,000 \mathrm{kN} / \mathrm{m}$.

Isso ocorre em solos de resistência maior, onde a mobilização do reforço é maior, porém poderiam ser consideradas deformações produzidas pela ruptura do reforço, embora, na modelagem o reforço fosse considerado como um material elástico.

As curvas de deformação de compatibilidade calculadas para cada tipo de fundação e para cada um dos valores de $\rho$, estão contidas no Apêndice IV. 


\subsubsection{Efeito da resistência não drenada na superfície, $S_{\mathrm{uo}}$}

Para observar o efeito de Suo nas deformações de compatibilidade do reforço, optou-se por elaborar gráficos similares aos apresentados por Hinchberger \& Rowe (2003) com o fim de explicar melhor o comportamento dos aterros e a influencia da camada de areia na superfície.

Nas Figura 2-27 a Figura 2-30 apresentam-se os resultados da influência da resistência não drenada na superfície Suo, assim como as curvas para $\rho=1,0$ $\mathrm{kPa} / \mathrm{m}$ e $1,5 \mathrm{kPa} / \mathrm{m}$ para diferente espessura da camada de areia.

$\mathrm{Na}$ Figura 4-26 a fundação com resistência maior $S_{\mathrm{u} 0}=5 \mathrm{kPa}$ apresenta deformações maiores $8 \%$, mas dentro dos limites de deformações reais. $O$ aumento das deformações varia diretamente com o aumento da resistência não drenada na superfície $\mathrm{S}_{\mathrm{u} 0}$.

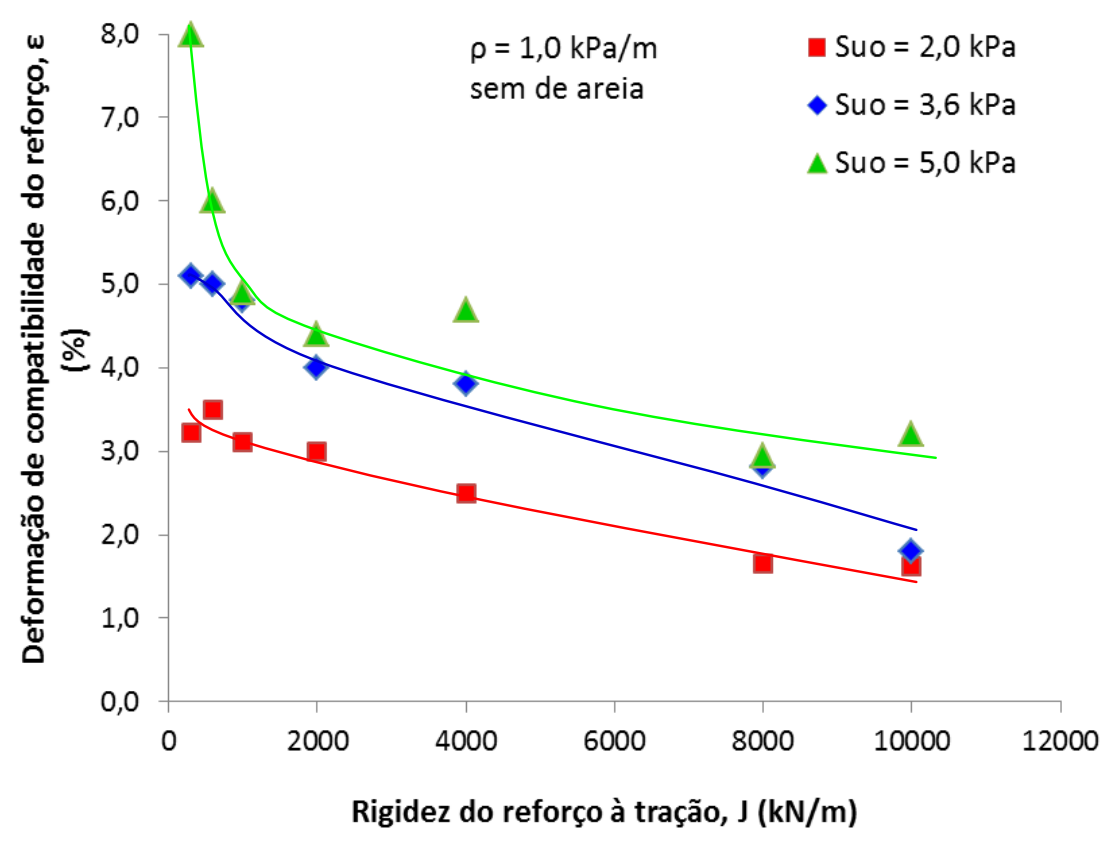

Figura 4-26 Efeito do $S_{\mathrm{u} 0}$ na deformação de compatibilidade do reforço na ruptura para $A=0 \mathrm{~m}$ e $\rho=1,0 \mathrm{kPa} / \mathrm{m}$.

Na Figura 4-27 (a) e (b) que os valores da deformação de compatibilidade estão na mesma faixa de valores, mostra-se o efeito da a espessura da camada de areia, a qual tem pouca influencia nas deformações, pois os valores não diferem 
muito para ambos casos.

(a)

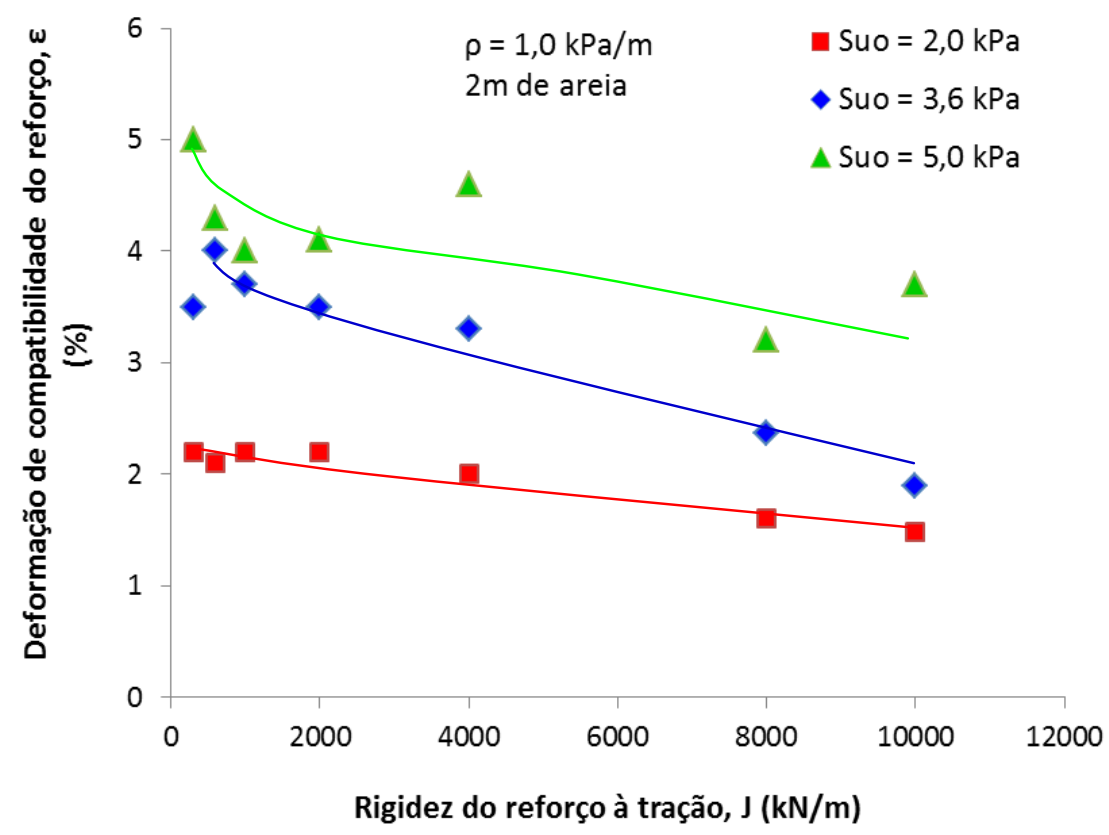

(b)

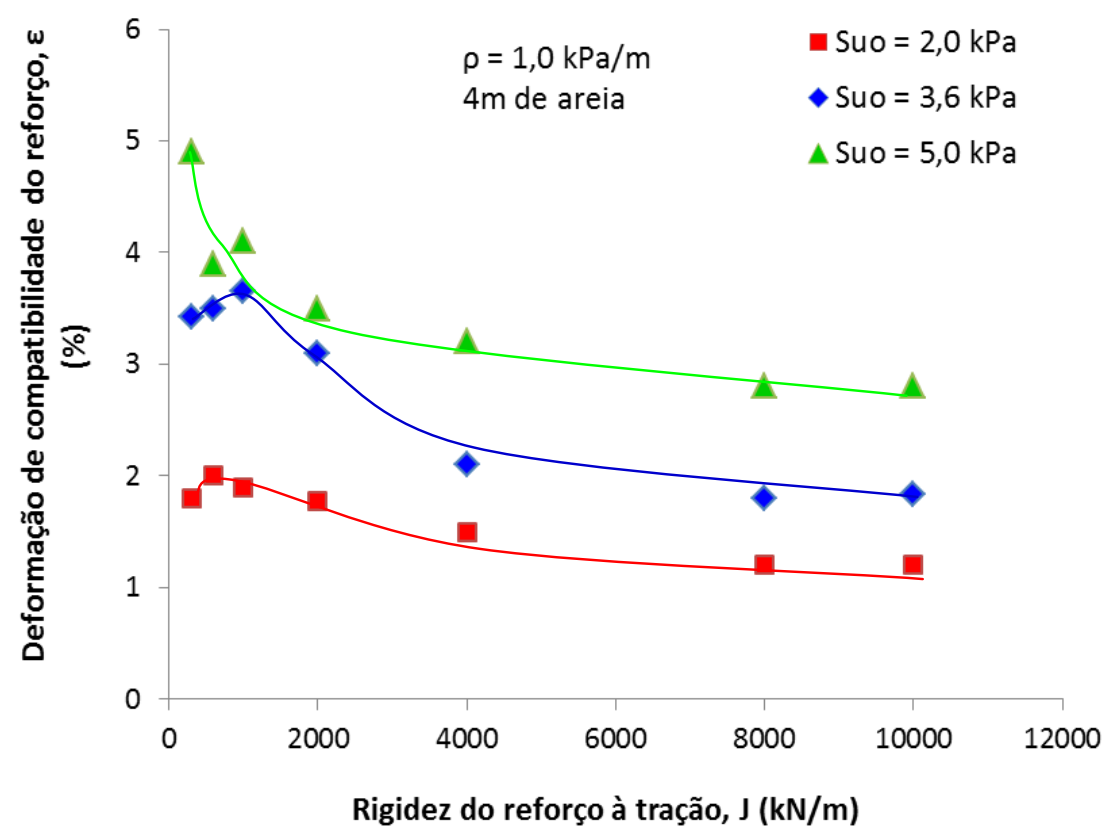

Figura 4-27 Efeito do $S_{u 0}$ na deformação de compatibilidade do reforço na ruptura para $A=2 \mathrm{~m}(\mathrm{a}), A=4 \mathrm{~m}(\mathrm{~b})$ e $\rho=1,0 \mathrm{kPa} / \mathrm{m}$. 
A Figura 4-28 mostra o efeito de $S_{u 0}$ nas deformações, e se observa um aumento nas deformações em comparação com o casos analisado de $\rho=1 \mathrm{kPa} / \mathrm{m}$, porque o aumento de $\rho$ nesse caso $1,5 \mathrm{kPa} / \mathrm{m}$ produz uma maior mobilização das tensões no reforço e porem maiores deformações. As deformações apresentam valores muito altos, sendo provável a ruptura estrutural do reforço.

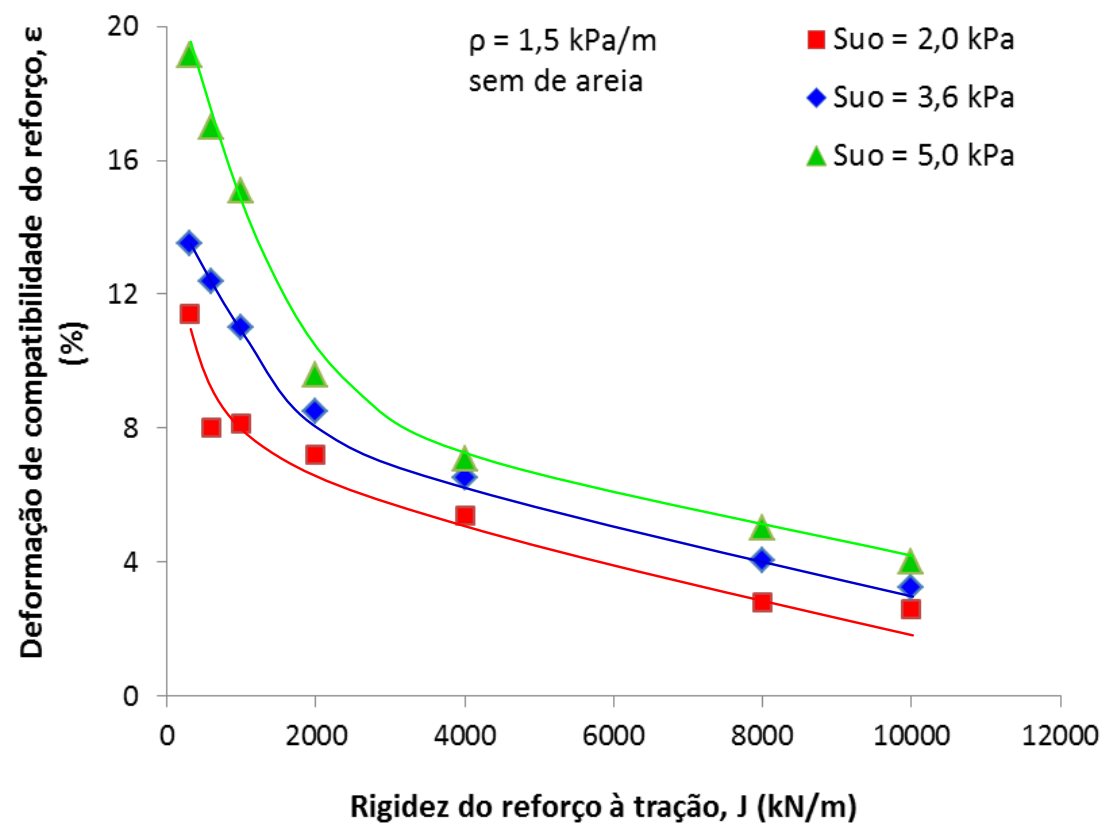

Figura 4-28 Efeito do $S_{u 0}$ na deformação de compatibilidade do reforço na ruptura para $A=0$ e $\rho=1,5 \mathrm{kPa} / \mathrm{m}$.

$\mathrm{Na}$ Figura 4-29 (a) e (b) se tem uma diminuição das deformações de compatibilidade devido a presença da areia, no caso com a espessura de areia de $2 \mathrm{~m}$, as deformações são maiores e no outro caso as deformações foram inibidas pela camada de areia de $4 \mathrm{~m}$.

O comportamento da deformação de compatibilidade frente à presença de areia é nítido em todos os casos. A fundação sem camada de areia apresentava deformações maiores em comparação ao outros casos com presença de areia na fundação, o efeito é similar ao aumento de $\rho$.

Assim, observa-se que os valores de deformação tendem a convergir para valores elevados de rigidez. 
(a)

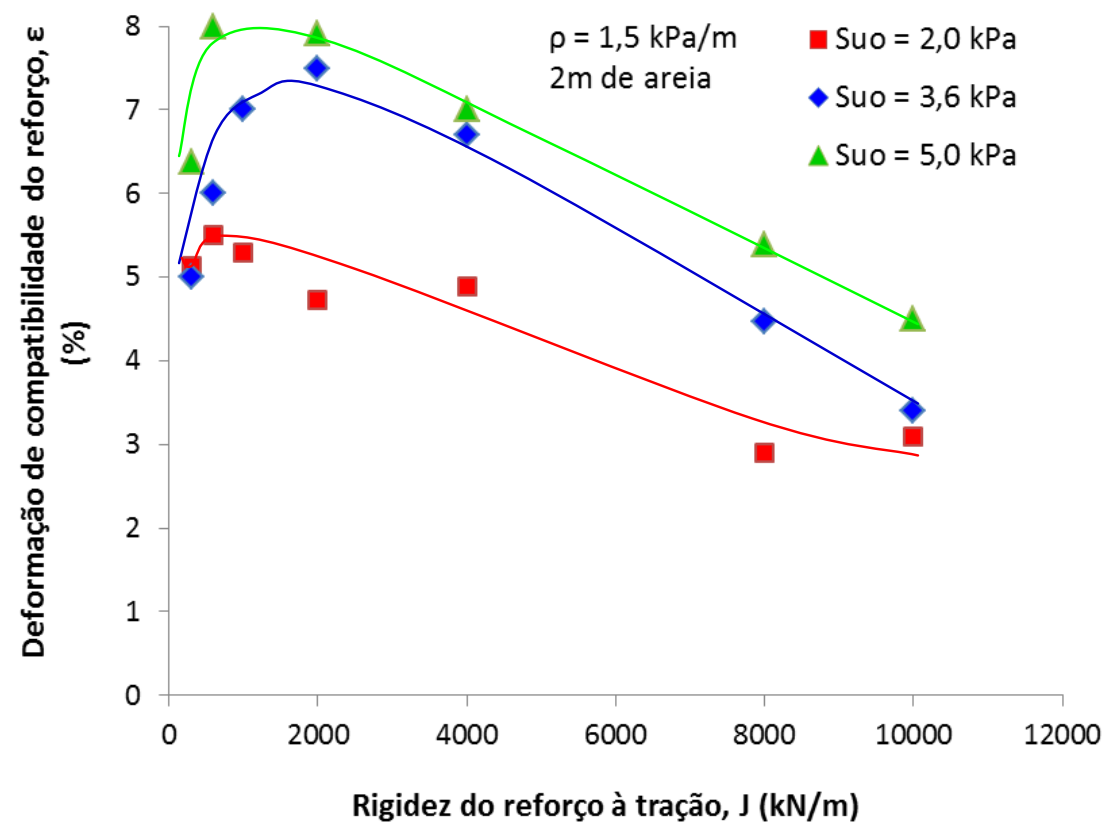

(b)

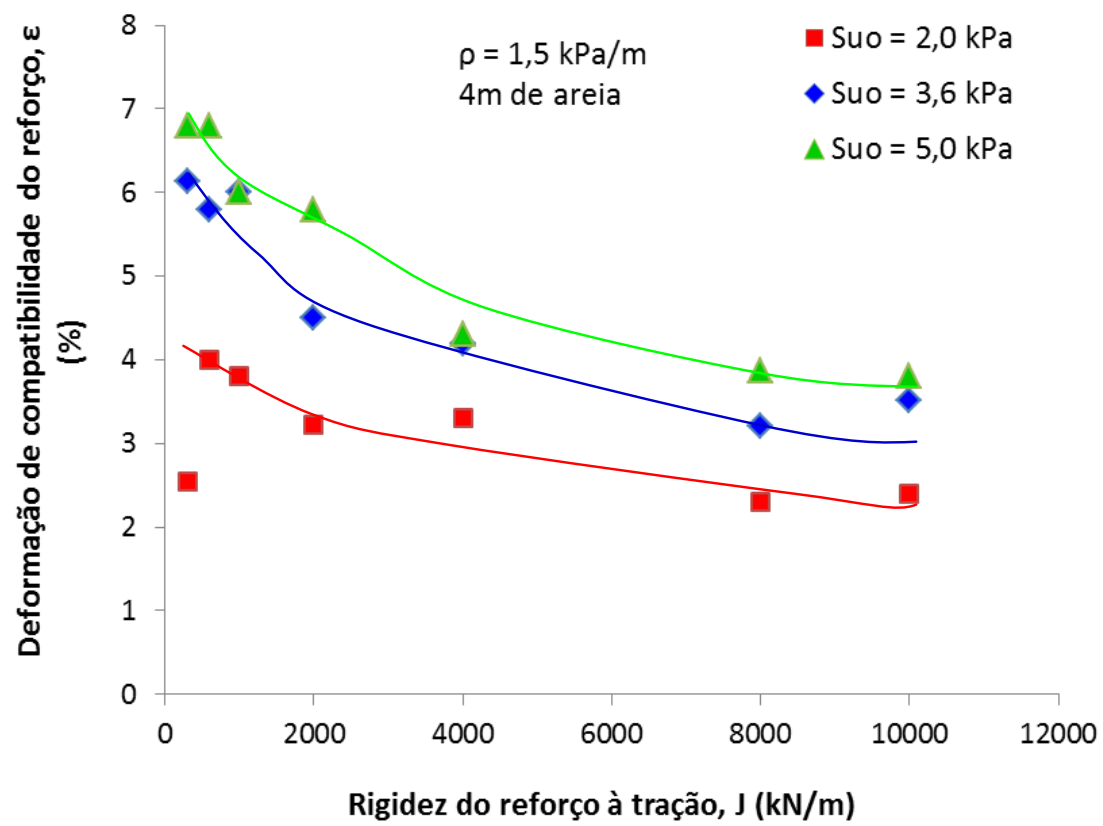

Figura 4-29 Efeito do $S_{u 0}$ na deformação de compatibilidade do reforço na ruptura para $A=0 \mathrm{~m}(\mathrm{a}), \mathrm{A}=2 \mathrm{~m}(\mathrm{~b})$ e $\rho=1,5 \mathrm{kPa} / \mathrm{m}$. 


\subsubsection{Variação dos recalques na base do aterro}

Com a finalidade de mostrar a influencia da camada de areia e da rigidez do reforço, foram analisados os recalques imediatos produzidos na base do aterro.

A Figura 4-30 mostra os recalques imediatos para uma fundação de solo mole sem areia, com valores máximos até $40 \mathrm{~cm}$ aproximadamente.

Observa-se também que os maiores recalques acontecem a uma distância aproximada de $5 \mathrm{~m}$ ao pé do talude, e os menores recalques no centro do aterro. Este fato pode ser explicado com os vetores de deslocamento do mecanismo de ruptura do item 4.3.3. Onde se explica como é que o mecanismo da ruptura começa a se desenvolver perto do talude do aterro, a concentração dos vetores deslocamentos produzem os maiores recalques.

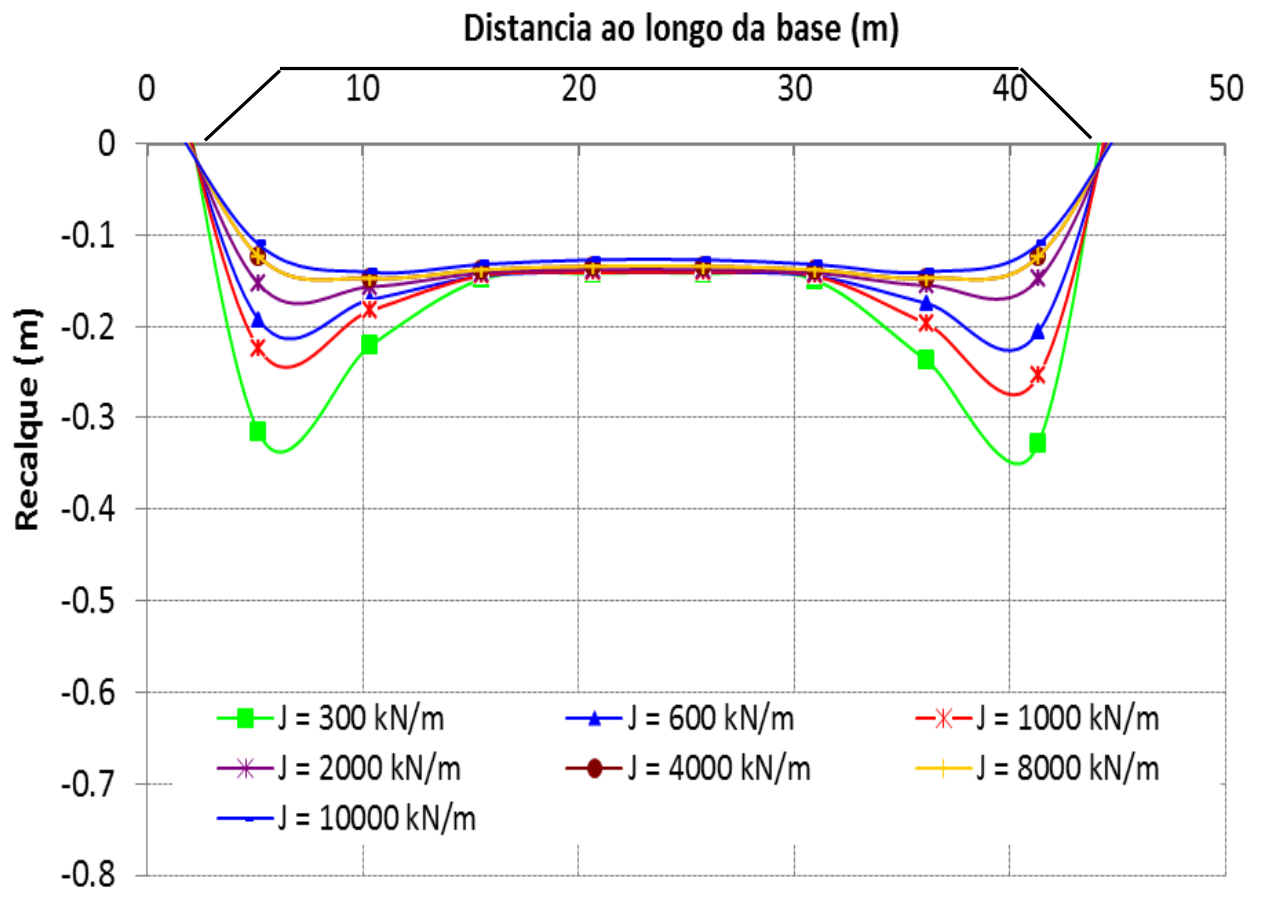

Figura 4-30 Recalques imediatos na base do aterro reforçado para $A=0 \mathrm{~m} \mathrm{e}$ $S_{\mathrm{uo}}=2 \mathrm{kPa}$ e $\rho=1,5 \mathrm{kPa} / \mathrm{m}$.

As alturas dos aterros analisados foram diferentes para os casos com areia e sem areia. Nos casos sem areia as alturas de ruptura atingidas foram de 2,25m no caso de rigidez do reforço $300 \mathrm{kN} / \mathrm{m}$ até $4,3 \mathrm{~m}$ para a rigidez de $10.000 \mathrm{kN} / \mathrm{m}$. 
Para levar o aterro à ruptura nas análises, as altura foram aumentadas nos casos com a camada de areia. Para a espessura de $2 \mathrm{~m}$ as altura de ruptura foram de $3 \mathrm{~m}$ para $\mathrm{J}=300 \mathrm{kN} / \mathrm{m}$ e $4,75 \mathrm{~m}$ para $\mathrm{J}=10,000 \mathrm{kN} / \mathrm{m}$.

A existência de uma camada de areia de $2 \mathrm{~m}$ diminui os recalques (Figura 4-31), a presença deste com maior resistência que o solo mole, confere uma maior resistência à fundação, porém, o mecanismo da ruptura vai deslocando-se ao centro do aterro e nesse caso os recalques máximos se produzem numa distância aproximada de $10 \mathrm{~m}$.

Distancia ao longo da base $(\mathrm{m})$

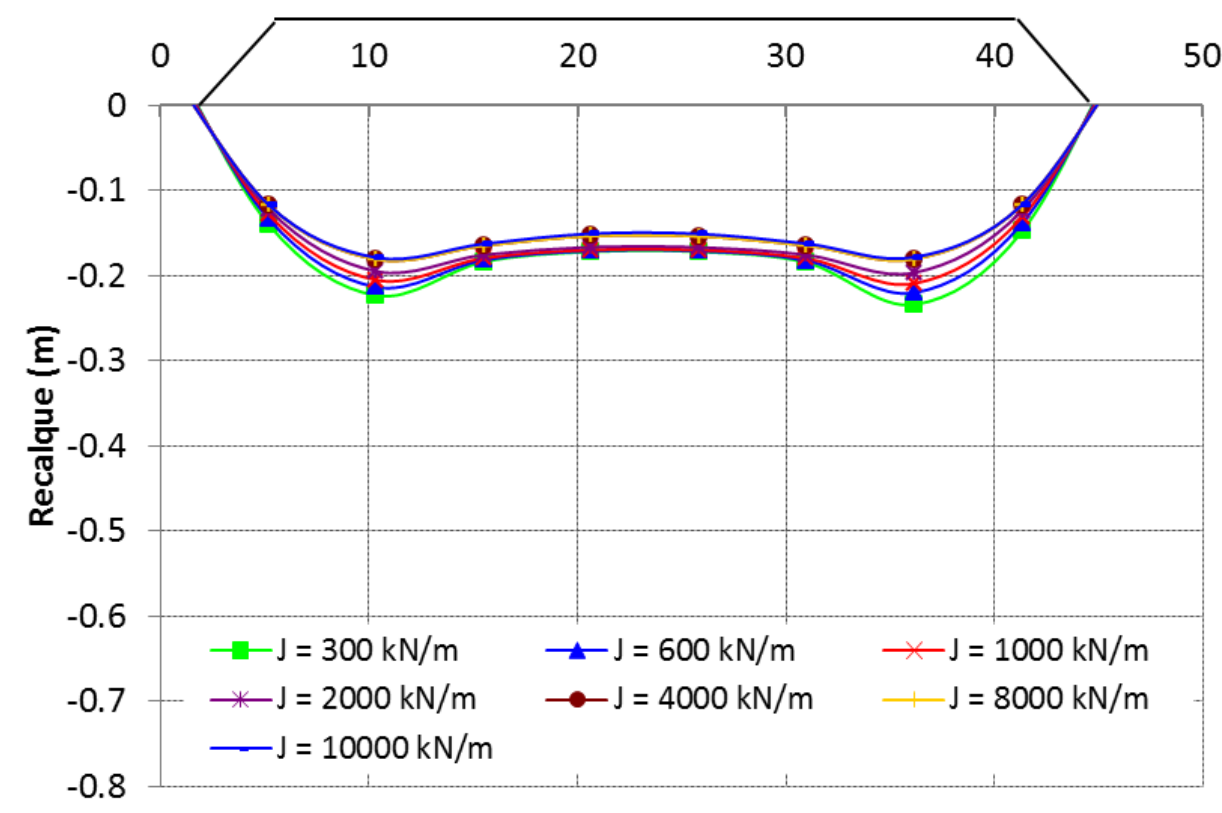

Figura 4-31 Recalques imediatos na base do aterro reforçado para $A=2 \mathrm{~m} \mathrm{e}$ $S_{\text {uo }}=2 \mathrm{kPa}$ e $\rho=1,5 \mathrm{kPa} / \mathrm{m}$.

No caso da Figura 4-32, a camada de $4 \mathrm{~m}$ de areia produz uma pequena diminuição dos recalques na base do aterro, situando os valores por embaixo dos $20 \mathrm{~cm}$. Mas nesse caso uma maior espessura da camada de areia torna-se mais importante do que a rigidez do reforço, isto se observa na distancia das curvas para diferentes valores de rigidez do reforço, $\mathrm{J}$.

As curvas indicam uma pequena diferença entre os valores, porém para um aumento da espessura da camada de areia a rigidez do reforço não tem muita 
influência nos recalques.

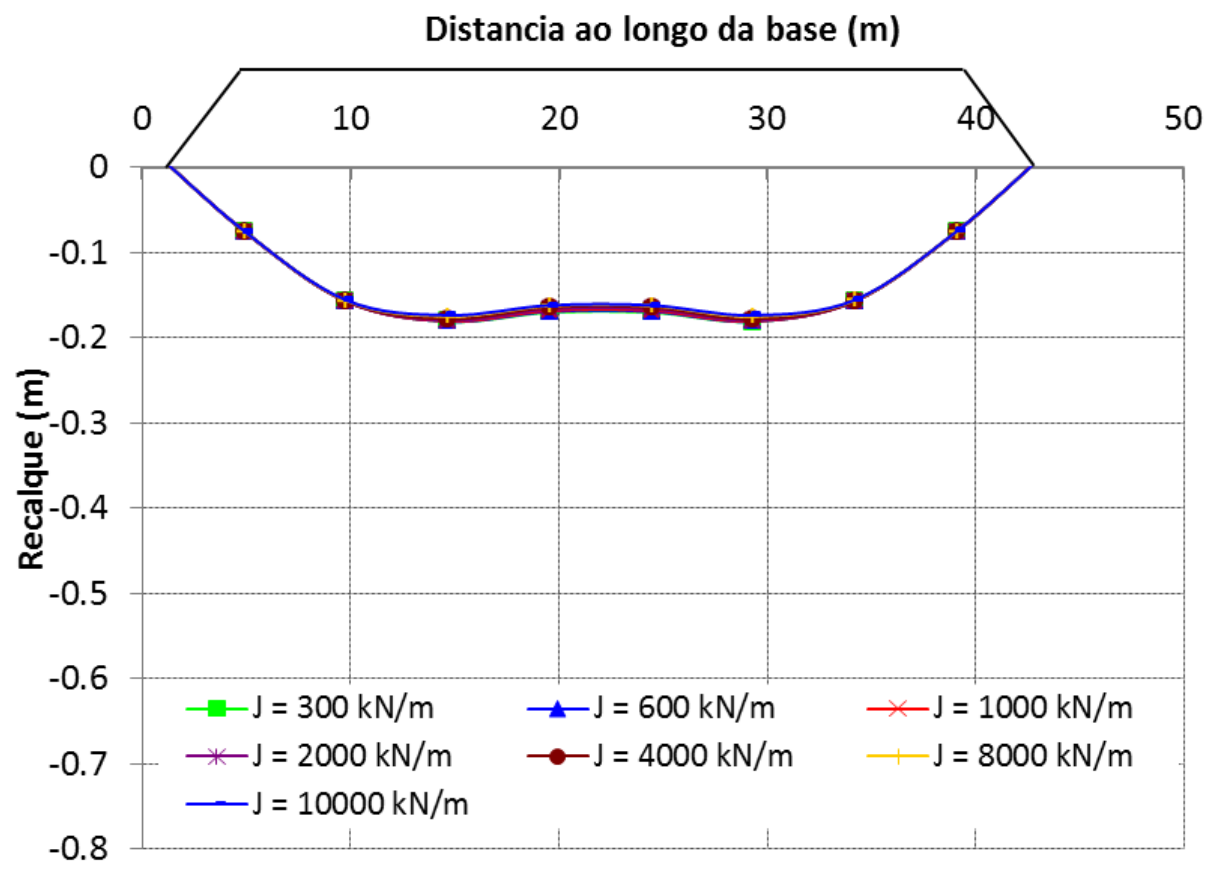

Figura 4-32 Recalques imediatos na base do aterro reforçado para $A=4 \mathrm{~m} \mathrm{e}$ $S_{\text {uo }}=2 \mathrm{kPa}$ e $\rho=1,5 \mathrm{kPa} / \mathrm{m}$.

Como a condição analisada é não drenada, a redução dos recalques imediatos esta relacionada com a redução dos deslocamentos horizontais, é por essa razão que são apresentados tanto os deslocamentos verticais como os horizontais.

\subsubsection{Influência nos deslocamentos horizontais}

Para avaliar o efeito da camada de areia no comportamento dos aterros reforçados foram analisados os deslocamentos horizontais no momento da ruptura.

Os resultados são apresentados de maneira similar aos resultados obtidos a través de um inclinômetro no pé do aterro, sobre uma fundação com parâmetros de solo de $\mathrm{S}_{\mathrm{uo}}=2 \mathrm{kPa}$ e $\rho=1,5 \mathrm{kPa} / \mathrm{m}$. Os resultados são mostrados na Figura 4-33 e Figura 4-35.

Na Figura 4-33 observa-se que quanto maior é a rigidez do reforço os deslocamentos são menores. No caso da fundação sem areia os deslocamentos máximos ocorrem aproximadamente a $2 \mathrm{~m}$ de profundidade. Os valores dos 
deslocamentos na superfície podem chegar até $80 \mathrm{~cm}$ aproximadamente.

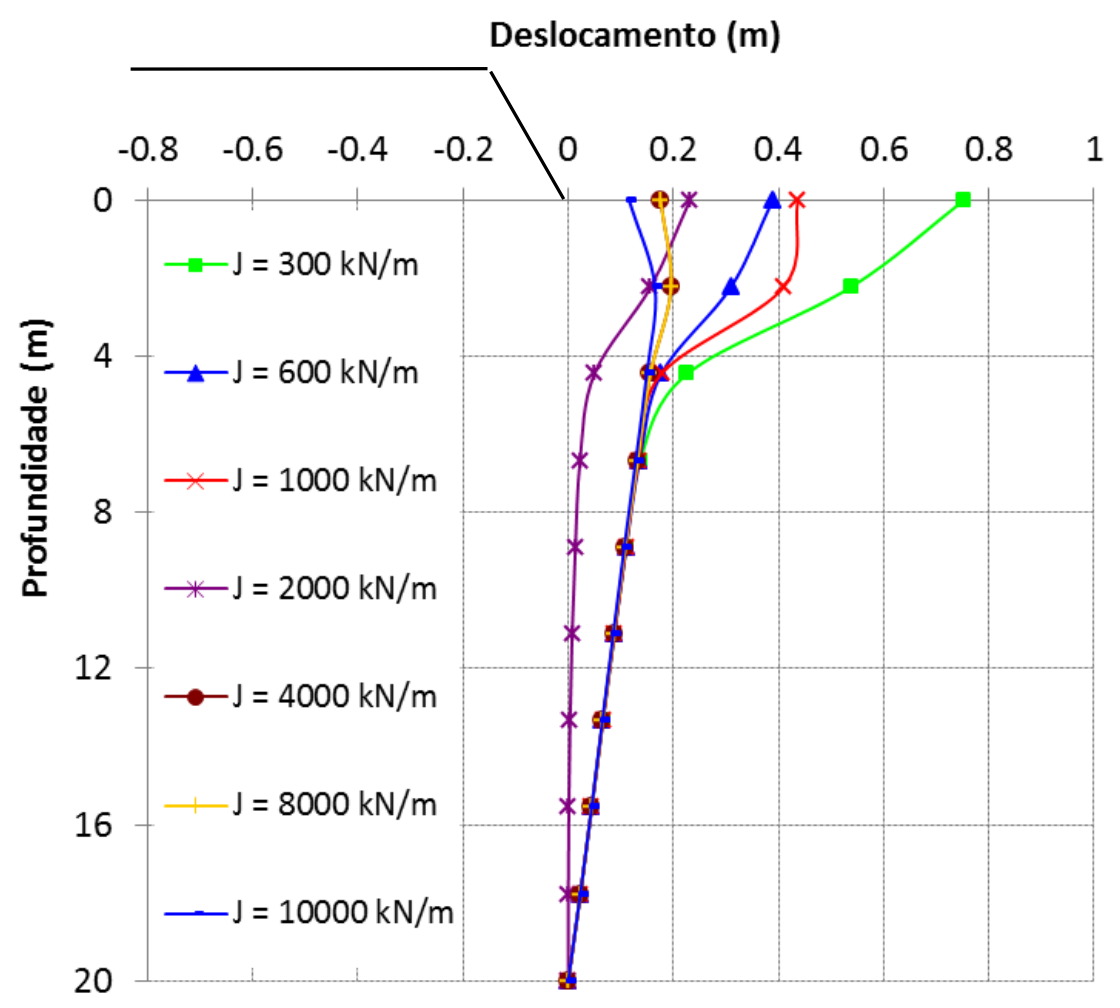

Figura 4-33 Deslocamentos horizontais no pé do aterro reforçado para $A=0$ $m$ e $S_{\text {uo }}=2 \mathrm{kPa}$ e $\rho=1,5 \mathrm{kPa} / \mathrm{m}$.

Na Figura 4-34, mostra que a presença da areia de $2 \mathrm{~m}$ dá um incremento na resistência da fundação e inibe os deslocamentos horizontais. Os valores são menores em comparação à Figura 4-33 da fundação sem areia, sendo que os máximos deslocamentos são de $20 \mathrm{~cm}$ na superfície.

Os deslocamentos aumentam visivelmente embaixo da camada de areia, fazendo com que os deslocamentos máximos permanecem na camada de argila. Os valores dos deslocamentos máximos estão próximos à ordem de 20 a $25 \mathrm{~cm}$. A uma profundidade aproximada de $2 \mathrm{~m}$. Nesse casos a presença da camada de areia na fundação tem uma contribuição notável na resistência e na redução dos deslocamentos. 


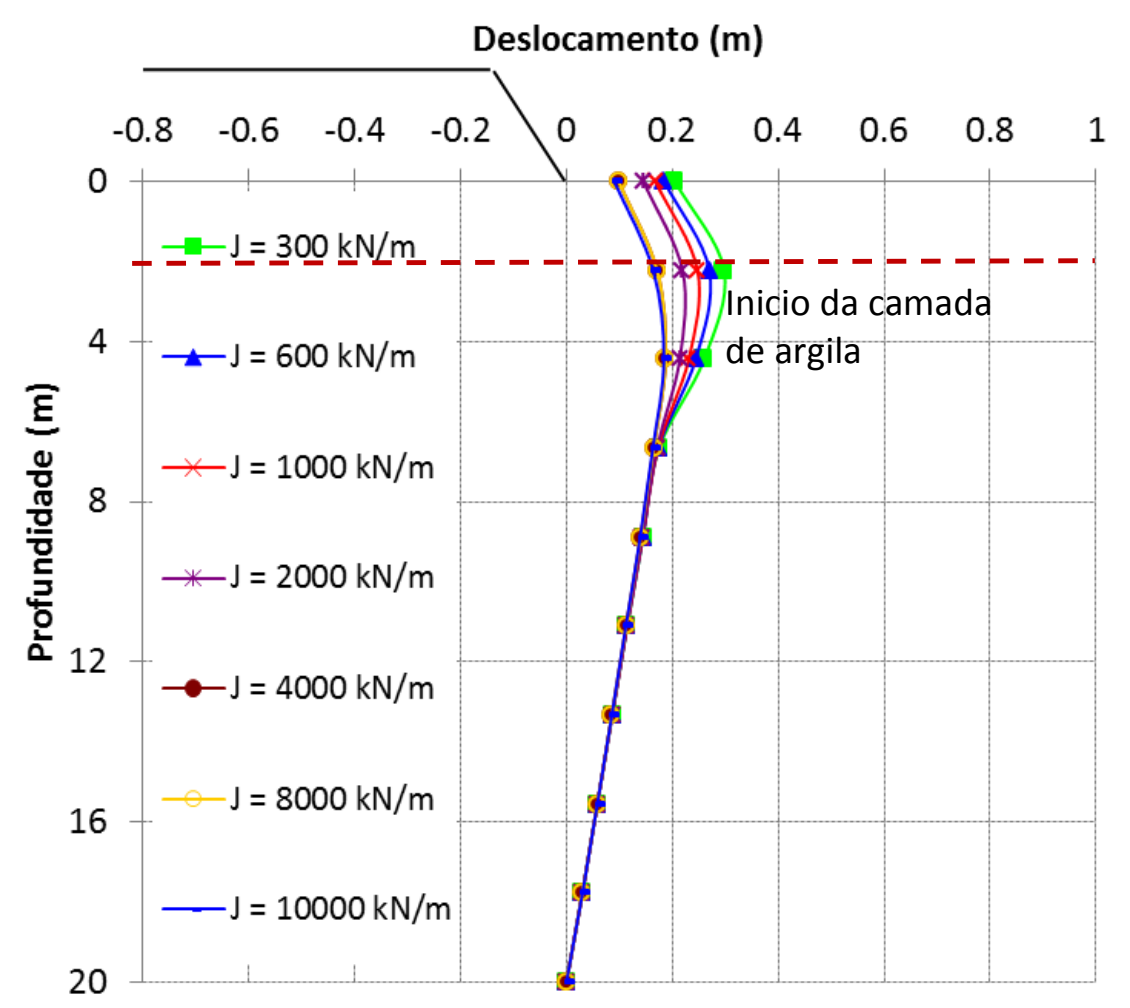

Figura 4-34 Deslocamentos horizontais no pé do aterro reforçado para $A=2$ $m$ e $S_{\mathrm{uo}}=2 \mathrm{kPa}$ e $\rho=1,5 \mathrm{kPa} / \mathrm{m}$

Na Figura 4-35, foi aumentada a espessura da camada de areia a $4 \mathrm{~m}$, se observa um comportamento diferente aos outros casos.

A contribuição da resistência da areia torna-se mais importante do que a influencia do reforço, observando as curvas muito próximas nota-se uma influencia quase nula do reforço.

Os deslocamentos máximos permanecem na camada de argila mole a uns $6 \mathrm{~m}$, aproximadamente.

Esses resultados estão em concordância com o concluído por Fahel (2003), numa instrumentação geotécnica de estruturas reforçadas sobre solos moles observou que o geossintético minimiza os deslocamentos provocados por recalques diferenciais do solo moles e uma lente de areia pode prover uma restrição significativa à movimentação lateral na fundação. Também foi observado que a profundidade onde ocorrem os maiores deslocamentos concorda com a posição do circulo crítico da análise de estabilidade. 


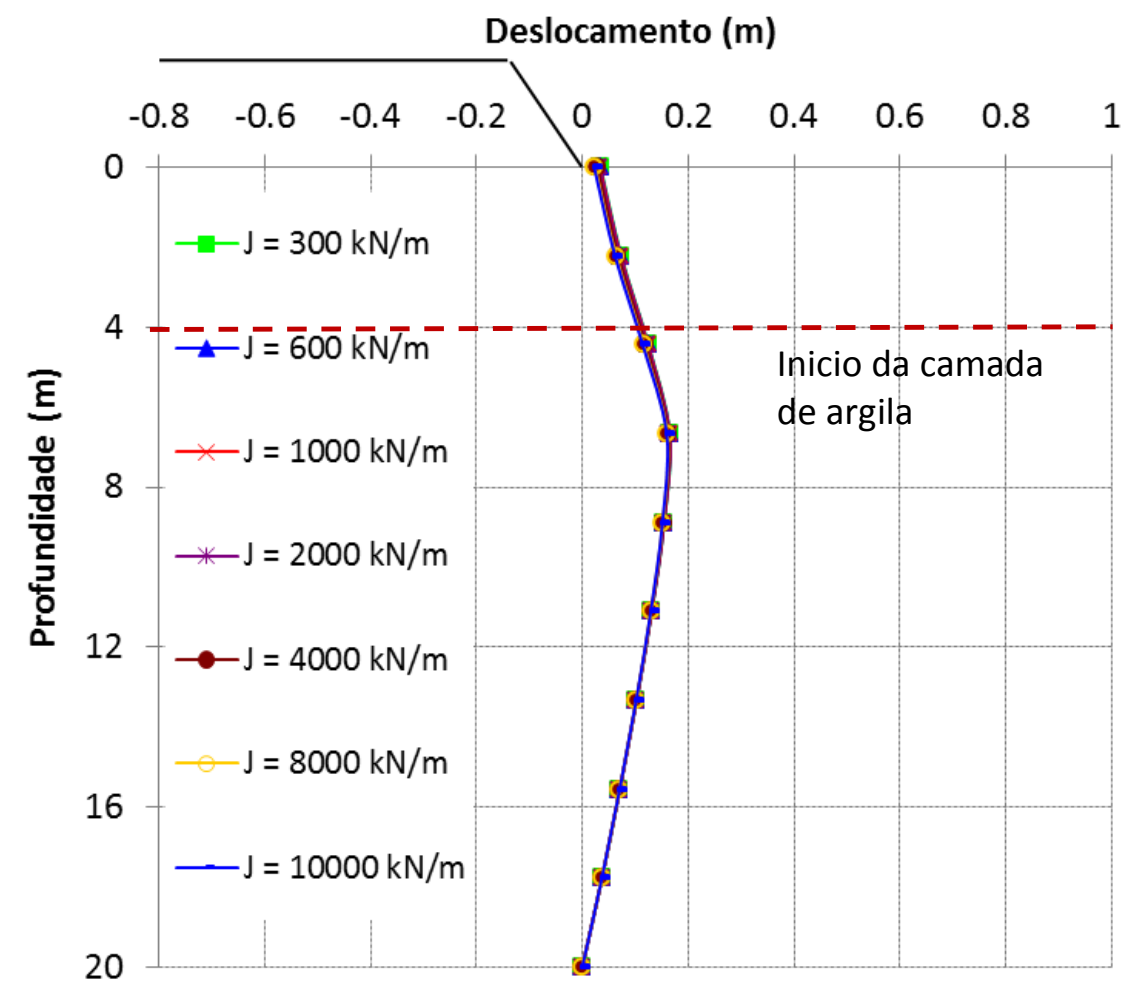

Figura 4-35 Deslocamentos horizontais no pé do aterro reforçado para $A=4$ $m$ e $S_{\mathrm{uo}}=2 \mathrm{kPa}$ e $\rho=1,5 \mathrm{kPa} / \mathrm{m}$

A Figura 4-36 mostra a comparação nos deslocamentos horizontais num aterro reforçado, tomando como variáveis a espessura da camada de areia; desde uma fundação sem areia até uma fundação com $4 \mathrm{~m}$ de espessura de areia; para aterros sem reforço e com reforço de rigidez 300 e $600 \mathrm{kN} / \mathrm{m}$.

A Figura 4-36, mostra uma referência do nível de profundidade, onde são produzidos os máximos deslocamentos. As alturas do aterro foram aumentadas com o objetivo de aumentar a sobrecarga e conseguir ruptura da fundação.

O comportamento foi o esperado. A areia provoca uma diminuição dos deslocamentos e os valores máximos ocorrem na camada de argila. 


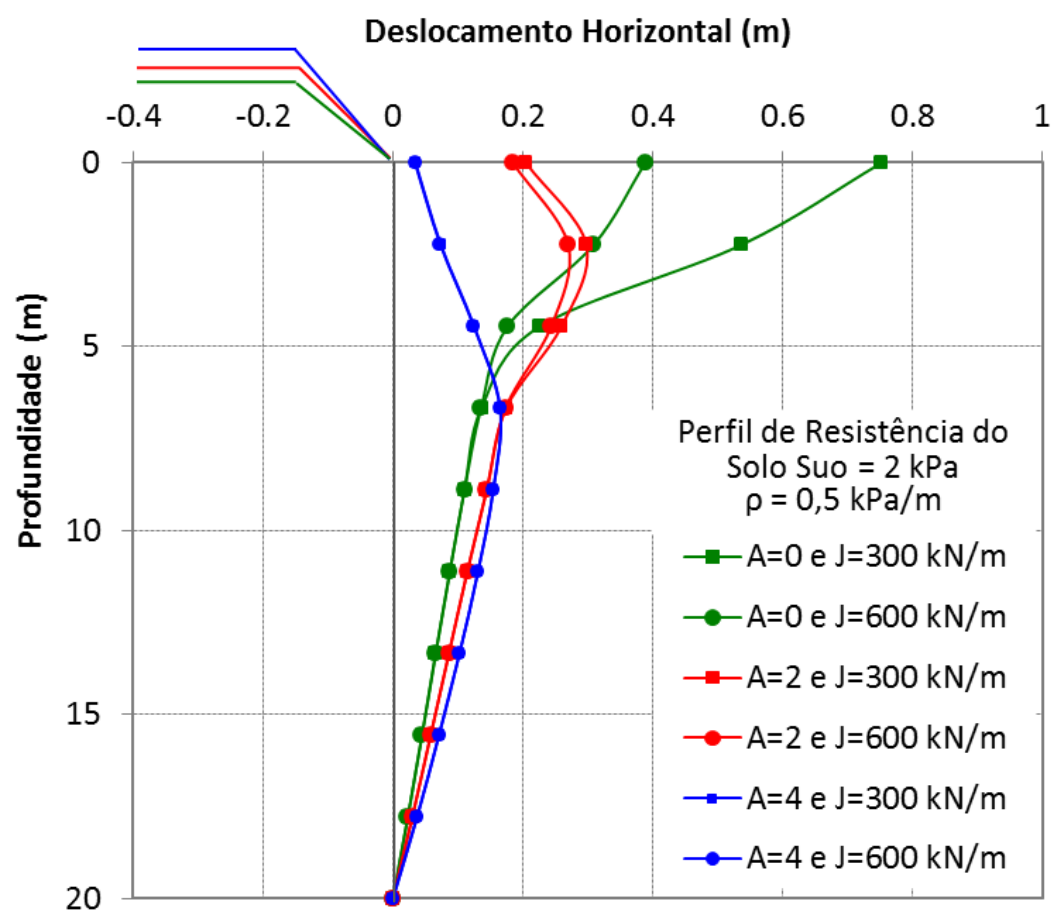

Figura 4-36 Efeito da espessura da camada de areia e rigidez do reforço nos deslocamentos horizontais do aterro na ruptura.

Dos resultados obtidos nas analises numéricas se conclui que a camada de areia interfere na interação solo-reforço e produze uma redução nas deformações do reforço e nos deslocamentos na fundação. O aumento da espessura da camada de areia tende a diminuir a contribuição do reforço, e a tendência é que se anularem.

Ė importante destacar que a esse resultados são semelhantes com os resultados de Oliveira et al (2010) onde os autores concluíram que a importância de uma camada superficial de areia era maior que a contribuição do reforço. 


\section{MODELO PARA O CÁLCULO DA DEFORMAÇÃO DO REFORÇO}

Neste item será apresentada uma proposta para o cálculo das deformações produzidas no reforço de aterros sobre solos moles de resistência não drenada, crescente com a profundidade. A proposta foi elaborada a partir dos resultados dos métodos numéricos empregados para obter expressões analíticas que estimam a deformação nas condições de trabalho antes da ruptura. A proposta também pode ser empregada para dimensionar o reforço calculando a rigidez para um fator de segurança determinado.

Os casos de aterros reforçados sobre solos moles existentes na literatura foram utilizados na validação do modelo.

\subsection{Aterros reforçados sobre solos moles}

A partir dos resultados do MEF foi possível estabelecer uma correlação para definir a deformação admissível do reforço em condição de trabalho, isto em função aos seguintes parâmetros: aumento da resistência não drenada na superfície Suo, o aumento da resistência com a profundidade $\rho$ e a rigidez do reforço $\mathrm{J}$.

A finalidade é dimensionar o reforço no projeto de aterros, conhecendo assim a deformação a ser atingida. O modelo é complementado com dados obtidos do modelo de Futai (2010) para calcular a deformação admissível de compatibilidade na ruptura e a altura de ruptura que pode ser obtida mediante as soluções de plasticidade.

A Figura 5-1 mostra os resultados das análises realizadas no PHASE 2, primeiro foram obtidos os gráficos $\mathrm{H}-\varepsilon_{\mathrm{a}}$, a altura do aterro e a deformação máxima admissível do reforço. Nessa figura observa-se a variação na inclinação da curva devido à plastificação do solo, o que expõe dois comportamentos bem diferenciados a partir do momento em que o solo começa a plastificar.

A plastificação é produzida pelo aumento dos deslocamentos na fundação devido ao incremento da altura do aterro. Ao iniciar a plastificação o comportamento muda, aumentando a inclinação da curva. 


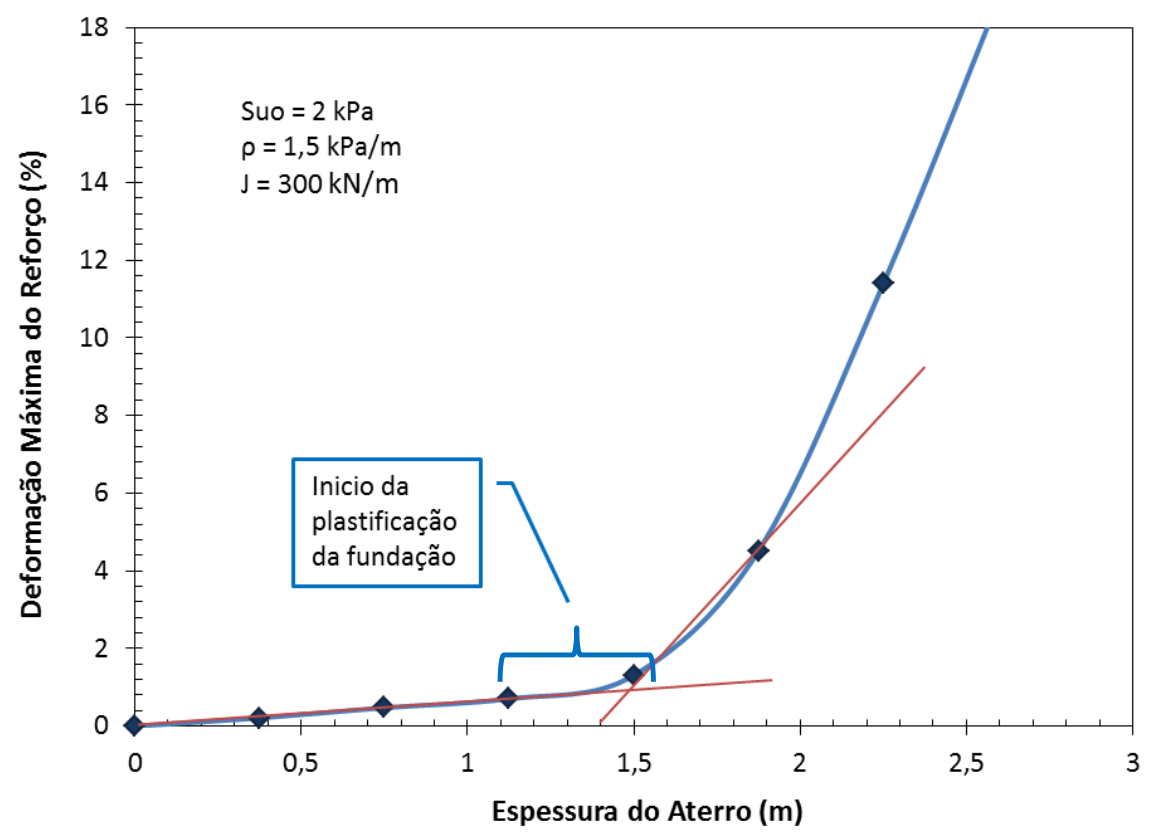

Figura 5-1 Deformação admissível de compatibilidade

Utilizando os resultados do aterro na ruptura as curvas foram normalizadas, colocando assim na unidade a condição de ruptura do aterro. A deformação máxima admissível é dividida pela deformação admissível de compatibilidade, assim como a altura atingida pelo aterro em cada estágio de construção é dividida pela altura da ruptura do aterro, este esquema é apresentado na Figura 5-2

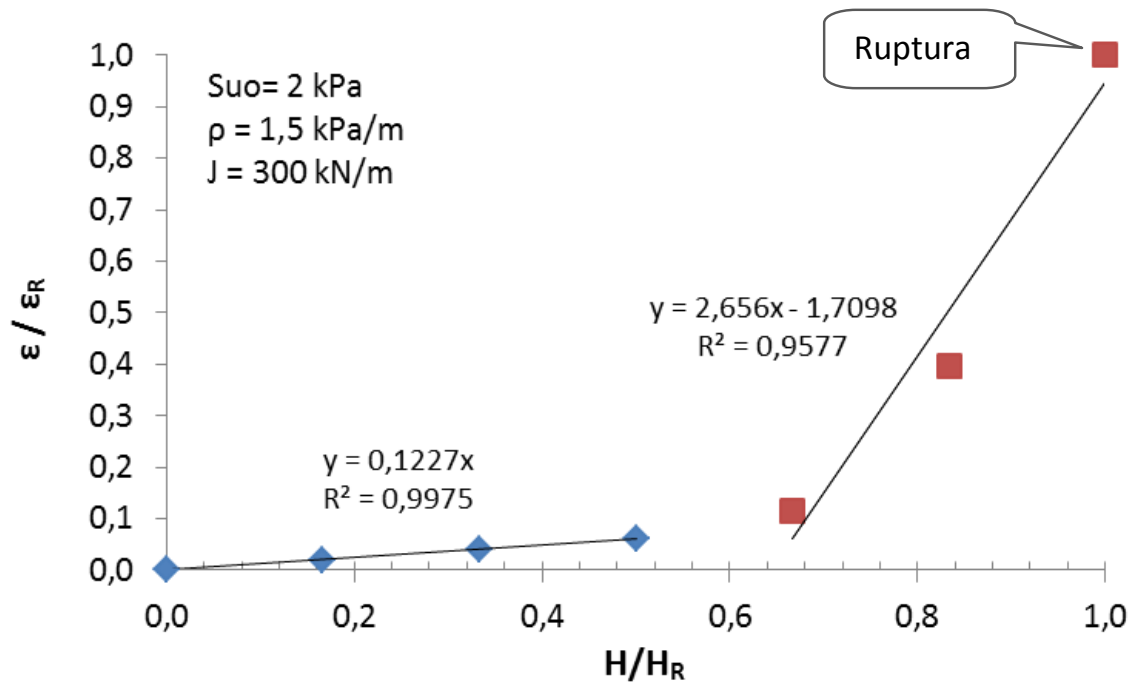

Figura 5-2 Curvas normalizadas 
Nessa normalização o momento da ruptura é representado no ponto onde a curva passa pelo ponto $(1,1)$ nos eixos horizontal e vertical para diferentes pares de resistências $S_{\text {uo }}$ e J. A área de interesse nesse gráfico encontra-se na zona antes daquele ponto que representa a ruptura do aterro, quando o aterro encontra-se nas condições de trabalho. A normalização foi realizada para cada caso de aterro analisado com variação de Suo, $\rho$ e J.

Na Figura 5-2, é notável uma variação na inclinação das curvas, porém a curva foi dividida em dois trechos lineares, sendo os pontos de interseção das retas chamadas de a para a coordenada horizontal e $\beta$ para a coordenada vertical, representando:

$$
\begin{gathered}
\alpha=\left(\frac{H}{H_{R}}\right) \mathrm{e} \\
\beta=\frac{\varepsilon}{\varepsilon_{R}}
\end{gathered}
$$

Os pontos $\alpha$ e $\beta$ são mostrados na Figura $5-3$, onde é visto o esquema do ponto de interseção das curvas normalizadas e dois comportamentos definidos.

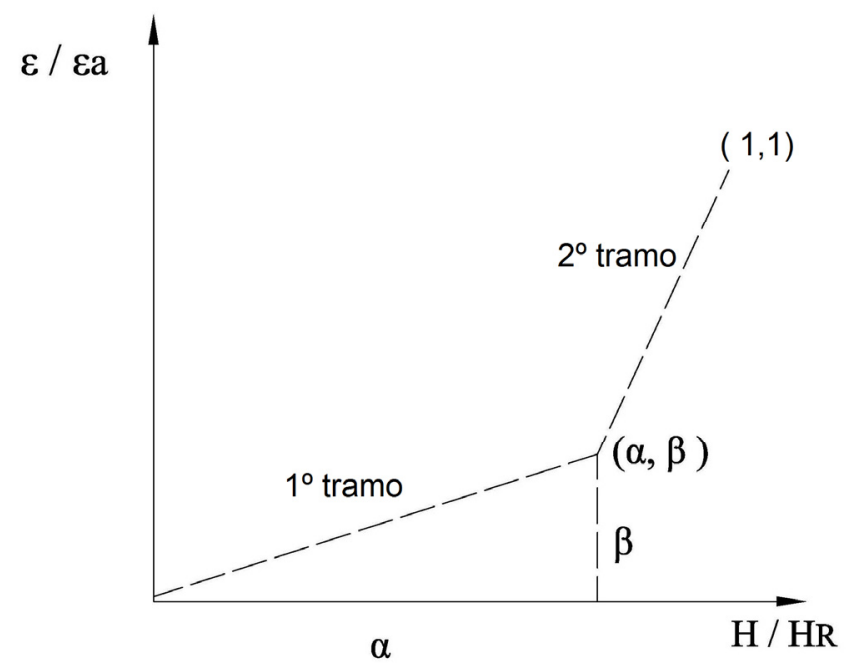

Figura 5-3 Definição dos pontos de interseção $\alpha$ e $\beta$

Da Figura 5-3 é possível obter as correlações para o primeiro e segundo tramo da curva: 
Primeiro tramo: $\frac{\varepsilon}{\varepsilon R}=\frac{\beta}{\alpha}\left(\frac{H}{H_{R}}\right)$

Segundo tramo: $\frac{\varepsilon}{\varepsilon R}=\frac{1-\beta}{1-\alpha}\left(\frac{H}{H_{R}}\right)+\frac{\beta-\alpha}{1-\alpha}$

$\alpha$ e $\beta$ foram correlacionadas com a rigidez do reforço $J$, para diferentes $\rho$ e $\mathrm{S}_{\mathrm{uo}}$ mediante a expressão $\left(\mathrm{S}_{\mathrm{uo}}+7,5 \rho\right)$ obtida de Futai $(2010)$. Os valores de J variam entre 300 a $10.000 \mathrm{kN} / \mathrm{m}$.

A seguir são apresentados os procedimentos utilizados na correlação $\alpha$ e $\beta$ com os parâmetros do solo e do reforço.

As Figura 5-4 a 5-6 mostram os gráficos $\alpha-J$, para cada variação de $S_{\mathrm{uo}}$ com valores de 2, 3,6 e $5 \mathrm{kPa}$ e $\rho$ de 1, 1,5 e $2 \mathrm{kPa} / \mathrm{m}$.

Observa-se que os valores de a encontram-se numa faixa de valores aproximadamente de 0,55 a 0,8 para todas as análises. Portanto, é possível considerar para cada análise de $\rho$ uma média dos valores de $\alpha$, pelo fato dos pontos estarem próximos a uma linha horizontal de valor constante.

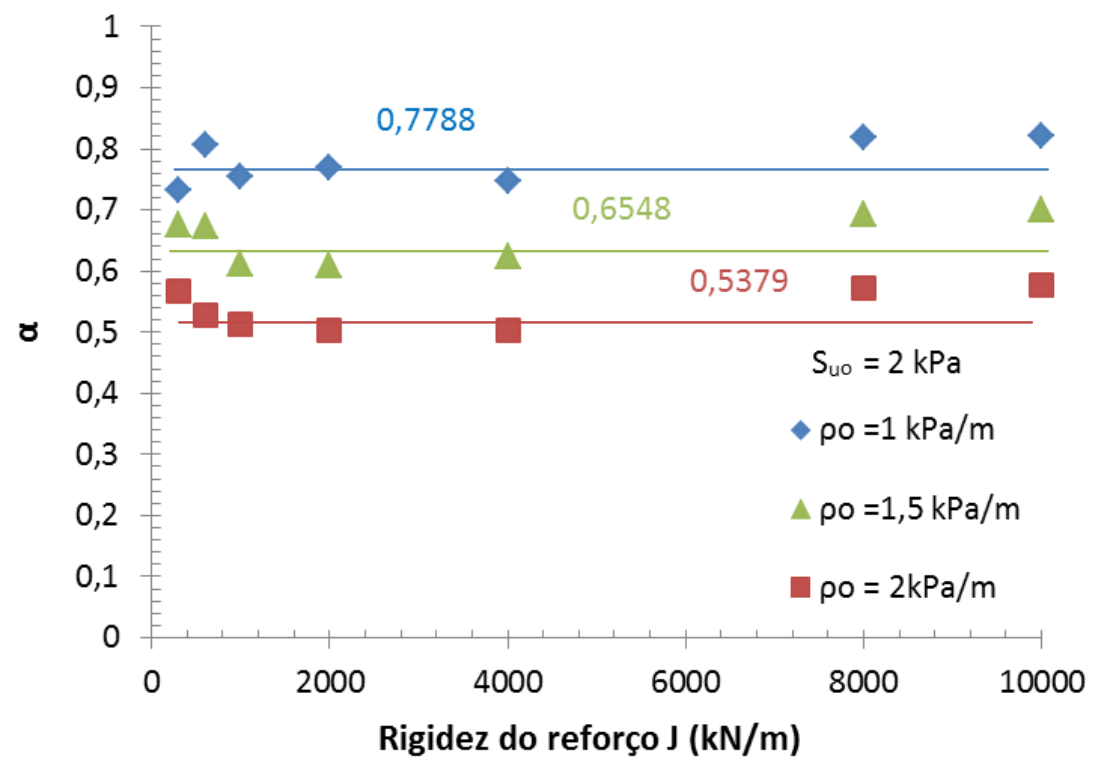

Figura 5-4 Correlação $\alpha$ para $S_{\text {uo }}=2 \mathrm{kPa}$ diferentes valores de $\rho$. 


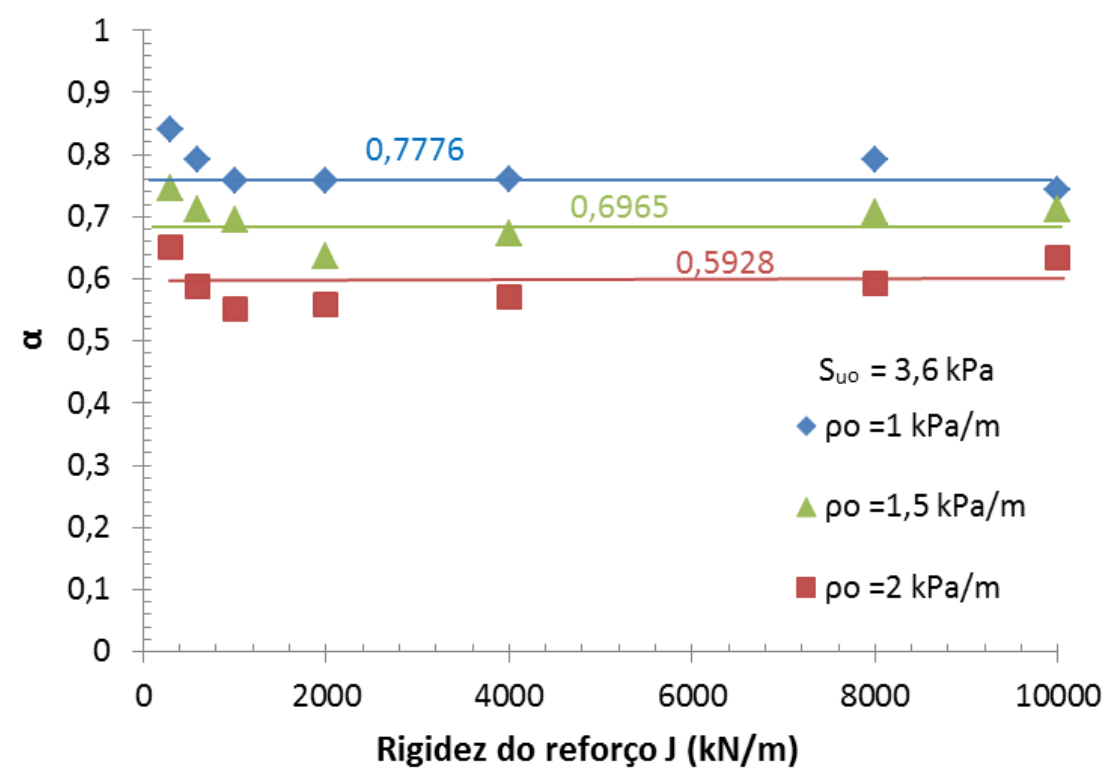

Figura 5-5 Correlação a para $S_{\text {ио }}=3,6 \mathrm{kPa}$ diferentes valores de $\rho$.

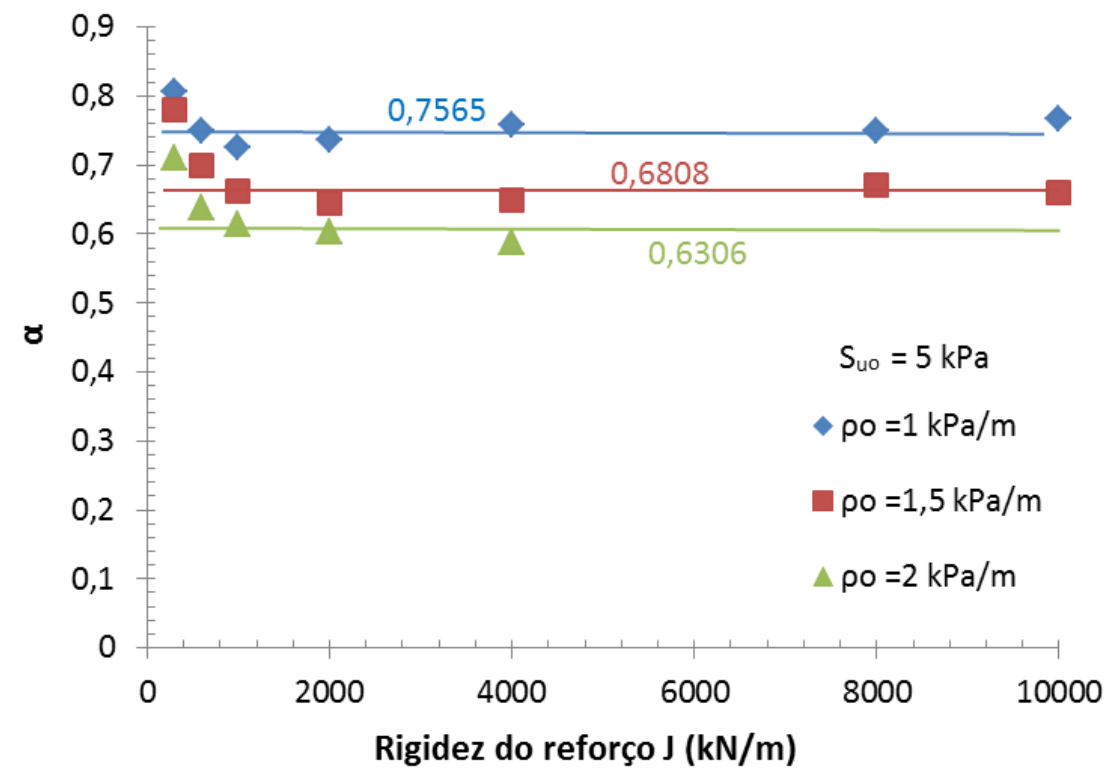

Figura 5-6 Correlação $\alpha$ para $S_{\text {uo }}=5 \mathrm{kPa}$ diferentes valores de $\rho$.

Os valores médios de $\alpha$ das análises de Suo e $\rho$ estão representados na TABELA 5-1. 
Tabela 5-1 Valores médios de $\alpha$ para diferentes correlações $S_{\text {uo }}+7,5 \rho$

\begin{tabular}{c|c|c|c}
\hline Suo (kPa) & $\boldsymbol{\rho}(\mathbf{k P a} / \mathbf{m})$ & Suo+7,5p & $\boldsymbol{\alpha}$ \\
\hline \multirow{2}{*}{2} & 1 & 9,50 & 0,7788 \\
& 1,5 & 13,25 & 0,6548 \\
& 2 & 17,00 & 0,5379 \\
\hline \multirow{2}{*}{3,6} & 1 & 11,10 & 0,7776 \\
& 1,5 & 14,85 & 0,6965 \\
& 2 & 18,60 & 0,5928 \\
\hline \multirow{2}{*}{5} & 1 & 12,50 & 0,7565 \\
& 1,5 & 16,25 & 0,6808 \\
& 2 & 20,00 & 0,6306 \\
\hline
\end{tabular}

Os pontos obtidos para cada combinação foram colocados num gráfico para obter a relação de a e $\left(S_{\text {uo }}+7,5 \rho\right)$. Os dados estão reunidos na Figura 5-7 mediante a expressão:

$$
\alpha=-0,0196\left(S_{\text {uо }}+7,5 \rho\right)+0,9685
$$

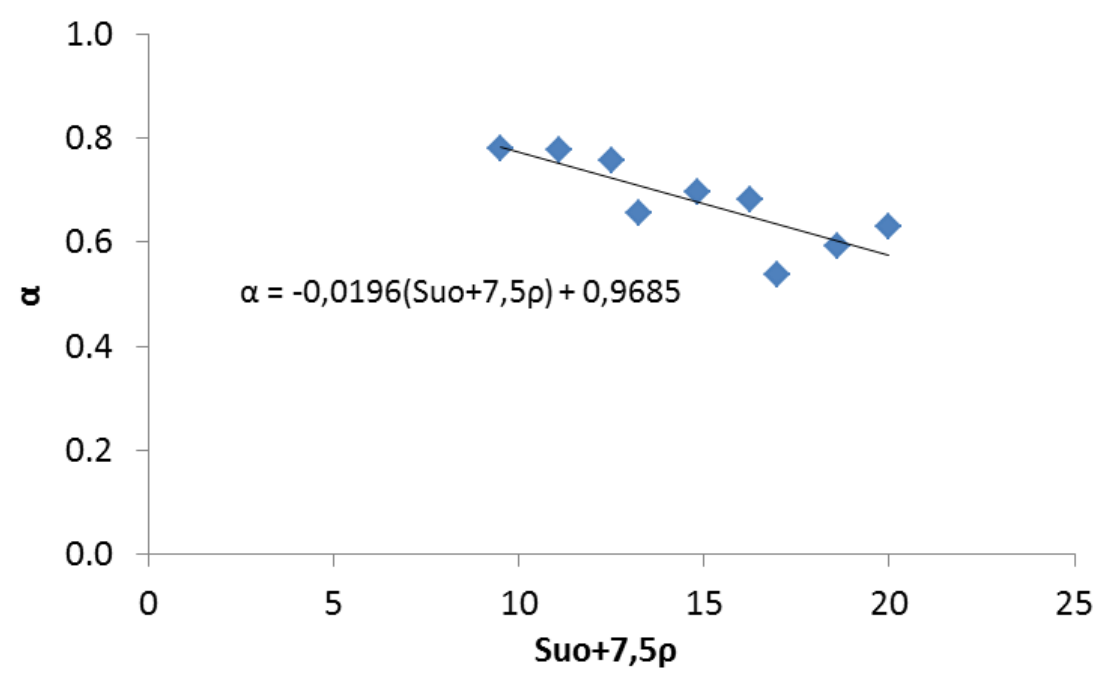

Figura 5-7 Correlação a para os valores analisados de Suo e $\rho$.

Para encontrar uma correlação entre $\beta$, J e a relação $\left(S_{\text {uo }}+7,5 \rho\right)$ foram elaborados os gráficos $\beta$ em função da rigidez do reforço J, onde se apresenta uma variação linear crescente para cada análise de $\rho$, mostrados na Figura 5-8. 


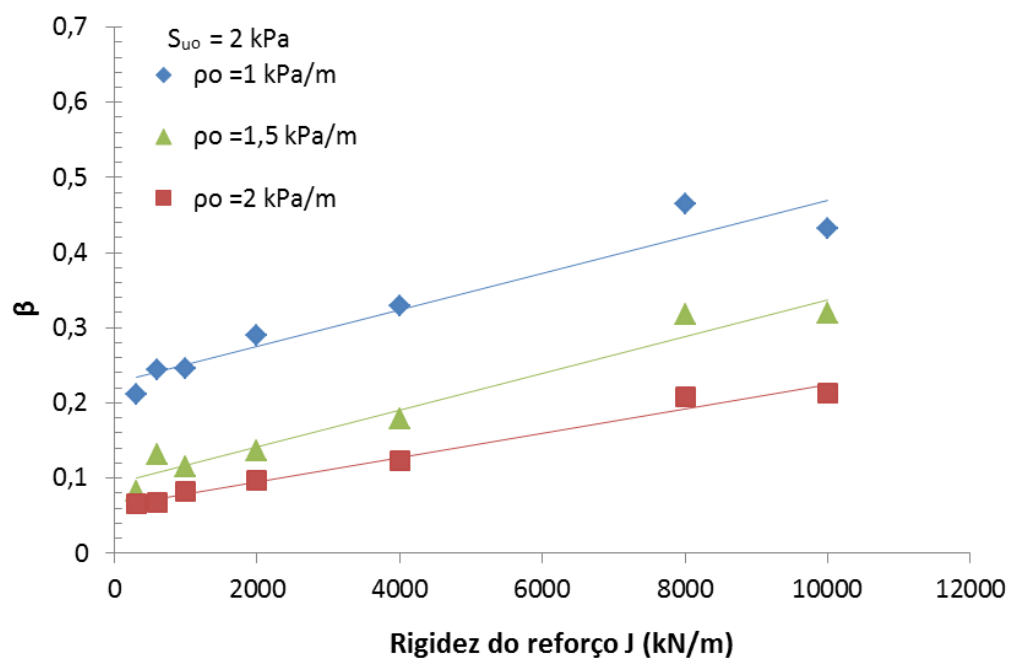

Rigidez do reforço J $(\mathrm{kN} / \mathrm{m})$

(a)
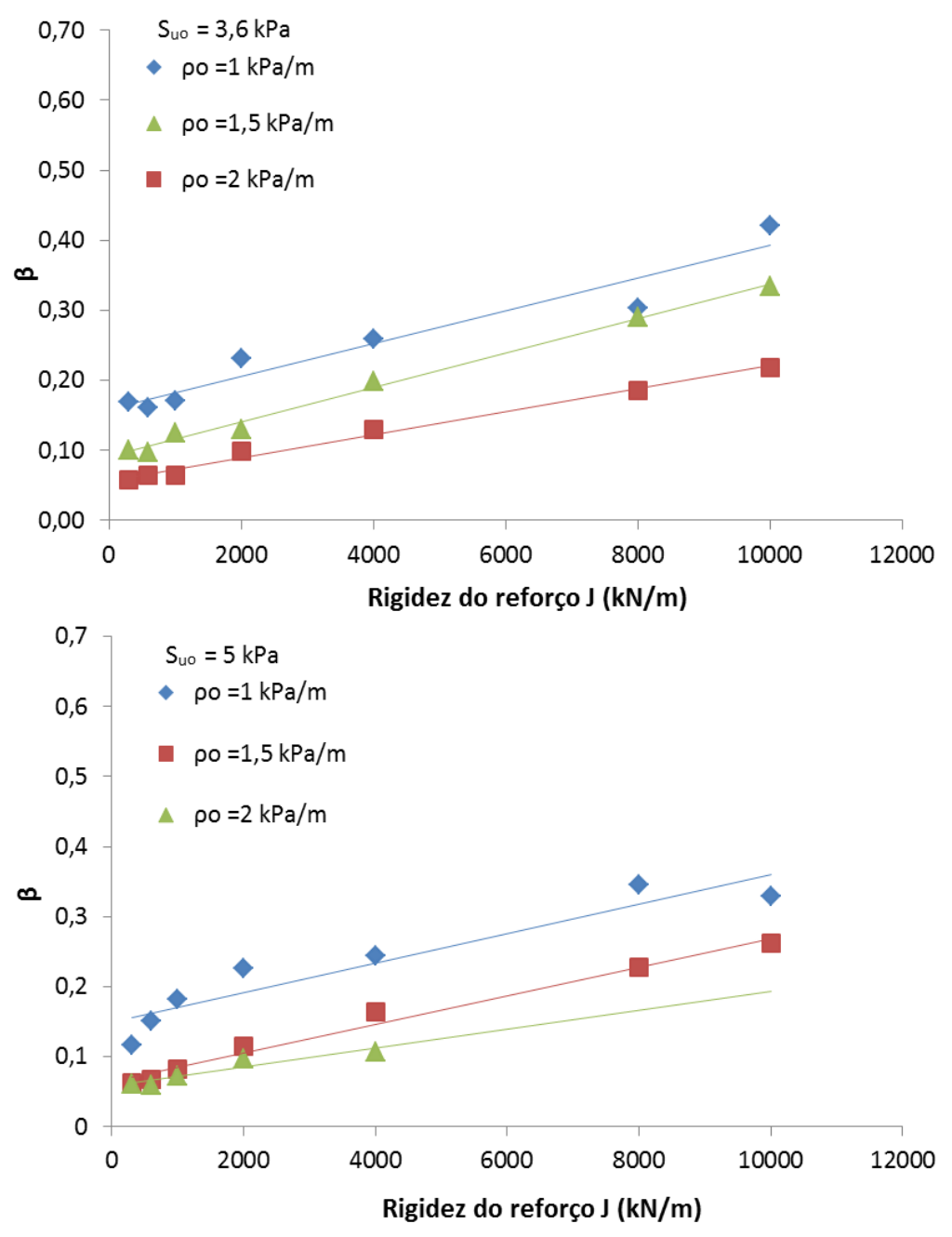

(b)

(c)

Figura 5-8 Valores $\beta$ para $S_{\mathrm{uo}}=2 \mathrm{kPa}(\mathrm{a}) ; 3,6 \mathrm{kPa}(\mathrm{b}) ; 5 \mathrm{kPa}$ (c) e diferentes valores de $\mathrm{J}$. 
Os valores de $\beta$ diminuem com o aumento dos parâmetros de resistência da fundação $\rho$ e $S_{u o}$. É possível explicar a variação de $\beta$ em função de $\mathrm{J}$ da expressão (5.2), quando a rigidez do reforço $J$ é menor causa maior deformação de compatibilidade $\mathcal{E}_{R}$, e vai diminuindo conforme aumenta essa rigidez, o que causa um aumento no valor de $\beta$. Além disso, o aumento da resistência do solo Suo provoca uma maior mobilização do reforço, porém há um aumento na deformação de compatibilidade, o que produz a redução de $\beta$.

$\mathrm{Na}$ análise de $\rho=2 \mathrm{kPa} / \mathrm{m}$ e $\mathrm{S}_{\mathrm{uo}}=5 \mathrm{kPa}$ os valores foram inferidos porque não foi possível alcançar a ruptura dos aterros (Figura 5-8 c). Na busca da correlação entre $\beta$, J e a relação $\left(S_{u o}+7,5 \rho\right)$ foram linearizados os coeficientes das linhas de tendência da Figura 5-8 numa expressão:

$$
\beta=a^{*} J+b
$$

Colocando os coeficientes a e $b$ em função de $\left(S_{\text {uo }}+7,5 \rho\right)$, obtém-se a expressão resultante:

$$
a, b=f\left(S_{u o}+7,5 \rho\right)
$$

Os coeficientes a e $b$ foram incluídos num gráfico em função de $\left(S_{u o}+7,5 \rho\right)$, para cada $S_{\text {uo }}$ e $\rho$. A variação de a está indicada na Figura 5-9 e os valores desse coeficiente que representa a inclinação das retas é ínfimo, porém foi considerado constante, resultando:

$$
a=0,00002
$$

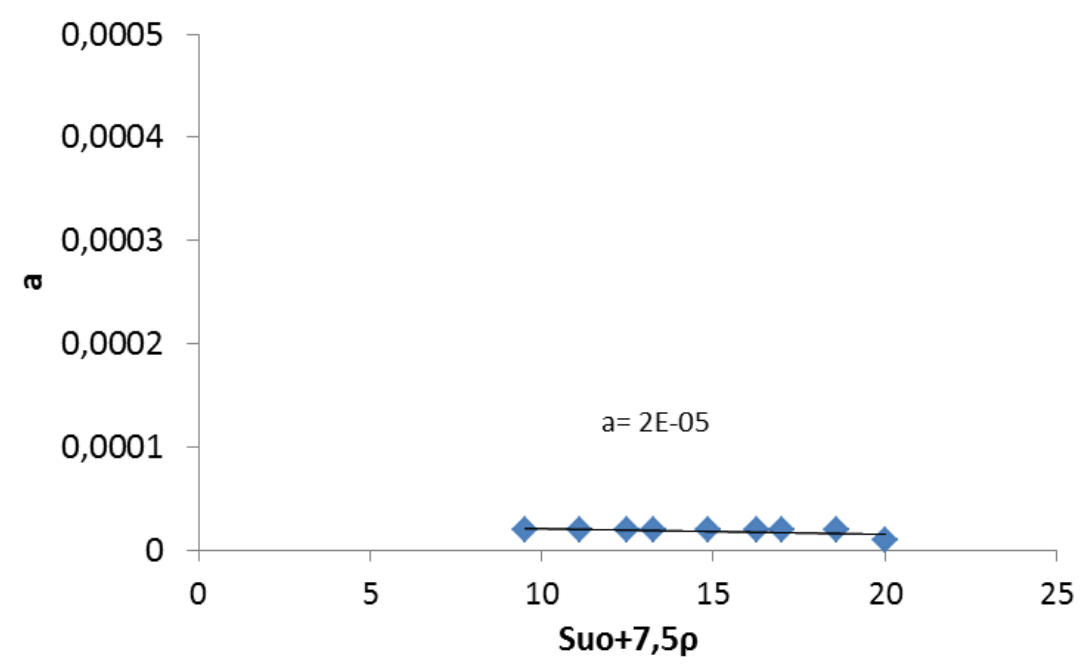

Figura 5-9 Correlação de a para os valores analisados de Suo e $\rho$. 
Um novo reajuste das linhas de tendência foi realizado levando em consideração o valor da inclinação das retas constante e igual a $2^{*} 10^{-5}$, e foram calculados os valores da intersecção com o eixo das ordenadas, $b$ (Figura 5-10).

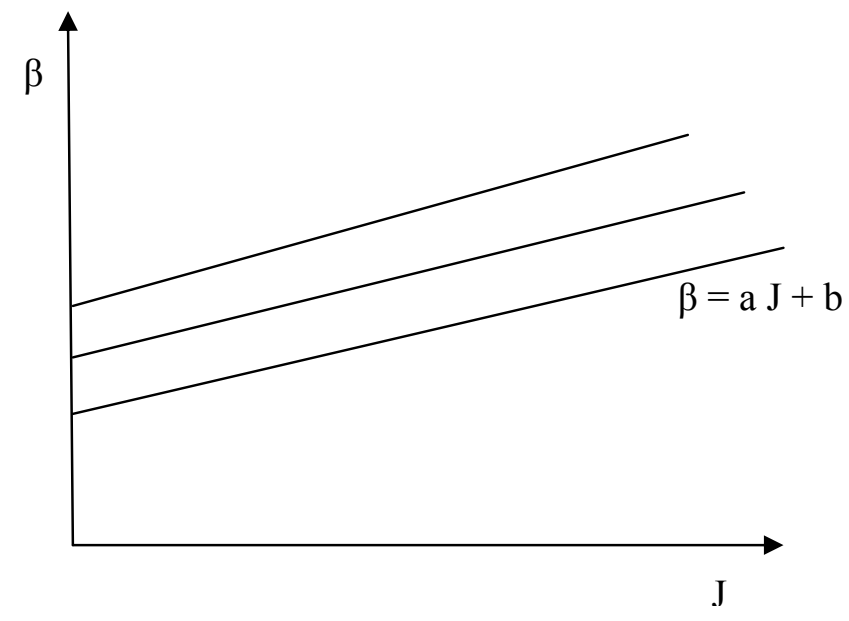

Figura 5-10 Correlação de $\beta$ com a rigidez do reforço J

As Figura 2-11 a Figura 2-13, apresentam os novos ajustes.

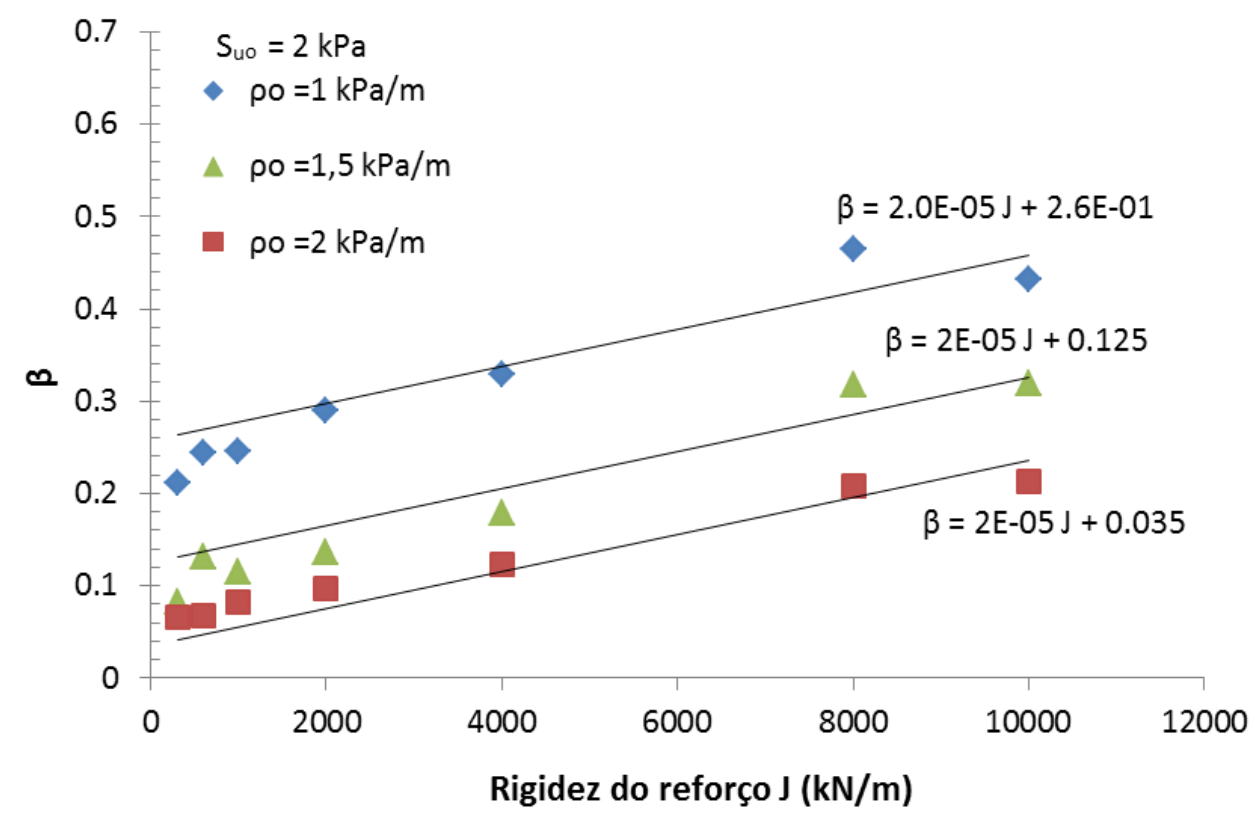

Figura 5-11 Correlação $\beta$ para $S_{\text {ио }}=2,0 \mathrm{kPa}$ diferentes valores de $\rho$. 


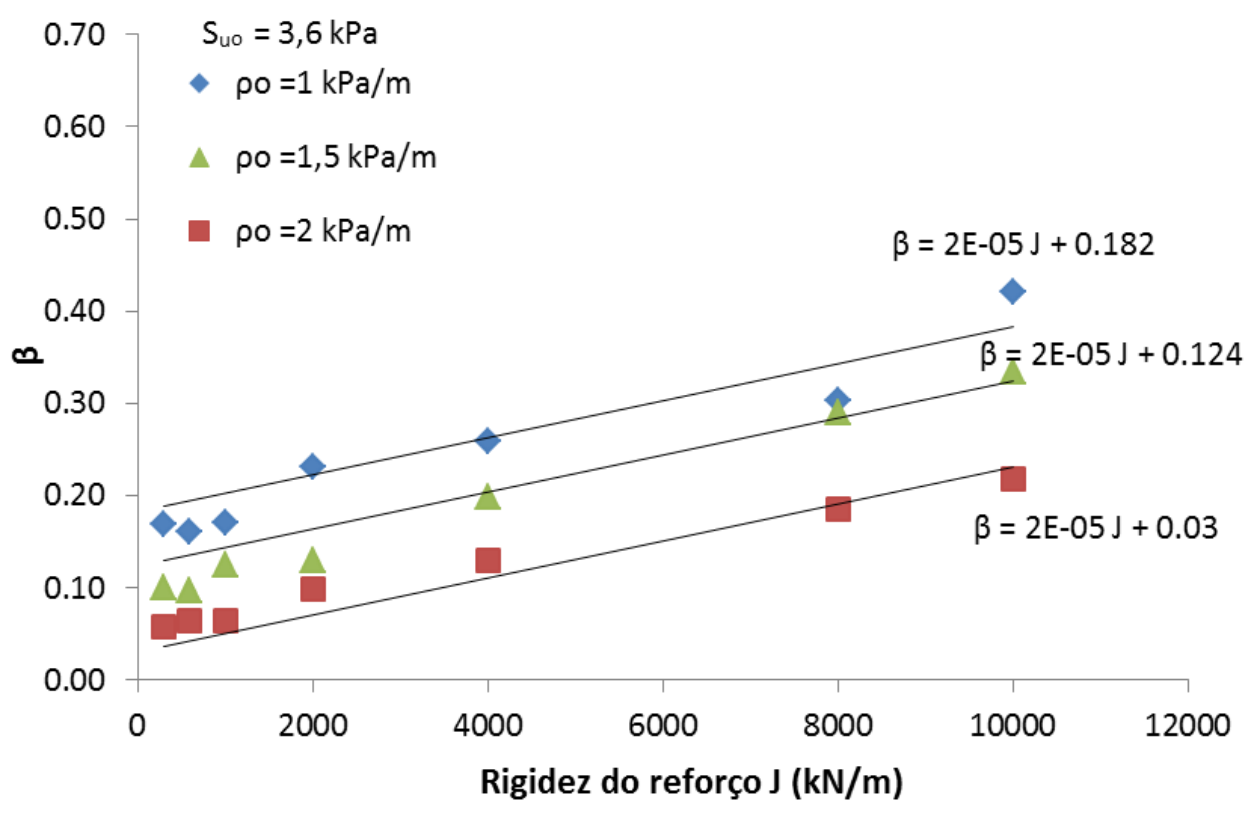

Figura 5-12 Correlação $\beta$ para $S_{u o}=3,6 \mathrm{kPa}$ diferentes valores de $\rho$.

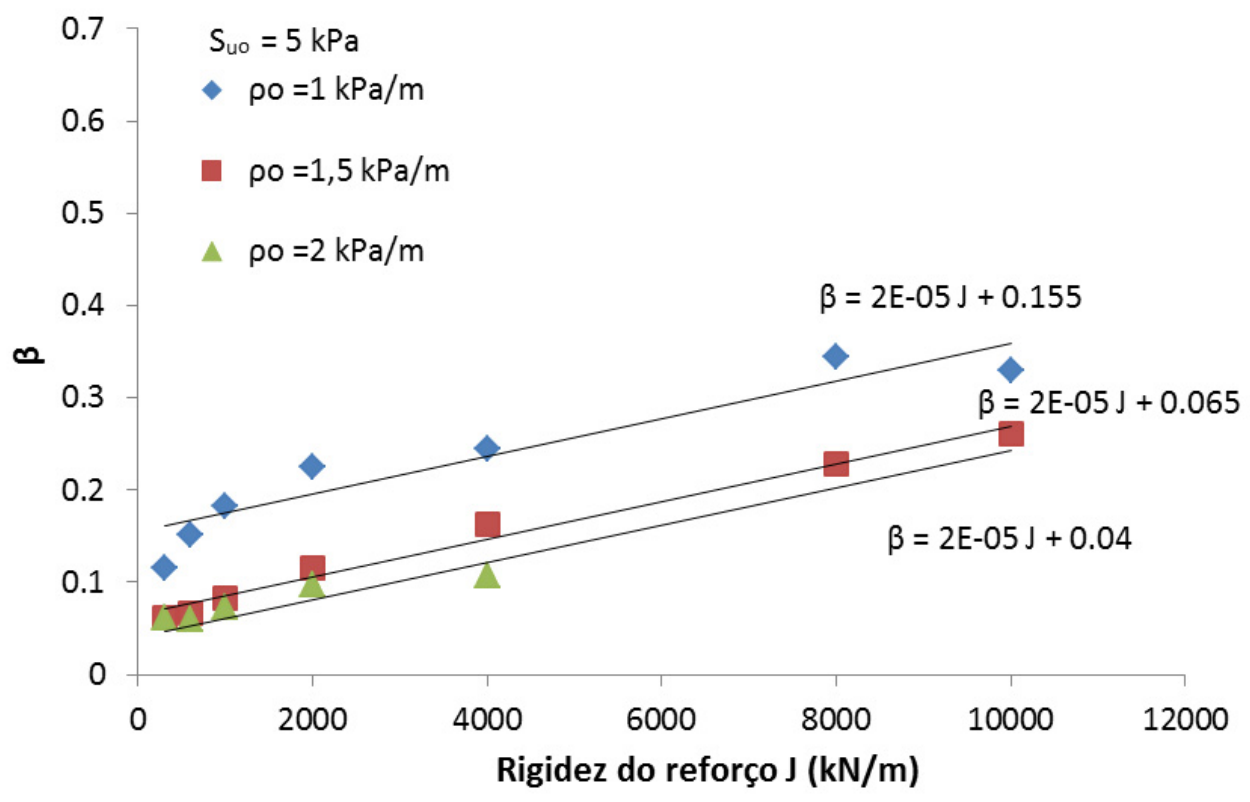

Figura 5-13 Correlação $\beta$ para $S_{\text {uo }}=5,0 \mathrm{kPa}$ diferentes valores de $\rho$.

A expressão para $b$ foi calculada mediante uma linha de tendência num gráfico em função dos pontos de interseção $b$ para cada combinação de $\left(S_{\text {uo }}\right.$ 
$+7,5 \rho)$, a qual é mostrada na Figura 5-14 e representada pela expressão:

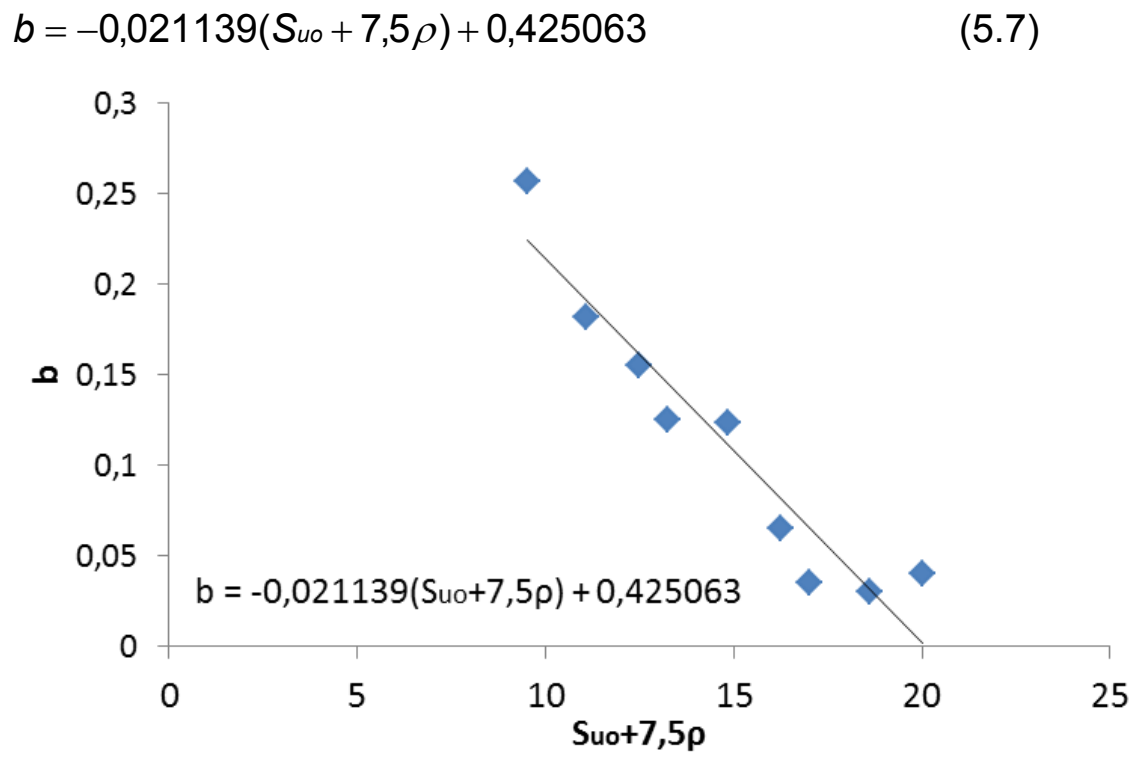

Figura 5-14 Correlação do b para os valores analisados de Suo e p.

A tendência dos valores de $b$ vem a ser sempre maior do que zero e $\left(S_{u o}\right.$ $+7,5 \rho)<20,5$

Com base nos resultados fornecidos é possível calcular $\beta$ mediante a expressão $\beta=a^{*} J+b$ :

$$
\beta=0,00002 J-0,021139\left(S_{u o}+7,5 \rho\right)+0,425063
$$

Da curva da Figura 5-3, onde foi normalizada a deformação máxima admissível dividida pela deformação admissível de compatibilidade, e a altura atingida em cada estágio de construção pela altura da ruptura do aterro, obteve-se as relações lineares (5.3) e (5.4). Com esses dados de $\alpha$ e $\beta$ é possível aplicar as expressões para calcular a deformação.

Primeiro tramo: $\frac{\varepsilon}{\varepsilon_{R}}=\frac{\beta}{\alpha}\left(\frac{H}{H_{R}}\right)$

Segundo tramo: $\frac{\varepsilon}{\varepsilon R}=\frac{1-\beta}{1-\alpha}\left(\frac{H}{H_{R}}\right)+\frac{\beta-\alpha}{1-\alpha}$ 
A expressão mostra a relação da variação de $\varepsilon$ em função aos parâmetros do solo de fundação e à rigidez do reforço J. O modelo para calcular a deformação do reforço a uma altura dada apresenta certos limites para os parâmetros da fundação. Para o aumento da resistência não drenada com a profundidade, valores de $\rho<2,5 \mathrm{kPa} / \mathrm{m}$, e para a resistência não drenada na superfície de Suo < $13,1 \mathrm{kPa}$.

Para aplicar o modelo é preciso ter os parâmetros do solo e a altura requerida do aterro reforçado. Além disso, é necessário calcular os valores na condição de ruptura para o aterro. A altura máxima que o aterro pode atingir antes de romper pode ser calculada aplicando as soluções de plasticidade e a deformação de compatibilidade pode ser calculada aplicando a proposta de Futai (2010), que provê os valores da deformação na ruptura.

Para explicar melhor a metodologia apresentada foi elaborado um fluxograma onde se indica a ordem da aplicação.

A proposta é aplicada para calcular a rigidez do reforço requerido para 0 aterro de uma altura dada e fator de segurança específico da obra. A sequência é repetida até a obtenção do valor de segurança desejado. 


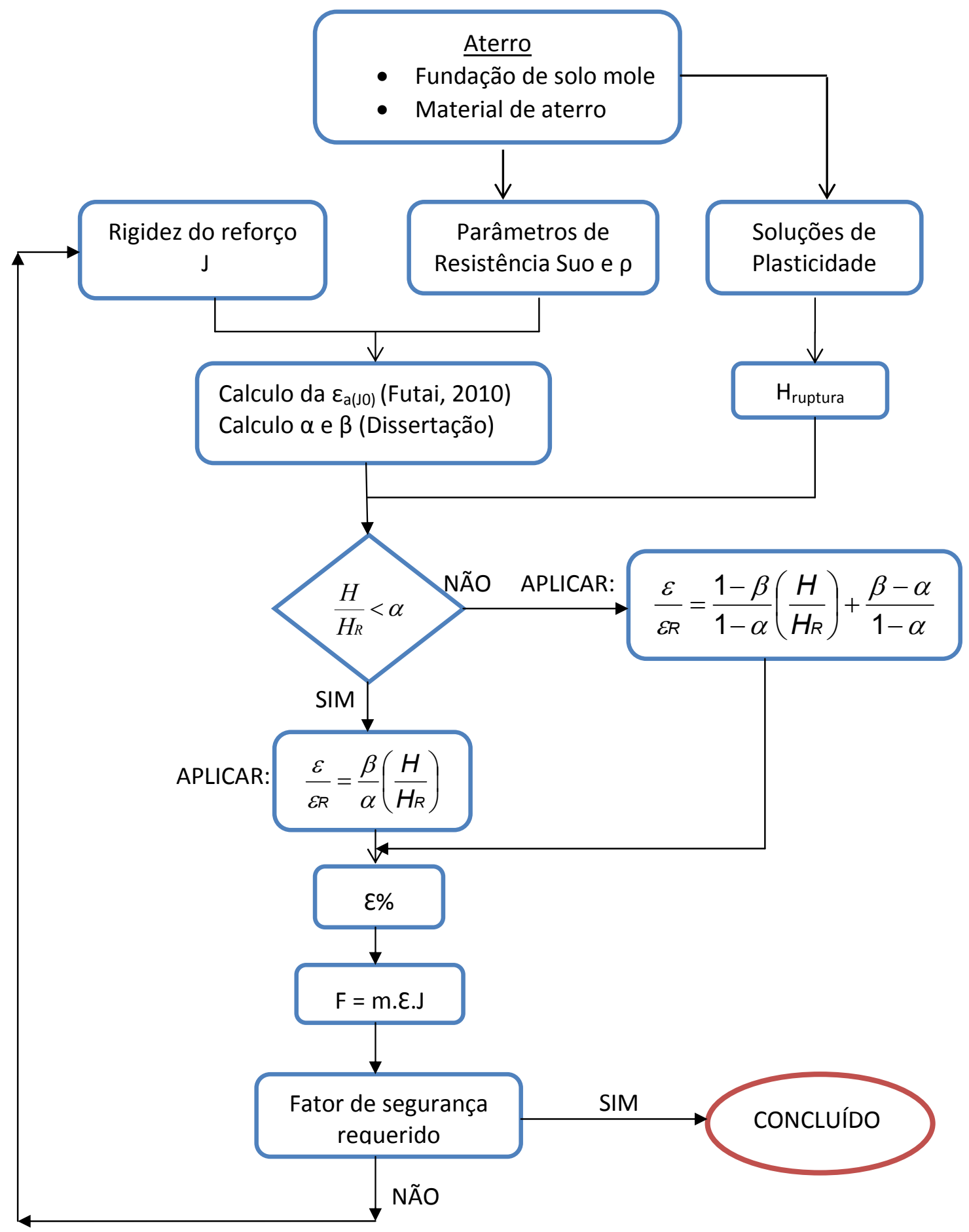

MUDAR O VALOR DE J

Figura 5-15 Sequência de utilização da metodologia apresentada. 


\subsection{Aplicação da metodologia proposta}

As soluções lineares apresentadas representam o momento durante e após a plastificação da fundação, e é válida nas condições de trabalho antes da ruptura do aterro. Para demostrar que a equação consegue representar o comportamento real de um aterro serão comparados com casos de aterros reais e simulados no MEF. Para isso, serão coletados dados disponíveis na literatura de aterros reforçados sobre solos moles instrumentados levados a ruptura e antes do rompimento. As literaturas com as informações necessárias para avaliar a metodologia foram: Rowe \& Söderman (1984), Oliveira (2006), Rowe \& Mylleville (1996) e Chai, Miura \& Shen (2002).

Os dados tomados são de aterros construídos e levados à ruptura e um aterro construído em duas etapas para que fosse dissipada a pressão dos poros. No caso do aterro construído em etapas (Rowe \& Mylleville, 1996) foram utilizados os dados do primeiro estágio antes de romper, a altura de ruptura foi obtida pelas soluções de plasticidade e a deformação de compatibilidade na ruptura através da proposta de Futai (2010) para aterros reforçados sobre solos moles e para os casos com presença de areia na fundação. Os dados necessários foram compilados e estão apresentados na Tabela 5-2.

Tabela 5-2 Dados de aterros reforçados sobre solos moles levados à ruptura e sem romper.

\begin{tabular}{|c|c|c|c|c|c|c|}
\hline Referência & $\begin{array}{l}\text { Suo } \\
(\mathrm{kPa})\end{array}$ & $\begin{array}{c}\rho \\
(\mathrm{kPa} / \mathrm{m})\end{array}$ & (Suo $+7,5 \rho)$ & $\begin{array}{c}\text { H colapso } \\
(\mathrm{m})\end{array}$ & $\begin{array}{c}\varepsilon(\%) \\
\text { ruptura }\end{array}$ & $\begin{array}{c}\mathrm{J} \\
(\mathrm{kN} / \mathrm{m})\end{array}$ \\
\hline Rowe e Soderman (1984) & 8 & 0 & 8 & 2,75 & 4,0 & 2000 \\
\hline Oliveira (2006) & 4,8 & 0,6 & 9,3 & 3,71 & $1,08^{*}$ & 1700 \\
\hline Rowe e Mylleville (1996) & 4 & 2 & 19 & $4,3+$ & $4,5^{*}$ & 450 \\
\hline Chai, Miura e Shen (2002) & 4,25 & 1,7 & 17 & 4,3 & 1,25 & 1600 \\
\hline
\end{tabular}

(+) Solução pela teoria da plasticidade

$\left.{ }^{*}\right)$ Modelo Futai (2010)

O primeiro caso aplicado na avaliação do modelo foi o aterro de Almere (Rowe \& Söderman, 1984). Nesse caso, há um excesso de 1\% na deformação do reforço devido à construção de uma barragem de contenção ao inicio da obra, como foi mencionado no Item 2.9.1. 
Os valores medidos in situ e os calculados no modelo são mostrados na Figura 5-16, onde se observa o primeiro e o segundo tramo. Nota-se que existe uma boa correlação do modelo aos valores observados no aterro. Nesses resultados já foi adicionado aquele excesso na deformação do reforço de $1 \%$ devido à barragem de contenção.

O valor constante da resistência com a profundidade na fundação pode gerar uma pequena diferença nos dados da Figura 5-16.

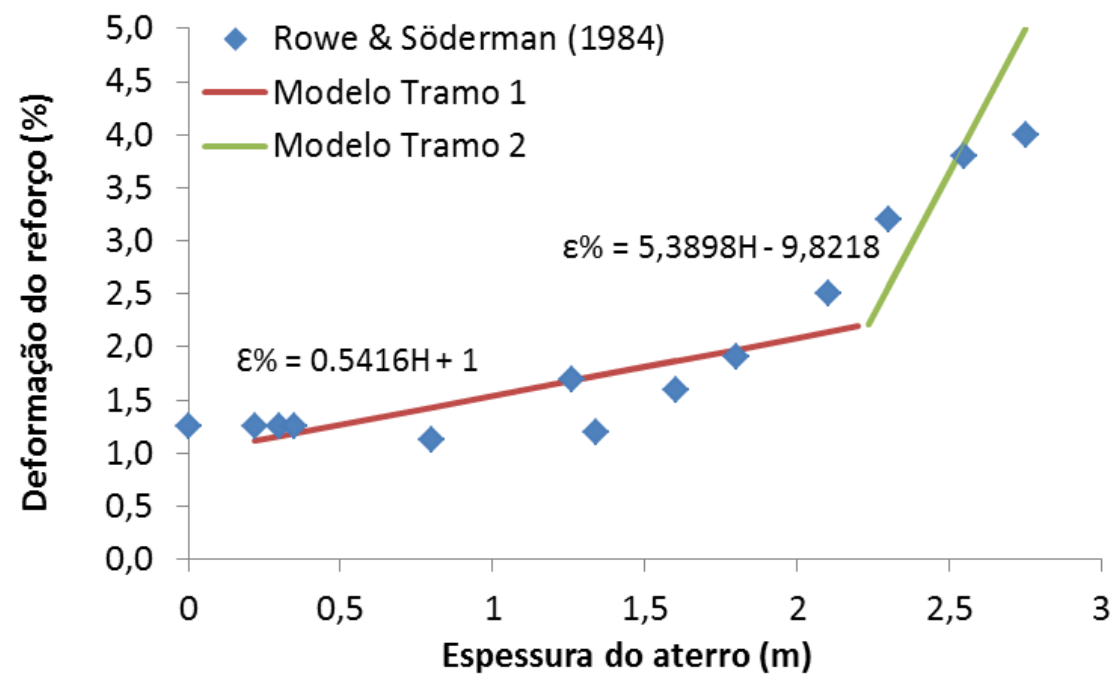

Figura 5-16 Validação do modelo pelo caso de Rowe \& Söderman (1984).

Os dados coletados para o aterro estudado por Rowe \& Mylleville (1996) foram do primeiro estágio I, considerado para dissipar a pressão de poros. Dos dados disponíveis, pode-se calcular deformação do reforço para 1,5m de material de aterro, no fim da construção do estágio I (Figura 2-31). Para completar os dados faltantes de deformação de compatibilidade e altura da ruptura foram calculados mediante a proposta de Futai (2010) e a solução da teoria de plasticidade.

No caso do aterro na China apresentado por Chai et al (2002), levado a ruptura, o aterro rompeu numa altura de 4,3m, com uma deformação $\varepsilon_{a}$ de 2,25\%. Dos dados disponíveis no artigo se tem uma deformação de 1,25\% para uma altura de $3,7 \mathrm{~m}$. O segundo tramo do modelo foi aplicado nesse caso.

Os resultados para ambos os aterros são apresentados na Tabela 5-3. 
Tabela 5-3 Valores de deformação de compatibilidade e altura na ruptura.

\begin{tabular}{l|c|c|c|c}
\hline \multicolumn{1}{c|}{ Referência } & $\begin{array}{c}\mathrm{H} \\
\text { colapso }(\mathrm{m})\end{array}$ & $\begin{array}{c}\varepsilon(\mathrm{a}) \\
\text { ruptura }(\%)\end{array}$ & $\begin{array}{c}\varepsilon(\%) \\
\text { medido }\end{array}$ & $\begin{array}{c}\varepsilon(\%) \\
\text { calculado }\end{array}$ \\
\hline Rowe e Mylleville (1996) & $4,3+$ & $4,43^{*}$ & 0,13 & 0,124 \\
\hline Chai, Miura e Shen (2002) & 4,3 & 2,25 & 1,25 & 1,51 \\
\hline
\end{tabular}

(+) Solução pela teoria da plasticidade

$\left(^{*}\right)$ Modelo Futai (2010)

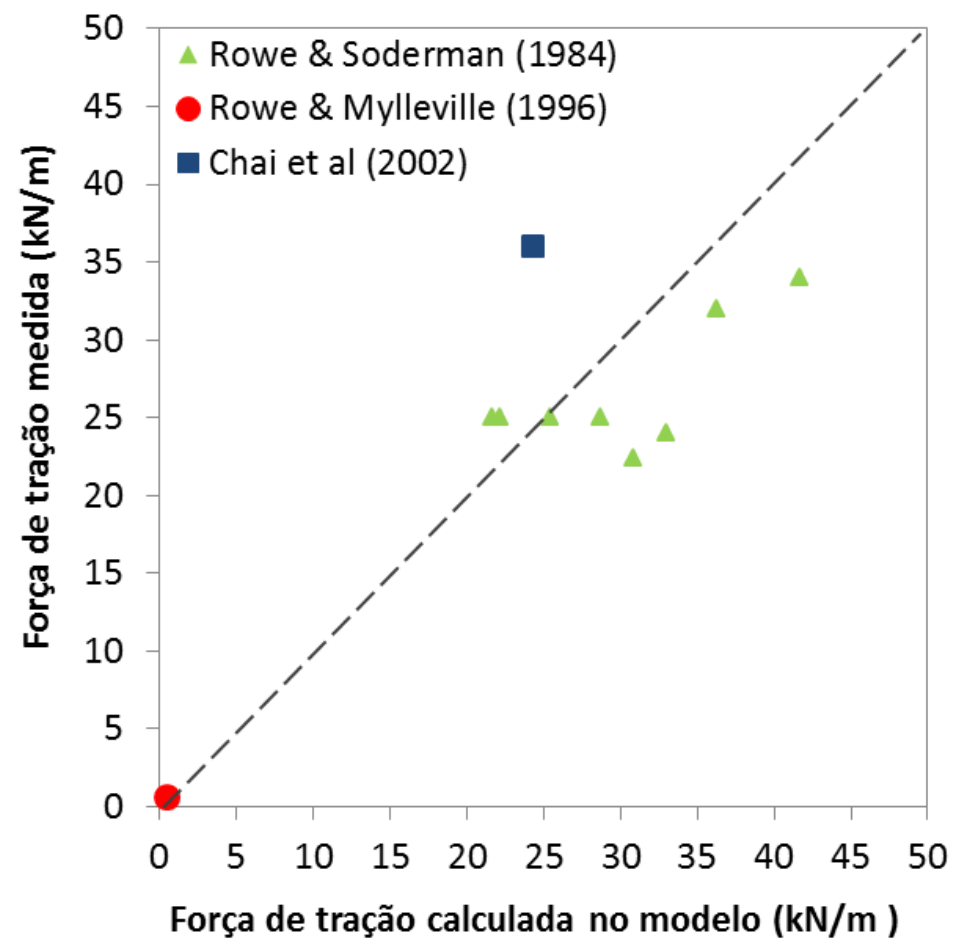

Figura 5-17 Comparação entre as forças de tração do reforço calculadas e medidas.

Os valores calculados da força de tração do reforço, empregando o modelo proposto nesta dissertação, para calcular as deformações foram comparados com os valores medidos in situ dos aterros apresentados. Os resultados apresentados para ambos os aterros mostram boa concordância no valor da deformação calculada pelo modelo proposto. 


\subsection{Aterros reforçados sobre solos moles com uma camada superficial de areia}

Como foi observado no Capitulo 4, a presença de uma camada superficial de areia tem influência na interação solo-reforço, provocando uma diminuição nas deformações do reforço, nos deslocamentos horizontais e ainda um aumento na altura.

Futai (2010) concluiu que a metodologia para calcular a deformação de compatibilidade apresentada por ele não podia ser aplicada diretamente a um solo com camada superior de areia. E assim foi adicionado um fator para corrigir o efeito da camada de areia na deformação de compatibilidade.

Através dos dados desta dissertação foi elaborado um gráfico (Figura 5-18) para comparar as espessuras da camada de areia com as deformações de compatibilidade do reforço $\varepsilon_{a(J 0)}$ e $\varepsilon_{a(J 12000)}$, as deformações são reduzidas com o aumento da espessura da camada de areia.

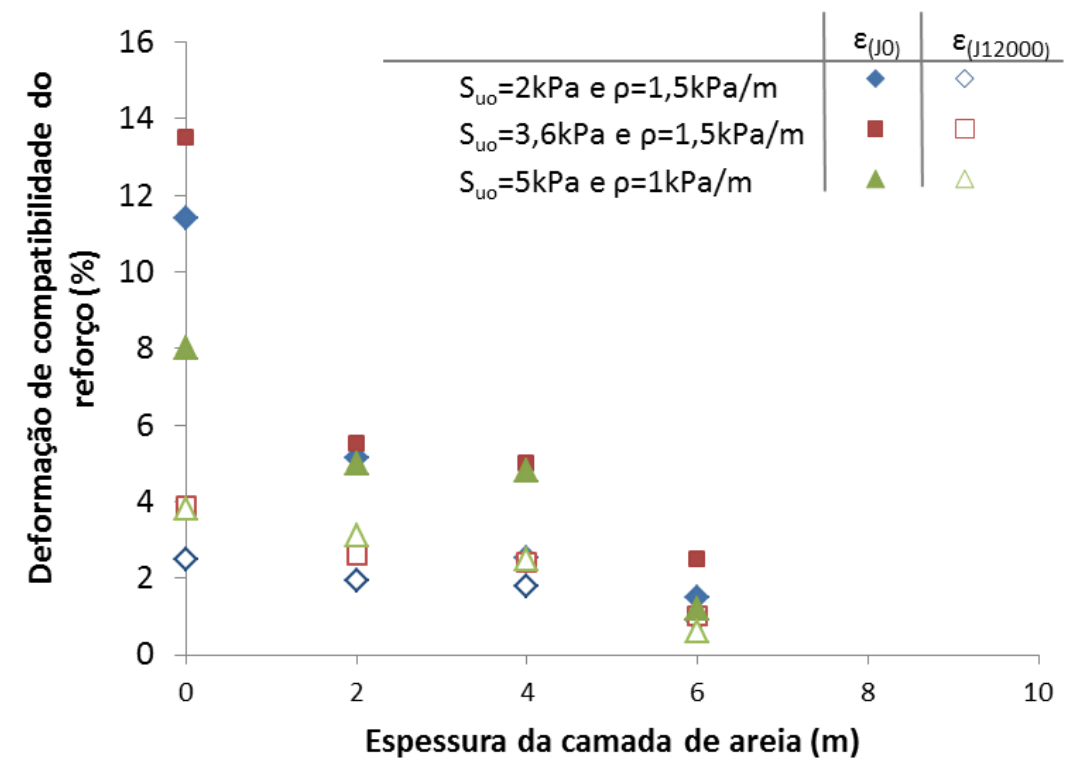

Figura 5-18 Variação das deformações de compatibilidade com a espessura da camada de areia.

No cálculo da proporção da redução da deformação foi elaborada a Figura 5-19 e foram usados os dados obtidos das análises MEF e complementados com os dados apresentados por Futai (2010). 


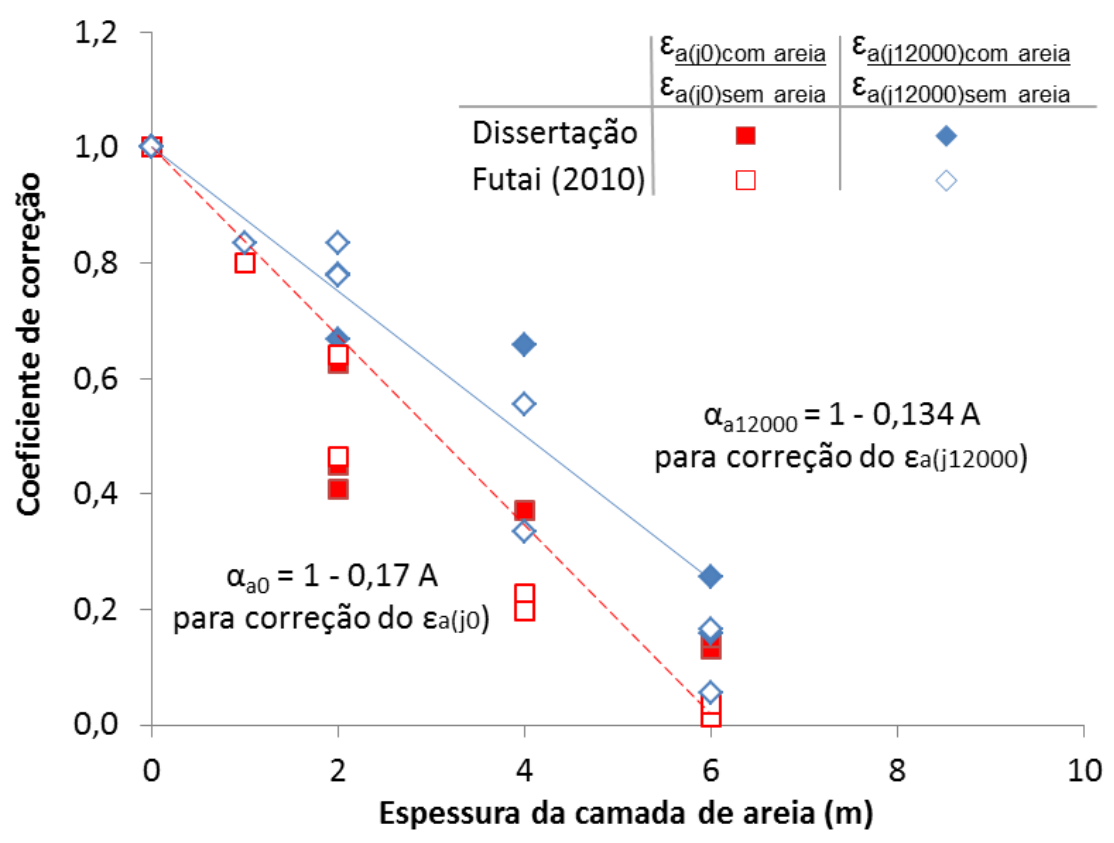

Figura 5-19 Fator de correção devido à presença da camada de areia $\alpha_{\mathrm{a}}$.

Da relação entre as deformações de compatibilidade com e sem camada de areia foram traçadas duas retas para encontrar a relação designada de Fator de correção $\alpha_{a o}$ por Futai (2010).

Os fatores de redução propostos nessa dissertação podem ser calculados mediante as seguintes expressões:

$$
\begin{aligned}
& \alpha_{a o}=1-0,17 \mathrm{~A} \\
& \alpha_{a 12000}=1-0,13 \mathrm{~A}
\end{aligned}
$$

A correção é válida para espessuras de camada de areia até $6 \mathrm{~m}$.

Para avaliar o modelo e o fator de correção apresentado, estes foram aplicados a um caso de aterro reforçado sobre solo mole com uma camada superficial de areia de 1,8m; o aterro AE2 dos aterros experimentais levados à ruptura de Oliveira (2006).

Através dos dados de esforços à tração providos da instrumentação com células de carga instaladas no aterro foi avaliado o modelo proposto para aterros reforçados, mostrado na Figura 5-20.

A Figura 5-20 mostra os diferentes casos da aplicação do modelo, o primeiro é aplicado diretamente com os dados disponíveis. Além disso, foi aplicado o fator 
de correção pela presença de areia e o terceiro caso mostra uma variação empregando a deformação de compatibilidade da proposta do Futai (2010).

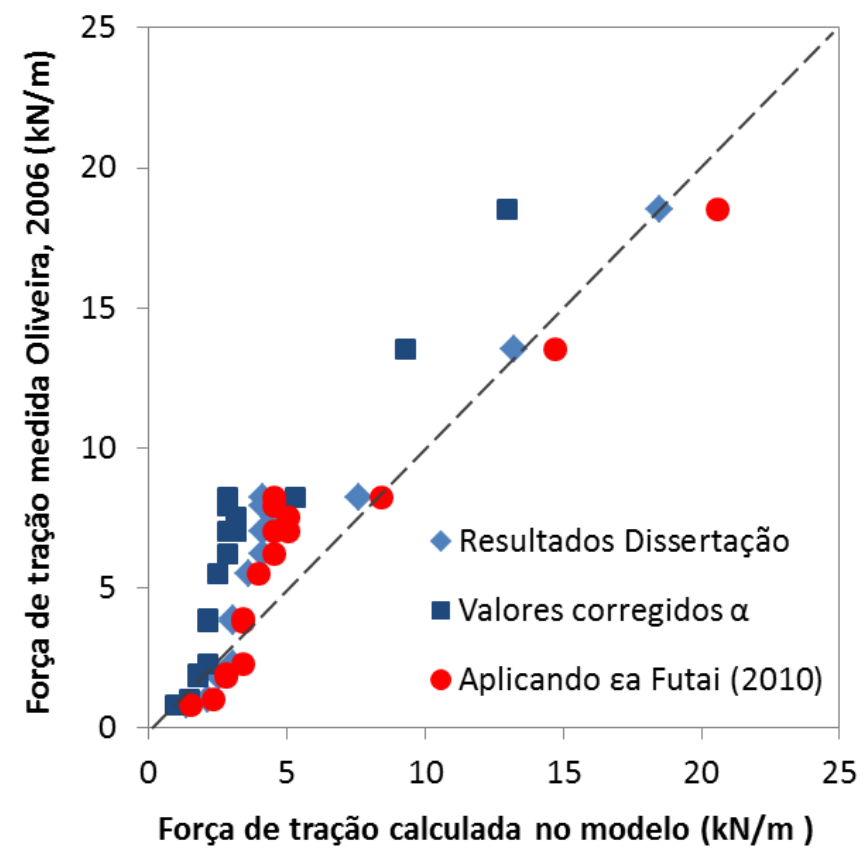

Figura 5-20 Comparação entre as forças de tração do reforço calculadas e medidas.

No primeiro caso as tensões calculadas mediante o modelo proposto estão bem próximas dos valores medidos.

No caso onde foi aplicado um Fator de correção $\alpha$ a, por apresentar uma camada de areia, foi realizado um ajuste pela presença da areia mediante a equação 5.9 .

O fator de correção para a deformação admissível é:

$\alpha_{a o}=1-0,17 \mathrm{~A}=1-0,19 \times 1,8=0,694$

Deformação $\varepsilon_{a}=1,1 \%$

Valor corregido da deformação: 0,694 x 1,1 = 0,763\%

O modelo foi aplicado mudando os dados de deformação de compatibilidade na ruptura, a qual foi calculada pela proposta de Futai (2010) incluindo o ajuste devido à presença da camada de areia $\alpha$ a. 
A deformação de compatibilidade corrigida foi de $1,2 \%$, e mediante a expressão:

$\varepsilon_{a(J 0)}=\alpha_{a o}\left(0,8+\left(c_{o}+7,5 \rho_{c}\right) / 9\right)=0,66 \times 1,1=1,2 \%$

Os valores corrigidos com essa proposta estão mais próximos aos dados coletados da literatura.

Com base nos resultados obtidos é possível utilizar os modelos apresentados para calcular a deformação no reforço para uma altura definida do aterro antes de atingir a ruptura, e assim dimensionar o reforço e avaliar a estabilidade.

\subsection{Comparação dos resultados}

A metodologia apresentada nessa dissertação foi aplicada para dimensionar o reforço num exemplo de aterro, os resultados foram corroborados com o Método de Rowe e Hinchberger (2003) e Metodo de Low et al. (1990)

Um aterro com 3,5m de altura e inclinação de $2 \mathrm{H}: 1 \mathrm{~V}$ e $30 \mathrm{~m}$ de largura da crista deve ser construído sobre um depósito de $20 \mathrm{~m}$ de espessura de argila mole.

Parâmetros da argila mole

$\mathrm{S}_{\mathrm{uo}}=5 \mathrm{kPa}$ e $\mathrm{P}=2 \mathrm{kPa} / \mathrm{m}$

Peso especifico do aterro $20 \mathrm{kN} / \mathrm{m}^{3}$

\subsubsection{Procedimento proposto para determinar a rigidez do reforço}

Aplicado o modelo proposto nesta dissertação para o cálculo de $\mathrm{J}, \circ$ fluxograma pode ser empregado criando uma folha de cálculo para encontrar a rigidez do reforço $\mathrm{J}$.

A princípio, pela avaliação da estabilidade do aterro reforçado, numa análise pelo método de equilíbrio limite, verificou-se que a força necessária no reforço para suportar o aterro de $3,5 \mathrm{~m}$ é $\mathrm{Tr}=125 \mathrm{kN} / \mathrm{m}$ para um $\mathrm{FS}=1,2$.

Calculou-se, variando os valores de $\mathrm{J}$ e obtendo a deformação para uma altura determinada de $3,5 \mathrm{~m}$.

-Para um J=3500 kN/m

$\left(S_{u o}+7,5 \rho\right)=5+7,5^{\star} 2=20 \mathrm{kPa}$ 


$$
\begin{aligned}
& \alpha=-0,0196\left(S_{\text {uо }}+7,5 \rho\right)+0,9685=-0,0196(20)+0,9685=0,577 \\
& \beta=0,00002 J-0,021139\left(S_{\text {uо }}+7,5 \rho\right)+0,425063= \\
& 0,00002(3500)-0,021139(20)+0,425063=0,149
\end{aligned}
$$

-Calculo da deformação admissível de compatibilidade (Futai 2010)

Para $\mathrm{J}>3000 \mathrm{kN} / \mathrm{m}$

$\varepsilon_{a}=\varepsilon_{a}(J 0)-\left(\varepsilon_{a}(J 0)-\varepsilon_{a}(J 12000)\right)(0,00011 J-0,3)$

Para $\mathrm{S}_{\mathrm{uo}}+7,5 \rho_{\mathrm{c}}>16,2 \mathrm{kPa}$

$\varepsilon_{a(J O)}=0,9\left(c_{o}+7,5 \rho_{c}\right)-11,98=6,02$

$\mathrm{S}_{\mathrm{uo}}+7,5 \rho_{\mathrm{c}}>18 \mathrm{kPa}$

$\varepsilon_{a(J 12000)}=0,5\left(c_{o}+7,5 \rho_{c}\right)-7=3$

$\varepsilon_{a}=5,8 \%$

-Calculo da altura do aterro perfeitamente reforçado

$\mathrm{H}_{\mathrm{u}}=4,8 \mathrm{~m}$.

$\frac{H}{H_{u}}>\alpha$ usar o segundo tramo do modelo: $\frac{\varepsilon}{\varepsilon R}=\frac{1-\beta}{1-\alpha}\left(\frac{H}{H_{R}}\right)+\frac{\beta-\alpha}{1-\alpha}$

Substituindo valores

$\varepsilon_{a}=2,5855 \mathrm{H}-6,64701$

para $\mathrm{H}=3,5 \mathrm{~m}$ a deformação no reforço é de $\varepsilon_{a}=2,402 \%$

A tensão mobilizada que produz essa deformação do reforço é de $T=m$. $\varepsilon_{a} J$ $\mathrm{T}_{\text {mob }}=0,02402 \times 3500=84,1 \mathrm{kN} / \mathrm{m}$

Analisando a estabilidade pelo equilíbrio limite se tem que para essa tensão mobilizada o $\mathrm{FS}=1,162$.

A sequência é repetida até a obtenção de um valor de fator de segurança desejado de 1,2 .

Os resultados são apresentados na Tabela 5-4.

Nos resultados se observa que os valores do fator de segurança por volta de 1,2 foram obtidos empregando nas análises valores de $\mathrm{J}$ na faixa de 4200 a 4350 $\mathrm{kN} / \mathrm{m}$. 
Tabela 5-4 Resultados do fator de segurança aplicando o modelo proposto.

\begin{tabular}{c|c|c|c|c|c|c}
\hline $\begin{array}{c}\mathbf{S}_{\mathrm{uo}} \\
(\mathbf{k P a})\end{array}$ & $\begin{array}{c}\boldsymbol{\rho} \\
\mathbf{( k P a / m )}\end{array}$ & $\begin{array}{c}\mathbf{H} \\
\mathbf{( m )}\end{array}$ & $\begin{array}{c}\mathbf{J} \\
\mathbf{( k N / m )}\end{array}$ & $\begin{array}{c}\boldsymbol{\varepsilon} \\
\mathbf{( \% )}\end{array}$ & $\begin{array}{c}\mathbf{T}_{\text {mob }} \\
(\mathbf{k N} / \mathbf{m})\end{array}$ & $\mathbf{F S}$ \\
\hline & & & 3500 & 2,402 & 84 & 1,16 \\
& & & 3800 & 2,382 & 91 & 1,18 \\
& & & 4000 & 2,369 & 124 & 1,19 \\
5 & 2 & \multirow{2}{*}{3,5} & 4200 & 2,355 & 99 & 1,19 \\
& & & 4350 & 2,344 & 102 & 1,20 \\
& & & 4500 & 2,33 & 133 & 1,21 \\
& & & 5000 & 2,31 & 116 & 1,23 \\
& & & 5500 & 2,25 & 124 & 1,24 \\
\hline
\end{tabular}

Os valores da Tabela 5-4 são mostrados na Figura 5-21, e se observa que para obter o fator de segurança maior ou igual a 1,2 o reforço empregado deve ter um $J_{\min }$ de $4350 \mathrm{kN} / \mathrm{m}$ e para essa altura a deformação e de $2,34 \%$.

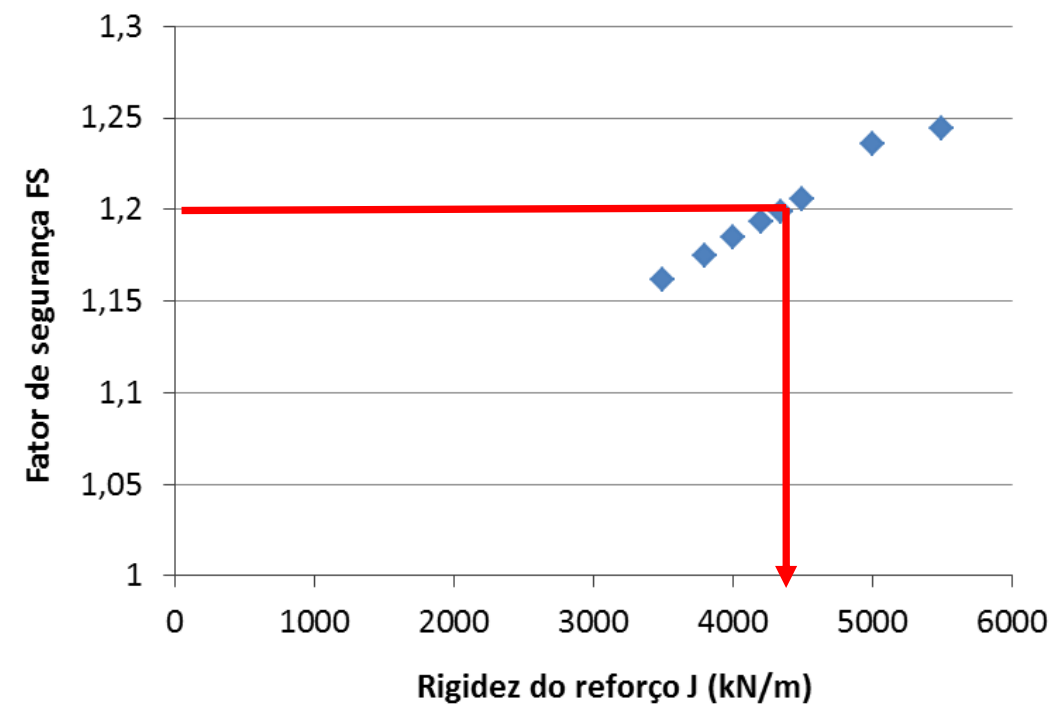

Figura 5-21 Variação do fator de segurança com o aumento da rigidez do reforço J.

\subsubsection{Procedimento de Rowe e Hinchberger (2003) para determinar a rigidez do reforço}

A seguir será empregada a metodologia proposta por Rowe e Hinchberger (2003) para dimensionar o reforço: 
- Parâmetros da resistência da fundação minorados.

Aplicando um fator parcial de PF $=1 / 1,2=0,83$ equivalente a um fator de segurança de 1,2 .

$\mathrm{S}_{\mathrm{uo}}{ }^{*}=\mathrm{PF} \times \mathrm{S}_{\mathrm{uo}}=0,83 \times 5=4,15 \mathrm{kPa}$

$\rho^{*}=P F \times \rho=0,83 \times 2=1,66 \mathrm{kN} / \mathrm{m}$

- Altura de colapso do aterro não reforçado, empregando uma análise de escorregamento circular com os parâmetros minorados, obteve-se a altura de colapso de 2,25m.

- Capacidade de carga para um aterro perfeitamente reforçado baseado na teoria da plasticidade e aplicando os parâmetros minorados da fundação, é estimada uma altura máxima de $3,8 \mathrm{~m}$.

- A deformação admissível para o aterro não reforçado de altura $H_{c}=2,25 m$ e incremento da resistência de $\rho^{*}=1,66 \mathrm{kN} / \mathrm{m}$, empregando o abado de Rowe e Hinchberger (2003) mostrado na Figura 2-18, deu $\varepsilon=6,2 \%$.

- Estabilidade do aterro reforçado, numa análise pelo método de equilíbrio limite com os parâmetros minorados, verificou-se que a força necessária no reforço para suportar o aterro de 3,5m é $\mathrm{Tr}=185 \mathrm{kN} / \mathrm{m}$ para um $\mathrm{FS}=1,2$.

A força requerida no reforço é maior que o indicado no item 5.4.1 onde $T=102$ $\mathrm{kN} / \mathrm{m}$, devido, neste caso, à estabilidade que foi analisada com os parâmetros minorados, e o aterro requer uma força maior por ser uma fundação com parâmetros de resistência menores.

Calculando o fator de correção

$$
\begin{aligned}
& \frac{H-H_{c}}{H_{u}-H_{c}}=\frac{3,5-2,25}{3,8-2,25}=0,8 \\
& \alpha r=1,15 \text { (da Tabela 2-3) } \\
& J_{M I N}=\frac{\alpha r . T_{r}}{\varepsilon_{a}}=\frac{1,15.185}{0,062}=3450 \mathrm{kN} / \mathrm{m} \text { (deformação no intervalo 0-6,2\%). }
\end{aligned}
$$

\subsubsection{Procedimento de Low et al. (1990) para verificar a estabilidade.}

Para um fator de segurança do aterro reforçado de $F_{r}=1,2$

Profundidade por onde passa o circulo critico $Z_{\text {crit }}=2,4$

Obteve-se os números de estabilidade N1 $=4,55, \mathrm{~N} 2=1,5$ e $\lambda=0,275$ e um fator 
de segurança $F o=0,72$ e $I_{R}=0,9$

$T=\left(1-\frac{F_{o}}{F_{r}}\right) \frac{\gamma H 2}{I_{R}}=109,34 \mathrm{kN} / \mathrm{m}$

O valor da tração mobilizada no reforço $\mathrm{T}$ requerido para se ter $\mathrm{um} \operatorname{Fr}=1,2$, a resistência de referência do reforço é dado por:

$T_{\text {ref }} \geq T . f_{m} . f_{m r} . f_{a}=109,34 \times 1,3 \times 1,3 \times 1=184,8 \mathrm{kN} / \mathrm{m}$

Para $\mathrm{J}>3000 \mathrm{kN} / \mathrm{m}$.

$\varepsilon_{a}$ da proposta do Futai (2010) é dado por:

$\varepsilon_{a(J 0)}=6,02 \%$ e $\varepsilon_{a(J 12000)}=3 \%$

$\varepsilon a=6-3(0,00011 \mathrm{~J}-0,3)$

$J=\frac{T}{\varepsilon_{a}}=\frac{184,8}{\varepsilon_{a}=6-3(0,00011 \mathrm{~J}-0,3)}=3154 \mathrm{kN} / \mathrm{m}$

O exemplo faz uma comparação dos valores de $\mathrm{J}$ obtidos mediante métodos diferentes. $\mathrm{O}$ modelo proposto pode ser utilizado para estimar a rigidez do reforço $\mathrm{J}$ e conhecer a tensão mobilizada pelo reforço e a deformação $\varepsilon$ produzida para uma altura dada.

A seguir apresenta se uma tabela comparativa dos resultados empregando a diferente metodologia.

\begin{tabular}{l|c}
\multicolumn{1}{c|}{ Método } & $\begin{array}{c}\text { Rigidez do reforço J } \\
\text { (kN/m) }\end{array}$ \\
\hline Proposto na Dissertação & $4200-4350$ \\
Rowe e Hinchberger (2003) & 3450 \\
Low et al. (1990) & 3154 \\
\hline
\end{tabular}

Num segundo exemplo de um aterro com $2,4 \mathrm{~m}$ de altura e inclinação de $2 \mathrm{H}: 1 \mathrm{~V}$ e $36 \mathrm{~m}$ de largura da crista deve ser construído sobre um deposito de $20 \mathrm{~m}$ de espessura de argila mole.

Parâmetros da argila mole: $\mathrm{S}_{\mathrm{uo}}=3,6 \mathrm{kPa}$ e $\mathrm{P}=1,5 \mathrm{kPa} / \mathrm{m}$

Peso especifico do material de aterro $20 \mathrm{kN} / \mathrm{m}^{3}$

A força necessária no reforço para suportar o aterro de 2,4m para um $\mathrm{FS}=$ 1,3. Calculou-se, variando os valores de $\mathrm{J}$ e obtendo a deformação para uma altura 
determinada de $2,4 \mathrm{~m}$.

-Para um $\mathrm{J}=14,85 \mathrm{kPa}$

$\alpha=-0,0196\left(S_{\text {uо }}+7,5 \rho\right)+0,9685=0,677$

$\beta=0,00002 \mathrm{~J}-0,021139\left(\right.$ S $\left._{\text {ио }}+7,5 \rho\right)+0,425063=0,293$

-Calculo da deformação admissível de compatibilidade (Futai 2010)

Para J>3000 kN/m, $\varepsilon_{a}=1,94 \%$

-Calculo da altura do aterro perfeitamente reforçado $\mathrm{H}_{\mathrm{u}}=3,3 \mathrm{~m}$.

Para $\mathrm{H}=2,4 \mathrm{~m}$ a deformação no reforço é de $\varepsilon_{a}=0,78 \%$ e a tensão mobilizada que produz essa deformação do reforço é de $T_{m o b}=68,4 \mathrm{kN} / \mathrm{m}$ e um $\mathrm{FS}=1,29$.

Tabela 5-5 Resultados do fator de segurança aplicando o modelo proposto.

\begin{tabular}{c|c|c|c|c|c|c}
\hline $\begin{array}{c}\mathbf{S}_{\text {uo }} \\
\mathbf{( k P a )}\end{array}$ & $\begin{array}{c}\mathbf{\rho} \\
(\mathbf{k P a} / \mathbf{m})\end{array}$ & $\begin{array}{c}\mathbf{H} \\
\mathbf{( m )}\end{array}$ & $\begin{array}{c}\mathbf{J} \\
\mathbf{( k N / m )}\end{array}$ & $\begin{array}{c}\boldsymbol{\varepsilon} \\
\mathbf{( \% )}\end{array}$ & $\begin{array}{c}\mathbf{T}_{\text {mob }} \\
\mathbf{( k N / m )}\end{array}$ & $\mathbf{F S}$ \\
\hline & & & 6000 & 0,778 & 47 & 1,21 \\
3,6 & \multirow{2}{*}{1,5} & 2 & 8000 & 0,78 & 62,5 & 1,26 \\
& & & 8500 & 0,781 & 66,4 & 1,28 \\
& & & $\mathbf{8 8 0 0}$ & $\mathbf{0 , 7 8 2}$ & $\mathbf{6 8 , 4}$ & $\mathbf{1 , 2 9}$ \\
\hline
\end{tabular}

Os resultados da Tabela 5-5 são mostrados na Figura 5-22.

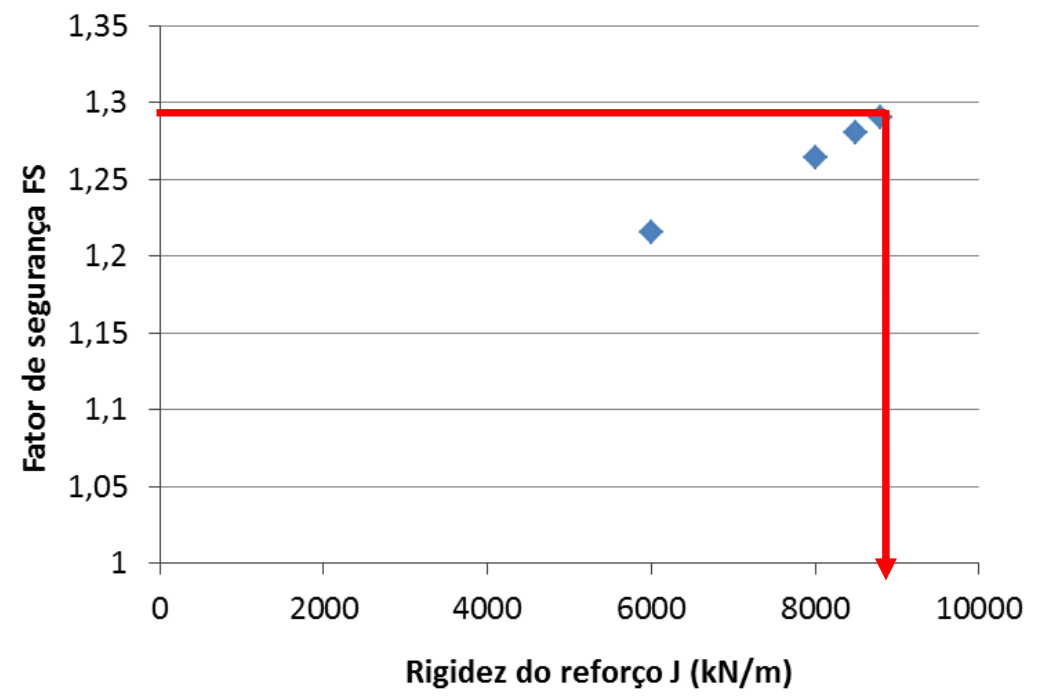

Figura 5-22 Variação do fator de segurança com o aumento da rigidez do reforço J para um aterro Suo $=3,6 \mathrm{kPa}$ e $\rho=1,5 \mathrm{kPa} / \mathrm{m}$

Nesse caso é necessário um reforço $\mathrm{J}>8000 \mathrm{kN} / \mathrm{m}$. A fim de verificar os 
resultados da proposta foi realizada uma análise pelo MEF empregando uma rigidez do reforço de $8800 \mathrm{kN} / \mathrm{m}$, a Figura 5-23 apresenta os resultados da força no reforço para uma altura de $2,4 \mathrm{~m}$.

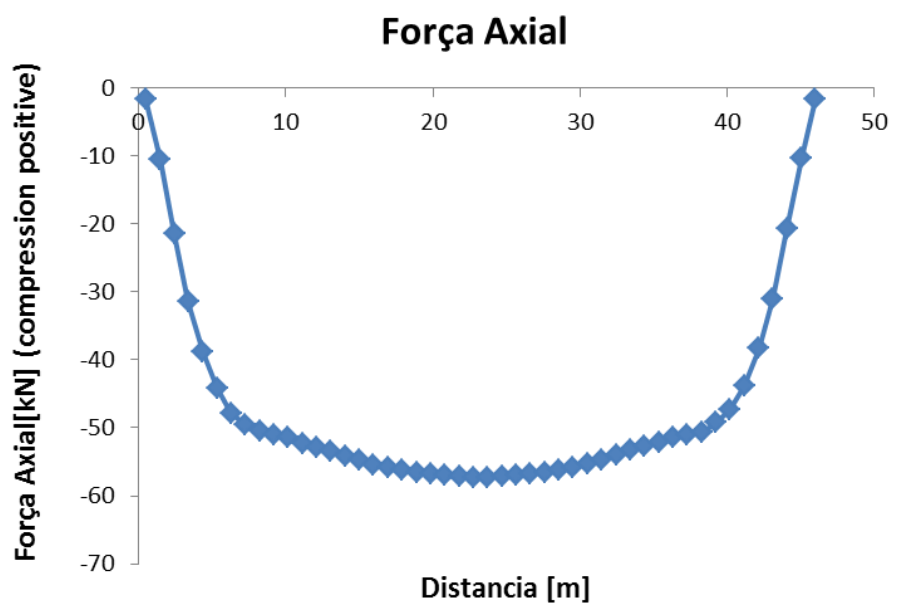

Figura 5-23 Força no reforço pelo MEF para uma rigidez de $\mathrm{J}=8800 \mathrm{kN} / \mathrm{m}$.

A análise dos resultados obtidos com as modelagens numéricas apresenta resultados muito próximos aos resultados calculados de forma analítica.

Para comparar os resultados foi calculada a rigidez do reforço pelo método de Rowe e Hinchberger (2003). Nesse caso os parâmetros da resistência da fundação minorados para um $\mathrm{FS}=1,3$ são $\mathrm{S}_{\mathrm{uo}}{ }^{*}=2,77 \mathrm{kPa}$ e $\rho^{*}=1,155 \mathrm{kN} / \mathrm{m}$.

- Altura de colapso do aterro não reforçado $\mathrm{H}_{\mathrm{c}}=1,36 \mathrm{~m}$.

- Capacidade de carga para um aterro perfeitamente reforçado, $\mathrm{H}_{\mathrm{u}}=2,55 \mathrm{~m}$.

- A deformação admissível para o aterro não reforçado de altura $H_{c}=1,36 m$ e, empregando o ábaco de Rowe e Hinchberger (2003) mostrado na Figura 2-18, deu $\varepsilon=3,6 \%$.

- Estabilidade do aterro reforçado, para uma altura de 2,4m é $\mathrm{Tr}=158 \mathrm{kN} / \mathrm{m}$ para um FS $=1,3$.

Calculando o fator de correção

$\frac{H-H_{c}}{H_{u}-H_{c}}=\frac{2,4-1,36}{2,55-1,36}=0,87$ e $\alpha r=1,4$ (da Tabela 2-3) 
$J_{M I N}=\frac{\alpha r \cdot T_{r}}{\varepsilon a}=\frac{1,4 \cdot 158}{0,036}=6144,4 \mathrm{kN} / \mathrm{m}$ (deformação no intervalo 0-3,6\%).

Observa-se que para este caso os valores da rigidez do reforço são altos.

Por fim, é válido ressaltar que as modelagens permitiram um modelo analítico para calcular a rigidez do reforço e estimar as deformações produzidas para uma altura dada. Uma sugestão para aplicar a metodologia proposta é fazer uma análise de estabilidade e definir a força no reforço necessária para garantir a estabilidade desejada, e assim verificar os resultados. 


\section{CONCLUSÕES E SUGESTÔES PARA TRABALHOS FUTUROS}

Neste capítulo são apresentadas as principais conclusões deste trabalho e algumas sugestões para futuras pesquisas.

$\mathrm{Na}$ presente dissertação logrou-se definir os limites de aplicação da teoria da plasticidade, análise limite e métodos numéricos em aterros reforçados com geossintéticos.

Apresenta-se uma proposta para calcular a deformação no reforço nas condições de trabalho dos aterros reforçados sobre solos moles de resistência não drenada crescente com a profundidade.

Os resultados da calibração do modelo geotécnico comparado com os resultados obtidos da literatura sugerem uma boa calibração do programa, apresentando-se umas algumas diferenças nos valores devido ao critério de ruptura utilizado.

Empregando o método dos elementos finitos, é possível simular os estágios de construção do aterro em solo mole, considerando os deslocamentos e as tensões mobilizadas no reforço. Além de permitir observar a plastificação do solo.

A utilização do conceito da altura líquida admissível (Hinchberger \& Rowe, 2003) foi útil para interpretar os resultados obtidos pelo MEF e, consequentemente, definir a altura de ruptura pela plastificação do solo.

Para os casos analisados os contornos obtidos de deformação permitem definir a forma da superfície de ruptura, tal como foi indicado nas figuras onde aparecem os vetores deslocamento.

Observou-se uma semelhança na geometria do mecanismo de ruptura obtido pelo MEF com a superfície critica circular obtida pela análise de equilíbrio limite.

Nos casos apresentados conseguiu-se analisar a contribuição da rigidez do reforço. O MEF permitiu conhecer a tensão que esta sendo mobilizada no reforço, a qual no pode ser fornecida com as analises por EL.

Observou-se que, quanto maior a rigidez do reforço maior será a força mobilizada, porém as deformações do reforço diminuem. 
Verificou-se a influência da rigidez do reforço na redução dos deslocamentos horizontais e verticais na fundação. As magnitudes dos deslocamentos foram reduzidas notavelmente com o aumento da rigidez.

Os exemplos apresentados pelo MEF demostram que um alto valor do módulo de rigidez do reforço pode melhorar substancialmente a estabilidade do aterro nos casos onde não se tenha influência da espessura da camada de areia.

As deformações do reforço determinadas pelo MEF podem ser usadas para escolher o reforço adequado para um aterro sobre solo mole de resistência crescente com a profundidade.

Nos aterros numa fundação só de argila, as alturas de ruptura dos aterros estão em função da rigidez do reforço.

Conseguiu-se analisar a contribuição na resistência da fundação, da espessura da camada de areia nas deformações.

Com a presença da camada de areia na fundação, as tensões cisalhantes foram menores do que os casos de fundação só de argila. Devido ao deslocamento do mecanismo de ruptura pela presença da areia, as tensões se concentram na parte central da fundação abaixo do corpo do aterro. Em uma fundação só de argila, as tensões se concentravam perto do pé do talude.

Analisando os gráficos dos deslocamentos obtidos, pode-se dizer que a areia aumenta a resistência da fundação e contribui a reduzir os deslocamentos horizontais e verticais.

As deformações significantes no geossintético começam a desenvolver-se com o incremento da plastificação da fundação. A presença da camada de areia faz que a ruptura ocorra com deformações no reforço mais baixas e por isso, a contribuição do reforço seria mais efetiva se fosse utilizado reforços de elevada rigidez. Porém, em todos os casos, há um limite a partir do qual não se consegue mais contribuição do reforço com o aumento da rigidez.

O cálculo de estabilidade por equilíbrio limite é uma ferramenta confiável, porém, é preciso conhecer a deformação admissível de compatibilidade do reforço no momento da ruptura do aterro reforçado ou a força de tração no reforço.

Com a metodologia aplicada, foi possível obter a deformação de compatibilidade do reforço na ruptura, e assim como a força mobilizada no reforço. 
Mediante uma análise de escorregamento foi possível avaliar a estabilidade do aterro.

A través dos resultados dos aterros analisados pelo MEF foi proposta uma metodologia para calcular a deformação do reforço nas condições de trabalho. 0 modelo considera os parâmetros de resistência da fundação e a rigidez do reforço para calcular as deformações.

Os casos empregados na avaliação do modelo foram de aterros levados à ruptura por apresentar maior quantidade de dados disponíveis e, além disso, foi possível empregar alguns casos de aterros antes de romper, completando os dados para a situação de ruptura, utilizando modelos e soluções já existentes. Os resultados obtidos da validação com casos de aterros construídos apresentaram boa concordância.

Com o modelo proposto é possível dimensionar o reforço, para esso é preciso conhecer a força requerida para garantir a estabilidade, e assim é possível obter a deformação produzida no reforço para uma altura dada.

A dissertação mostra que aplicação das soluções baseadas na teoria da plasticidade, as deformações admissíveis do reforço calculadas pelo MEF junto com a análise de equilíbrio limite, podem ser usadas para escolher o reforço adequado para um aterro reforçado sobre solo mole com a resistência crescente com a profundidade.

Aumentando as análises para diferentes valores de $\rho$ e Suo seria possível ampliar a faixa de valores para analisar, sabendo que existem fundações com valores muito altos de $\rho$ e Suo.

Observando a importância da camada de areia seguem algumas sugestões para futuras pesquisas:

Calcular o valor da espessura da camada de areia para a qual o reforço não é mais mobilizado. Além disso, podem ser realizadas análises para fundações com a camada de areia a diferente profundidade.

Considerar o adensamento produzido durante a construção para obter resultados mais próximos aos reais nos estudos de aterros. 


\section{REFERÊNCIAS BIBLIOGRÁFICAS}

ALMEIDA, M. S.S. Aterros sobre solos moles da concepção à avaliação do desempenho. Rio de Janeiro: UFRJ, 1996. 215p.

BATISTA, N. A. Influência da rigidez do reforço em aterros sobre solos moles. 2007. 142p. Dissertação (Mestrado) - ITA, Instituto Tecnológico de Aeronáutica, São José dos Campos, 2007.

BUENO, B. S. Propriedades, Especificações e Ensaios. In: IV Congresso Brasileiro de Geossintéticos e V Congresso Brasileiro de Geotecnia Ambiental, Porto Alegre, RS. Anais do 4o Simpósio Brasileiro de Geossintéticos, 2003. p. 163176.

CAMPOS, S. A. Reforço de aterro sobre solo mole com geossintéticos: comportamento ao longo do tempo. 2003. 151p. Dissertação (Mestrado) Escola Politécnica, Universidade de São Paulo, São Paulo, 2003.

CARDOSO, C. A. Estudos numéricos de aterros estaqueados reforçados com geogrelha. 2009. 216p. Dissertação (Mestrado) - COPPE, Universidade Federal do Rio de Janeiro, Rio de Janeiro, 2009.

CHAl, J. -C., ZHU, H. -H., Behavior of reinforced embankments over soft subsoil. Proc. of Inter. Seminar on Practice and Advance in Geotechnical Engineering, Shanghai, China.

CHAI, J. -C., MIURA, N., SHEN, S. -L. Performance of embankments with and without reinforcement on soft subsoil. Can.Geotech. J. 39: 838-848, 2002.

COMMITTEE ON PLACEMENT AND IMPROVEMENT OF SOILS OF THE GEOTECHNICAL ENGINEERING DIVISION OF THE AMERICAN SOCIETY OF CIVIL ENGINEERS. Soil Improvement, history, capabilities, and outlook. pp. 121-122. New York, USA 1978.

CRISTOPHER, B. R., HOLTZ, R.D., BERG R.R. Geosynthetic reinforced embankments on soft foundations. Proceedings of the United Engineering Foundation, ASCE Geo-Institute Soft Ground Technology Conference 2000, The 
Netherlands. Soft Ground Technology (GSP 112), p. 206-236, 2001.

DANTAS, B. T. Análise do comportamento de estruturas de solo reforçado sob condições de trabalho. 2004. 209p. Tese (Doutorado) - COPPE, Universidade Federal do Rio de Janeiro, Rio de Janeiro, 2006.

DA SILVA, A. F. Análise de estabilidade á ruptura global de aterros sobre solos moles reforçados com geossintéticos considerando os efeitos do tempo. 2003. 160p. Dissertação (Mestrado) - Instituto Tecnológico de Aeronáutica, São José dos Campos, SP, 2003.

ELIAS, V., CHRISTOPHER, B.R., BERG, R.R. Mechanically stabilized earth walls and reinforced soil slopes - Design and construction guidelines", Federal Hwy. Administration Rep. No. FHWA-NHI-00-043, Washington, D.C.

FAHEL, A. R. Desempenho de encontros de ponte reforçados com geogrelhas sobre solos moles. 2003. 247p. Tese (Doutorado) - UnB, Universidade de Brasília, Brasília/DF, 2003.

FORMIGHERI, L. E. Comportamento de um aterro sobre argila mole da Baixada Fluminense. 2003. 182p. Dissertação (Mestrado) - Pontifícia Universidade Católica do Rio de Janeiro, Rio de Janeiro, 2003.

FUERTES, M. A., MONTEZ, F., FUTAI, M. M. Definição dos limites de aplicação da análise de equilíbrio limite e métodos numéricos em aterros reforçados com geossintéticos. In: COBRAMSEG XV, 2010 Gramado. CD-ROM.

FUERTES, M. A., FUTAI, M. M. Estudio numérico de terraplenes reforzados con geosintéticos sobre suelos blandos con una capa de arena. In: Congreso Argentino de Mecánica de Suelos e Ingeniería Geotécnica XX, 2010 Mendoza. Anais XX CAMSIG 2010. p. 259-266.

FUTAI, M. M. Considerações sobre a Influência do Adensamento Secundário e do Uso de Reforços em Aterros sobre Solos Moles. 2010. 197p. Tese (Livre Docência) - Escola Politécnica, Universidade de São Paulo, São Paulo, 2010.

HINCHBERGER, S. D., ROWE, and R. K. Geosynthetic reinforced 
embankments on soft clay foundations: predicting reinforcement strains at failure. Geotextiles and Geomembranes, v. 21, p.151-175, 2003.

HOULSBY G. T., JEWELL, R. A. Analysis of unreinforced embankments on soft clay by plasticity theory. Numerical Methods in Geomechanics, Innsbruck, p. 1443-1448, 1988.

HUMPHREY, D. N., HOLTZ, R. D., Reinforcement embankments- A review of case histories. Geotextiles and Geomembranes, 4, 129-144, 1986.

INGOLD, T.S. Reinforced Earth. Thomas Telford Ltd, Londres, 1982.

INGOLD, T. S. \& MILLER, K.S. Geotextiles Handbook. Londres: Thomas Telford. 1988.

JEWELL, R. A. The mechanics of reinforced embankments on soft soils. Geotextiles and Geomembranes, v. 7, p.237-273, 1988.

JOHN, N.W.M. Geotextiles. New York: Blackie and Son Ltd. 1987.

KOERNER, R. M. Designing with Geosynthetics. 3ed. New Jersey: Prentice Hall, 1994.

MASSAD, F. Obras de Terra. 1. ed. São Paulo: Oficina de Textos, 2003. v.1.170 p.

MASSAD, F. Os Edifícios de Santos e a História Geológica Recente da Baixada Santista. In: V Simpósio de Prática de Engenharia Geotécnica da Região Sul GEOSUL 2006, 2006, Porto Alegre. V Simpósio de Prática de Engenharia Geotécnica da Região Sul GEOSUL 2006, 2006. v. I. p. 1-10.

MASSAD, F. Baixada Santista: Implicações da Historia Geológica no Projeto de Fundações. Solos e Rochas, 22, (1): 3-49, São Paulo, Abril, 1999.

MORAES, C. M. Aterros reforçados sobre solos moles - Análise numérica e analítica. 2002. 223p. Dissertação (Mestrado) - COPPE, Universidade Federal do Rio de Janeiro, Rio de Janeiro, 2002. 
OLIVEIRA, H. M. Comportamento de aterros reforçados sobre solos moles levados á ruptura. 2006. 495p. Tese (Doutorado) - COPPE, Universidade Federal do Rio de Janeiro, Rio de Janeiro, 2006.

OLIVEIRA, H. M., EHRLICH, M., ALMEIDA, M. S. S., Embankments over soft clay deposits: the contribution of basal reinforcement and surface sand layer to stability. ASCE, 260-240.

PALMEIRA, E. M., PEREIRA, J. H. F., SILVA, A. R. L., Back analyses of geosynthetic reinforced embankments on soft soils. Geotextiles and Geomembranes, 16, 273-292, 1998.

PAULSON, J. N., Geosynthetic Material and Physical properties relevant to soil reinforcement applications. Geotextiles and Geomembranes 6, 211-223, 1987.

PINTO, C.S. (1994) Aterros na Baixada, Associação Brasileira de Mecânica dos Solos- Núcleo Regional de São Paulo - ABMS, Brasil, Cap. 10, p. 244-245.

ROCSCIENCE (2005). PHASE2 v.6.0, Theory Manual Rocscience, Toronto, Ontario, Canada.

ROWE, R. K., MYLLEVILLE, B. L. J., A geogrid reinforced embankment on peat over organic silt: a case history. Can.Geotech. J. 33: 106-122, 1996.

ROWE, R. K., HINCHBERGER, S. D., The significance of rate effects in modeling the Sackville test embankment. Can.Geotech. J. 35: 500-516, 1998.

ROWE R. K., SODERMAN K. L. Comparison of predicted and observed behavior of two test embankments, Geotextiles and Geomembranes, Inglaterra, v. 1, p.143-160, 1984.

ROWE, R. K., SODERMAN, K. L. Geotextile reinforcement of embankments on peat. Geotextiles and Geomembranes, Inglaterra, v. 2, p.277-298, 1985.

ROWE, R. K., SODERMAN, K. L. Stabilization of very soft soils using high strength geosynthetics: the role of the Finite Element Analyses. Geotextiles and Geomembranes, v. 6, p.53-80, 1987. 
ROWE, R. K., SODERMAN, K. L. An approximate method for estimating the stability of geotextile - reinforced embankments, Can.Geotech. J., v. 22, p. 392 398, 1985.

ROWE, R. K., LI, A. L., Geosynthetic - reinforced embankments over soft foundations, Geosynthetics International, 12, No. 1, p. 50-84, 2005.

TERZAGHI, K., PECK, R.B., MESRI, G. Article 38 of Soil Mechanics in Engineering Practice. Wiley, New York, 1996, p. 289-290.

SILVA, U. R. Análise do comportamento de aterros reforçados sobre solos moles: um estudo de caso da Rodovia BA-685, Santa Cruz Cabrália, BA. 2008. 204p. Dissertação (Mestrado) - COPPE, Universidade Federal do Rio de Janeiro, Rio de Janeiro, 2008.

SPOTTI, A. P. Aterro estaqueado reforçado instrumentado sobre solo mole. 2006. 394p. Tese (Doutorado) - COPPE, Universidade Federal do Rio de Janeiro, Rio de Janeiro, 2006.

VERTEMATTI, J. C. Coordenador Manual Brasileiro de Geossintéticos. São Paulo: Edgard Blucher, 2004.

WOOD, D. M. Geotechnical Modelling (Applied Geotechnics, vol. 1). Taylor \& Francis, 2004 


\section{APÊNDICE I}

Neste apêndice, são apresentados os resultados das alturas da ruptura e as deformações máximas do reforço, em função da rigidez do reforço à tração $\mathrm{J}$ para diferentes parâmetros da fundação como resistência não drenada na superfície de Suo $=2 \mathrm{kPa}, 3,6 \mathrm{kPa}$ e $5 \mathrm{kPa}$ e aumento de resistência com a profundidade de $\rho=$ $1,5 \mathrm{kPa} / \mathrm{m}$ a $2 \mathrm{kPa} / \mathrm{m}$. 

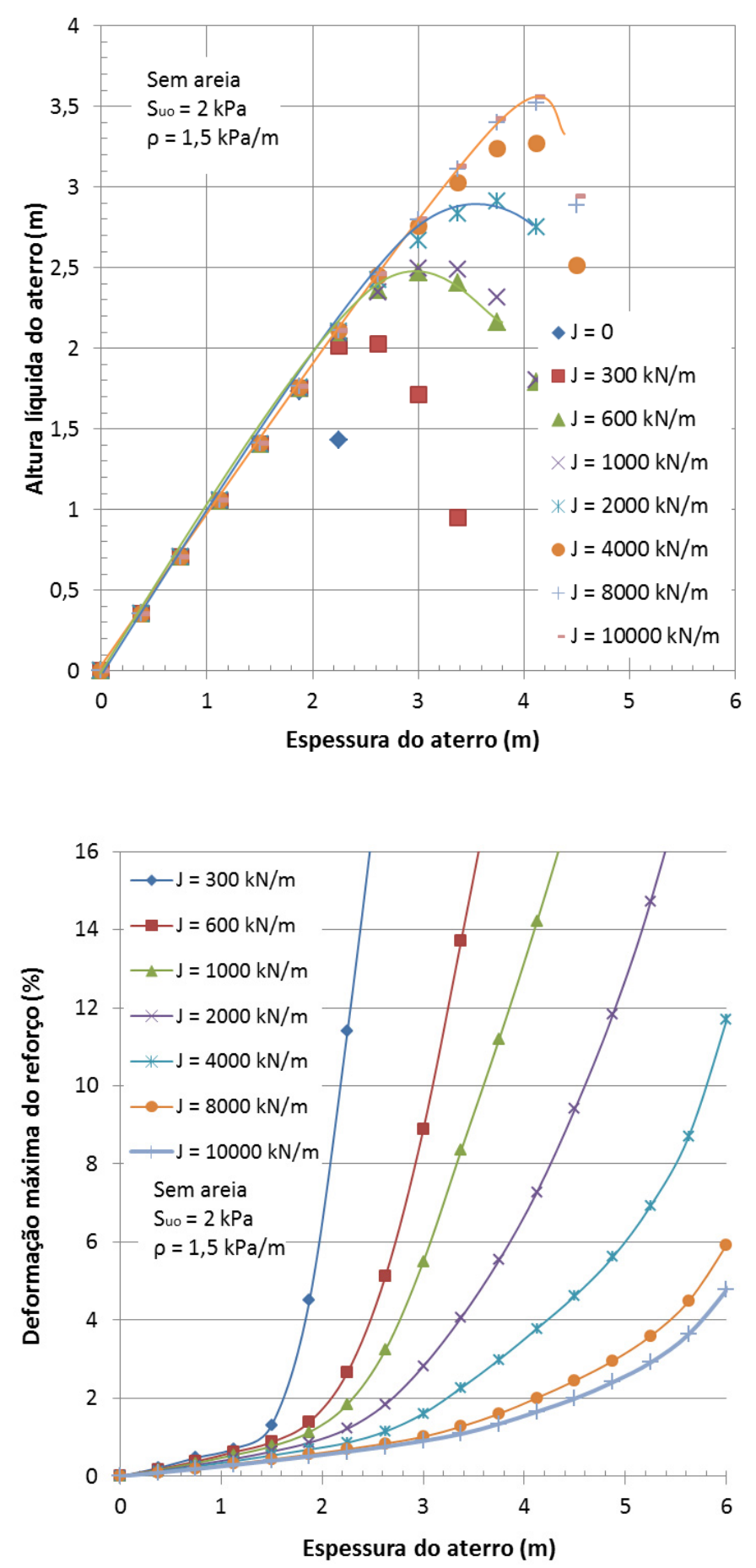

Figura l-1 Alturas de ruptura e deformações máximas do reforço com o aumento da rigidez do reforço $\mathrm{J} \mathrm{kN} / \mathrm{m}$ para uma fundação sem areia de $\mathrm{Suo}=2$ $\mathrm{kPa}$ e $\rho=1,5 \mathrm{kPa} / \mathrm{m}$. 

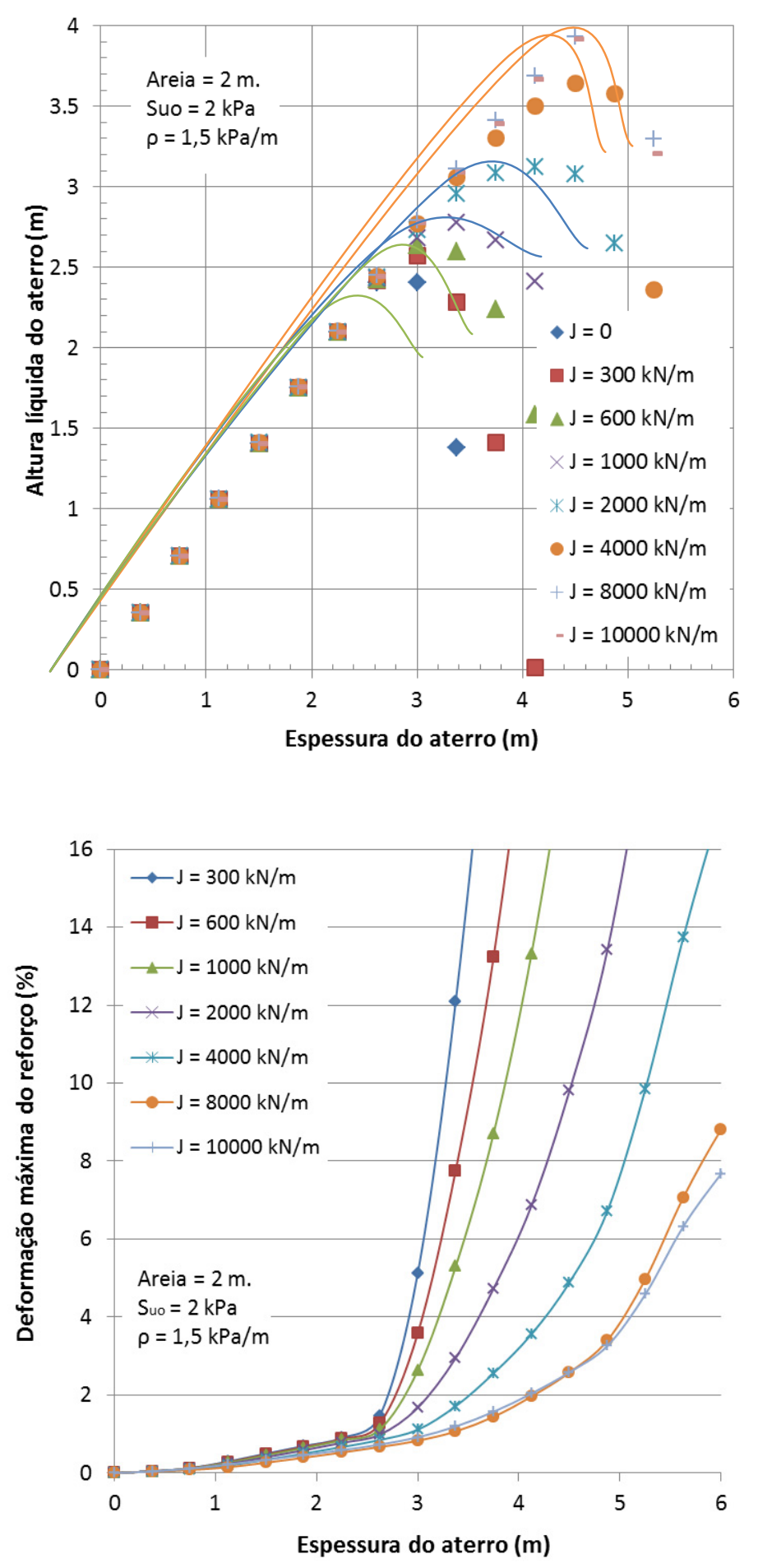

Figura l-2 Alturas de ruptura e deformações máximas do reforço com o aumento da rigidez do reforço $\mathrm{J} \mathrm{kN} / \mathrm{m}$ para uma fundação de $\mathrm{Suo}^{2}=2 \mathrm{kPa} e$ $\rho=1,5 \mathrm{kPa} / \mathrm{m}$ com $2 \mathrm{~m}$ de areia. 

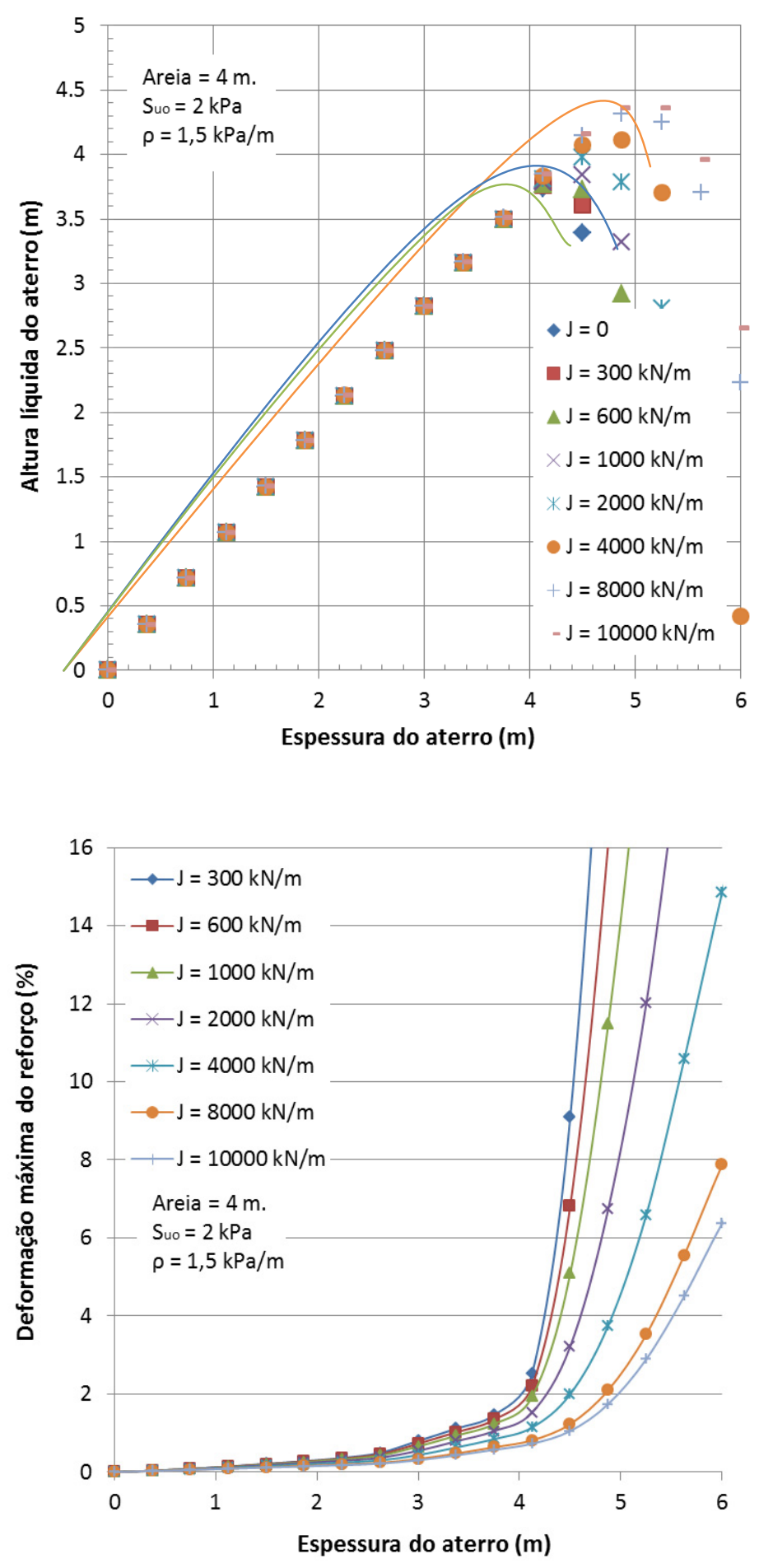

Figura l-3 Alturas de ruptura e deformações máximas do reforço com o aumento da rigidez do reforço $\mathrm{J} \mathrm{kN} / \mathrm{m}$ para uma fundação de $S_{u o}=2 \mathrm{kPa} e$ $\rho=1,5 \mathrm{kPa} / \mathrm{m}$ com $4 \mathrm{~m}$ de areia. 

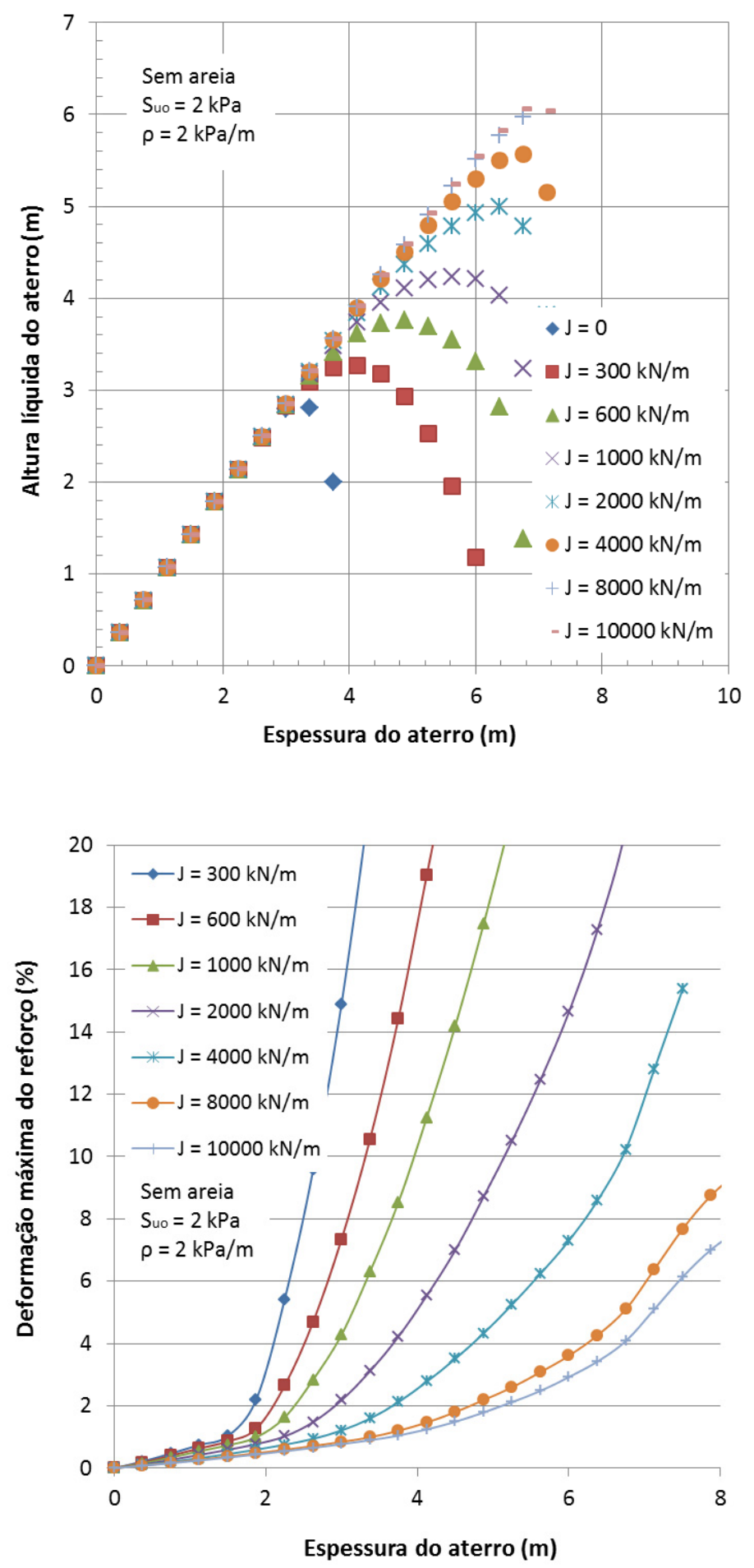

Figura l-4 Alturas de ruptura e deformações máximas do reforço com o aumento da rigidez do reforço $\mathrm{J} \mathrm{kN} / \mathrm{m}$ para uma fundação sem areia de $\mathrm{Suo}=2$ $\mathrm{kPa}$ e $\rho=2,0 \mathrm{kPa} / \mathrm{m}$. 

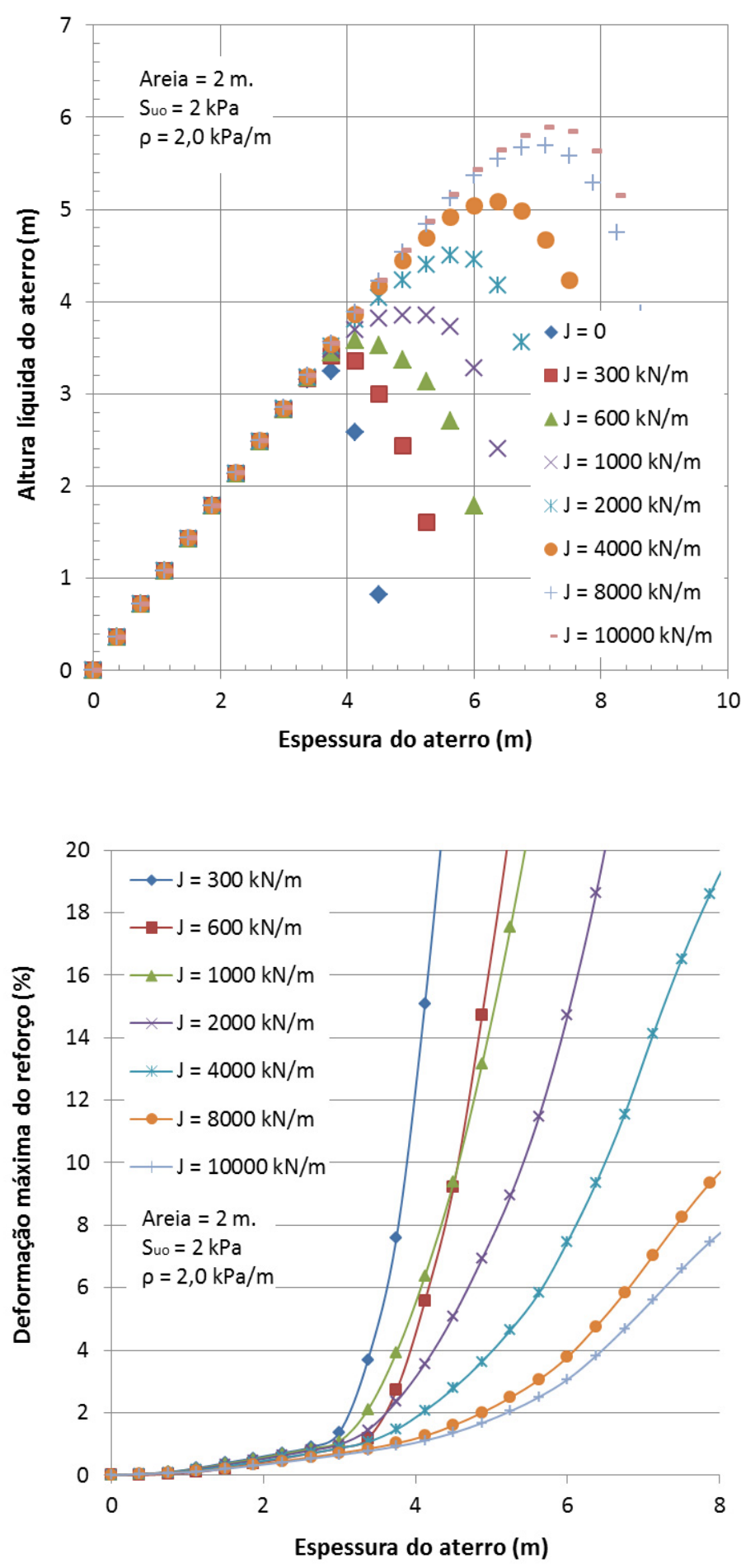

Figura l-5 Alturas de ruptura e deformações máximas do reforço com o aumento da rigidez do reforço $\mathrm{J} \mathrm{kN} / \mathrm{m}$ para uma fundação de $\mathrm{Suo}=2 \mathrm{kPa} e$ $\rho=2,0 \mathrm{kPa} / \mathrm{m}$ com $2 \mathrm{~m}$ de areia. 

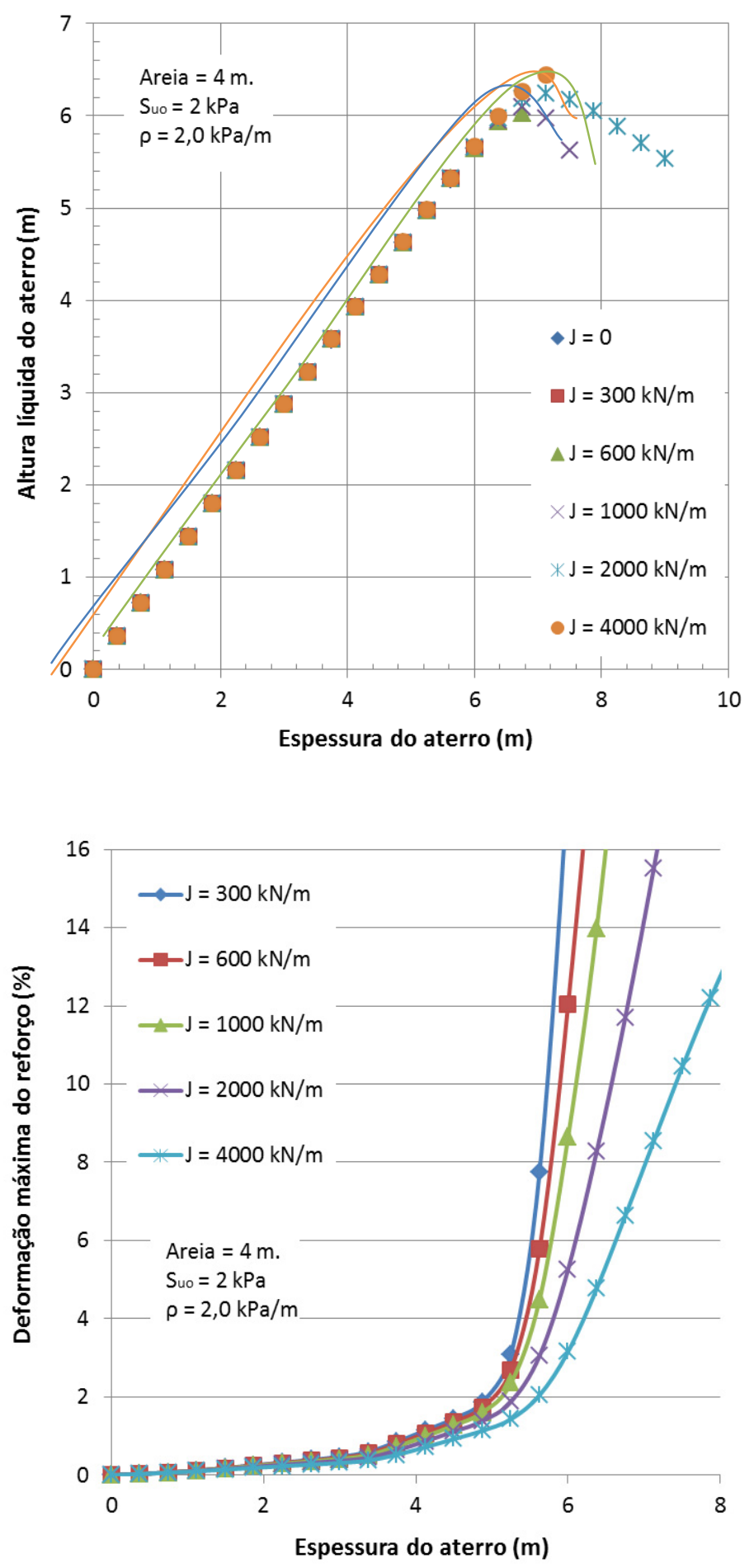

Figura l-6 Alturas de ruptura e deformações máximas do reforço com o aumento da rigidez do reforço $\mathrm{J} \mathrm{kN/m}$ para uma fundação Suo $=2 \mathrm{kPa}$ e $\rho=2,0$ $\mathrm{kPa} / \mathrm{m}$ com $4 \mathrm{~m}$ de areia. 

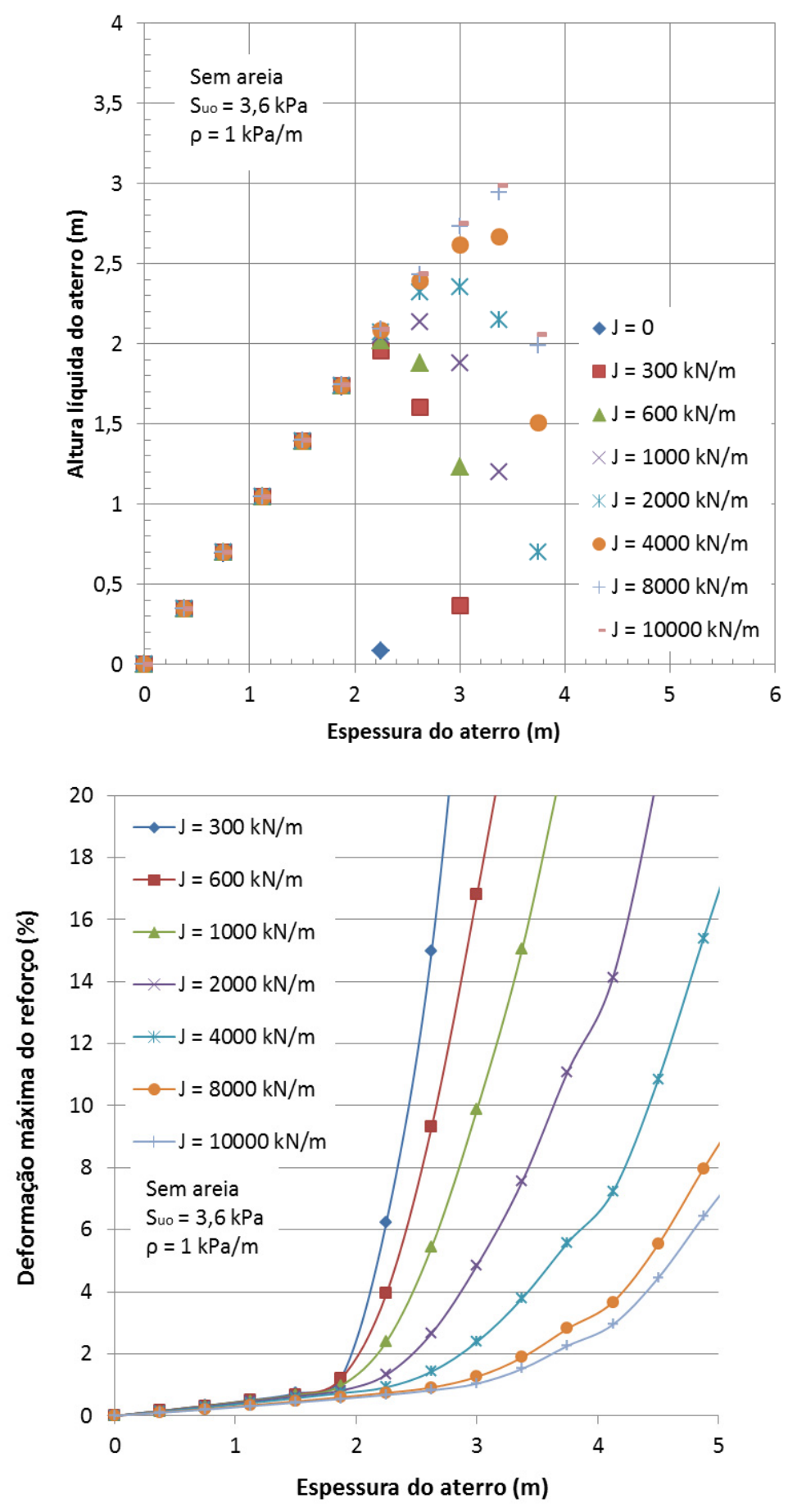

Figura l-7 Alturas de ruptura e deformações máximas do reforço com o aumento da rigidez do reforço $\mathrm{J} \mathrm{kN/m}$ para uma fundação sem areia de $S_{u o}=3,6 \mathrm{kPa}$ e $\rho=1,0 \mathrm{kPa} / \mathrm{m}$. 

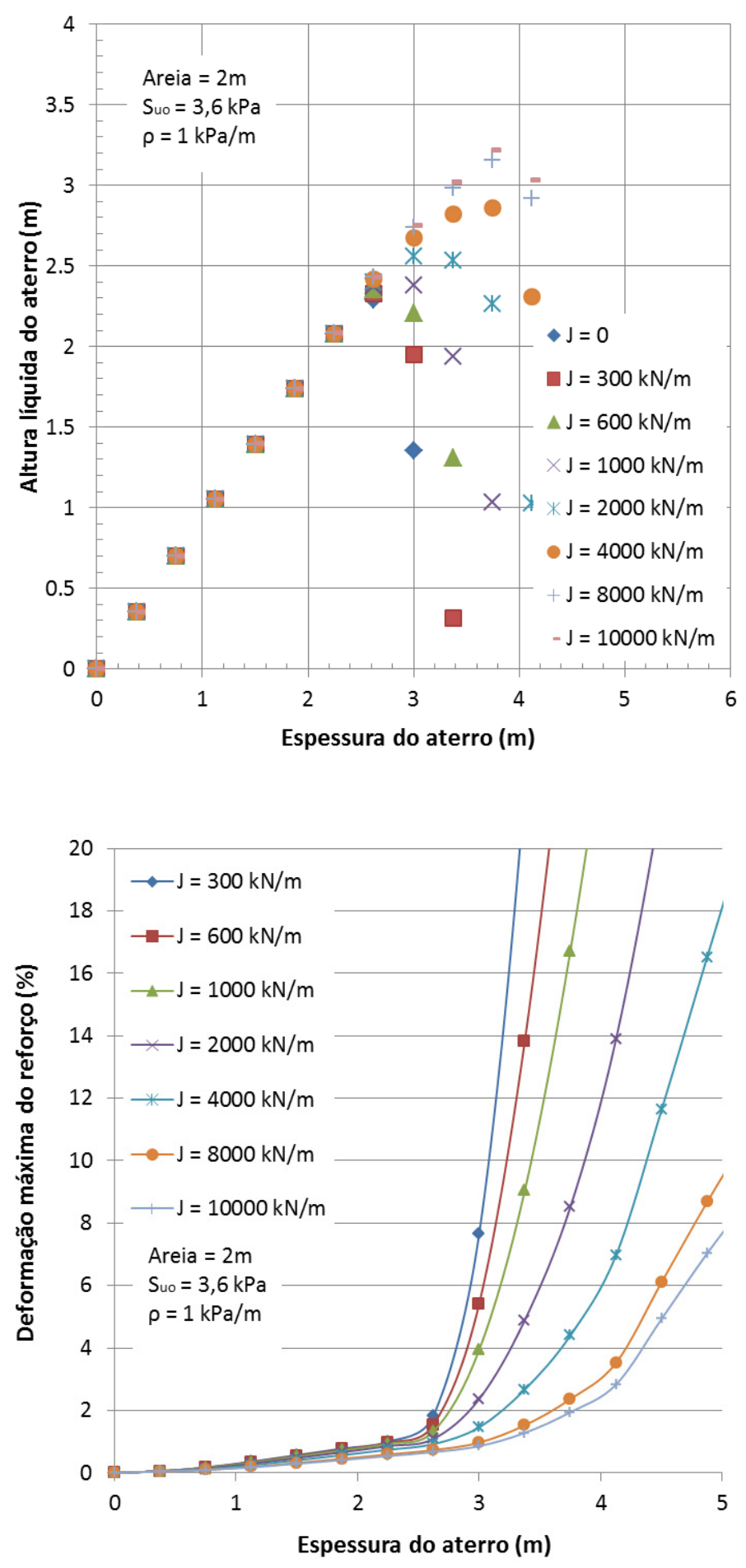

Figura l-8 Alturas de ruptura e deformações máximas do reforço com o aumento da rigidez do reforço $\mathrm{J} \mathrm{kN/m}$ para uma fundação de Suo $=3,6 \mathrm{kPa} e$ $\rho=1,0 \mathrm{kPa} / \mathrm{m}$ com $2 \mathrm{~m}$ de areia. 

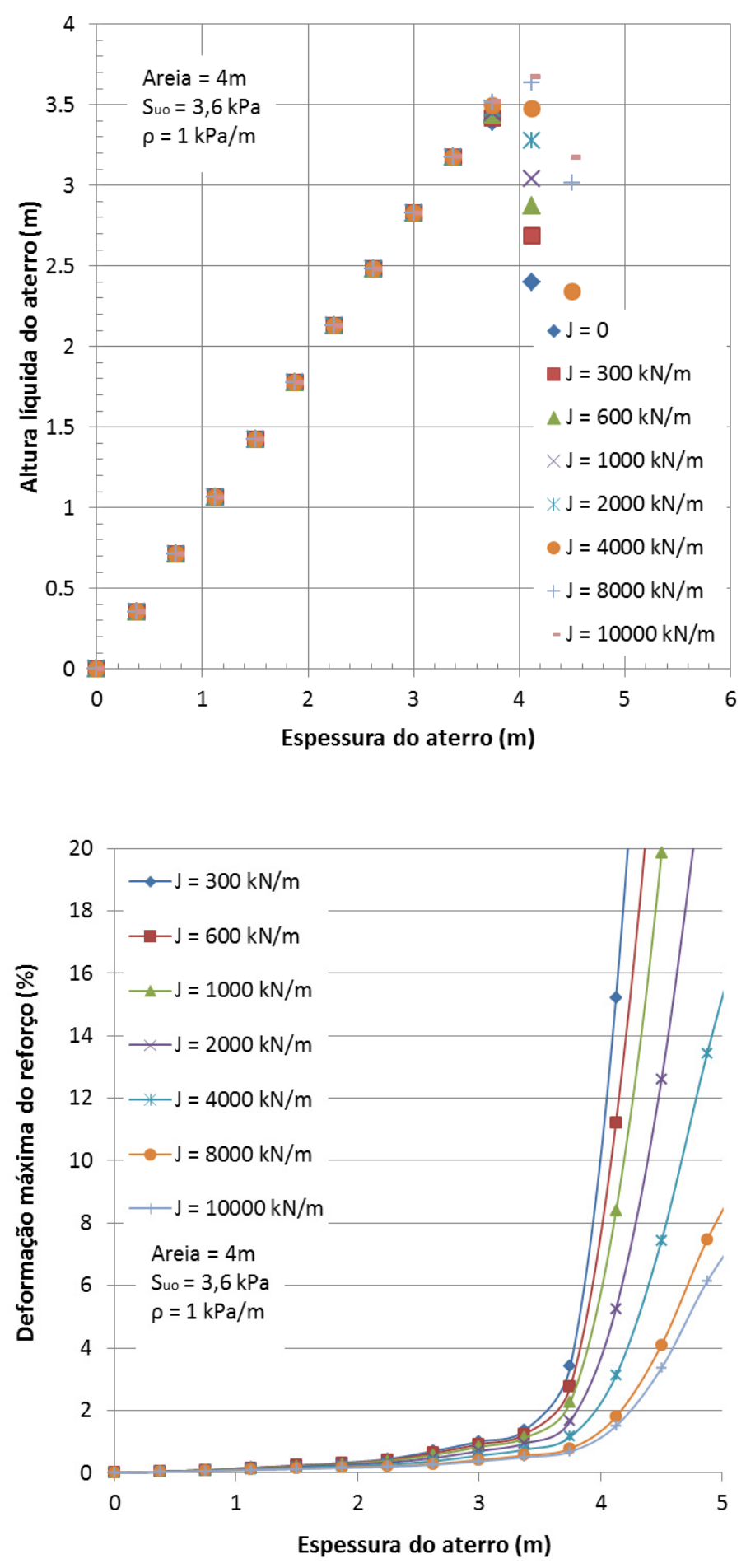

Figura I-9 Alturas de ruptura e deformações máximas do reforço com o aumento da rigidez do reforço $\mathrm{J} \mathrm{kN} / \mathrm{m}$ para uma fundação Suo $=3,6 \mathrm{kPa}$ e $\rho=1,0$ $\mathrm{kPa} / \mathrm{m}$ com $4 \mathrm{~m}$ de areia. 

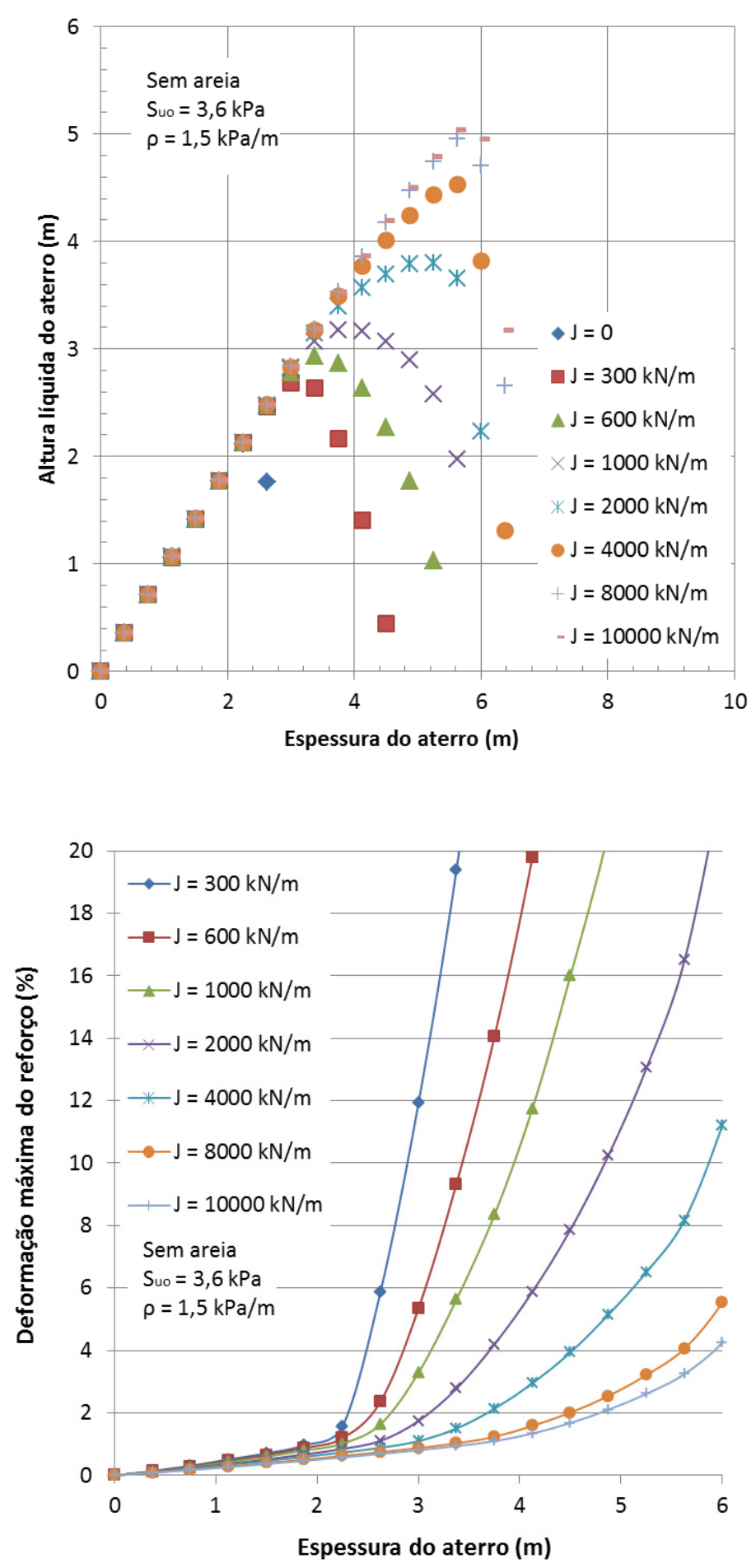

Figura l-10 Alturas de ruptura e deformações máximas do reforço com o aumento da rigidez do reforço $\mathrm{J} \mathrm{kN} / \mathrm{m}$ para uma fundação sem areia de Suo $=3,6 \mathrm{kPa}$ e $\rho=1,5 \mathrm{kPa} / \mathrm{m}$. 

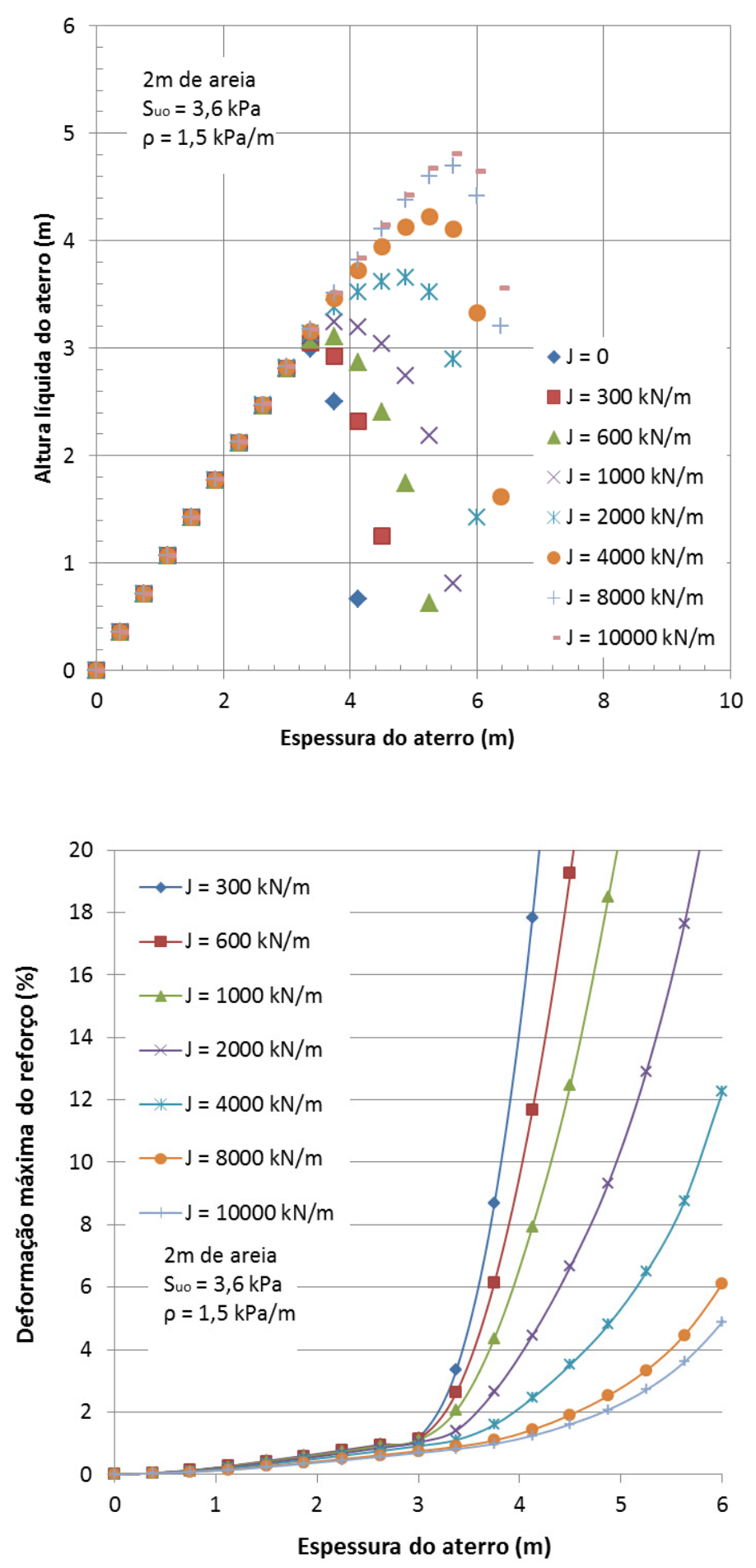

Figura l-11 Alturas de ruptura e deformações máximas do reforço com o aumento da rigidez do reforço $\mathrm{J} \mathrm{kN/m}$ para uma fundação de Suo $=3,6 \mathrm{kPa} e$ $\rho=1,5 \mathrm{kPa} / \mathrm{m}$ com $2 \mathrm{~m}$ de areia. 

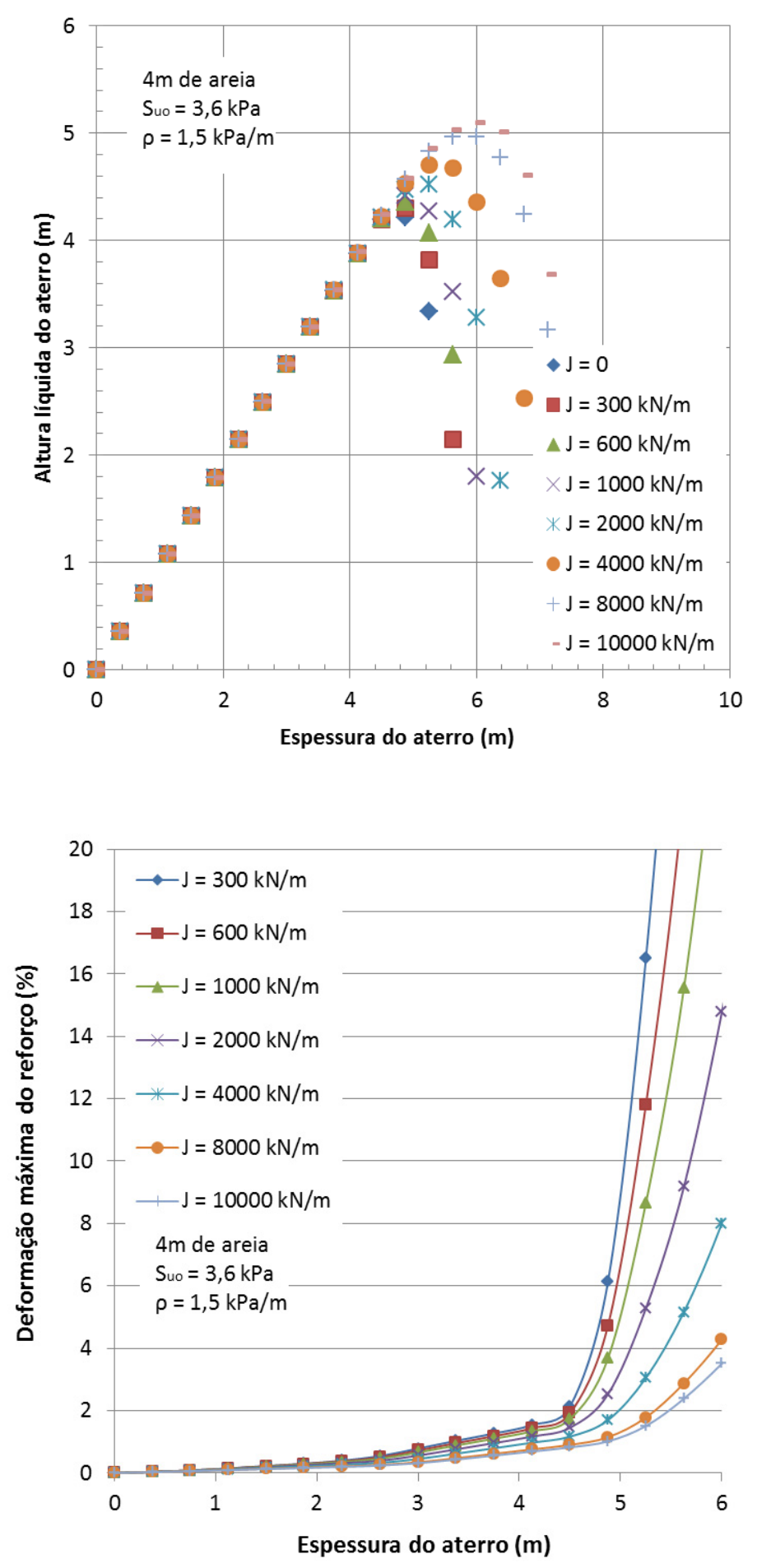

Figura l-12 Alturas de ruptura e deformações máximas do reforço com o aumento da rigidez do reforço $\mathrm{J} \mathrm{kN} / \mathrm{m}$ para uma fundação $\mathrm{Suo}_{\mathrm{o}}=3,6 \mathrm{kPa}$ e $\rho=1,5$ $\mathrm{kPa} / \mathrm{m}$ com $4 \mathrm{~m}$ de areia. 

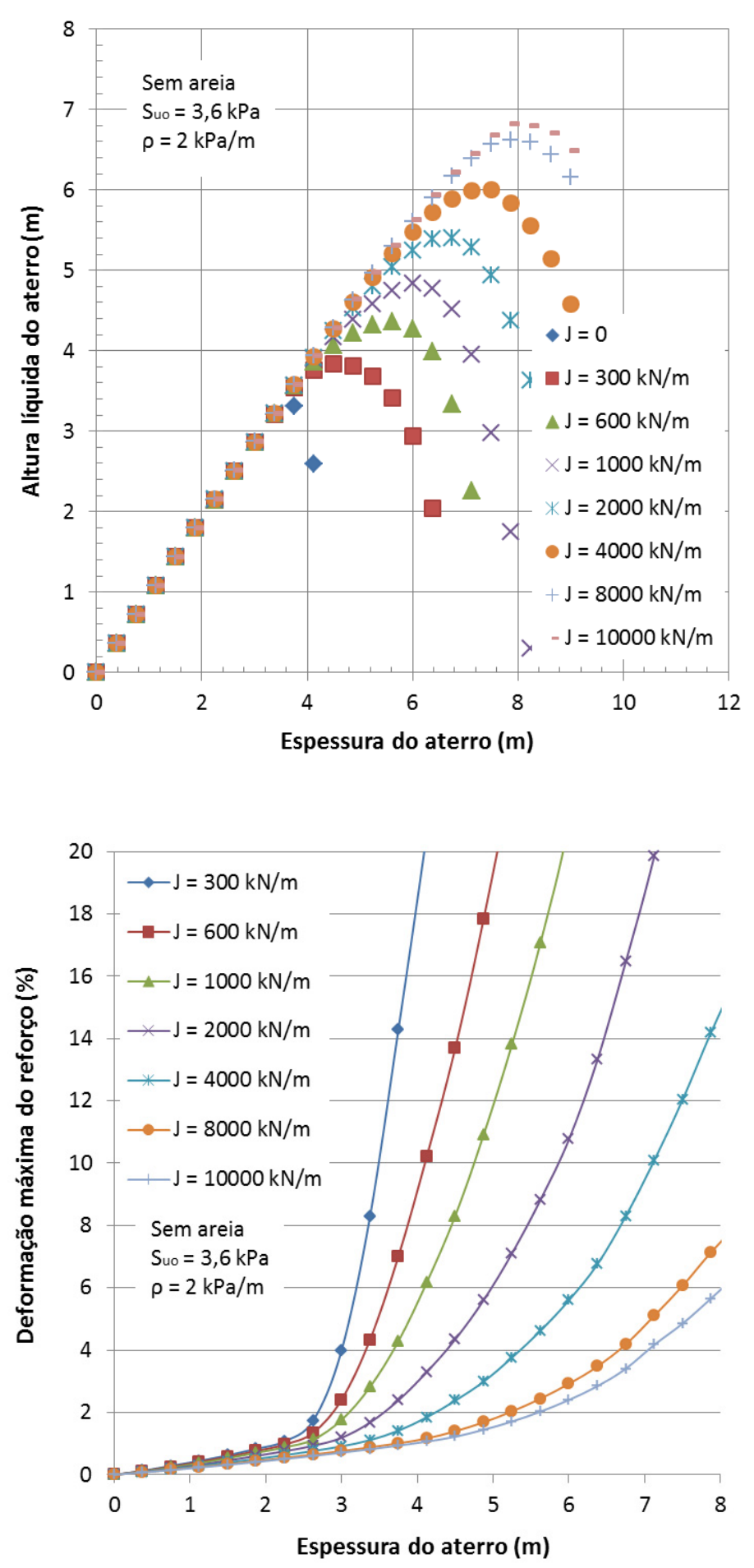

Figura l-13 Alturas de ruptura e deformações máximas do reforço com o aumento da rigidez do reforço $\mathrm{J} \mathrm{kN} / \mathrm{m}$ para uma fundação sem areia de Suo $=3,6 \mathrm{kPa}$ e $\rho=2,0 \mathrm{kPa} / \mathrm{m}$. 

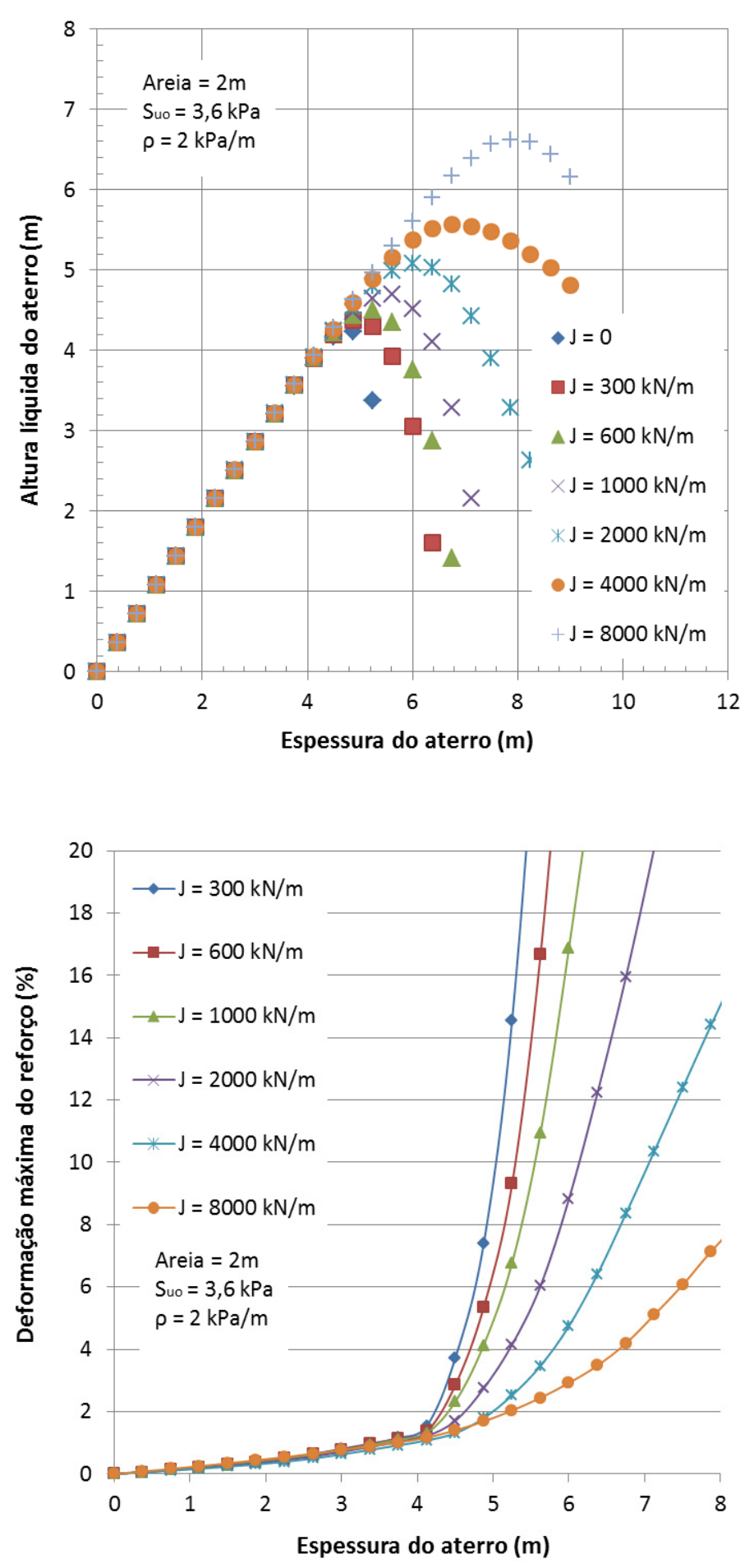

Figura l-14 Alturas de ruptura e deformações máximas do reforço com o aumento da rigidez do reforço $\mathrm{J} \mathrm{kN/m}$ para uma fundação de $\mathrm{Suo}_{\mathbf{1}}=3,6 \mathrm{kPa} e$ $\rho=2,0 \mathrm{kPa} / \mathrm{m}$ com $2 \mathrm{~m}$ de areia. 

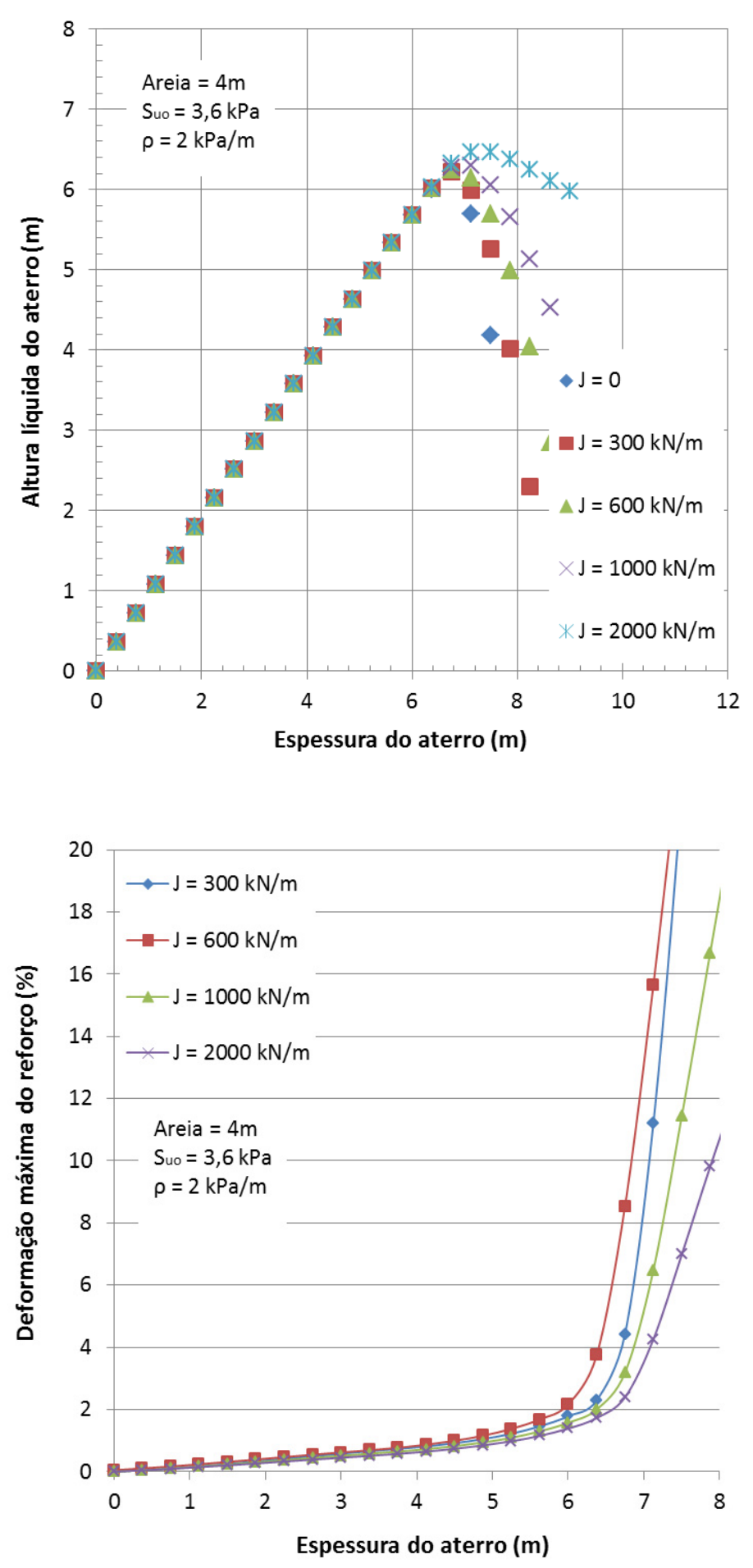

Figura I-15 Alturas de ruptura e deformações máximas do reforço com o aumento da rigidez do reforço $\mathrm{J} \mathrm{kN} / \mathrm{m}$ para uma fundação Suo $=3,6 \mathrm{kPa}$ e $\rho=2,0$ $\mathrm{kPa} / \mathrm{m}$ com $4 \mathrm{~m}$ de areia. 

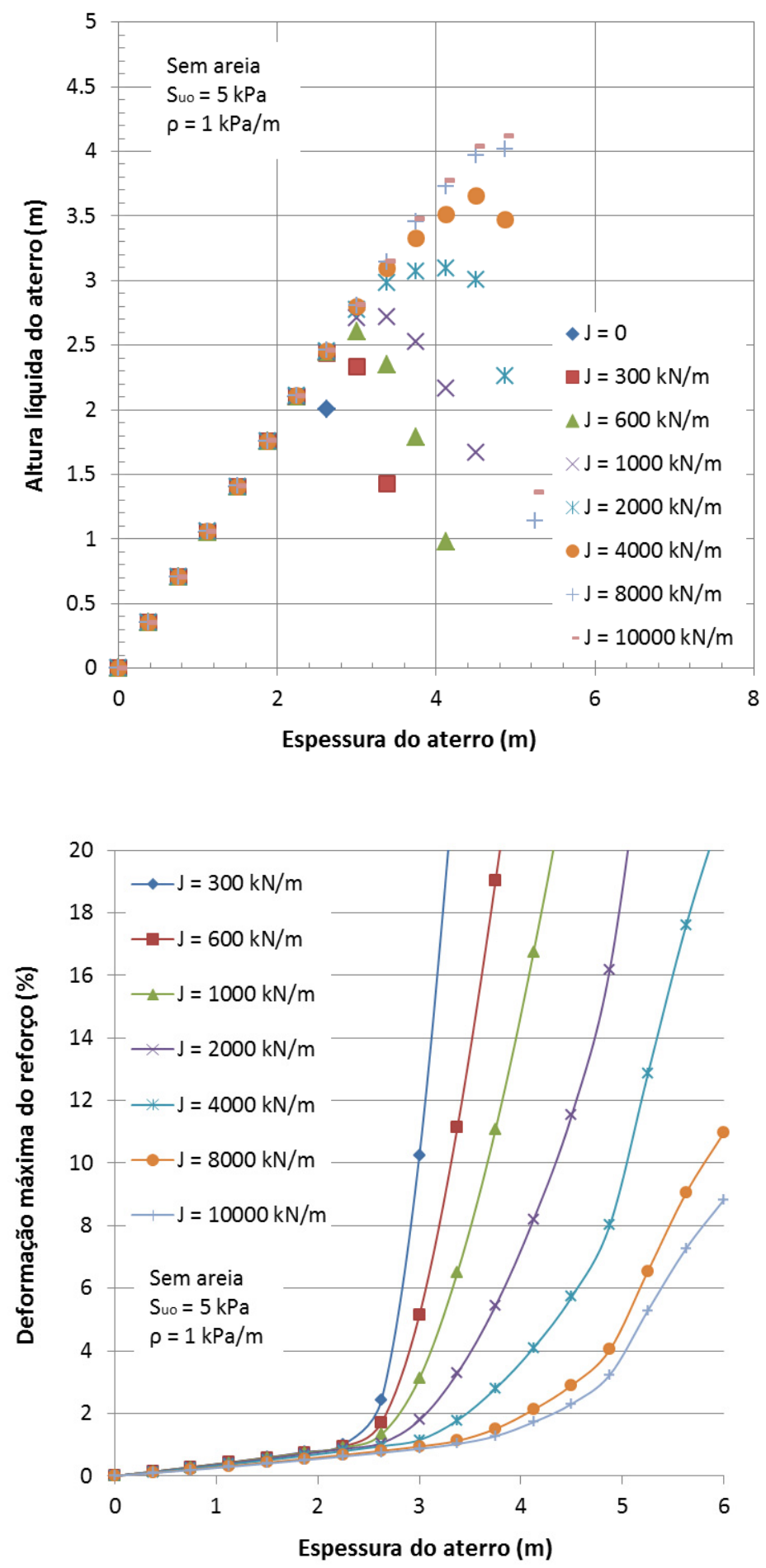

Figura l-16 Alturas de ruptura e deformações máximas do reforço com o aumento da rigidez do reforço $\mathrm{J} \mathrm{kN/m}$ para uma fundação sem areia de Suo=5 $\mathrm{kPa}$ e $\rho=1,0 \mathrm{kPa} / \mathrm{m}$. 

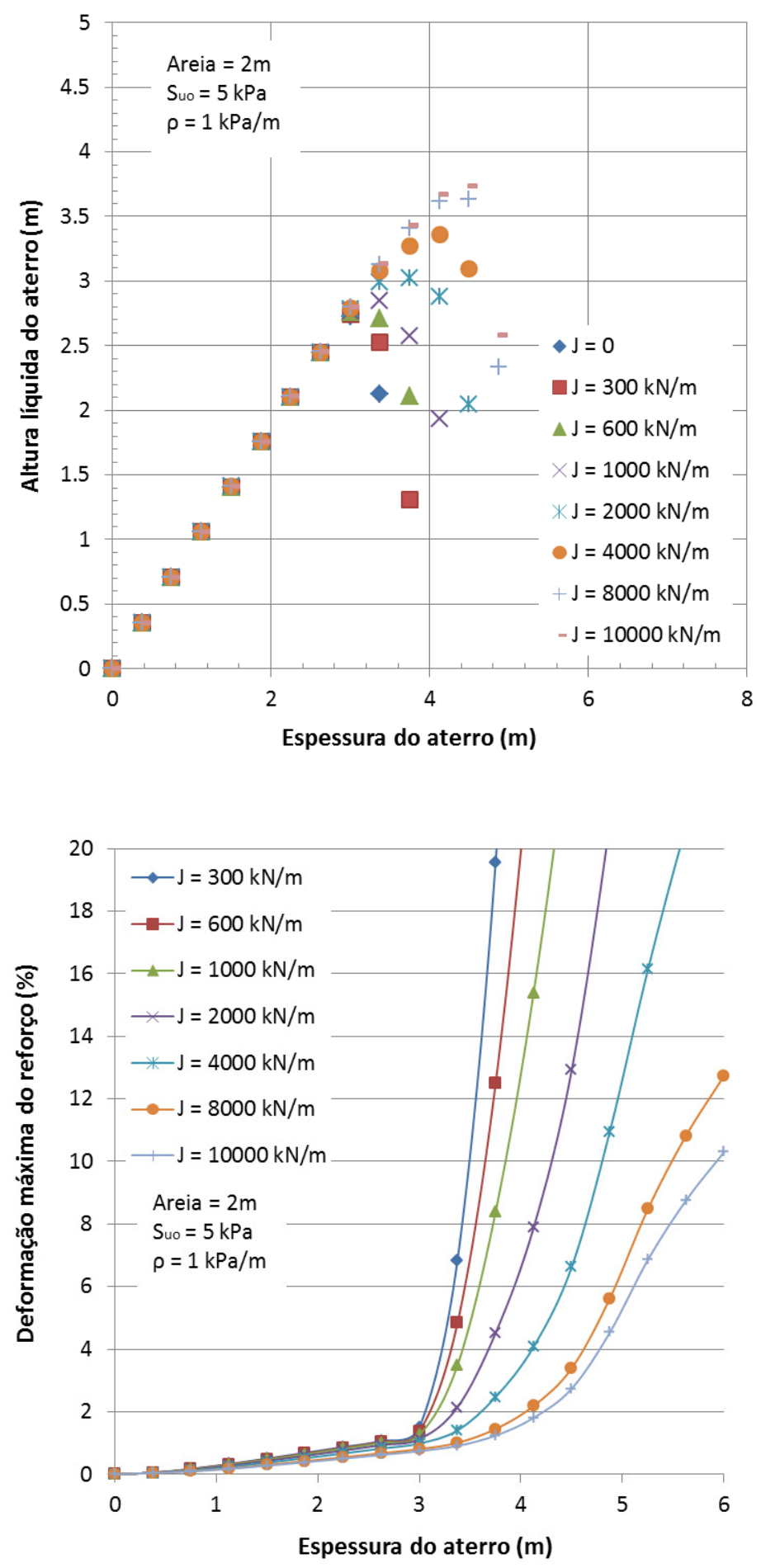

Figura l-17 Alturas de ruptura e deformações máximas do reforço com o aumento da rigidez do reforço $\mathrm{J} \mathrm{kN/m}$ para uma fundação de $S_{u o}=5 \mathrm{kPa}$ e $\rho=1,0$ $\mathrm{kPa} / \mathrm{m}$ com $2 \mathrm{~m}$ de areia. 

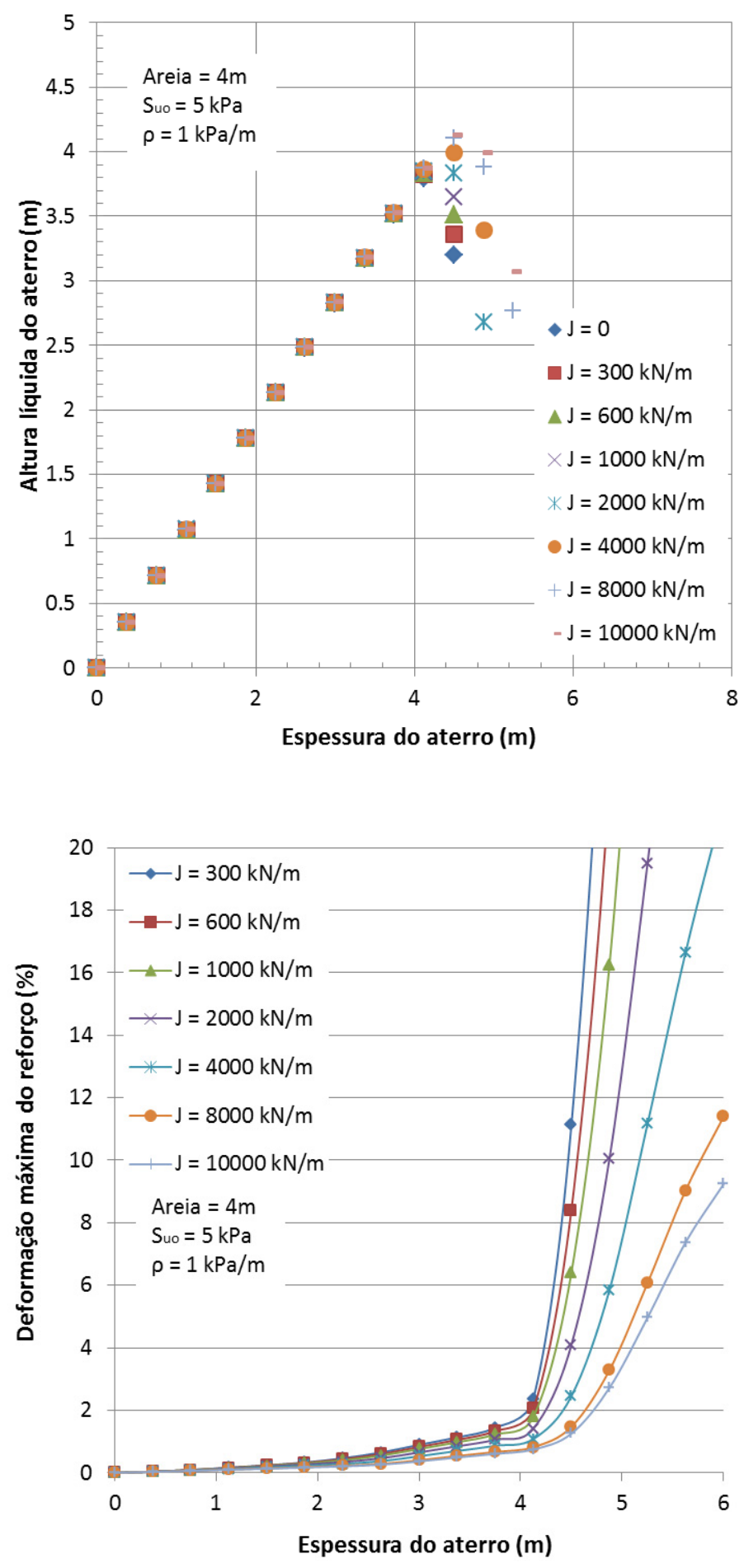

Figura l-18 Alturas de ruptura e deformações máximas do reforço com o aumento da rigidez do reforço $\mathrm{J} \mathrm{kN/m}$ para uma fundação Suo $=5 \mathrm{kPa}$ e $\rho=1,0$ $\mathrm{kPa} / \mathrm{m}$ com $4 \mathrm{~m}$ de areia. 

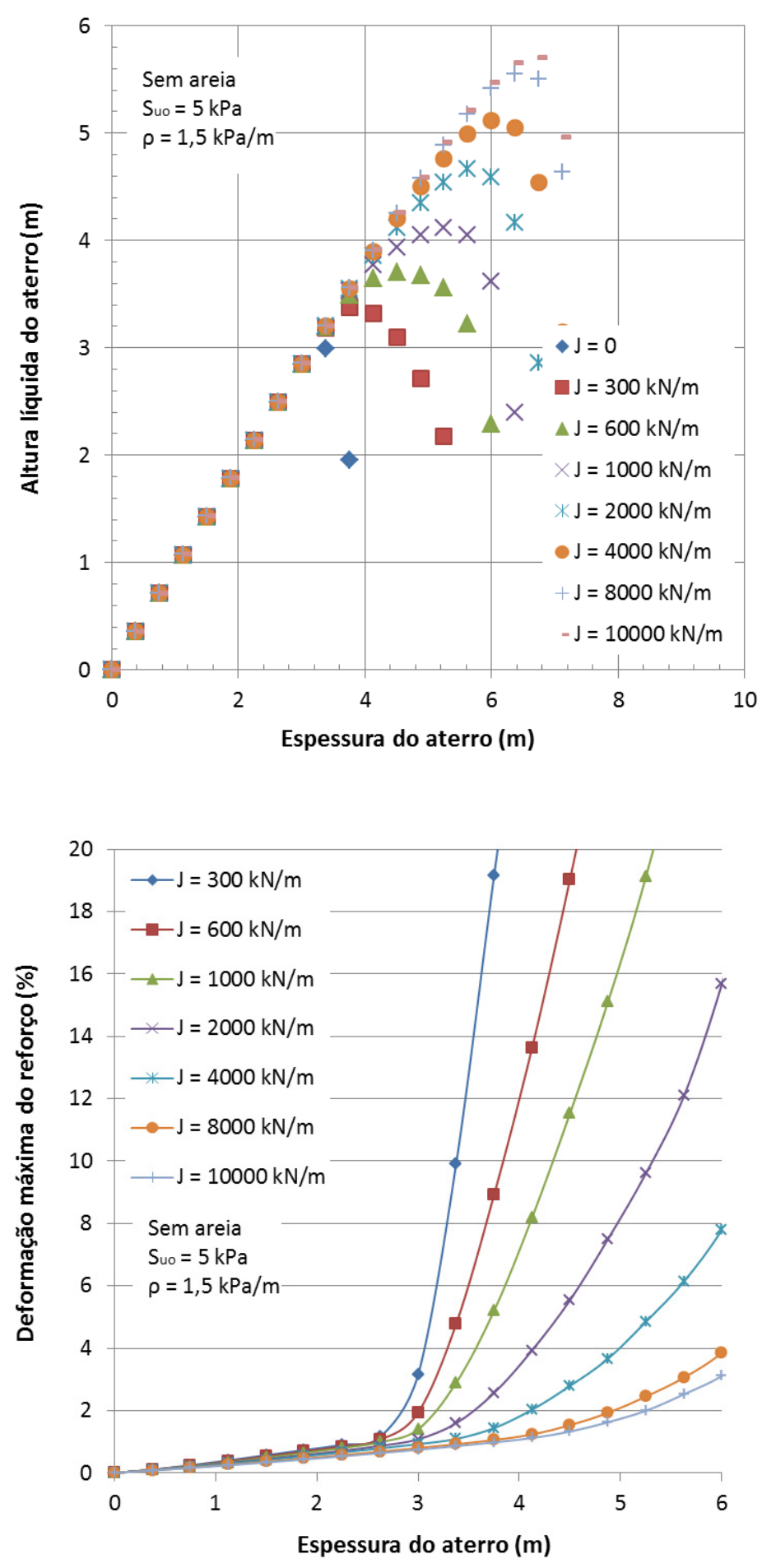

Figura l-19 Alturas de ruptura e deformações máximas do reforço com o aumento da rigidez do reforço $\mathrm{J} \mathrm{kN/m}$ para uma fundação sem areia de Suo $=5$ $\mathrm{kPa}$ e $\rho=1,5 \mathrm{kPa} / \mathrm{m}$. 

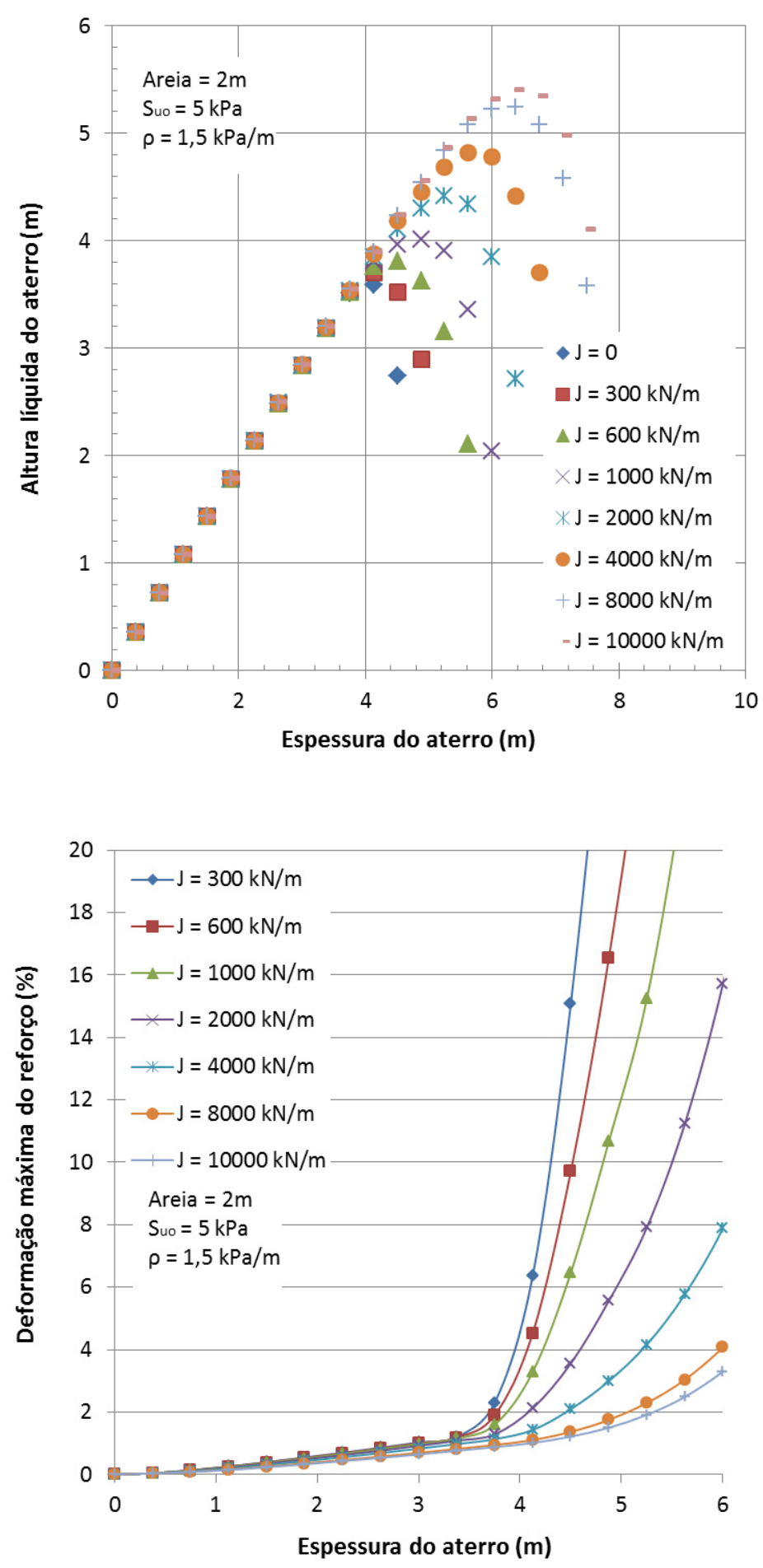

Figura I-20 Alturas de ruptura e deformações máximas do reforço com o aumento da rigidez do reforço $\mathrm{J} \mathrm{kN/m}$ para uma fundação de Suo $=5 \mathrm{kPa}$ e $\rho=1,5$ $\mathrm{kPa} / \mathrm{m}$ com $2 \mathrm{~m}$ de areia. 

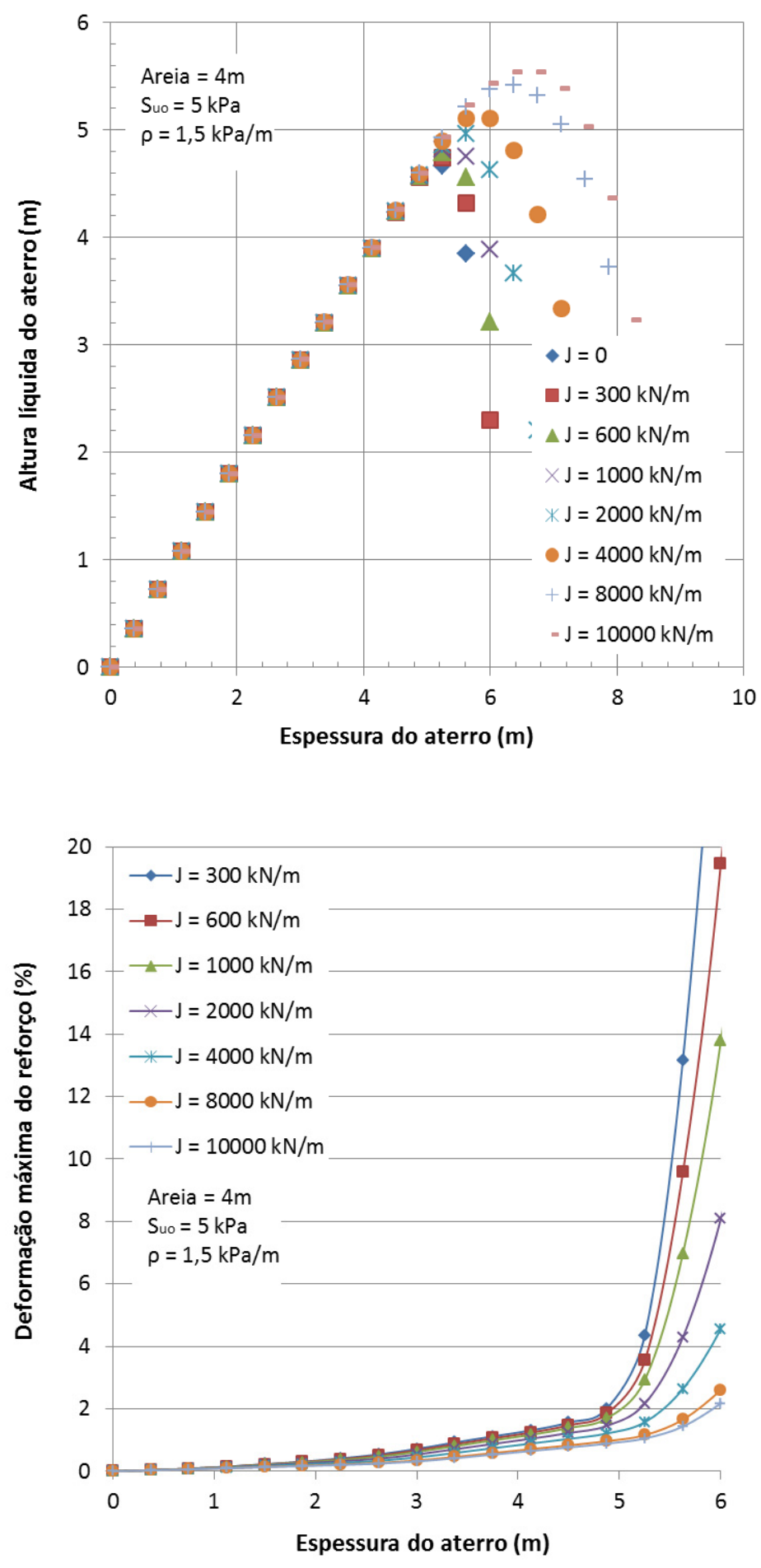

Figura l-21 Alturas de ruptura e deformações máximas do reforço com o aumento da rigidez do reforço $\mathrm{J} \mathrm{kN/m}$ para uma fundação Suo $=5 \mathrm{kPa}$ e $\rho=1,5$ $\mathrm{kPa} / \mathrm{m}$ com $4 \mathrm{~m}$ de areia. 

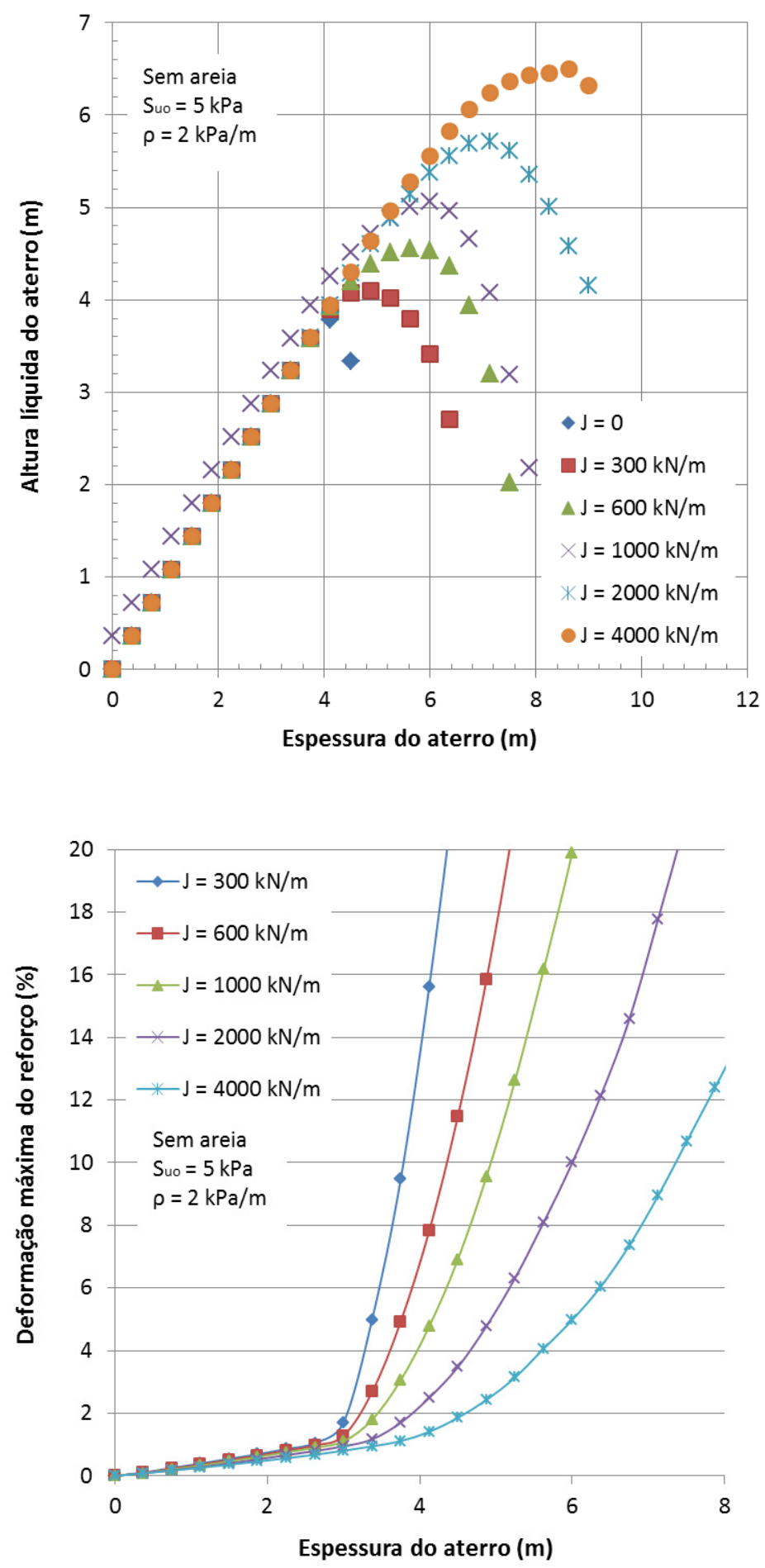

Figura I-22 Alturas de ruptura e deformações máximas do reforço com o aumento da rigidez do reforço $\mathrm{J} \mathrm{kN/m}$ para uma fundação sem areia de Suo=5 $\mathrm{kPa}$ e $\rho=2,0 \mathrm{kPa} / \mathrm{m}$. 

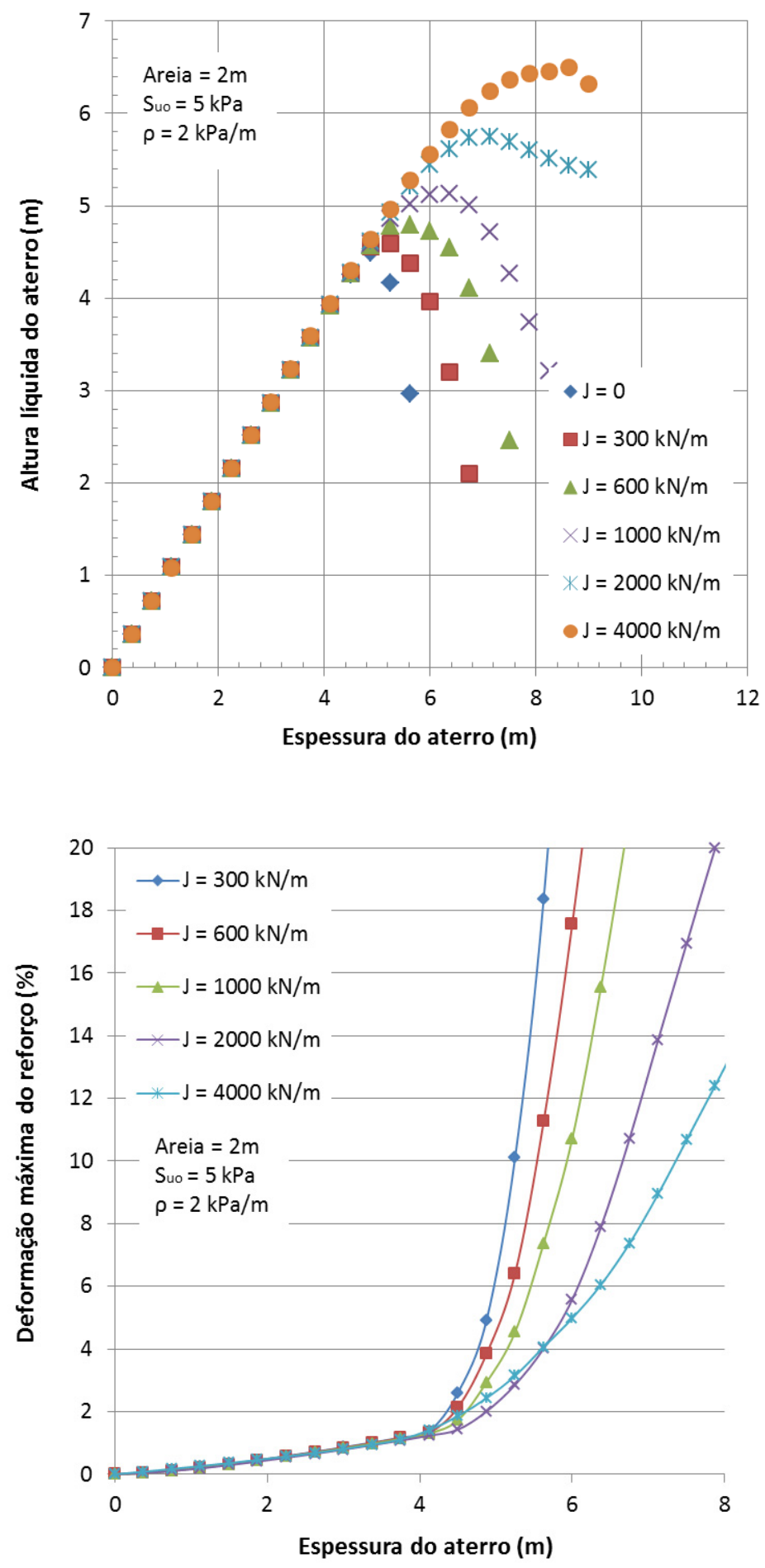

Figura l-23 Alturas de ruptura e deformações máximas do reforço com o aumento da rigidez do reforço $\mathrm{J} \mathrm{kN/m}$ para uma fundação de $\mathrm{Suo}_{0}=5 \mathrm{kPa}$ e $\rho=2,0$ $\mathrm{kPa} / \mathrm{m}$ com $2 \mathrm{~m}$ de areia. 


\section{APÊNDICE II}

Foram calculados os ganhos porcentuais em relação à altura de ruptura de aterros não reforçados, Para Suo $=2 \mathrm{kPa}, 3,6 \mathrm{kPa}$ e $5 \mathrm{kPa}$. Na fundação sem areia o desempenho do reforço é melhor, os reforços podem aumentar até $58 \%$ a altura de ruptura. Com a presença da camada de areia de $2 \mathrm{~m}$, os ganhos na altura são menores.

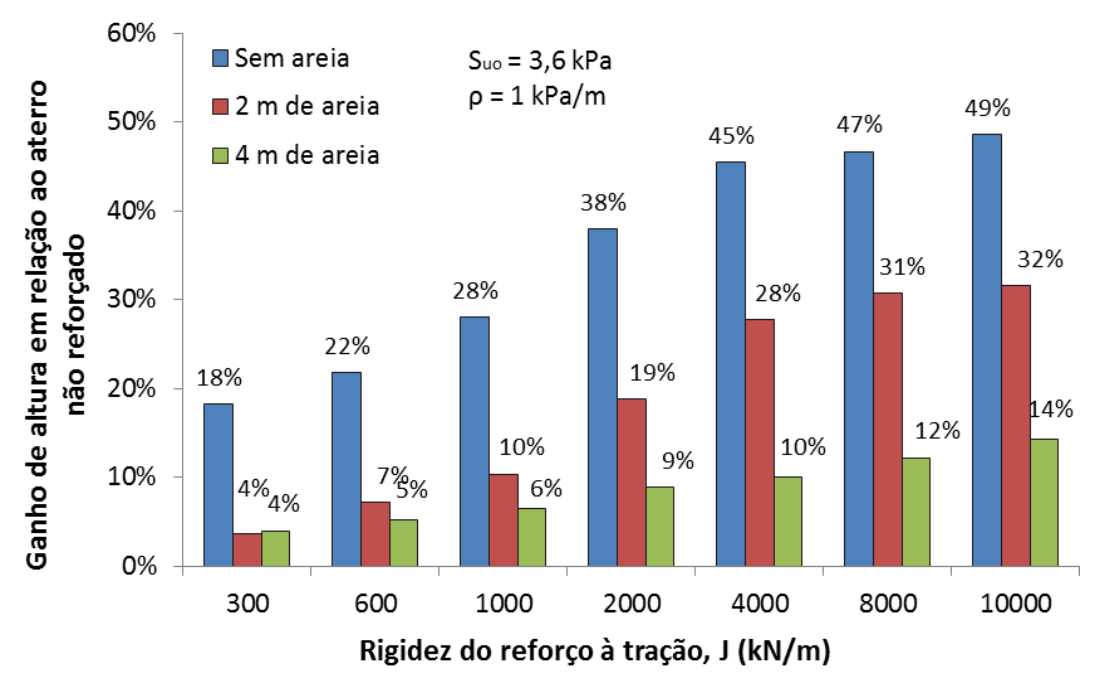

Figura Il-1 Ganho de altura em função da rigidez à tração do reforço para Suo $=3,6 \mathrm{kPa}$ e $\rho=1,0 \mathrm{kPa} / \mathrm{m}$.

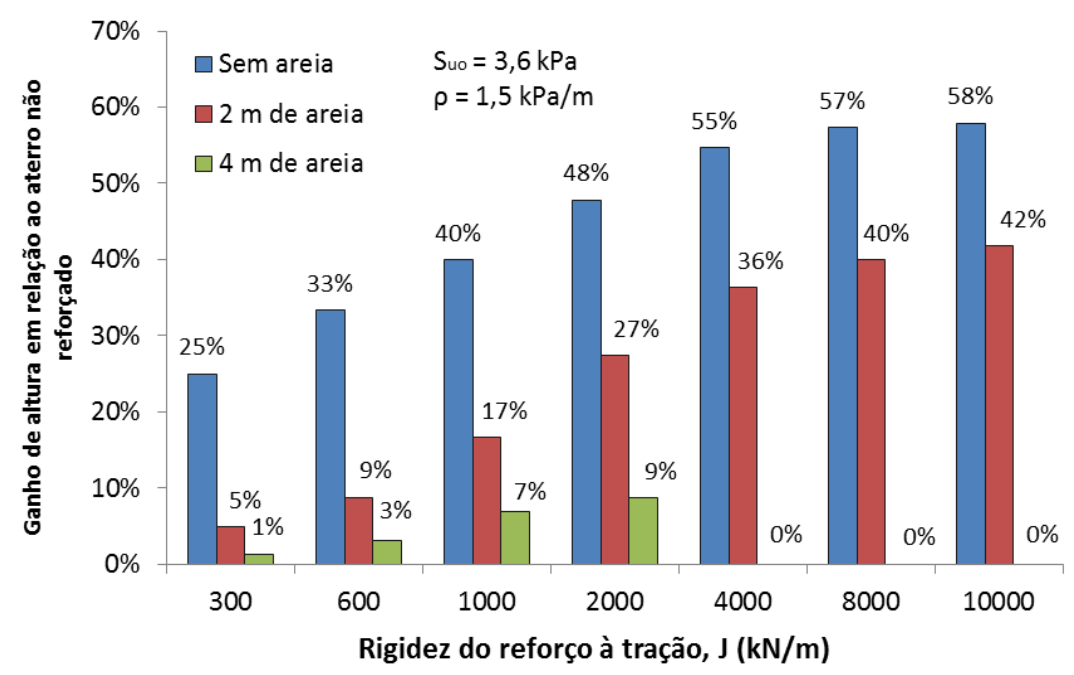

Figura II-2 Ganho de altura em função da rigidez à tração do reforço para Suo $=3,6 \mathrm{kPa}$ e $\rho=1,5 \mathrm{kPa} / \mathrm{m}$. 
Quando aumenta a resistência da fundação pela camada de areia de $4 \mathrm{~m}$ e pelo aumento do parâmetro $\rho$, a eficiência do reforço é menor, observa-se que com o aumento da rigidez do reforço, não se tem mais ganho na altura.

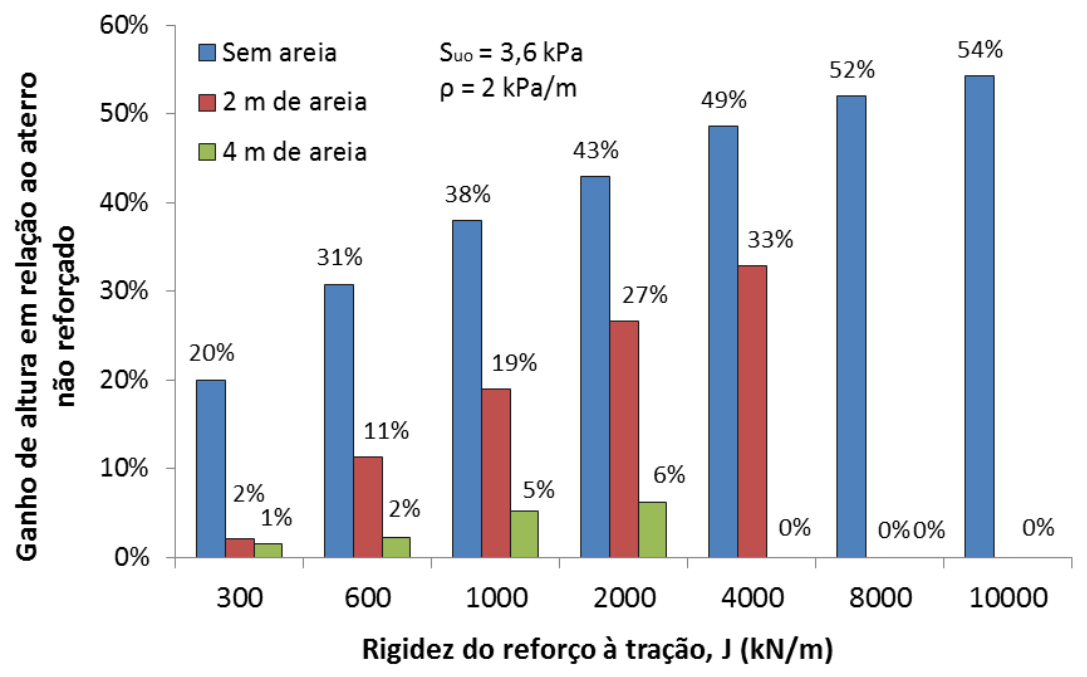

Figura II-3 Ganho de altura em função da rigidez à tração do reforço para Suo $=3,6 \mathrm{kPa}$ e $\rho=2,0 \mathrm{kPa} / \mathrm{m}$.

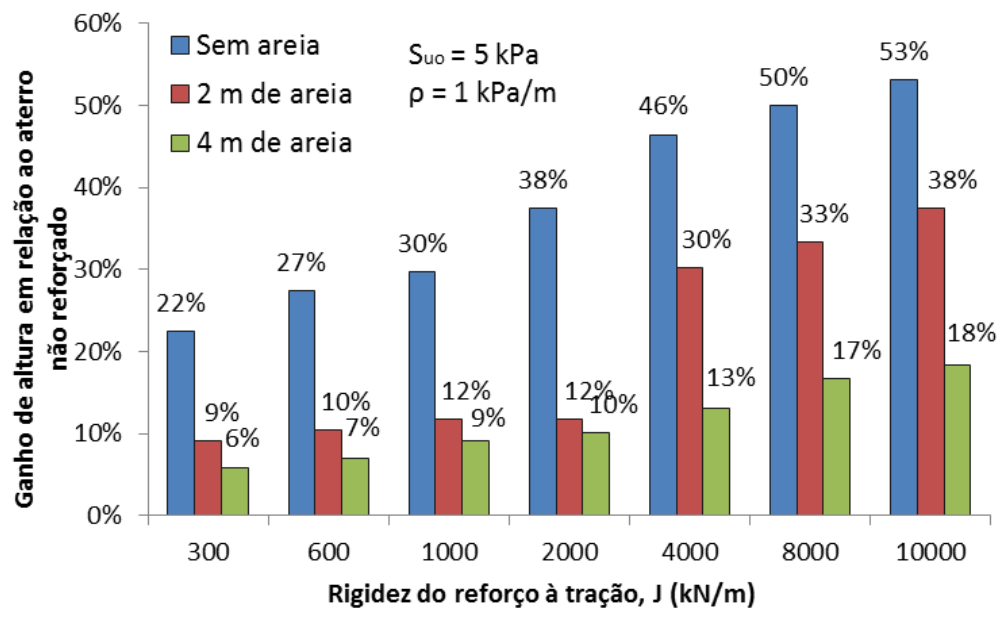

Figura II-4 Ganho de altura em função da rigidez à tração do reforço para Suo $=5 \mathrm{kPa}$ e $\rho=1,0 \mathrm{kPa} / \mathrm{m}$. 


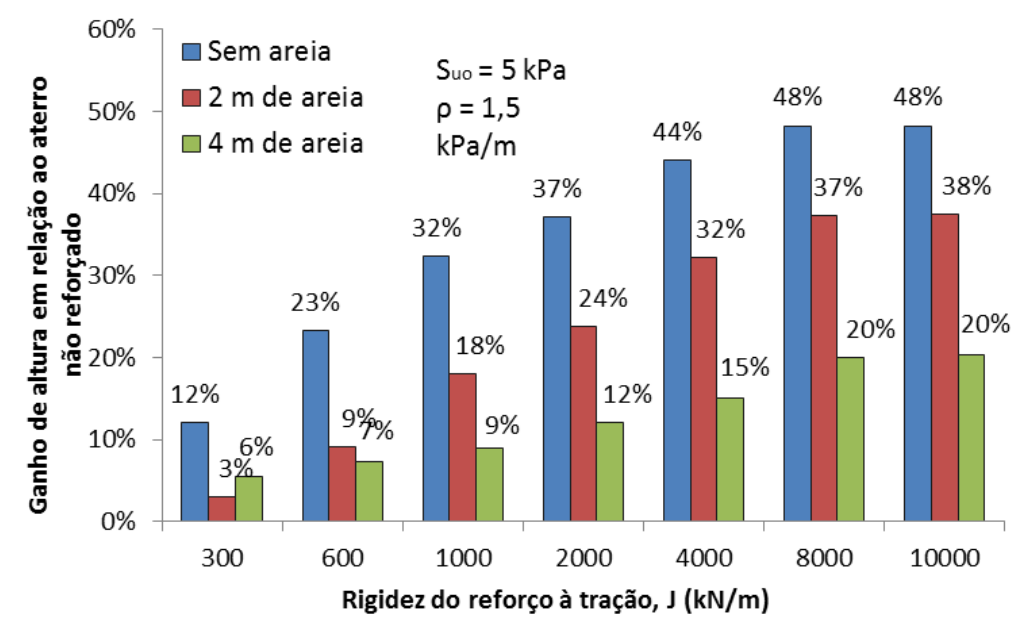

Figura II-5 Ganho de altura em função da rigidez à tração do reforço para Suo $=5 \mathrm{kPa}$ e $\rho=1,5 \mathrm{kPa} / \mathrm{m}$.

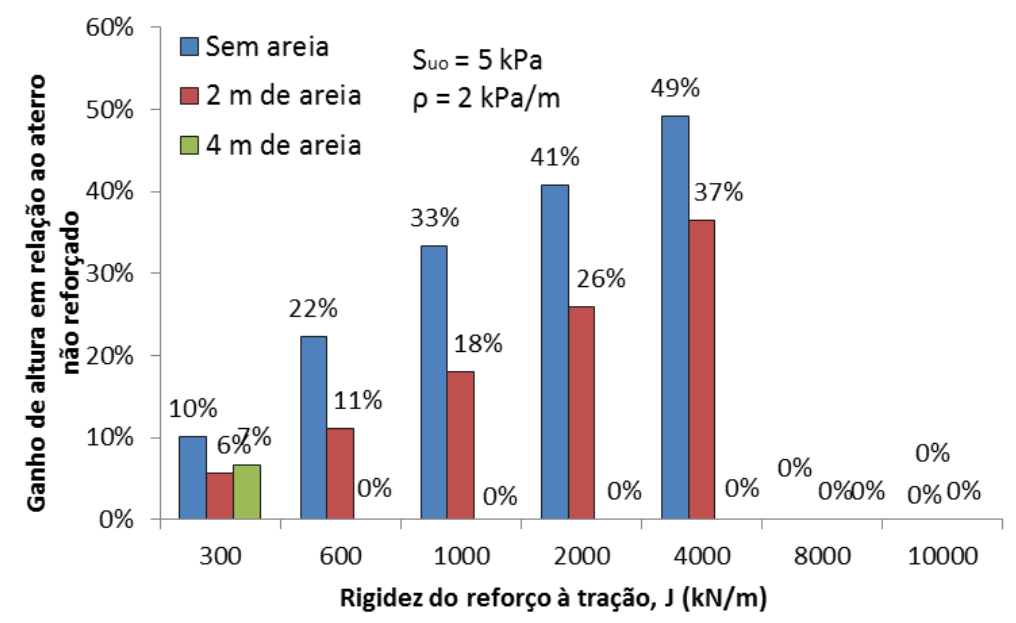

Figura II-6 Ganho de altura em função da rigidez à tração do reforço para Suo $=5 \mathrm{kPa}$ e $\rho=2,0 \mathrm{kPa} / \mathrm{m}$. 


\section{APÊNDICE III}
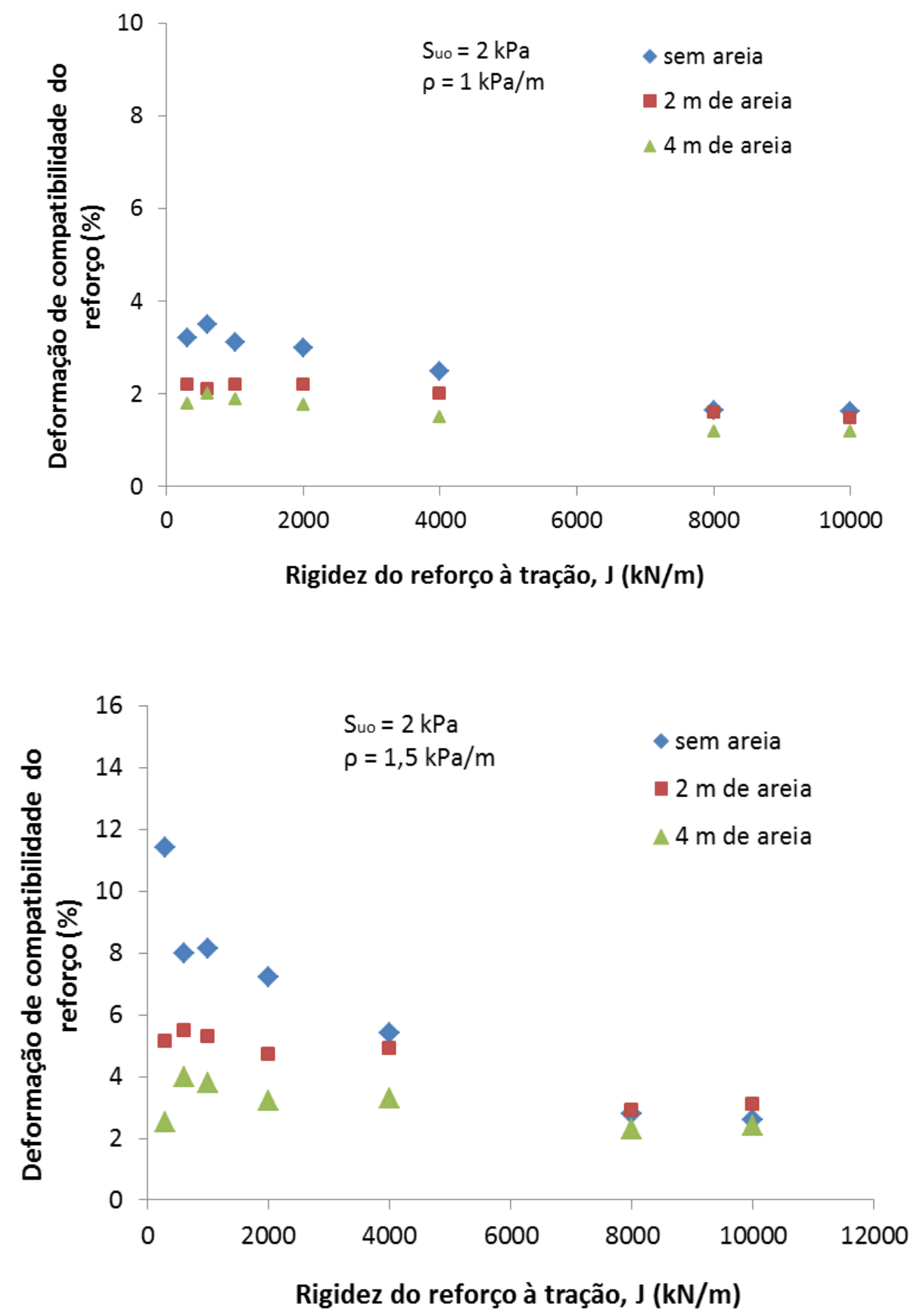

Figura III-1 Variação da deformação de compatibilidade do reforço com a rigidez do reforço e com a espessura da camada de areia para Suo $=2 \mathrm{kPa}$ e $\rho$ $=1 \mathrm{a} 1,5 \mathrm{kPa} / \mathrm{m}$. 

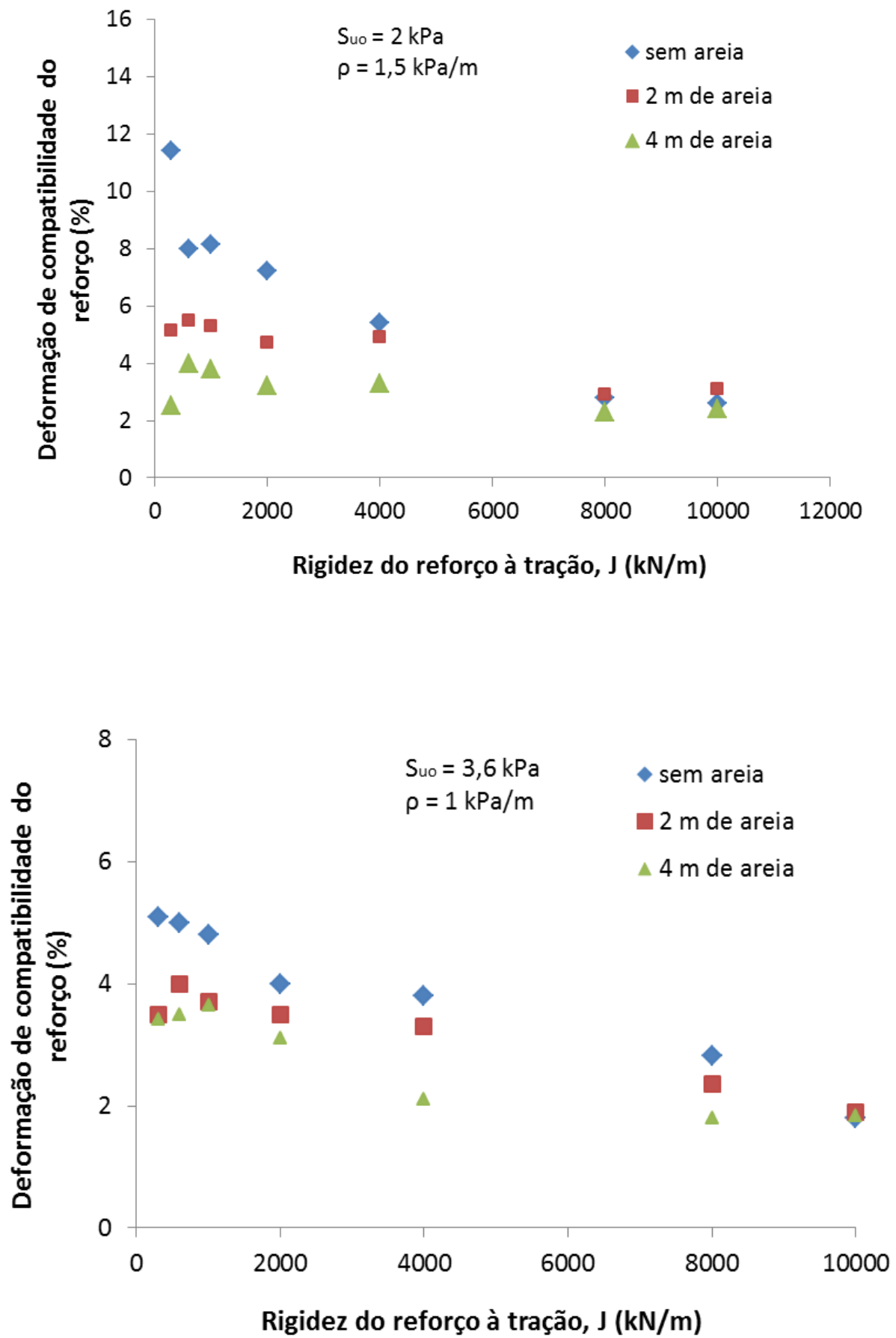

Figura III-2 Variação da deformação de compatibilidade do reforço com a rigidez do reforço e com a espessura da camada de areia para Suo $=2 \mathrm{kPa} e$ $3,6 \mathrm{kPa}$ e $\rho=1$ a $1,5 \mathrm{kPa} / \mathrm{m}$. 


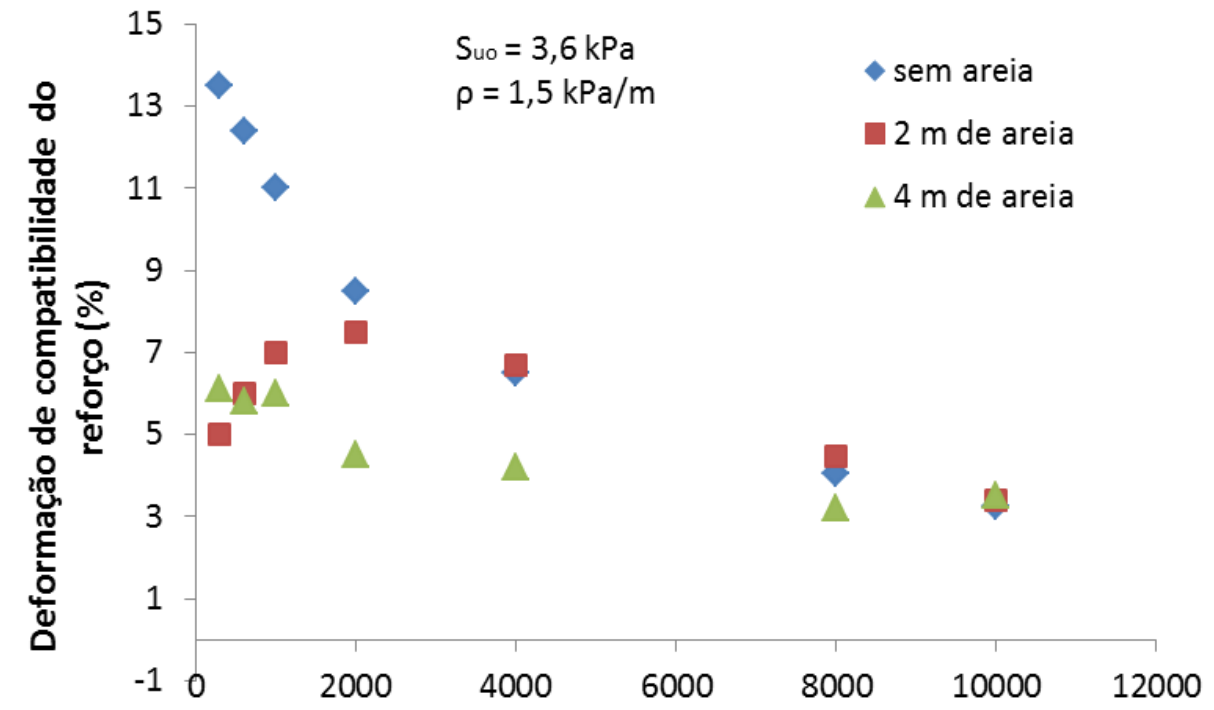

Rigidez do reforço à tração, J (kN/m)

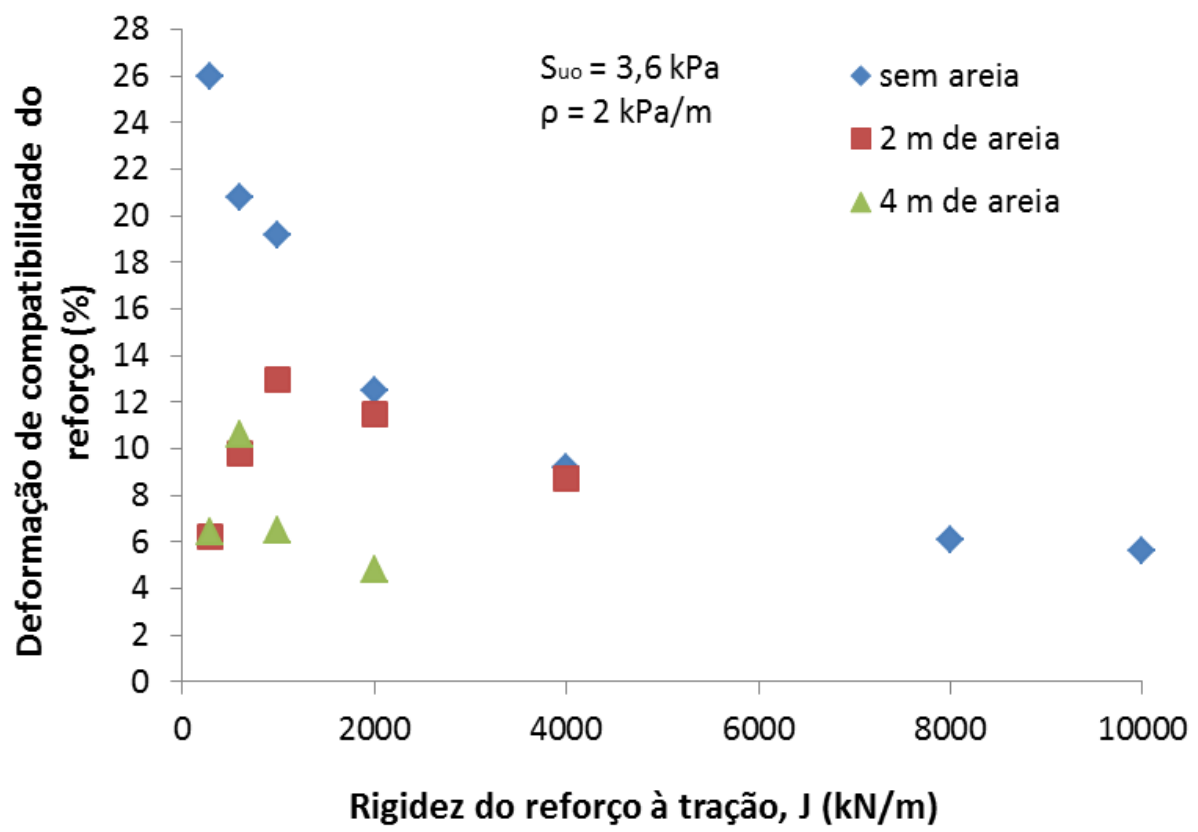

Figura III-3 Variação da deformação de compatibilidade do reforço com a rigidez do reforço e com a espessura da camada de areia para Suo $=3,6 \mathrm{kPa} e$ $\rho=1,5$ a $2,0 \mathrm{kPa} / \mathrm{m}$. 

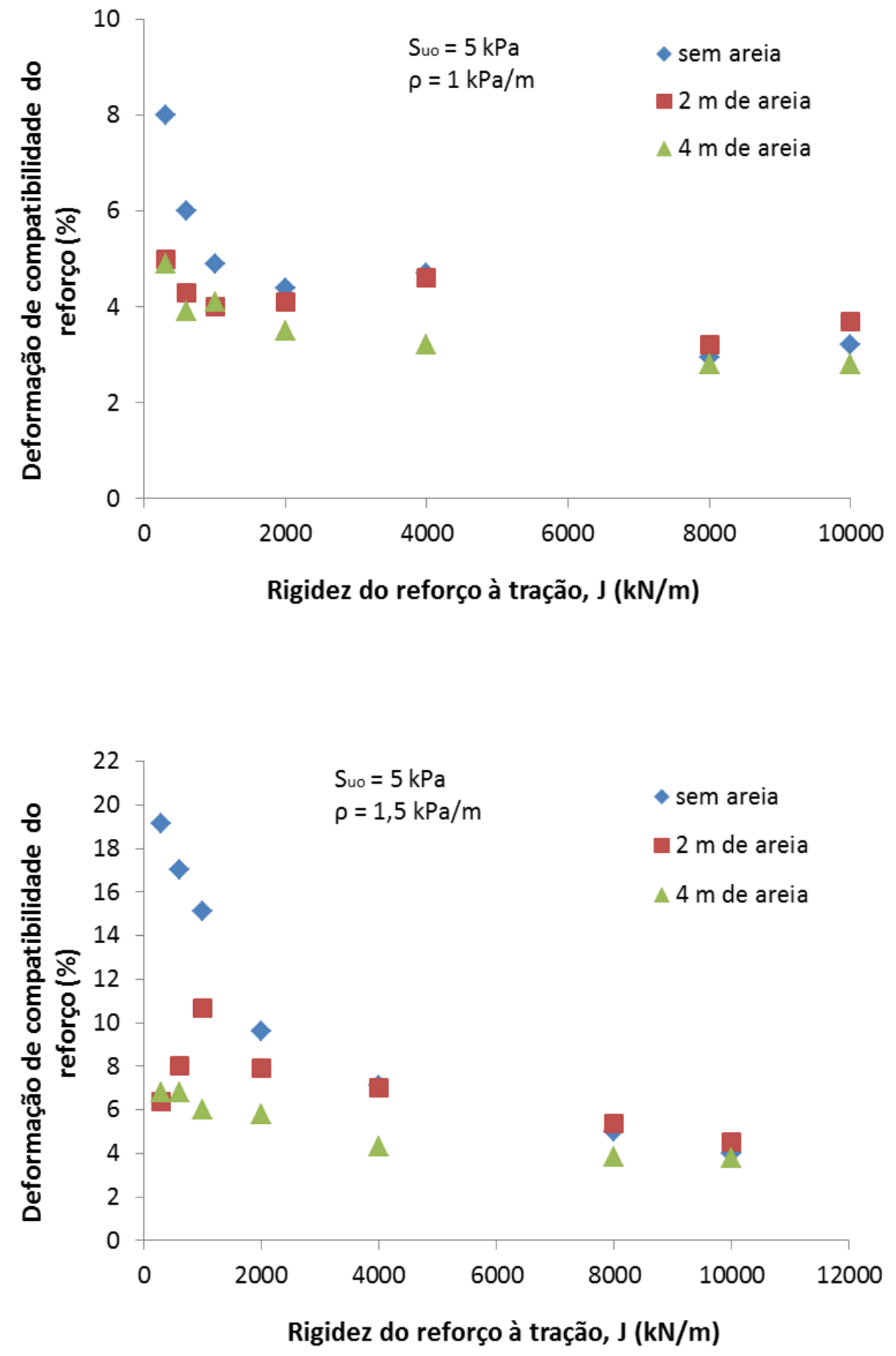

Figura III-4 Variação da deformação de compatibilidade do reforço com a rigidez do reforço e com a espessura da camada de areia para Suo $=5,0 \mathrm{kPa} e$ $\rho=1$ a $1,5 \mathrm{kPa} / \mathrm{m}$. 


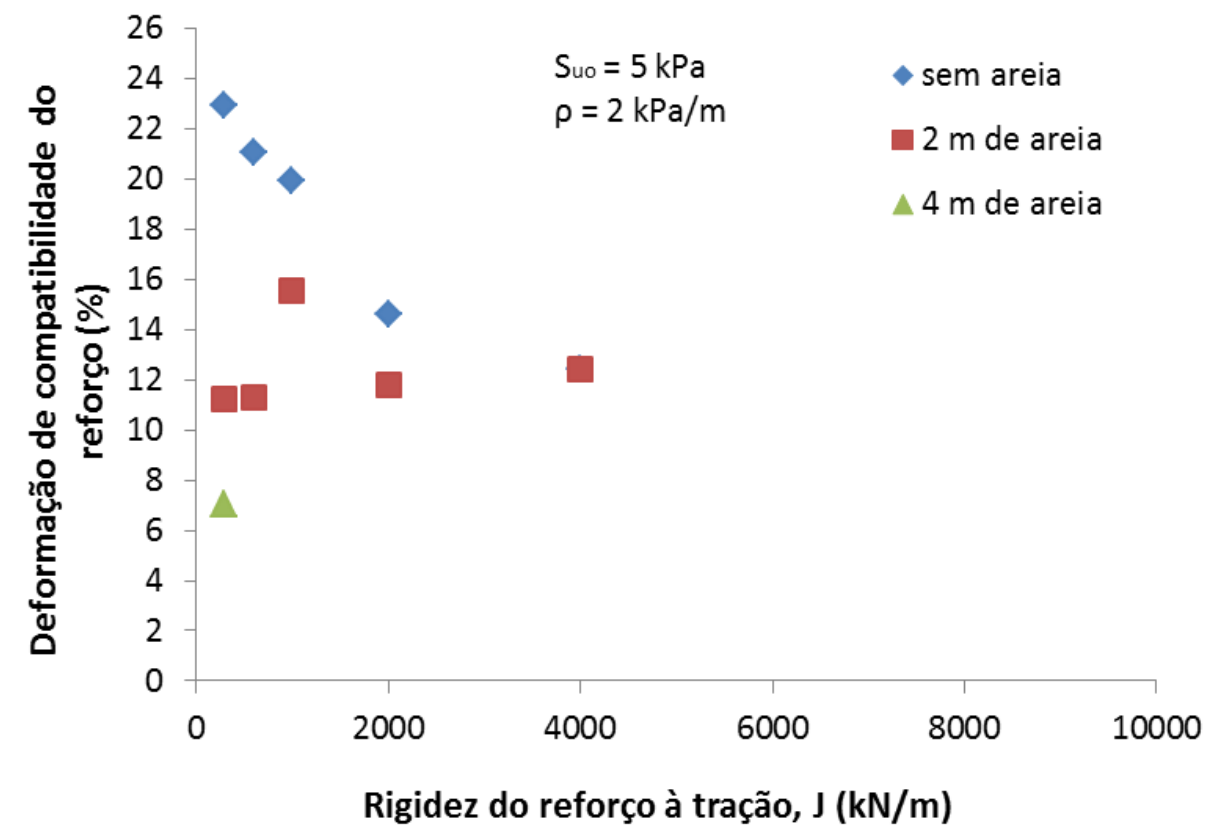

Figura III.5 Variação da deformação de compatibilidade do reforço com a rigidez do reforço e com a espessura da camada de areia para Suo $=5,0 \mathrm{kPa} e$ $\rho=2,0 \mathrm{kPa} / \mathrm{m}$. 


\section{APÊNDICE IV}

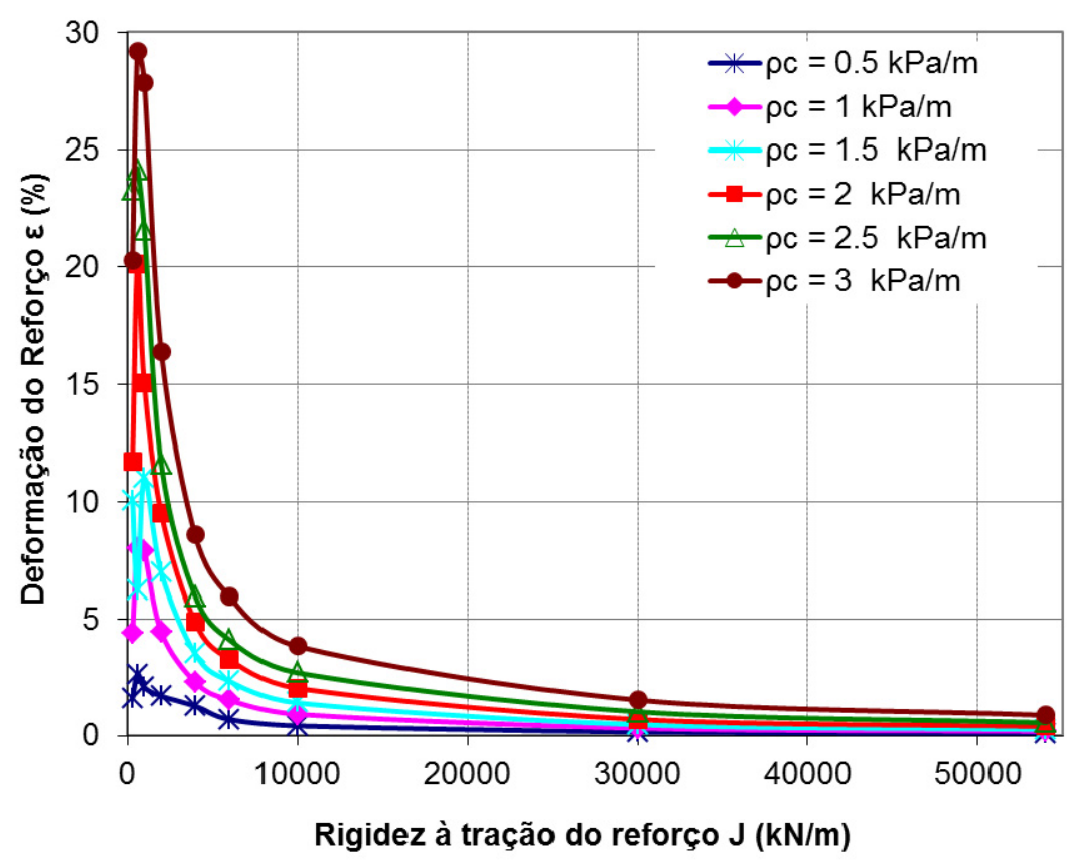

Figura IV-1 Efeito do $\rho c$ nas deformações do reforço na ruptura para $A=0 \mathrm{~m}$ e $S_{\text {uo }}=2 \mathrm{kPa}$.

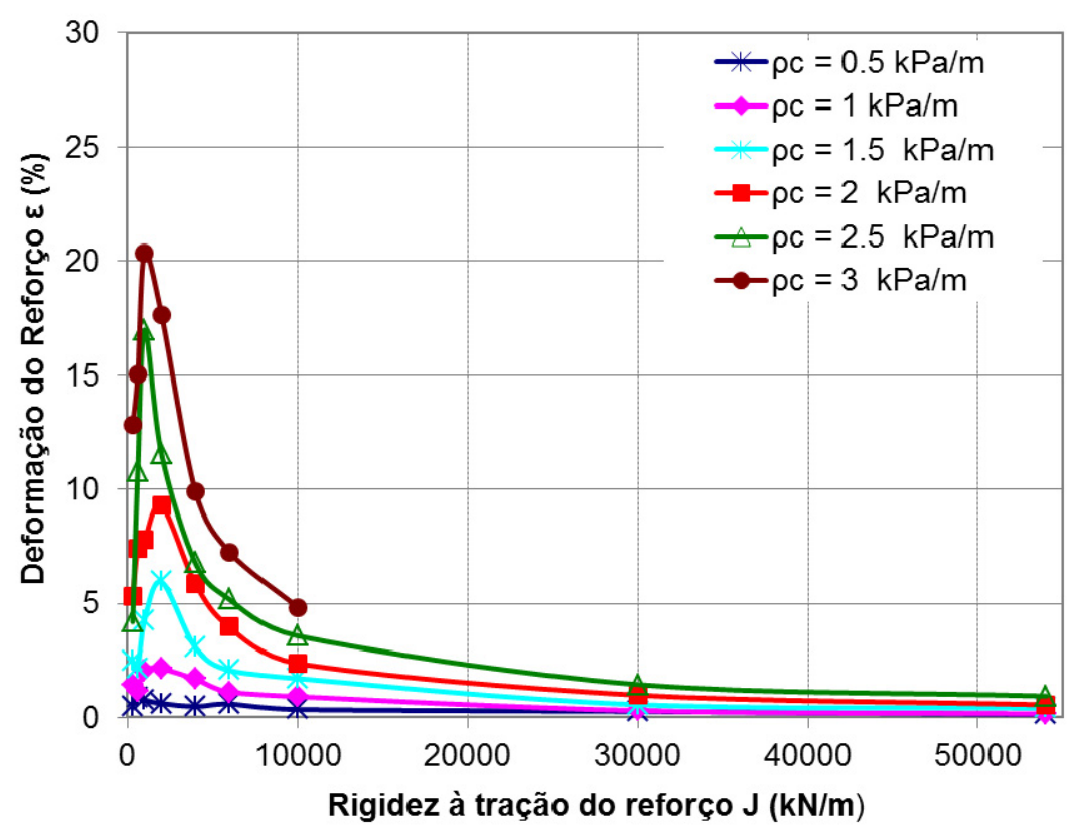

Figura IV-2 Efeito do $\rho c$ nas deformações do reforço na ruptura para $A=2 \mathrm{~m}$ e $S_{\text {uo }}=2 \mathrm{kPa}$. 


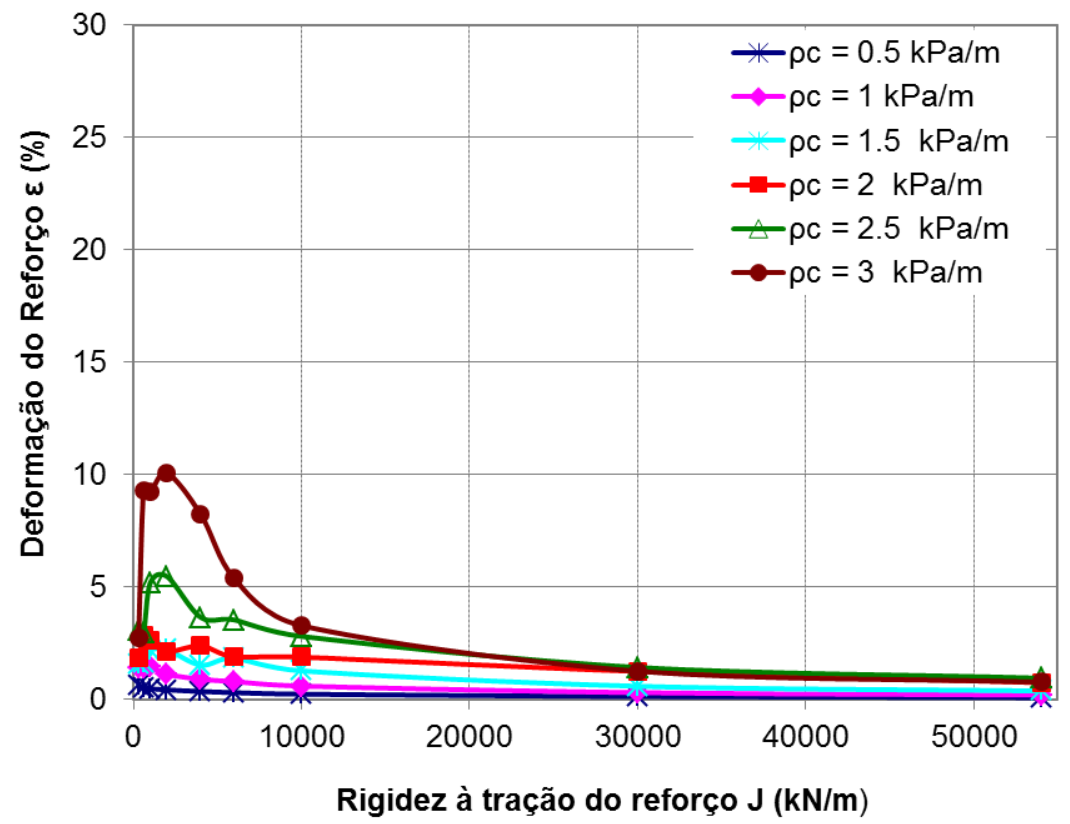

Figura IV-3 Efeito do $\rho c$ nas deformações do reforço na ruptura para $A=4 \mathrm{~m}$ e $S_{\mathrm{uo}}=2 \mathrm{kPa}$.

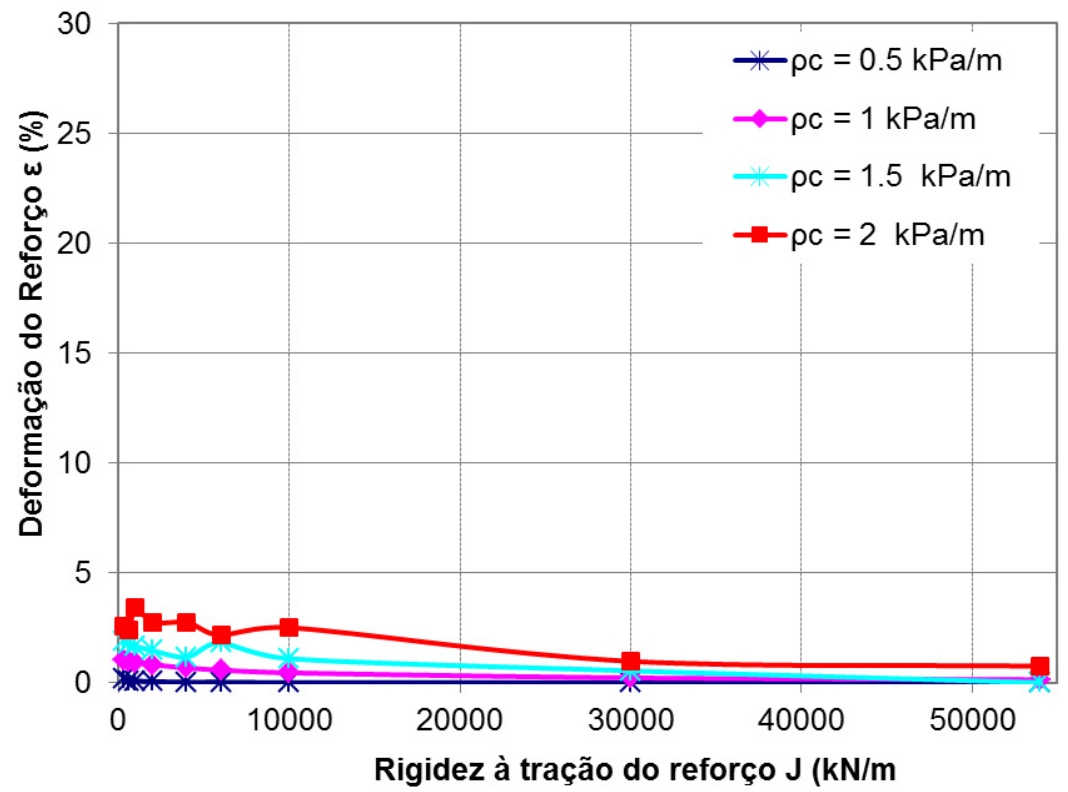

Figura IV-4 Efeito do $\rho c$ nas deformações do reforço na ruptura para $A=6 \mathrm{~m}$ e $S_{\mathrm{uo}}=2 \mathrm{kPa}$. 